NOTE TO USERS

This reproduction is the best copy available.

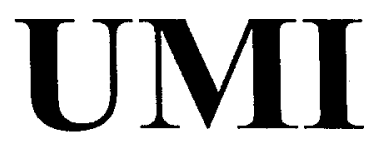

Reproduced with permission of the copyright owner. Further reproduction prohibited without permission. 
Reproduced with permission of the copyright owner. Further reproduction prohibited without permission. 


\title{
PAVEMENT EVALUATION STRATEGIES AND WAYS TO IMPROVE THE PERFORMANCE OF ASPHALT OVERLAYS
}

\author{
By
}

Sohail Afzal, B.E. (Civil)

\author{
A project \\ Presented to Ryerson University \\ In partial fulfillment of the \\ requirement for the degree of \\ Master of.Engineering \\ In the Program of \\ Civil Engineering
}

Toronto, Ontario, Canada, 2004

(C) Sohail Afzal 2004 
UMI Number: EC52974

\section{INFORMATION TO USERS}

The quality of this reproduction is dependent upon the quality of the copy submitted. Broken or indistinct print, colored or poor quality illustrations and photographs, print bleed-through, substandard margins, and improper alignment can adversely affect reproduction.

In the unlikely event that the author did not send a complete manuscript and there are missing pages, these will be noted. Also, if unauthorized copyright material had to be removed, a note will indicate the deletion.

(B)

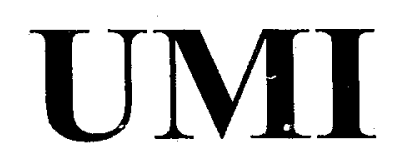

UMI Microform EC52974

Copyright 2008 by ProQuest LLC.

All rights reserved. This microform edition is protected against unauthorized copying under Title 17, United States Code.

ProQuest LLC

789 E. Eisenhower Parkway

PO Box 1346

Ann Arbor, MI 48106-1346 


\section{AUTHOR'S DECLARATION}

I hereby declare that I am the sole author of this project.

1 authorize Ryerson University to lend this project to other institutions or individuals for the purpose of scholarly research.

Sohail Afzal

Department of Civil Engineering

Ryerson University

I further authorize Ryerson University to reproduce this project by photocopying or by other means, in total or in part, at the request of other institutions or individuals for the purpose of scholarly research.

\section{Sohail Afzal}

Department of Civil Engineering

Ryerson University 


\section{Ryerson University}

\section{School of Graduate studies}

The undersigned certify that they have read, and recommend to the School of Graduate Studies for acceptance, a project entitled "Pavement Evaluation and Potential Use of Shingles in Asphalt"

Submitted in partial fulfillment of the requirements for the degree of Master of Engineering.

\begin{tabular}{|r|r|}
\hline & Department of Civil Engineering \\
\hline & Department of Civil Engineering \\
\hline & Date \\
\hline
\end{tabular}




\title{
PAVEMENT EVALUATION STRATEGIES AND WAYS TO IMPROVE THE PERFORMANCE OF ASPHALT OVERLAYS
}

\author{
Sohail Afzal \\ Master of Engineering, 2004 \\ Department of Civil Engineering \\ Ryerson University
}

\begin{abstract}
Highway rehabilitation is a blooming industry in the world and in particular North America. Highway agencies over the years have experienced problems in addressing pavement deteriorations, troubles with underlying pavement materials and management and evaluation of the existing pavements. This study has two objectives

The first objective is to discuss the types of distresses in both flexible and rigid pavements, pavement evaluation methods and equipment in use, pavement condition rating system, process of field investigation, life cycie cost analysis, and pavement selection strategies. A case study of Highway 401 eastbound collector lanes (from Avenue road to Highway 404) was carried out to demonstrate the process of pavement evaluation and design.

The second objective is to undergo an experimental program to evaluate the potential use of shingle waste into Superpave 19.0 and 12.5 asphalt mixes. The evaluation of volumetric properties of the mixes was performed. The trials demonstrated that volumetric properties of the mixes can be achieved at a lower asphalt content. Performance of mixes containing shingles was evaluated through various Highway agencies proved that incorporation of shingles enhances the performance of HMA mixes by improving durability, and increasing rutting resistance, while achieving comparable fatigue resistance.
\end{abstract}




\section{ACKNOWLEDGMENTS}

The author greatly thanks his project supervisor Dr. Medhat $H$. Shehata for his exceptional supervision, guidance and directions. His technical support, reasonable care and advice at each step during my entire study period are enormous.

I would also gratefully acknowledge the valuable assistance, kind support and cooperation of my Program Director, Dr. Mohamed Lachemi, and the Chair of Civil Engineering Department, Dr. Said M. Easa, during my stay at Ryerson University.

I am also grateful to my parents, brothers, sisters, friends and colleagues at my job for their continued support, pray and love. I am also grateful to all my colleagues at Ryerson University for their moral and technical support.

Deepest gratitude from my heart to my wife and daughter, who had to sacrifice their needs and time to support me to finish my studies.

Finally, I am grateful to the Grace of God for the countless blessings I have received. 


\section{Dedicated}

To

My loving parents

And

Lovely dạghter

(vii) 


\section{TABLE OF CONTENTS}

Executive Summary

Chapter 1 Pavement Distresses 2

1.1 Type of Pavement distresses $\quad 2$

1.2 Fracture/Cracking $\quad 2$

1.2.1 Reflective Cracking 3

1.2.2 Edge Cracking 3

1.2.3 Block Cracking 3

1.2.4 Alligator Cracking 3

1.2.5 Linear Cracking 3

1.3 Distorîion 5

1.3.1 Rutting 5

1.3.2 Corrugation and Shoving 5

1.3.3 Settlement and Grade Separation 5

1.3.4 Upheave or Swell 5

1.3.5 Utility Cut and/or Patch Failure 9

1.4 Disintegration

1.4.1 Raveling $\quad 9$

1.4.2 Pot Holes 9

1.5 Skid Resistance 9

1.6 Surface Treatment Distresses $\quad 12$

$\begin{array}{ll}\text { 1.6.1 Bleeding or flushing } & 12\end{array}$

$\begin{array}{ll}1.6 .2 \text { Polished Aggregate } & 12\end{array}$

1.7 Types of Distress in Rigid Pavement 12

\begin{tabular}{ll}
1.7 .1 Cracking & 12 \\
\hline
\end{tabular}

1.7.1.1 Linear Cracking . $\quad 12$

1.7.1.2 Corner Cracking 14

1.7.1.3 Shattered Slab $\quad 14$

$\begin{array}{lll}1.7 .2 & \text { Deformation } & 16\end{array}$

1.7.2.1 Punch Out $\quad 16$

1.7.2.2 Faulting 16

1.7.2.3 Blow ups $\quad 16$

1.7.2.4 Pumping $\quad 16$

$\begin{array}{lll}\text { 1.7.3 Disintegration } & 18\end{array}$

1.7.3.1 Durability Cracking (D Cracking) 18

1.7.3.2 Scaling/Crazing/Map Cracking 18

1.7.3.3 Joint and Corner Spalling 18

$\begin{array}{ll}\text { 1.7.3.4 Polished Aggregate } & 18\end{array}$ 
Chapter 2 Pavement Performance and Evaluation 22

2.1 Roughness 23

2.1.1 Measurement of Roughness 23

2.1.2 Present Serviceability Rating (PSR) 23

2.13 International Roughness Index (IRI) 24

2.2 Roughness 24

2.2.1 Survey 24

2.2.2 Profilographs $\quad 25$

2.2.3 Roughness Type Road Roughness Meters 26

2:2.4 Profiling Devices $\quad 26$

2.3 Surface Distresses $\quad 28$

2.4 Skid Resistance 28

2.4.1 Measurement of skid Resistance 28

2.4.2 Measurement Techniques for Skid Resistance 29

2.4.2.1 Locker Wheel Tester 29

2.4.2.2 Spin Up Tester $\quad 30$

2.4.2.3 Surface Texture Measurements $\quad 30$

2.4.2.4 Image Processing Equipment 30

2.5 Pavement Structural Evaluation 31

2.5.1 Measurement of Deflection 32

2.5.2 Measurement Techniques $\quad 32$

2.5.2.1 Static Deflection Equipment $\quad 32$

2.5.2.2 Steady State Deflection equipment 33

2.5.2.3 Impact Load Response $\quad 34$

2.5.2.4 Ground Penetration Radar $\quad 35$

2.5.3 Correlation between Deflection Measuring Equipment 36

2.6 Pavement Condition Rating system $\quad 37$

2.6.1 Pavement Serviceability Index 38

2.6.2 Other Pavement Condition Rating Systems 39

2.7 Field Investigations $\quad 39$

2.7.1 Process of Field Investigation $\quad 40$

2.7.2 Use of Pavement Investigation Results 41

Chapter 3 Life Cycle Cost Analysis $\quad 43$

3.1 Consideration of Different Options and their Maintenance 43

3.1.1 Analysis period 44

3.1.2 Estimation of Agency Cost $\quad 44$

3.1.3 User Cost Estimation 44 
3.1.4 Economic Indicators 44

3.2 Economic Benefits of Using Shingles 45

Chapter 4 Pavement Evaluation of Highway 401- Case Study 46

4.1 Field Investigation Involved in Pavement 46

4.1.1 Visual Pavement $C \cdot$ sdition $\quad 46$

4.1.2 Non Destructive Pavement Testing 47

4.1.3 Pavement Coring 48

4.1.4 Pavement Boreholes 48

4.2 Laboratory Testing $\quad 48$

4.3 Highway 401 Data Analysis $\quad 51$

4.4 Traffic Analysis $\quad 55$

4.5 Remaining Life Analysis/Prediction $\quad 57$

4.6 Design and Recommendation 58

Chapter 5 Potential Use of Shingles $\quad 59$

5.1 Processing of Roofing Waste $\quad 60$

5.2 Factors Affecting Recycling of Shingles $\quad 61$

5.3 Potential Benefits of Using Asphalt Shingles $\quad 62$

5.4 Description of Experimental Program - 62

5.5 Material Used In Study $\quad 62$

5.5.1 Coarse Aggregate $\quad 62$

5.5.2 Fine Aggregates $\quad 65$

$\begin{array}{ll}5.5 .3 \text { Shingles } & 65\end{array}$

5.5.4 Asphalt Cement $\quad 68$

5.6 Mix Design $\quad 68$

5.6.1 Asphalt Concrete Sample Preparation 68

5.6.2 Superpave Gyratory Compactor $\quad 69$

$\begin{array}{ll}\text { 5.6.3 Required No. of Gyration } & 70\end{array}$

5.6.4 Calculation for $\% \mathrm{G}_{\mathrm{mm}} \quad 70$

5.7 Results of Experimental Program $\quad 71$

5.7.1 Superpave 19.0 with Shingles $\quad 71$

5.7.2 Superpave 19.0 without Shingles $\quad 75$

$\begin{array}{ll}\text { 5.7.3 Superpave } 12.5 \text { with Shingles } & 77\end{array}$

5.7.4 Superpave 12.5 without Shingles $\quad 81$

5.8 Field Performance of Shingles added Mixes 83

Chapter 6 Conclusion $\quad 84$

6.1 Other Considerations $\quad 84$ 
Appendix 1

Aggregate Blends

88

Appendix 2

Results of Volumetric Properties

89

Appendix 3

Gyratory Compactor Data Sheets

90

(xi)

Reproduced with permission of the copyright owner. Further reproduction prohibited without permission. 


\section{List of Figur 3}

Figure 1.1 Reflective cracking in flexible Pavement 4

Figure 1.2 Progressive side edge cracking 4

Figure 1.3 Severe block cracking in asphalt pavement 6

Figure 1.4 Alligator cracking in flexible pavement 6

Figure 1.5 Linear cracking in flexible pavement 7

Figure 1.6 Severe rutting in asphalt rutting $\quad 7$

Figure 1.7 Corrugation at right shoulder of flexible pavement 8

Figure 1.8a Depression in flexible pavement 8

Figure 1.8b Frost heave 10

Figure 1.9 Utility patch 10

Figure 1.10 Raveling in surface course 11

Figure 1.11a New and deteriorated pot holes 11

Figure 1.11b Bleeding/flushing at driving lanes 13

Figure 1.12 Polished aggregate 13

$\begin{array}{lll}\text { Figure } 1.13 \quad \text { Linear cracking } & 14\end{array}$

Figure 1.14 Corner cracking in concrete pavement 15

Figure 1.15 PCC slab punch out $\quad 15$

Figure 1.16 Severe faulting in composite pavement 17

Figure 1.17 Severe blowup in PCC slab 17

Figure 1.18 Water accumulations due to pumping 19

Figure 1.19 Durability cracking 19

Figure 1.20 Joint concrete spalling 20

Figure 1.21 Polished aggregates 20

Figure 1.22 Utility cuts for maintenance

Figure 2.1 Individual Present Serviceability 23

Figure 2.2 IRI roughness scale $\quad \cdot \quad 24$

$\begin{array}{lll}\text { Figure } 2.3 & \text { Profilograph } & 25\end{array}$

Figure 2.4 Dakota road profiler 27

Figure 2.5 Benkelman beam in use 33

Figure 2.6 Dynaflect 34

Figure 2.7 Road rater 35

Figure 2.8 FWD Impulse Loading Mechanism 36

Figure 2.9 Pavement performance using PSI 39

Figure 4.1 Distribution of DLT results for entire project 52

Figure 4.2 Distribution of DLT results for Lane1 53

Figure 4.3 Distribution of DLT results for Lane2 53

Figure 4.4 Distribution of DLT results for Lane3 54

Figure 4.5 Distribution of DLT results for Lane4 54 
Figure 4.6 Distribution of DLT results for Lane5 55

Figure 4.7 Projected AADT with 2\% annual growth rate 56

Figure 4.8 Projected ESAL's with $2 \%$ annual growth rate 56

Figure 5.1 Graphical representation of grain size analysis for $19 \mathrm{~mm}$ aggregate 64

Figure 5.2 Graphical representation of grain size analysis for 12.5 aggregate 65

Figure 5.3 Graphical representation of grain size analysis for fine aggregate 66

Figure 5.4 Graphical representation of grain size analysis of shingles 67

$\begin{array}{lll}\text { Figure 5.5 Superpave 19.0 with shingles mix properties curve } & 72\end{array}$

Figure 5.6 Superpave 19.0 with shingles mix properties curve considering Asphalt content of Shingles $\quad 74$

Figure 5.7 Superpave 19.0 without shingles mix properties curve $\quad 76$

$\begin{array}{lll}\text { Figure } 5.8 & \text { Superpave } 12.5 \text { with shingles mix properties curve } & 78\end{array}$

Figure 5.9 Superpave 12.5 with shingles mix properties curve considering Asphalt content of Shingles $\quad 80$

Figure 5.10 Superpave 12.5 without shingles mix properties curve 82 


\section{List of Tables}

Table 2.1 Skid Resistance No. table 29

Table 4.1 JRCP core thickness and strength 49

Table 4.2 Chloride lon content in JRCP cores 50

Table 4.3 Summary of FWD Analysis of Load Deflection Transfer 51

Table 4.4 Input parameters for ESAL calculation 55

Table 5.1 Grain size analysis results for $19.0 \mathrm{~mm}$ course aggregate 63

Table 5.2 Grain size analysis results for $12.0 \mathrm{~mm}$ course aggregate $\quad 64$

Table 5.3 Grain size analysis results for fine aggregate (sand) 66

Table 5.4 Grain size analysis results for shingles 67

$\begin{array}{lll}\text { Table } 5.5 & \text { Blend for various mixes } & 69\end{array}$

$\begin{array}{lll}\text { Table 5.6 Detail about gyration and traffic } & 70\end{array}$

Table $5.7 \quad$ Test results for Superpave 19.0 with shingles 71

Table 5.8 Test Results for Superpave 19.0 with Shingles considering Asphalt content of Shingles

73

Table 5.9 Test results for Superpave 19.0 without shingles 75

Table 5.10 Test results for Superpave 12.5 with shingles 77

Table 5.11 Test Results for Superpave 12.5 with Shingles considering Asphalt content of Shingles $\quad 79$

Table 5.12 Test results for Superpave 12.5 without shingles 81 


\section{Executive Summary}

Transportation infrastructure is a basic requirement for the development of any country or nation. Transportation is directly related to the economic growth of the country. Due to new developments and ever-increasing demands, highway engineering is facing new challenges including road safety, geometrics and pavement engineering. More research to meet the new challenges is now required. Modern and efficient road construction using asphalt concrete and Portland cement concrete and modern paving equipment have made it possible to construct complex transportation infrastructure.

Pavement rehabilitation is a growing industry in North America. This project encompasses pavement rehabilitation strategies, pavement distress and evaluation, and the potential use of shingles to improve the structural capacity of asphalt mixtures.

The first chapter of this study briefly reviews the commonly observed types of distress in flexible and rigid pavements in North America.

The second chapter of this report describes various techniques, equipment and methods used in the industry for the structural evaluation of pavements. The chapter also briefly explains the various pavement condition rating systems used by various agencies, including Ministry of Transportation Ontario, to describe the present condition of a road pavement. These systems are based only on visual assessment. The chapter also focuses on the field investigation process required for any pavement rehabilitation project. It describes the process of field investigation, interpretation and analysis of the field data, and the design and selection of structural design alternatives.

The third chapter of this proinct discusses the most important aspect of pavement rehabilitation projects: Life Cycle Cost Analysis and Pavement Selection.

In Chapter four, the writer describes a Case Study, the "Pavement Evaluation of Highway 401".

Chapter five of this report focuses on investigating the potential use of shingles in Superpave mixes, i.e. Superpave 19 and Superpave 12.5. Mix designs are prepared and tested in Ryerson Asphalt laboratory according to Superpave mix design methods and guidelines. The use of shingles can improve the performance of asphalt overlays. Conclusions and concerns regarding the use of shingles are also discussed Chapter five. 


\section{CHAPTER 1}

\section{PAVEMENT DISTRESS}

Pavement management includes the planning, programming, financing and administration of pavement maintenance. A well designed and constructed asphalt pavement will provide a smooth riding surface which will carry the expected load. This chapter of the report discusses the various kinds of distress found in both flexible and rigid pavements. Distress in any pavement can be related to the following causes:

- Wheel load

- Environment

- Poor drainage

- Material deficiencies

- Construction related deficiencies

- External causes

Sometimes distresses may be caused by a combination of these factors.

\subsection{Types of Distress In Flexible Pavement}

Asphalt pavement is flexible and composed of designed asphalt layers laid on well compacted granular materials. The definition of the surface distress as defined by the Highway Research Board is as follows:

"Any indication of poor or unfavorable pavement performance or signs of impending failure; any unsatisfactory performance of a pavement short of failure" (Highway Research Board, 1970).

Asphalt pavement distress can be generally classified as one of the following types:

1. Fracture/Cracking

2. Distortion

3. Disintegration

4. Skid resistance

5. Surface treatment distresses

\subsection{Fracture / Cracking}

Fracture/cracking may take many forms. Water, incompressible materials (sand, rocks etc) and frost susceptible materials (sandy silt) may penetrate through a crack to the underlying pavement structure. It will damage the pavement and affect the pavement performance. Following are the different types of flexible pavement cracks. 


\subsubsection{Reflective cracking}

These are cracks in asphalt overlays that show the crack pattern in the underlying pavement. These cracks may be longitudinal, transverse, diagonal, or block depending on the nature of the underlying pavement distress. The major cause is vertical and horizontal movements by expansion and contraction in the pavement due to temperature or moisture changes. The picture presented in Figure 1.1 shows reflective cracking. It was taken at Highway 400 north of Gibson River, Ontario.

\subsubsection{Edge Cracking}

These are longitudinal cracks combined with alligator cracking. They are generally 30 to $60 \mathrm{~cm}$ and extend to the shoulders. Generally, these cracks are due to the poor side drainage and lack of lateral support. The picture presented in Figure 1.2 shows side edge cracking in the City of Vaughan, Ontario

\subsubsection{Block Cracking}

Block cracks are interconnected cracks that form a series of large cracks. They are generally 1 to $3 \mathrm{~m}$ across and usually have sharp corners or angles. They may be caused by volume change. This volume change is common in fine aggregate asphalt mixes that have a high content of low penetration asphalt and adsorptive aggregates. However, the most common cause is the cycle of daily temperature and the hardening of asphalt. Block cracking is not fatigue related. The picture presented in Figure 1.3 shows block cracking at Highway 69, north of Muskoka Road 5, Ontario.

\subsubsection{Alligator cracking}

Alligator cracks are interconnected cracks. They look like a series of small blocks and resemble alligator's skin. Alligator cracking is caused by the deflection of the pavement surface. An other cause may be the weakening of the subgrade or granular base due to moisture, insufficient pavement thickness, poor drainage, thinner asphalt thickness and overloading of the pavement. The picture presented in Figure 1.4 shows alligator cracking at Highway 69 , south of Muskoka Road 5, Ontario.

\subsubsection{Linear cracking (longitudinal)}

Linear cracks generally consist of paving joint cracks, construction joints, shoulder joint cracks, widening cracks, and longitudinal, transverse and diagonal cracks. Transverse and diagonal cracks result from the contraction of the pavement (low temperature 


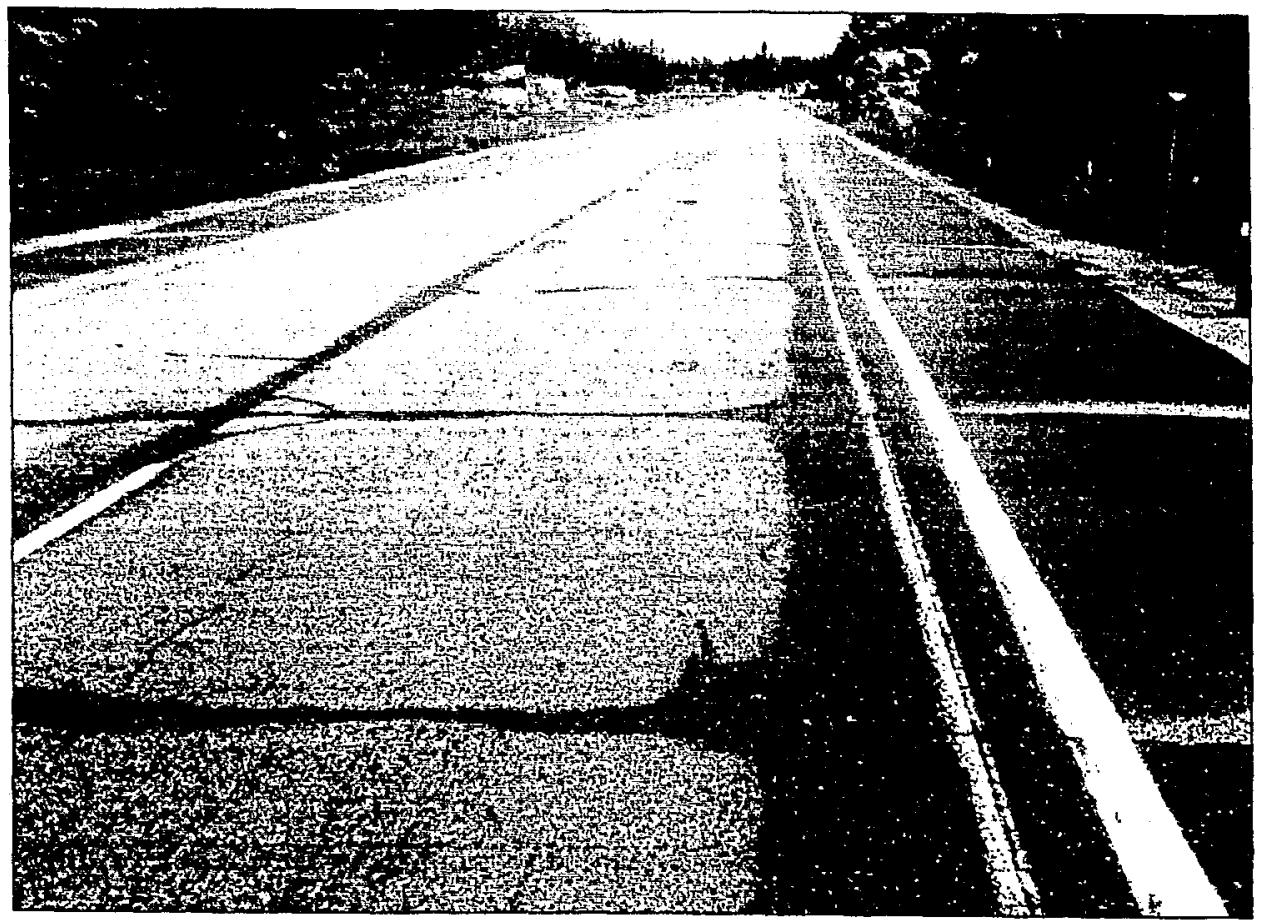

Figure 1.1 Reflective cracking in flexible pavement

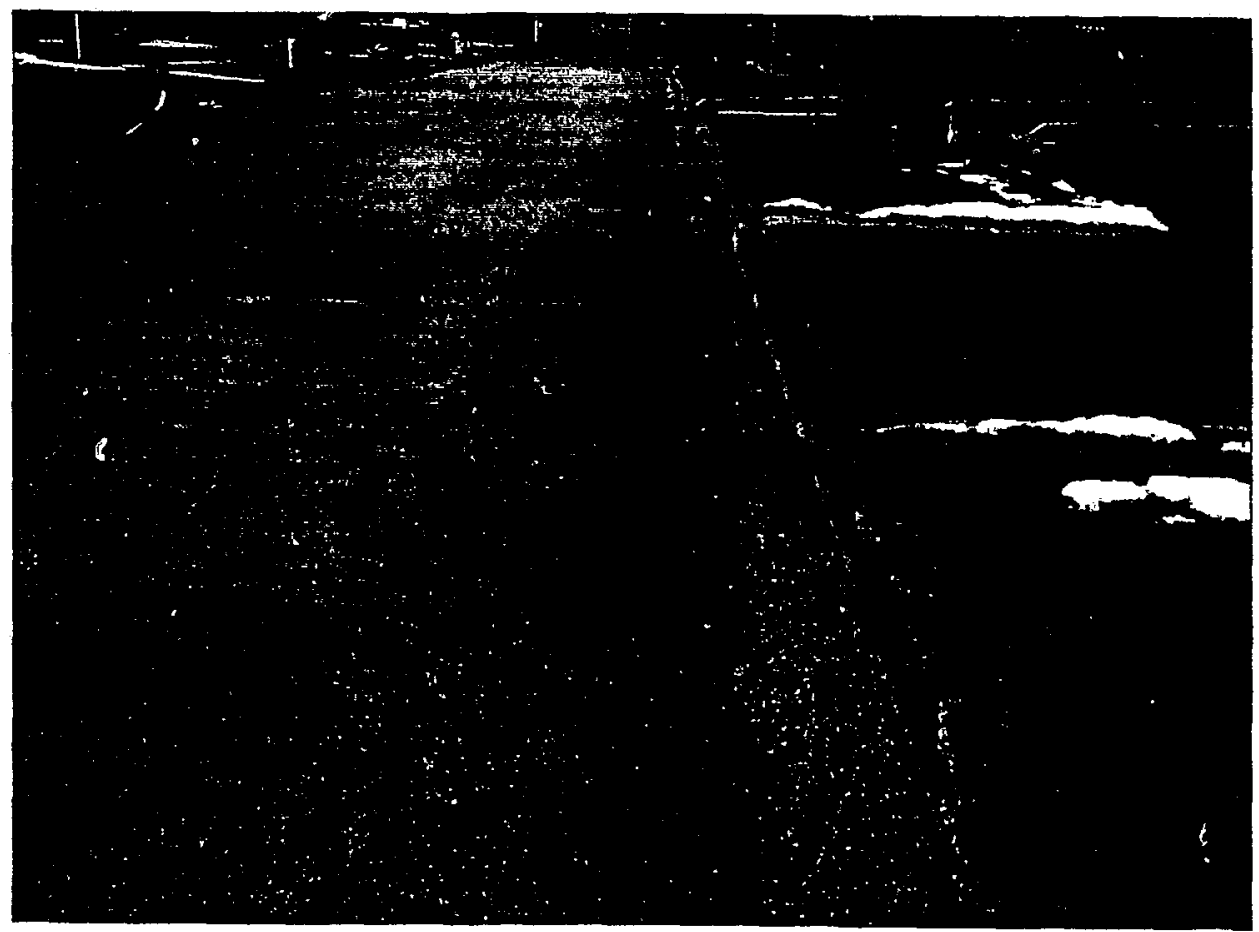

Figure 1.2 Progressive side edge cracking in flexible pavement

Reproduced with permission of the copyright owner. Further reproduction prohibited without permission. 
cracking), or may be due to shrinkage of the cement treated aggregate base or subgrade soils. Longitudinal cracks in the wheel path are normally fatigue related and eventually progress into alligator cracking or wheel track rutting. The picture presented in Figure 1.5 shows fatigue cracking at Highway 69, south of Muskoka Road 5, Ontario.

\subsection{DISTORTION}

Pavement distortion is due to asphalt layer instability and weakening of the granular base or subgrade. It may or may not be combined with cracks. Distortion may take various forms. Some of the forms are described in the following paragraphs.

\subsubsection{Corrugation and Shoving}

Corrugation and shoving are a form of plastic movement in the asphalt pavement surface. They normally occur at points of severe horizontal stress, for example traffic starts and stops, on hills where vehicles brake on the downgrade, on sharp horizontal curves, or at intersections. Corrugation and shoving usually occur in asphalt layers due to a lack of mix stability. Stability deficiencies may result from mixtures too rich in asphalt cement, too high in fine aggregate content, with round and smooth textured aggregates, or too soft asphalt cement. The picture presented in Figure 1.7 shows corrugation at Highway 69, north of Muskoka Road 5, Ontario.

\subsubsection{Settlement or Grade depression}

Depressions are low areas of limited size that may be combined with asphalt cracking. These depressions collect water and are not only a source of pavement deterioration, but are also hazardous to motorists and road traffic safety. A depression may be caused by traffic overloading, consolidation of the subgrade, settlement, or failure of the lower pavement layers. Settlements are commonly seen in marshy areas. The picture presented in Figure 1.8 a shows depression in flexible pavement.

\subsubsection{Upheave or Swell}

Upheave or swell is the localized upward displacement of a pavement due to swelling of the subgrade or some portion of the pavement structure. Frost heave is a very common type of distress in northern areas of Ontario. Upheave is most commonly caused by the expansion of the ice lenses in the lower layers of the pavement or subgrade. The presence of silty material is also a major cause of frost heave because silty materials are highly frost susceptible. High moisture content due to entrapped water or to seepage water, is also a major cause of frost heave. The picture presented in Figure $1.8 \mathrm{~b}$ shows frost heave at Highway 69, north of Muskoka Road 5, Ontario. 


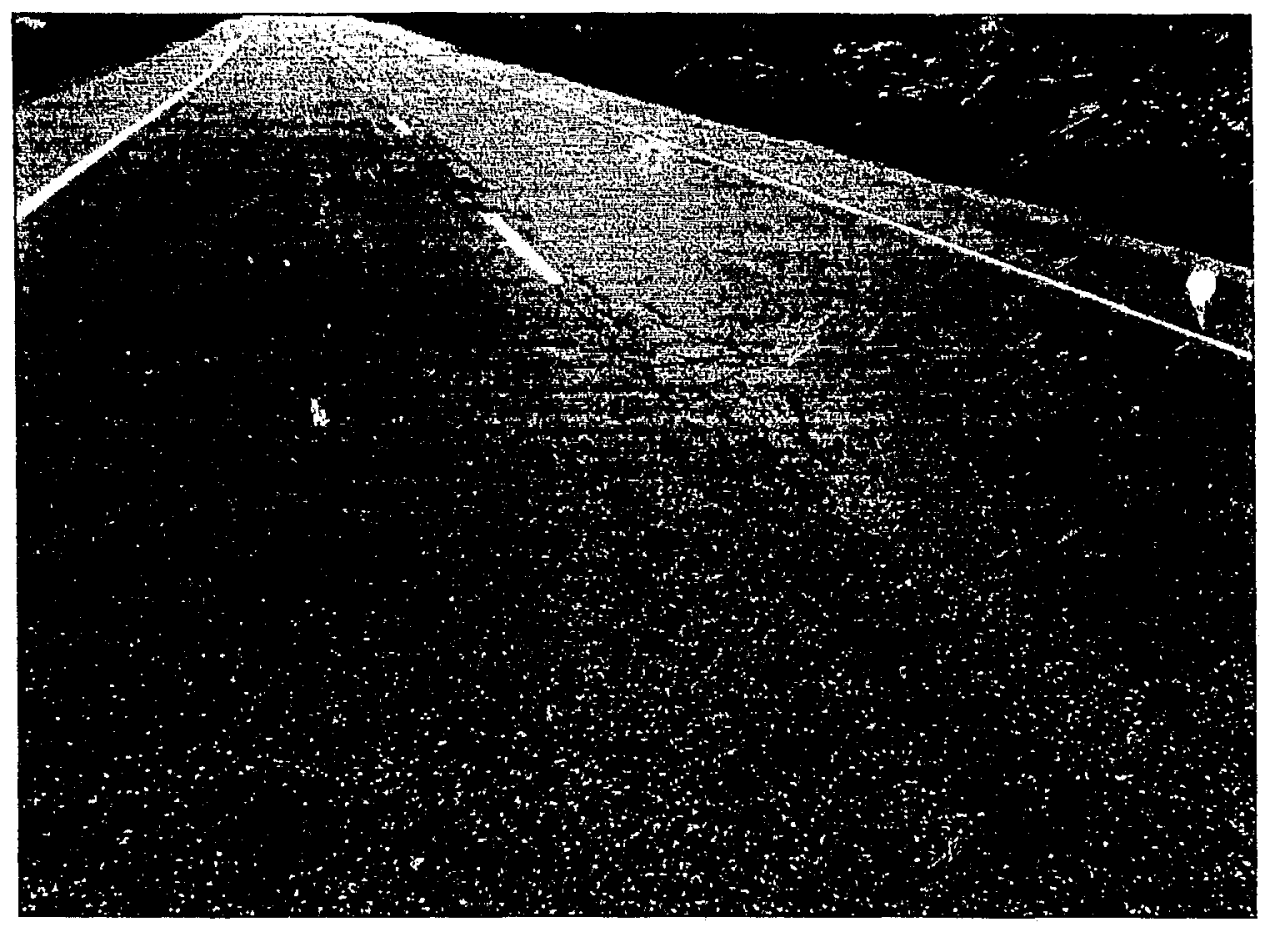

Figure 1.3 Severe block cracking in asphalt pavement

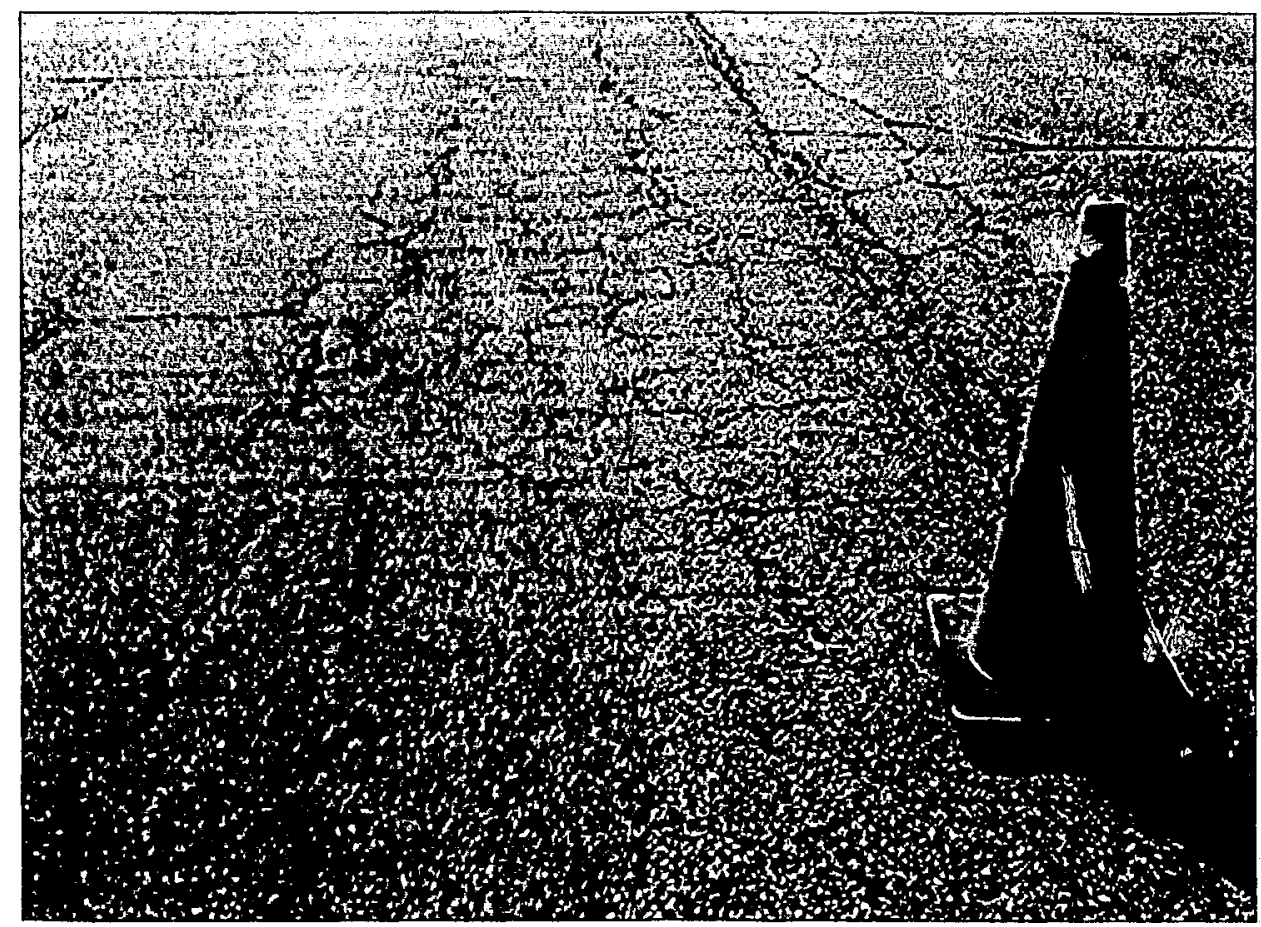

Figure 1.4 Alligator cracking in flexible pavement 


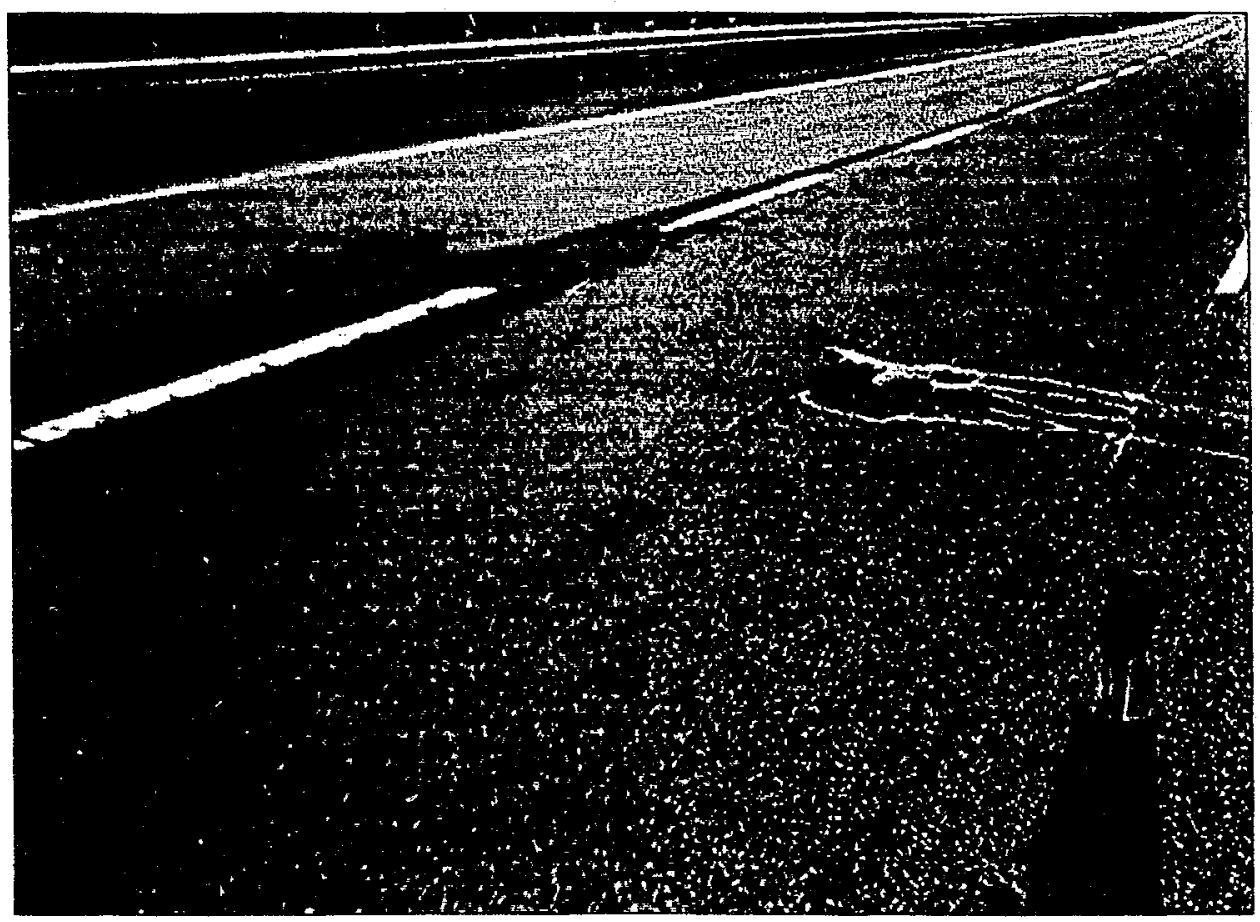

Figure 1.5 Linear cracking in flexible pavement

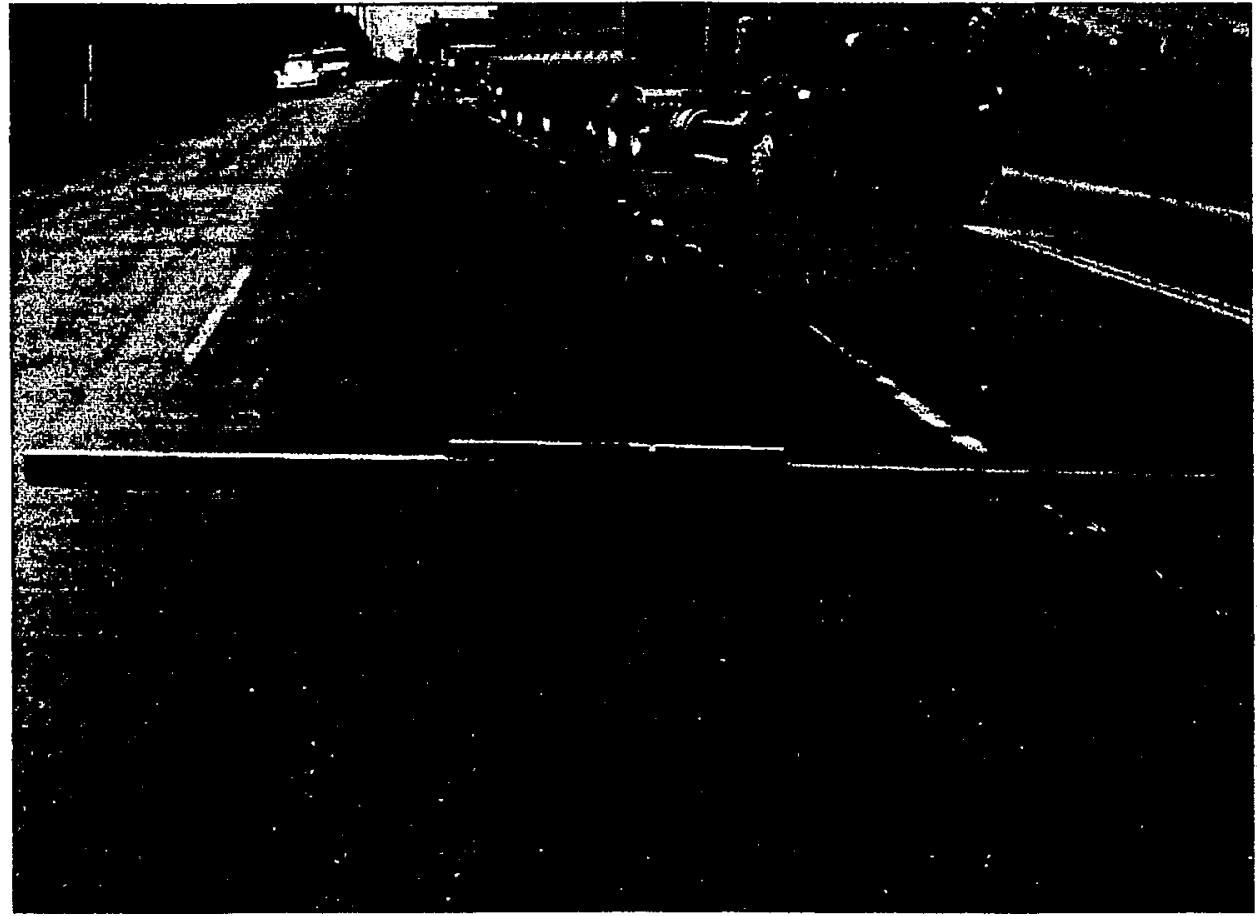

Figure 1.6 Severe rutting in asphalt pavement

Reproduced with permission of the copyright owner. Further reproduction prohibited without permission. 


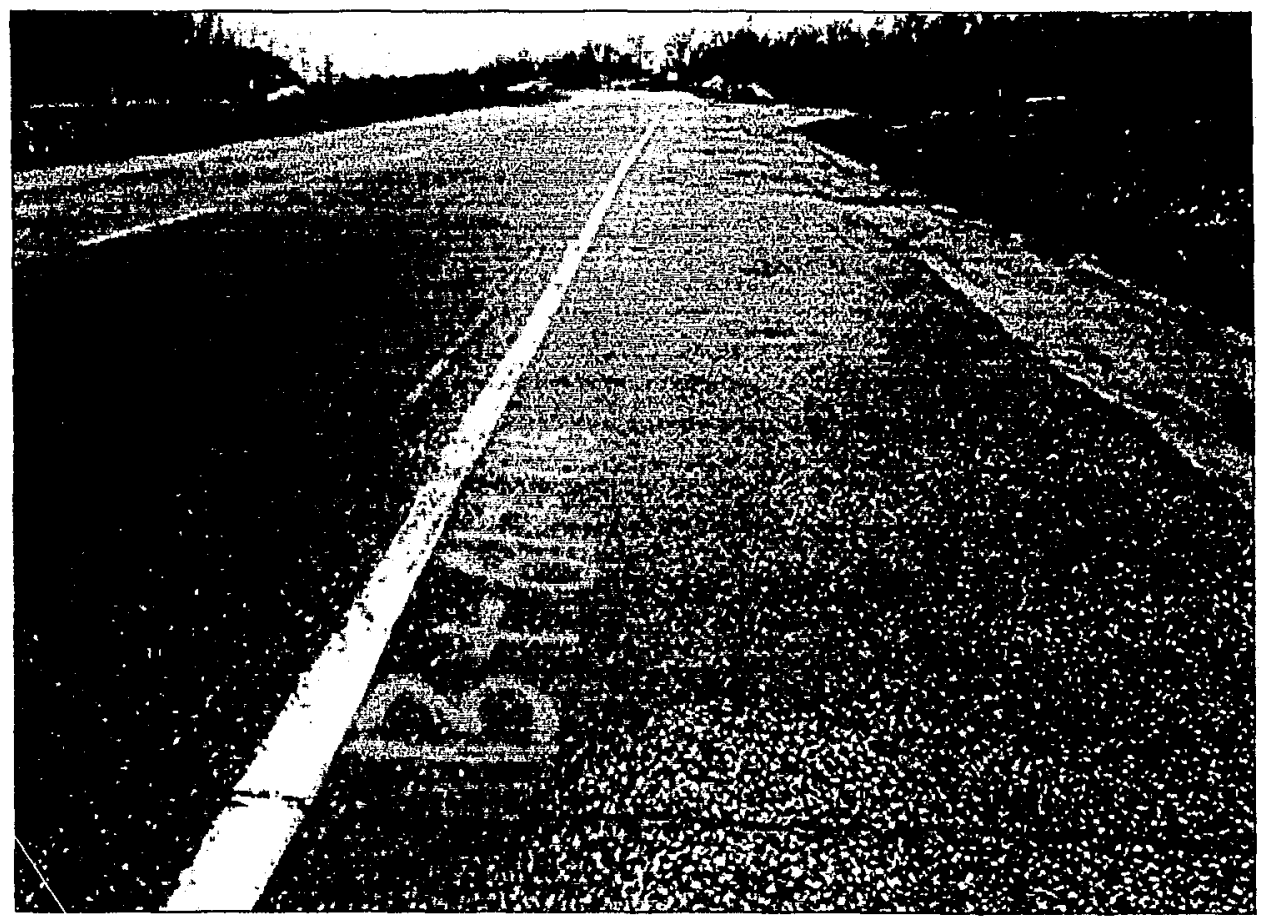

Figure 1.7 Corrugation at right shoulder of flexible pavement

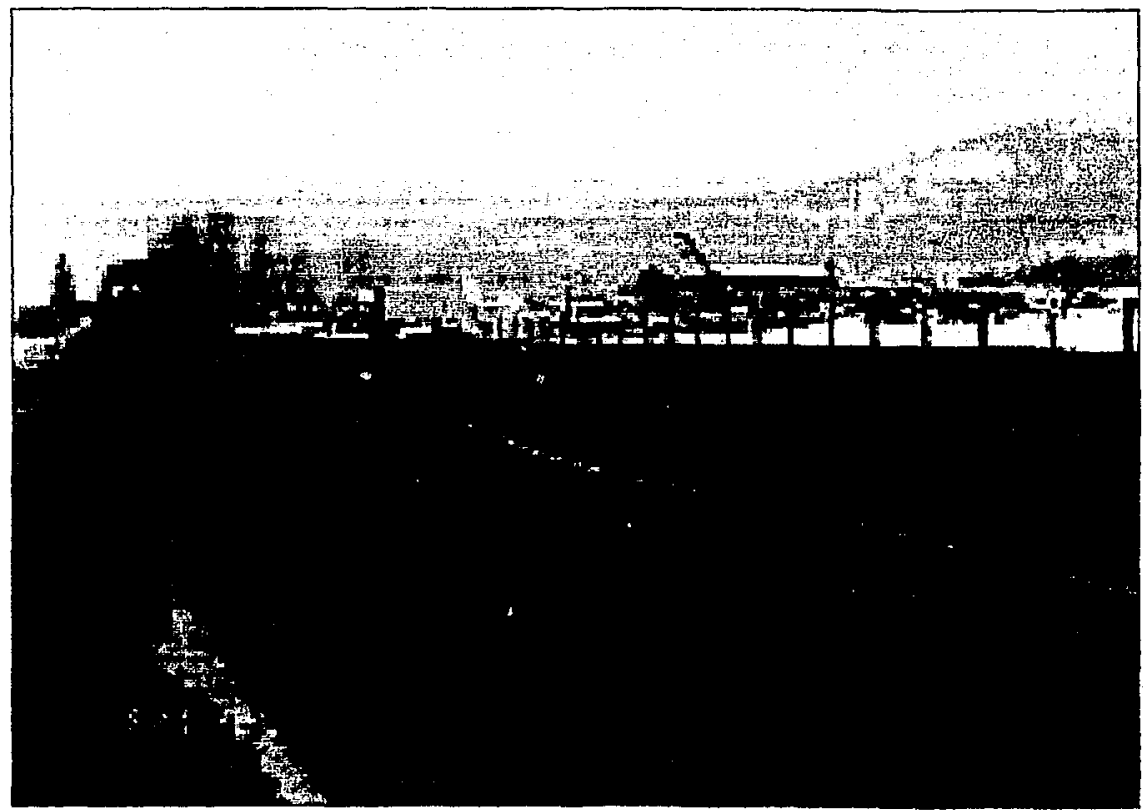

Figure 1.8 a Depression in flexible pavement

Source: National Center for Asphalt Technology "WSDOT Pavement Guide" 


\subsubsection{Utility Cut and/or Patch failure}

Utility cuts are made for utility installations, or to repair a localized area in the existing pavement. Deteriorated patches may cause disintegration, distortion, cracking, and spalling between the patch and the original surface. The picture presented in Figure 1.9. shows a utility patch in the City of Vaughan, Ontario.

\section{1,4 DISINTEGRATION}

Disintegration is the breaking up of a pavement into small, loose fragments. There are generally two types of disintegration. They are described below.

\subsubsection{Raveling}

Raveling is the progressive separation of aggregate particles from the pavement surface. Raveling progresses downward or from the edges inward. Usually, the fine particles come apart first and leave small holes in the pavement surface. Raveling is usually caused by a lack of HMA compaction, construction of a thin lift during cold weather, dirty or disintegrated aggregate, too little asphalt in the mix, or stripping of the aggregates. The process of raveling always requires the presence of both traffic and water. The picture presented in Figure 1.10 shows raveling at Guelph Line Road, Halton Region, Ontario.

\subsubsection{Pot Holes}

Pot holes are bowl shaped holes resulting from localized disintegration of aggregates. Pot holes are the result of distress which are not correctly or timely addressed. Pot holes extend through or into the aggregate base. Most pot holes occur in pavements having a thin asphalt concrete surface on an untreated base. The picture presented in Figure 1.11a shows pot holes at Highway 25, Halton Region, Ontario.

\subsection{SKID HAZARDS}

Dry pavements are not usually slippery. However, several factors can make a pavement slippery when wet. One of the most common causes of slippery asphalt pavements is a thin film of water on the smooth surface. Smooth pavement is generally due to a film of asphalt on the surface, or polished aggregate in the surface course. Open friction asphalt mixes are generally used to provide proper friction and appropriate drainage of the surface water. 


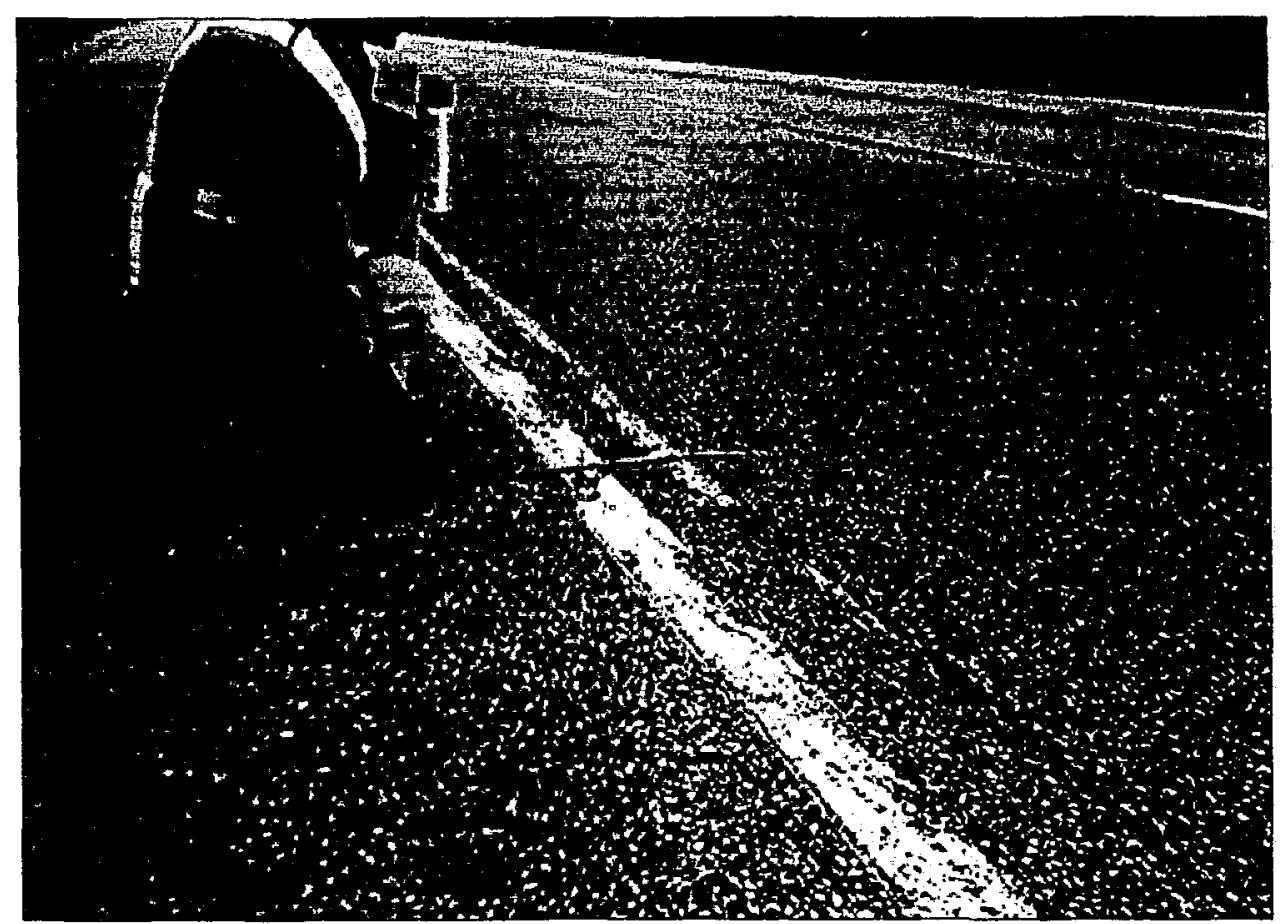

Figure 1.8 b Frost upheave

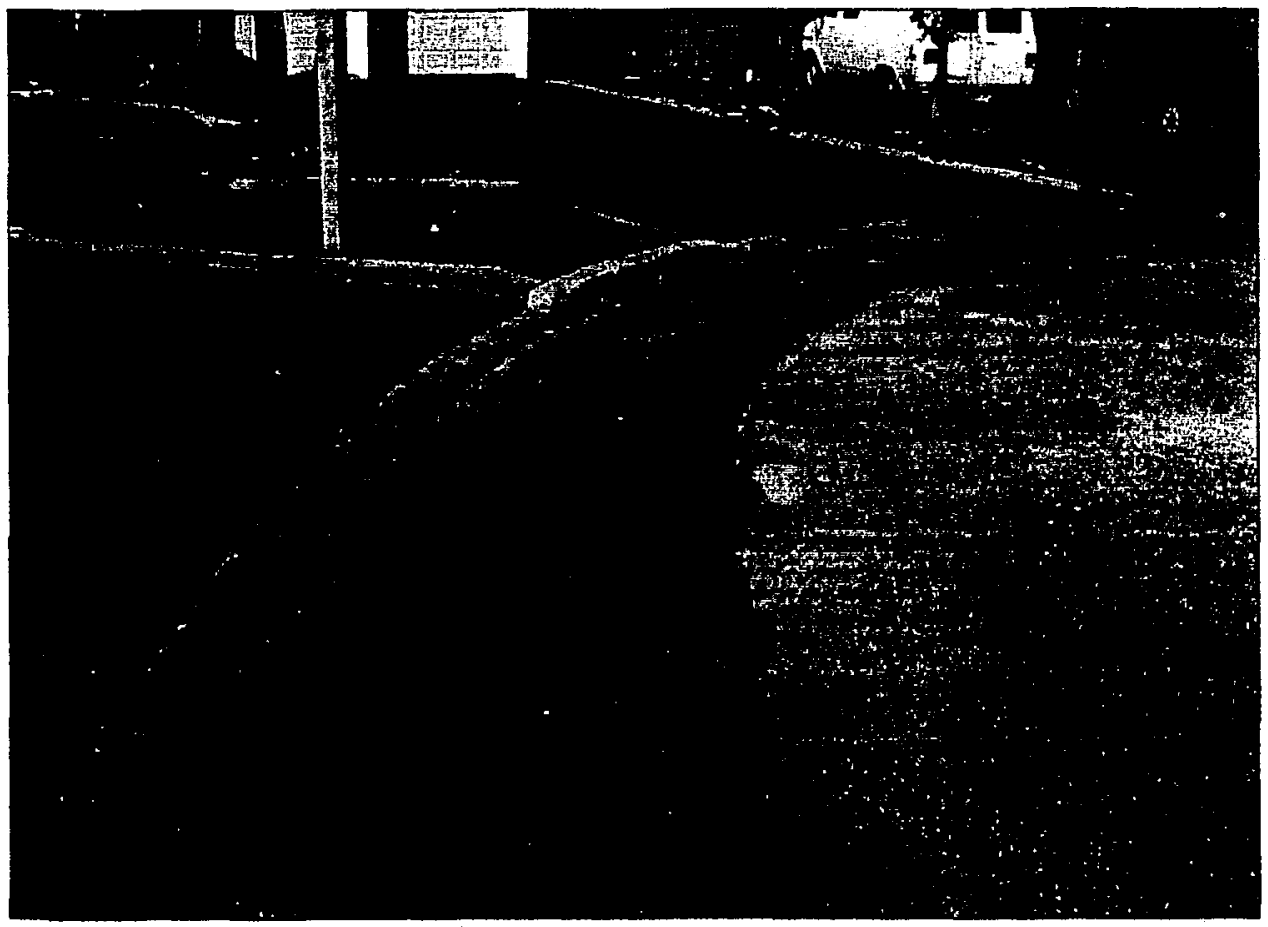

Figure 1.9 Utility Patch (Dark portion)

Reproduced with permission of the copyright owner. Further reproduction prohibited without permission. 


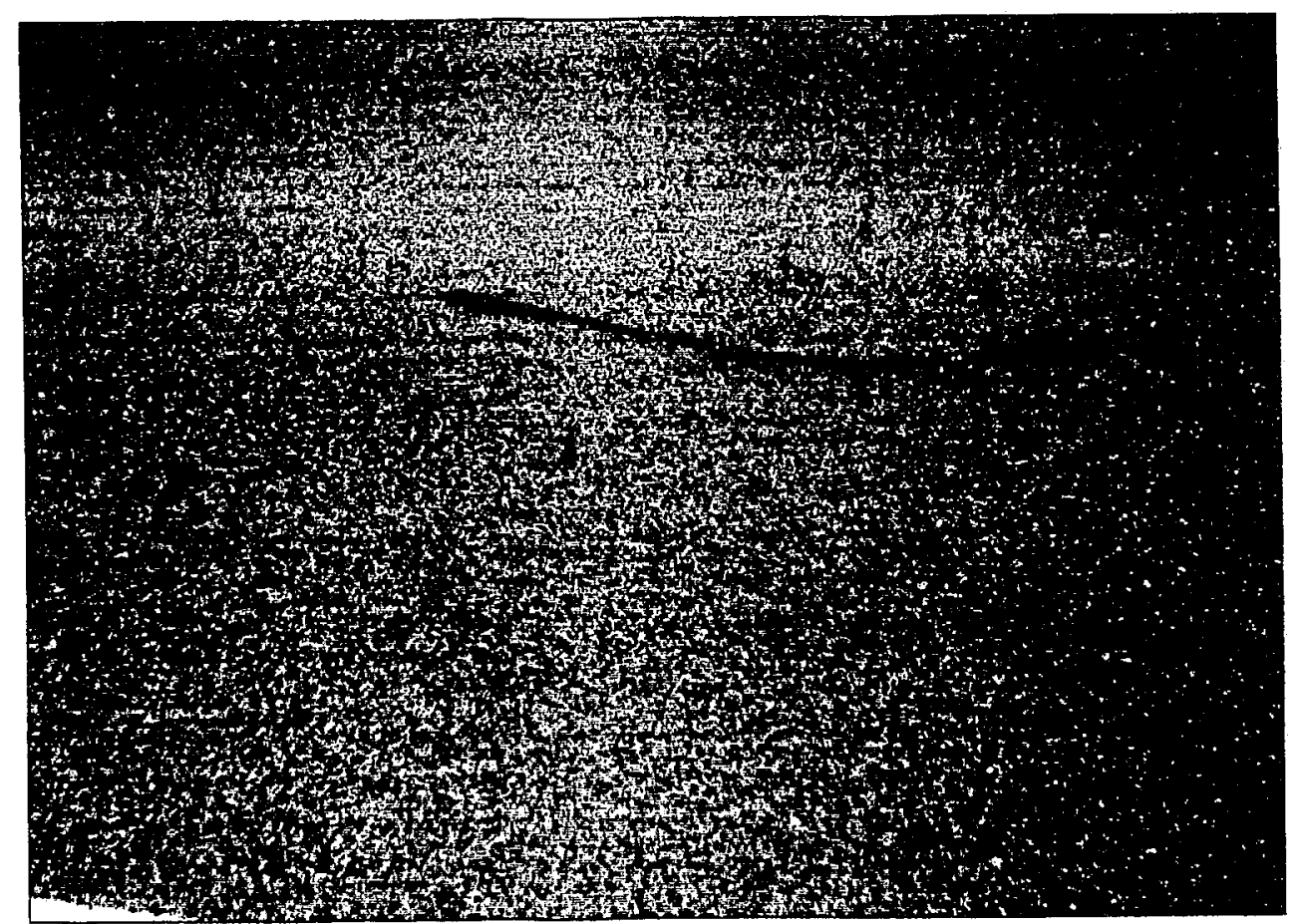

Figure 1.10 Raveling in surface course

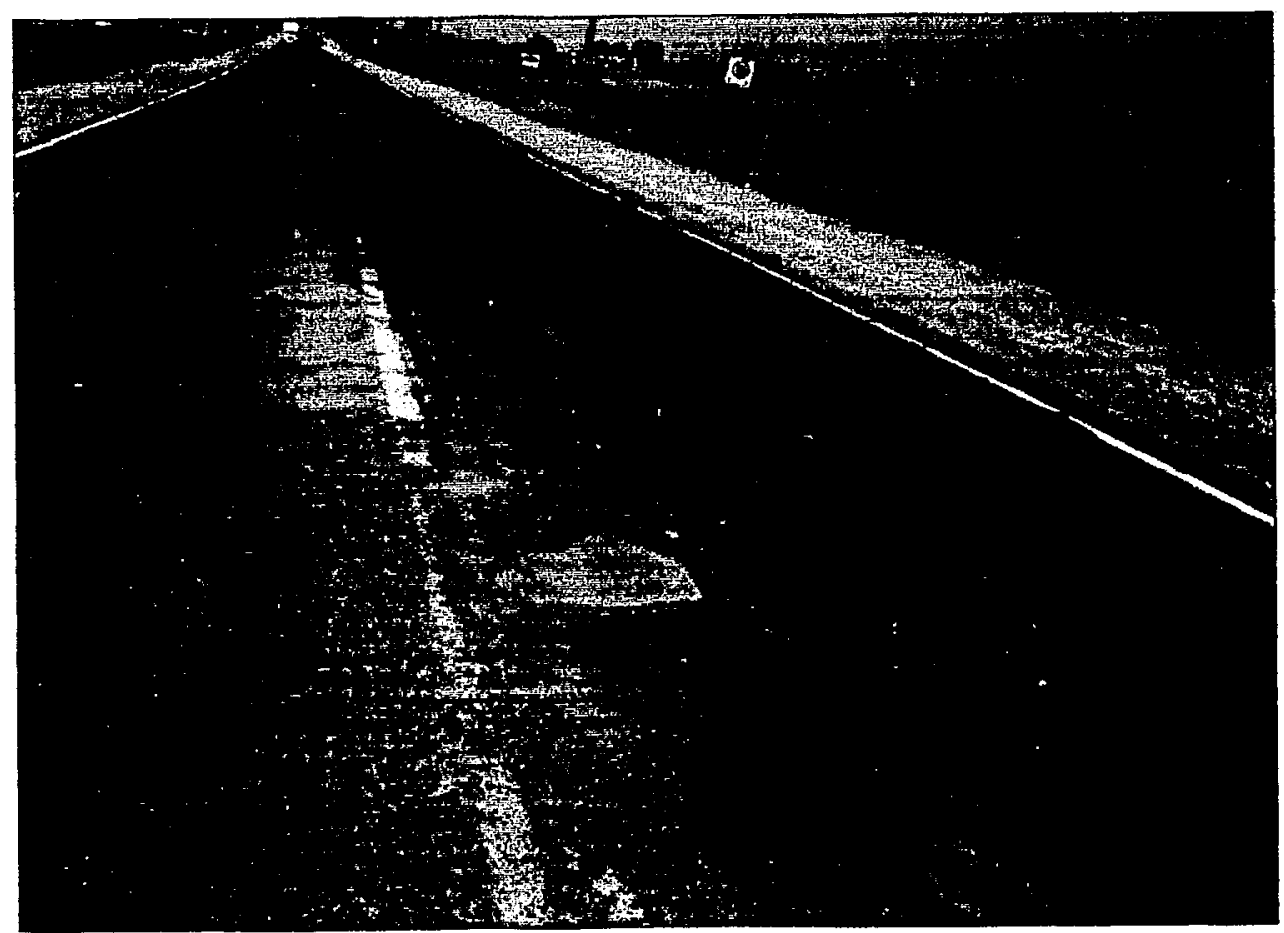

Figure 1.11 a Repaired pot holes

Reproduced with permission of the copyright owner. Further reproduction prohibited without permission. 


\subsection{SURFACE TREATMENT DISTRESSES}

\subsubsection{Bleeding or flushing}

Bleeding/flushing is the upward movement of asphalt cement on the surface. Bleeding can easily be identified as the pavement surface has a glassy appearance that may be sticky to the touch. Bleeding usually occurs in hot weather. The common cause of bleeding is excessive asphalt cement in the pavement asphalt layers. The picture presented in Figure $1.11 \mathrm{~b}$ shows bleeding in an existing pavement.

\subsubsection{Polished aggregate}

These are aggregate particles in the pavement surface that have been polished and become smooth. Polished aggregate includes both smooth uncrushed gravels and crushed rock that wears down quickly under the action of traffic. Limestone is more likely to wear quickly as compared to other coarse aggregates because it is low in hardness. The picture presented in Figure 1.12 shows an example of polished aggregates.

\subsection{TYPES OF DISTRESS IN RIGID PAVEMENT}

Rigid pavement distress can be classified as:

1. Cracking

2. Deformation

3. Disintegration

\subsubsection{Cracking}

Cracking occurs in rigid pavements as a result of relatively large volume changes produced in concrete by temperature variations. Cracks commonly result from the stresses caused by the contraction or warping of the pavement. Concrete expansion joints are provided at frequent intervals to accommodate concrete expansion. Concrete expansion joints on Highway 401 in the Greater Toronto Area (GTA) area are provided at $17 \mathrm{~m}$ intervals while, at the present time, expansion joints are provided at $4-5 \mathrm{~m}$ intervals.

\subsubsection{Linear cracking}

These are normally longitudinal, transverse and diagonal cracks. Longitudinal cracks run para.rel to the longitudinal joints. Transverse crack runs parallel to the transverse joints. Diagonal cracks form a triangle with the longitudinal edge and a transverse joint or crack. Linear cracking can be result from a number of causes. The principal causes 


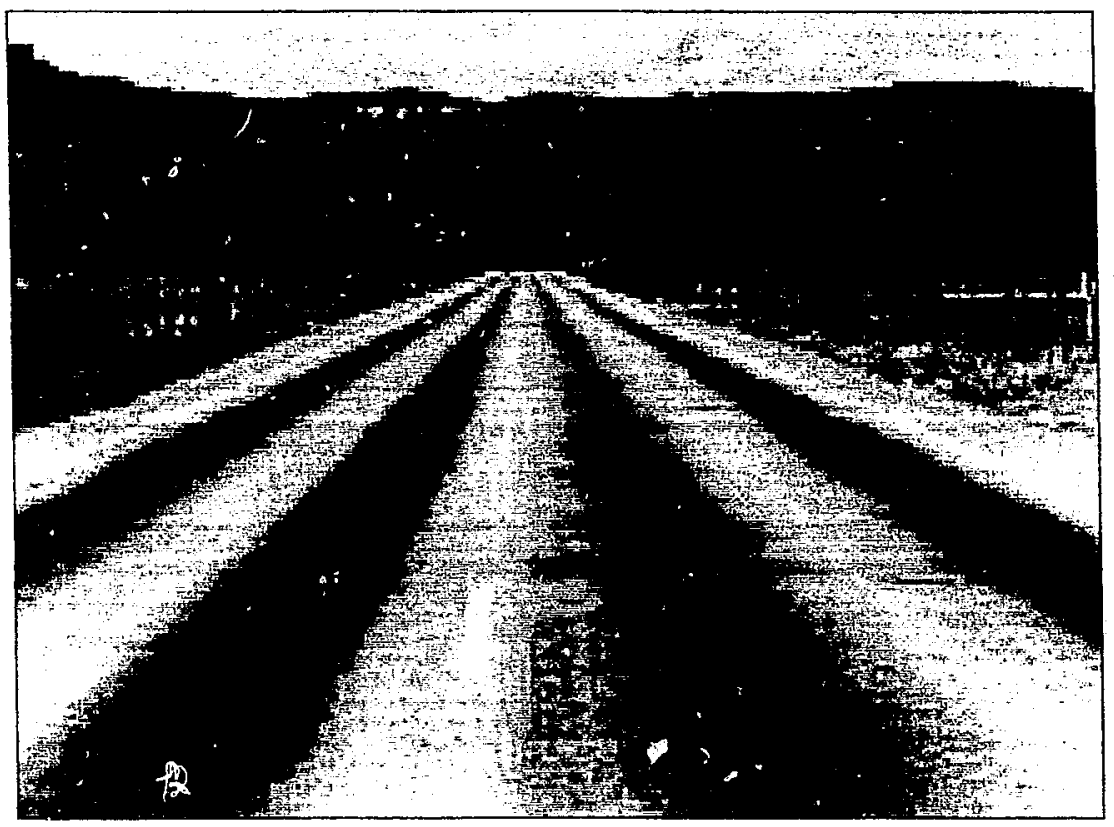

Figure $1.11 \mathrm{~b}$ bleeding/flushing on ariving lanes

Source: National Center for Asphalt Technology "WSDOT Pavement Guide

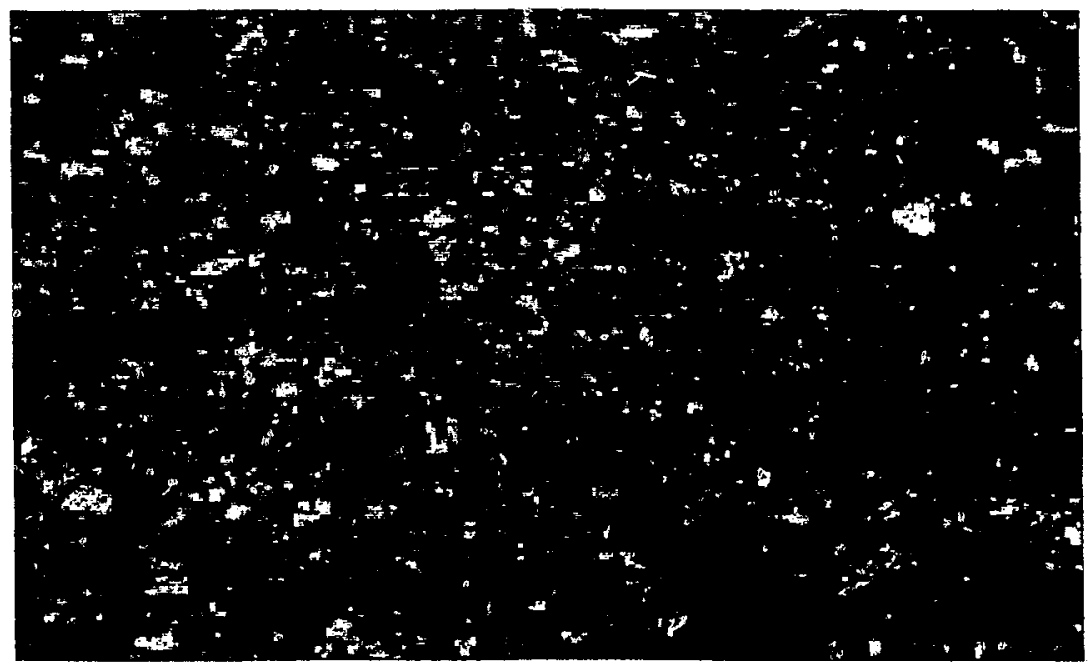

Figure 1.12 Polished Aggregate

Source: Federal Highway Administration (FWHA) 
include: traffic overload; warping or curling stresses; loss of support; improper length to width ratio; improper joint, and lack of proper load transfer. The picture presented in Figure 1.13 shows linear cracking in a rigid pavement.

\subsubsection{Corner Cracking}

These cracks progress to the full depth of the slab and are confined to one quadrant of the slab. Corner breaking is due to overloading combined with a loss of subgrade support. Loss of subgrade support is the result of pumping or poor load transfer at the transverse and longitudinal joints. The picture presented in Figure 1.14 shows corner cracking in a rigid pavement.

\subsubsection{Shattered Slab}

A shattered slab is the result of the breaking up of the concrete slab into four or more pieces. This distress is caused by poor subgrade support and fatigue of the concrete slab. However, overloading has a major effect in breaking the slab.

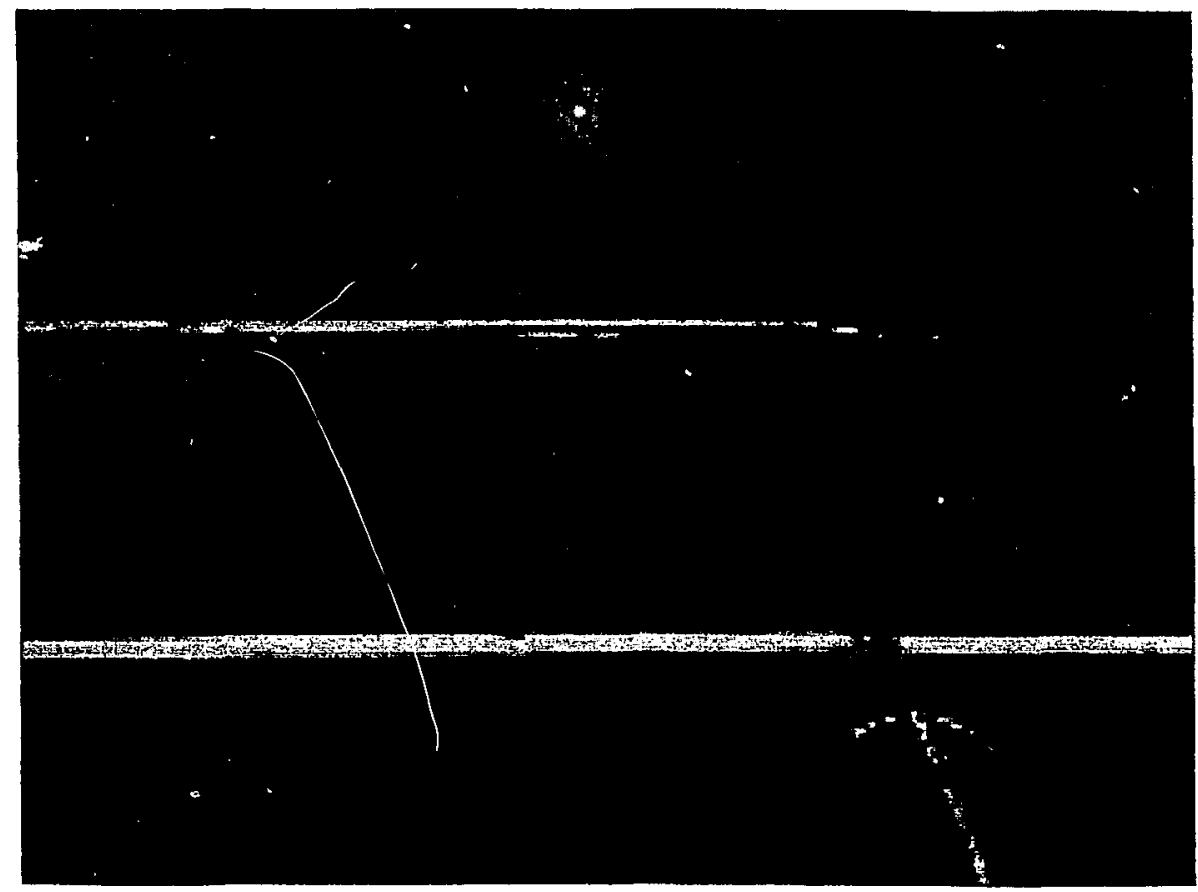

Figure 1.13 Linear cracking

Source: National Center for Asphalt Technology "WSDOT Pavement Guide" 


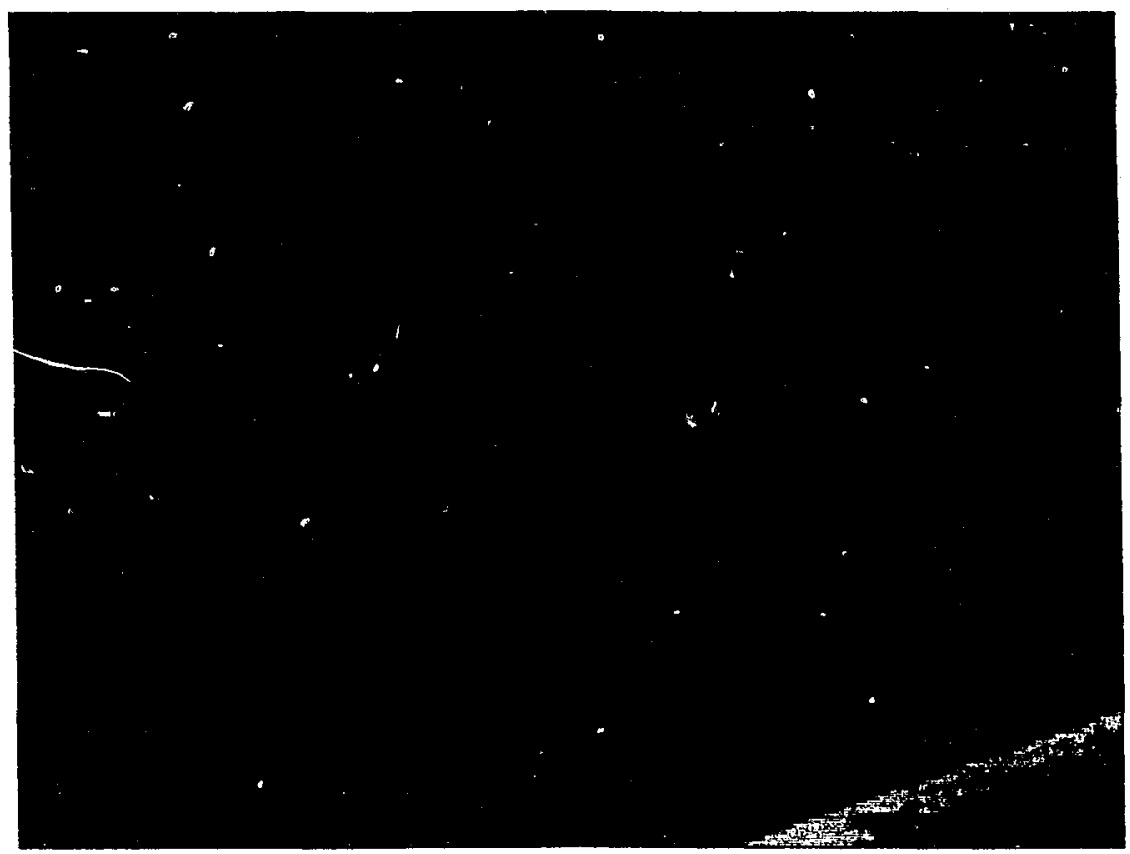

Figure 1.14 Corner cracking in concrete pavement Source: National Center for Asphalt Technology "WSDOT Pavement Guide"

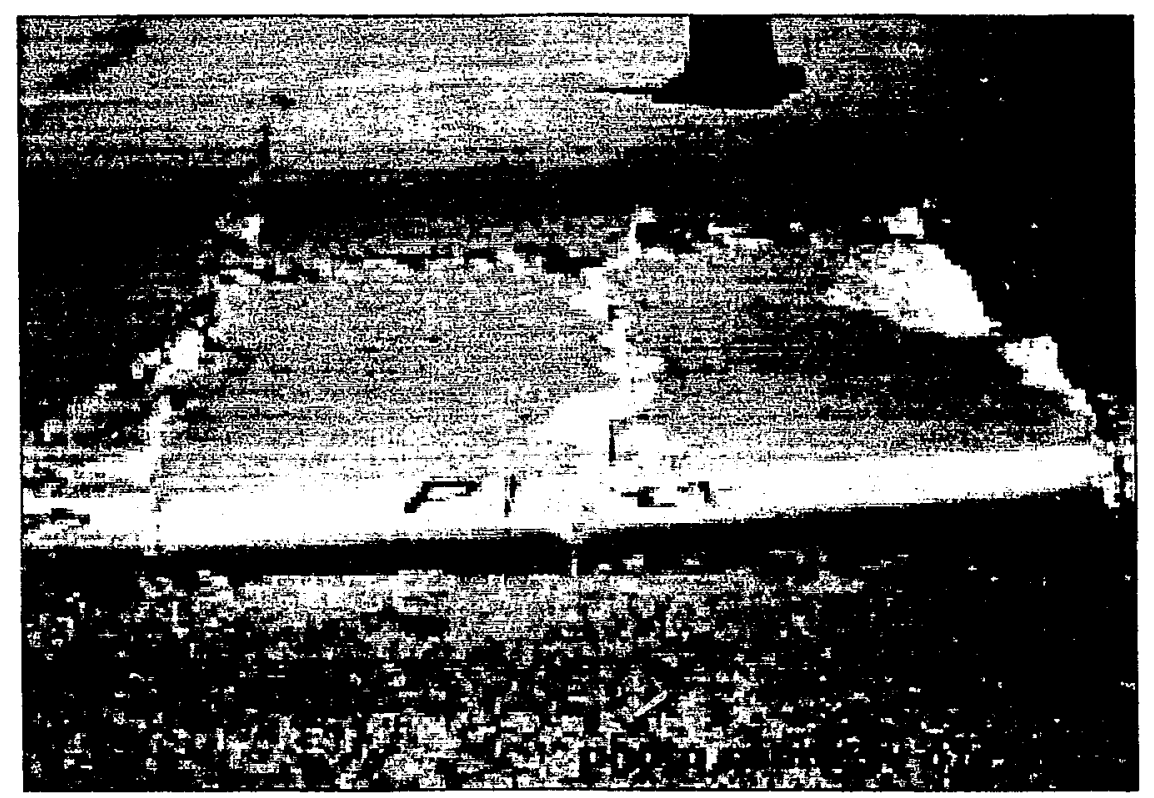

Figure 1.15 PCC slab punch out

Source: Federal Highway Administration 


\subsubsection{DEFORMATION}

Deformation is any change of the pavement surface from its original shape. Major causes of deformation are expansive soils, frost susceptible soils, and foundation settlement.

\subsubsection{Punch Out}

A punch out is a localized area of a Portland Cement Concrete (PCC) pavement broken into small pieces. Punch outs are caused by repetition heavy loads combined with a thin slab section, or a construction deficiency such as honey combing. The picture presented in Figure 1.15 shows severe punch out in a rigid pavement.

\subsubsection{Fauiting}

Faulting is an elevation difference across a joint or crack. It commonly develops due to the pumping of base or subgrade material and also to the consolidation or shrinkage in volume of the underneath pavement layers. The picture presented in Figure 1.16 shows severe faulting in a composite pavement.

\subsubsection{Blow ups}

A blow up is a localized upward movement of PCC pavement, usually occurring at a transverse crack or joint. Blowup may also happen at drainage structure or utility cuts. Most blow ups are caused by excessive expansion of the slab during hot weather. Infiltration of incompressible materials into the joints/ cracks prevents expansion of the concrete slab and results in severe blow ups. The picture presented in Figure 1.17 shows severe blow ups in Portland Cement Concrete (PCC) pavement.

\subsubsection{Pumping}

Pavement pumping is the ejection of water and suspended fines by deflection of a pavement slab at joints or cracks when a load passes over. The ejection usually carries subgrade particles in suspension from underneath the slab up through the cracks and joints, and along the pavement edges. Pumping can often be identified by stains or excess base material on the pavement surface along the joint or crack. The picture presented in Figure 1.18 shows water accumulation along the joint due to pumping action. 


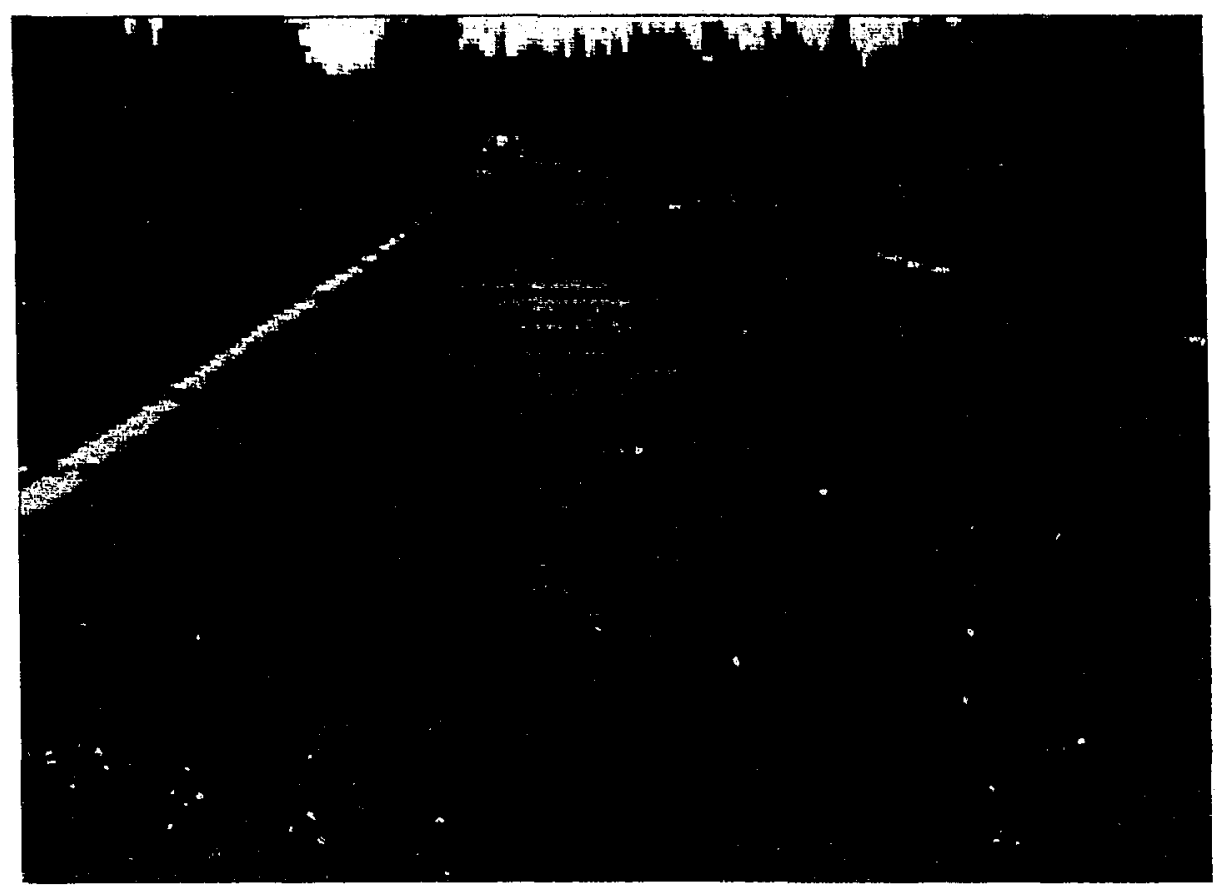

Figure 1.16 Severe faulting in composite pavement

Source: National Center for Asphalt Technology "WSDOT Pavement Guide"

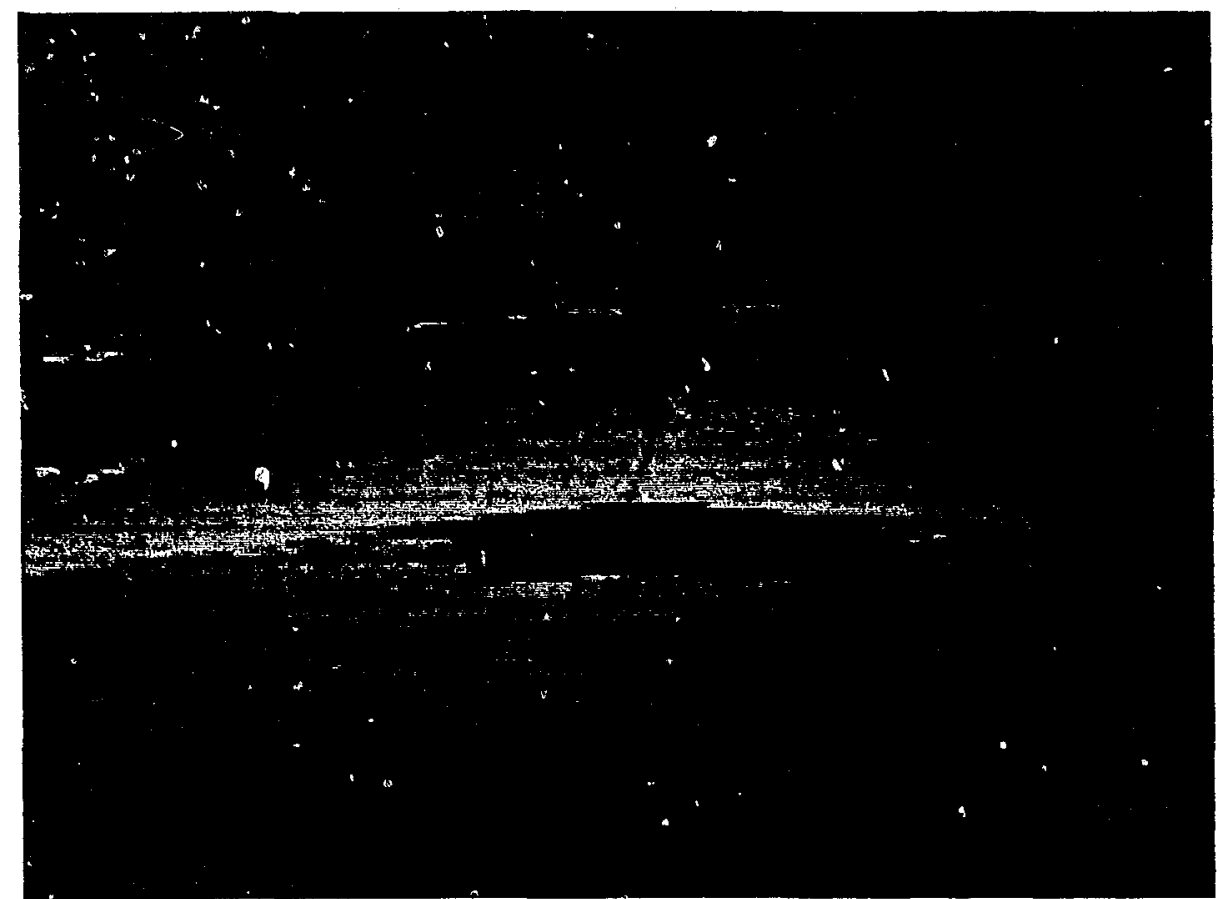

Figure 1.17 Severe Blowup in PCC slab

Source: National Center for Asphalt Technology "WSDOT Pavement Guide" 


\subsubsection{DISINTEGRATION}

Disintegration is the breaking up of a pavement into small, loose fragments. This includes the displacement of aggregate particles. If disintegration is not stopped in the early stages, it will continue and will lead to the complete failure of the pavement.

\subsubsection{Durability Cracking (D Cracking)}

Durability cracking is the progressive formation of fine cracks in concrete. It can be seen on the surface as fine cracks at very close intervals, parallel to the edges and joints, and curving around corners. Durability cracking usually starts at the bottom of the slab and only becomes visible when it reaches the surface. The picture presented in Figure 1.19 shows durability cracking in a rigid pavement.

\subsubsection{Scaling/Crazing/Map Cracking}

Scaling is the peeling away of the concrete surface. It can progress deep into the pavement. The major causes of scaling are the physical action of de-icing materials, over-finishing, improper mixing, unsuitable aggregates and improper curing.

\subsubsection{Joint and Corner Spalling}

Joint and corner spalling are the breakup or disintegration of the concrete at longitudinal or transverse pavement joints or cracks. Spalling is usually the result of poor joint or crack sealing, which allows incompressible material to enter the joint or crack. The picture presented in Figure 1.20 below shows severe joint concrete spalling.

\subsubsection{Polished Aggregates}

A major cause of slippery PCC pavements is polished aggregates in the surface. If poor quality aggregates, i.e. aggregates low in hardness, are used in a mix, they wear down and quickly become polished under traffic. The picture presented in Figure 1.21 shows polished aggregate on a concrete pavement surface.

\subsubsection{Patches or Utility Cuts}

Patches are any pavement area that has been replaced with asphalt or PCC to repair a pavement defect. A patch may be used to repair a pavement trench or hole made to create access to underlying utility lines. It is not a type of distress but it may cause deterioration where there is a lack of compaction and settlement or other poor workmanship. The picture presented in Figure 1.22 shows an example of a utility cut made for maintenance. 


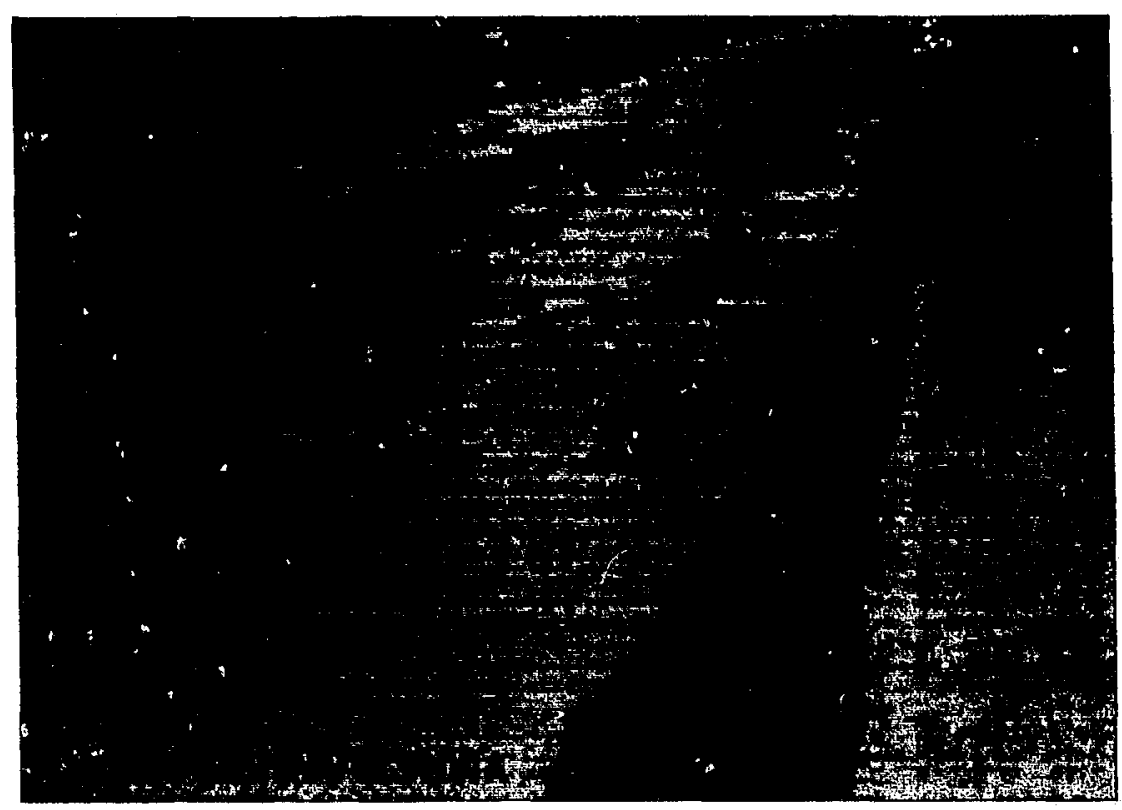

Figure 1.18 Water accumulation due to pumping Source: Federal Highway Administration

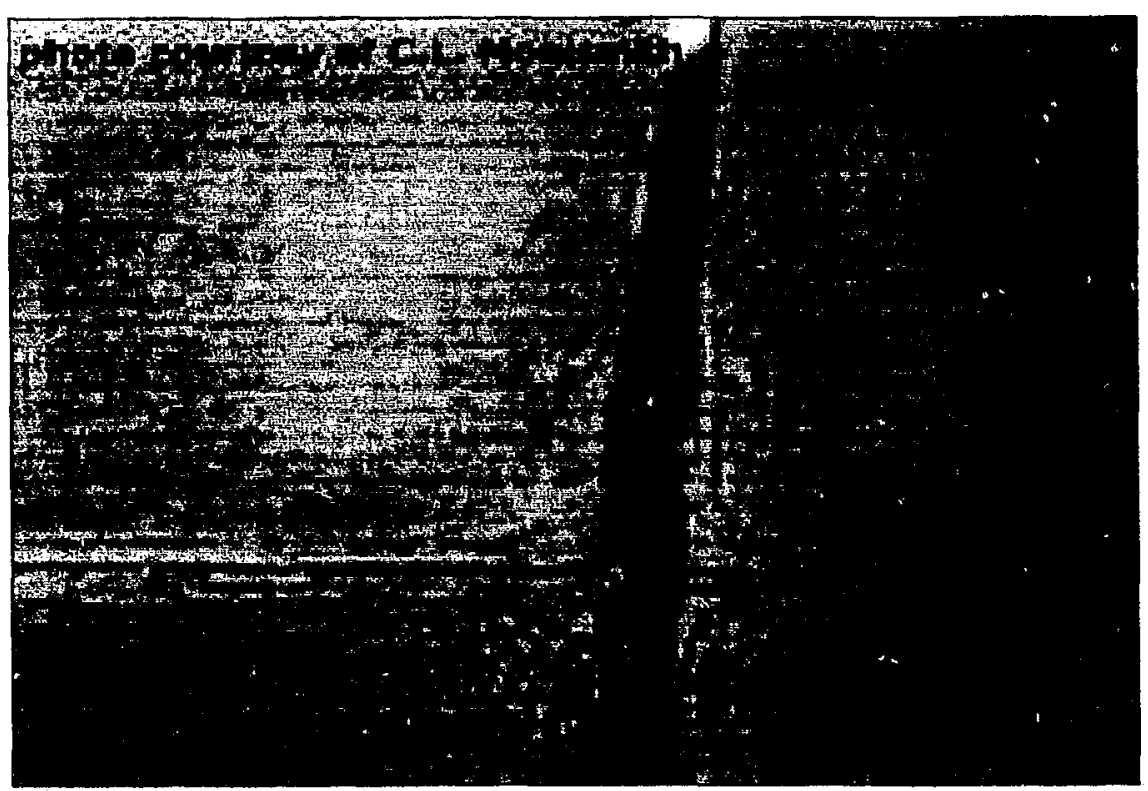

Figure 1.19 Durability cracking

Source: C. L Monismith, http:hotmix.ce.washington.edu 


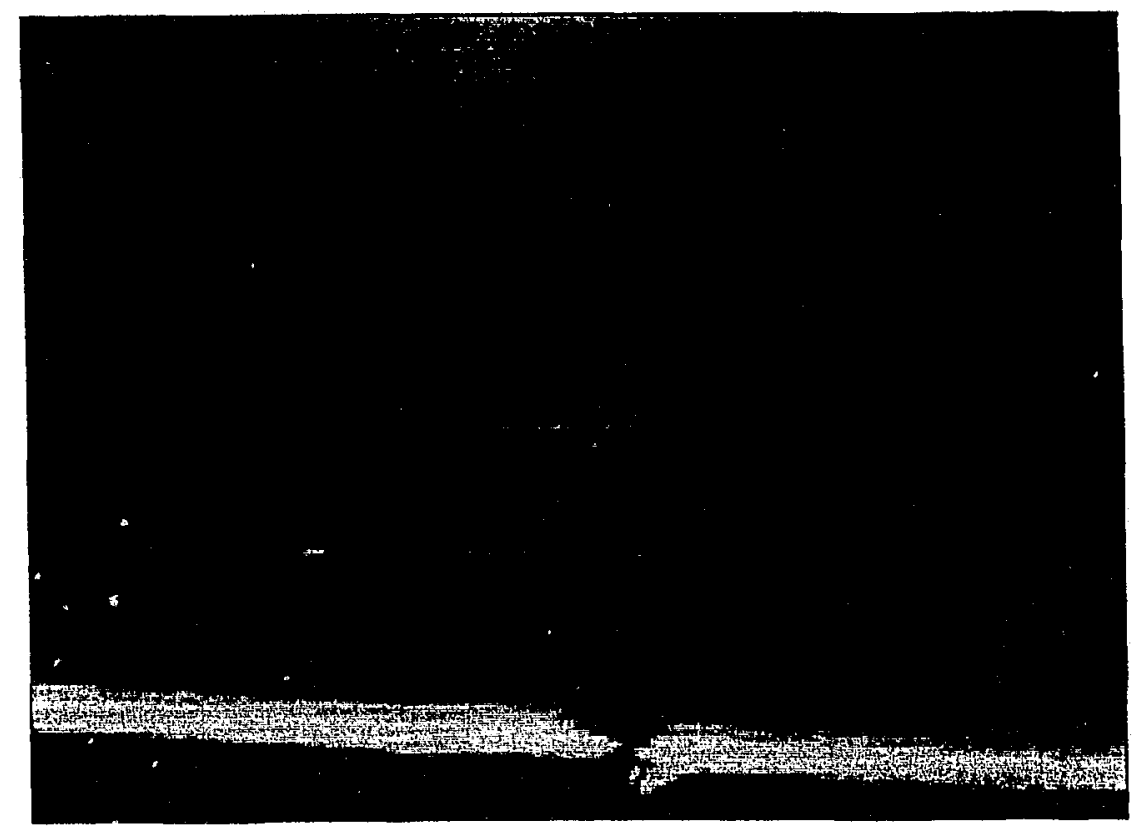

Figure 1.20 Joint concrete spalling

Source: National Center for Asphalt Technology "WSDOT Pavement Guide"

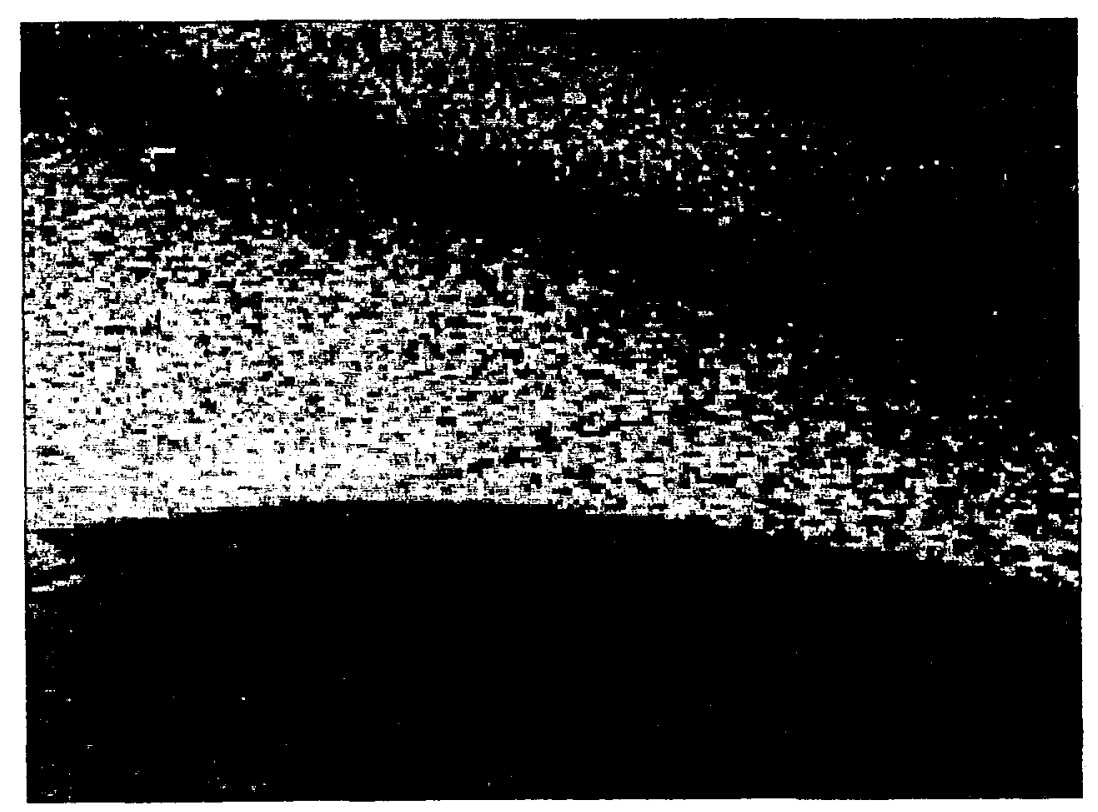

Figure 1.21 Polished aggregate

Source: National Center for Asphalt Technology "WSDOT Pavement Guide" 


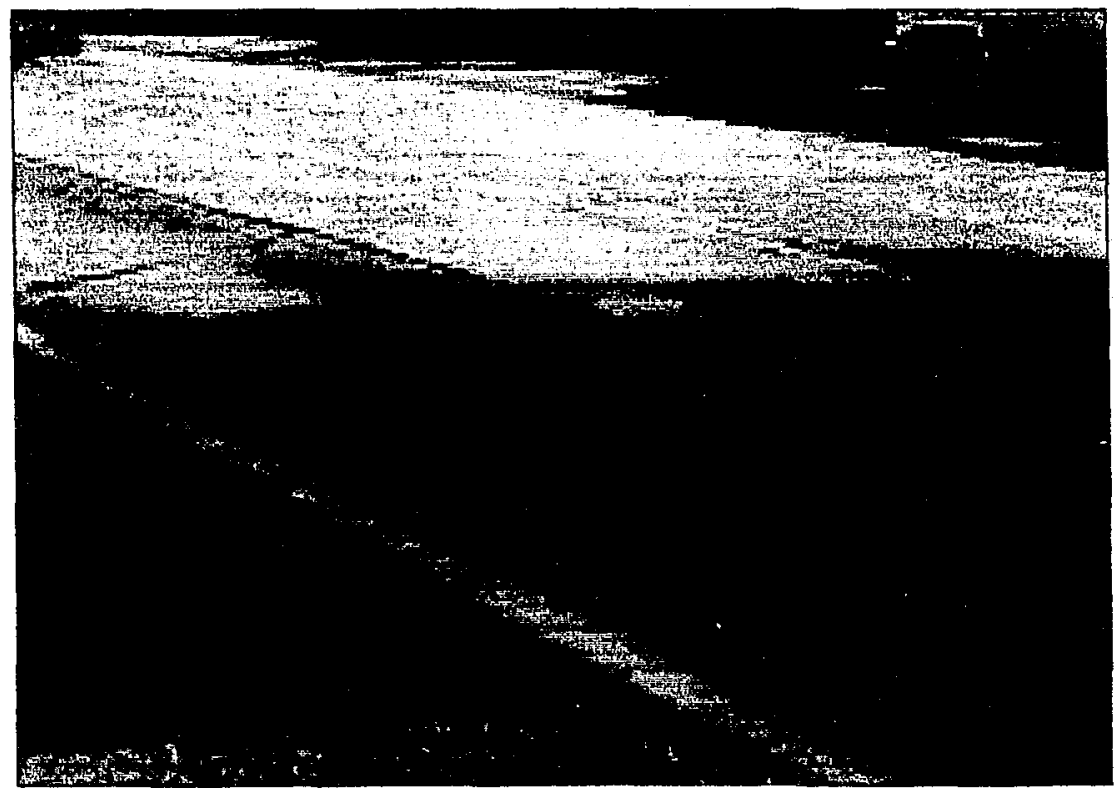

Figure 1.22 Utility cut for maintenance

Source: National Center for Asphalt Technology "WSDOT Pavement Guide" 


\section{CHAPTER 2}

\section{PAVEMENT PERFORMANCE AND EVALUATION}

Pavement performance is a function of the pavement's relative ability to serve traffic over a certain period of time. Originally, a pavement's ability to serve traffic was determined by visual inspection and experience, and it was carried out subjectively. However, experience is difficult to transfer from one person to another. Decisions vary from person to person and are not consistent (22).

In the late 1950s, systems of objective measurement were established to measure a pavement's condition and performance. These systems, along with visual distress surveys, were used for maintenance and rehabilitation decisions. With the passage of time, these systems have been refined and upgraded (22). They are used to provide a rapid and objective means for deciding the following:

\section{- Maintenance priorities}

Condition data such as roughness, distress and deflection are used to establish a priority list of sites most in need of maintenance and rehabilitation. The sites in the poorest condition (low rating) are then evaluated more closely to determine suitable repair strategies.

\section{- Maintenance and rehabilitation strategies}

Data from visual distress surveys are used to develop a master plan on a year-to-year basis. This plan states which strategy (patching, surface treatments, overlays, recycling, etc.) is most appropriate for a given pavement condition.

\section{- Prediction of pavement performance}

Data, such as riding quality, skid resistance, distress, or a combined rating; are interpreted to assist in preparing long-range budgets or in estimating the condition of pavements in a network for a fixed given budget.

Today, pavement performance is largely defined by evaluation of the following categories:
1. Roughness
2. Surface distress
3. Skid resistance
4. Structure evaluation 


\subsection{ROUGHNESS}

Pavement roughness is generally defined as pavement surface deficiencies that adversely affect the riding quality of a vehicle. Roughness is an important pavement characteristic because it affects not only riding quality, but also vehicle delay costs, fuel consumption and maintenance costs. The term "smoothness" may also be used to describe the same pavement quality.

\subsubsection{Measurement of Roughn'ss}

Roughness is typically measured using the Present Serviceability Rating (PSR) or the International Roughness Index (IRI).

\subsubsection{Present Serviceability Rating (PSR)}

The AASHO Road Test (Highway Research Board, 1962) defines pavement serviceability in terms of the Present Serviceability Rating (PSR), which is based on individual observation. PSR is defined as

"The judgment of an observer as to the current ability of a pavement to serve the traffic it is meant to serve" (Highway Research Board, 1962).

To develop the original AASHO Road Test PSR scores, observers drove around test tracks and rated their ride using the scale presented in Figure 2.1 below. This subjective scale ranges from 5 (excellent) to 0 (non drivable). Since PSR is based on passenger observations of ride quality, it generally reflects road roughness because roughness largely refers to the riding quality of the pavement (22).

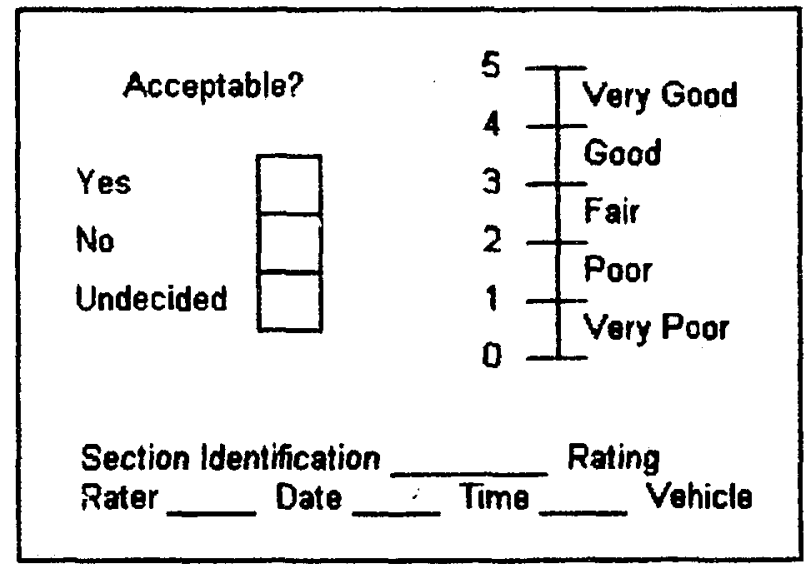

Figure 2.1 Individual Present Serviceability Rating (22) 


\subsubsection{International Roughness Index (IRI)}

The International Roughness Index (IRI) was developed by the World Bank in the 1980 s (UMTRI, 1998). The IRI is used to define the condition of the longitudinal profile of a traveled wheel track using a standardized roughness measurement. The commonly used units are meters per kilometer $(\mathrm{m} / \mathrm{km})$ or millimeters per meter $(\mathrm{mm} / \mathrm{m})$. The $\mid \mathrm{RI}$ is based on the Average Rectified Slope (ARS). It is a ratio of a standard vehicle's accumulated suspension motion (in $\mathrm{mm}$, inches, etc.) divided by the distance traveled by the vehicle during the measurement $(\mathrm{km}, \mathrm{mi}$, etc.). The IRI is equal to the ARS multiplied by $1,000(22,23)$. The open-ended IRI scale is shown in Figure 2.2.

\subsection{Roughness Measurement Techniques}

The equipment used to collect data in roughness surveys can be divided into four broad categories:
1. Survey
2. Profilographs
3. Response Type Road Roughness Meters
4. Profiling Devices

\subsubsection{Survey}

A survey can be performed by a survey crew. A survey provides an accurate measurement of the pavement profile. However, the use of surveys for large projects is impractical, expensive and time consuming.

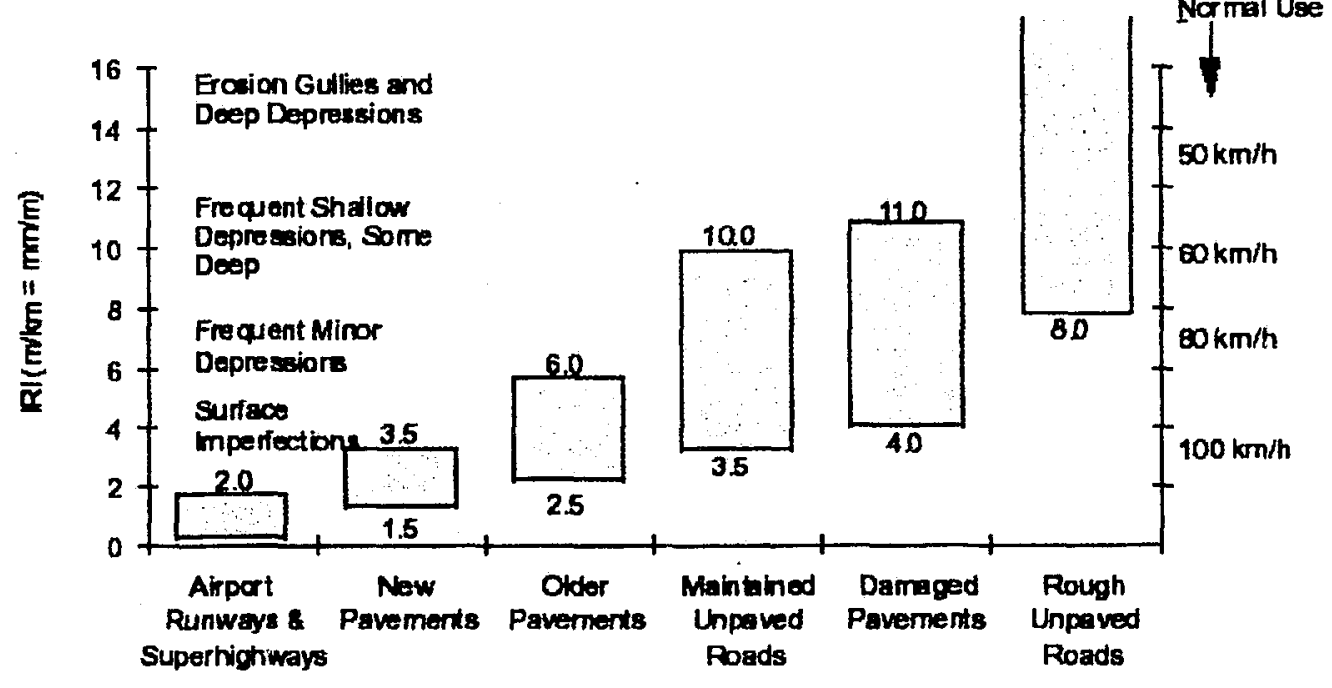

Figure 2.2 IRI Roughness Scale (22) 
The dipstick profiler can be used to collect a relatively small quantity of pavement profile measurements. The Dipstick Profiler consists of an inclinometer enclosed in a case supported by two legs separated by $305 \mathrm{lnm}$ (12 in.). Digital displays are attached at each end of the instrument. Each display reacis the elevation of the leg at its end relative to the elevation of the other leg (22).

The operator then "walks" with the dipstick on a pre-marked pavement section. Readings are recorded as the operator traverses the section. The device records 10 to 15 readings per minute. Software analysis provides a profile accurate to $\pm 0.127 \mathrm{~mm}$ ( $\pm 0.005 \mathrm{in}$ ). A section of a pavement can be surveyed by a single operator in about half the time of a traditional survey crew. The dipstick is commonly used to measure a profile for calibration of complex instruments.

\subsubsection{Profilographs}

Profilographs have been in use for many years. They are available in a variety of different forms, configurations, and brands. Due to their design they are not practical for network condition surveys. Their most common use today is for rigid pavement construction inspection, quality control, and acceptance (22).

Profilographs have a mounted sensing wheel, which provides a free vertical movement at the center of the frame. The deviation against a reference plane, established from the profilograph frame, is recorded (automatically in some models) on graph paper from the motion of the sensing wheel. Profilographs can detect very slight surface deviations or undulations up to about $6 \mathrm{~m}(20 \mathrm{ft})$ in length.

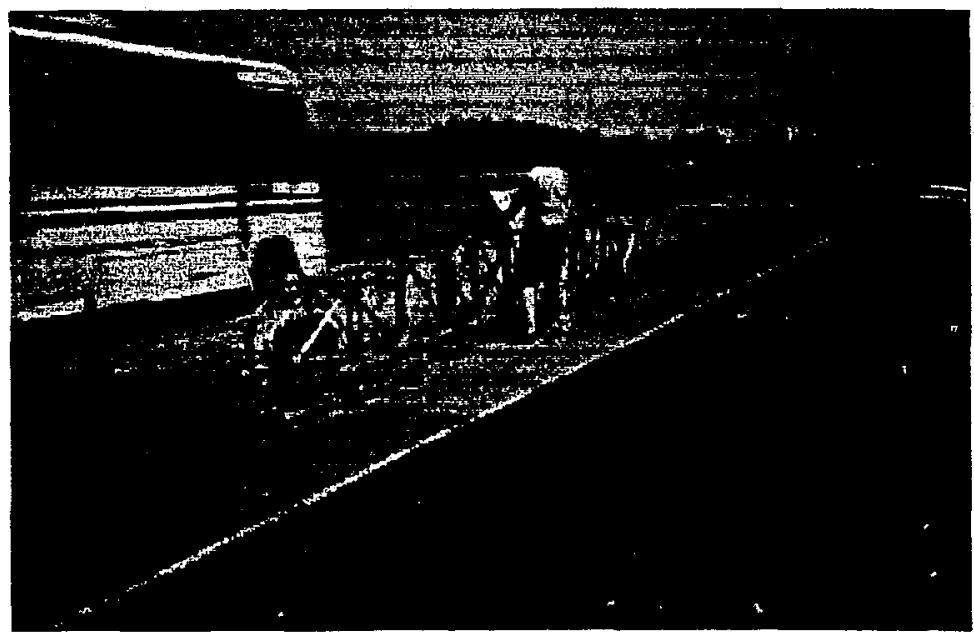

Figure 2.3 Profilograph

Source: National Center for Asphalt Technology "WSDOT Pavement Guide" 


\subsubsection{Response Type Road Roughness Meters (RTRRMs)}

The third category of roughness data collection equipment are Response Type Road Roughness Meters (RTRRMs), known as "road meters". RTRRM systems are adequate for routine monitoring of a pavement network and for providing an overall picture of the condition of the network.

RTRRMs measure the vertical movements of the rear axle of an automobile or the axle of a trailer relative to the vehicle frame. The meter is installed in vehicles and a displacement transducer is installed on the body. It is located between the middle of the axle and the body of a passenger car or trailer. The transducer detects small increments of axle movement relative to the vehicle body.

The disadvantage of a RTRRM is that the measurement of axle body movement vs time depends on the dynamics of the particular measuring vehicle. It has the following two undesired effects (22);

- Roughness measuring methods have not been stable over time. Measurements made today with road meters cannot be compared with confidence to those made several years ago.

- Roughness measurements have not been transportable. Road meter measurement made by one system are seldom reproducible by another.

\subsubsection{Profiling Devices}

Profiling devices are used to provide accurate, scaled, and complete information on the pavement profile within a certain range. Nowadays, the equipment in use has become fairly expensive and complex.

The earliest profiling devices measured pavement profiles using measurement systems that had a direct contact with the pavement. Several contact systems were used, and are still in use today. In 1968, the French Road Research Laboratory developed the Longitudinal Profile Analyzer (APL) which does not require direct contact with the pavement.

Systems used today in the United States and Canada are frequently installed in vans which contain microcomputers and other data handling and processing instrumentation. The non-contact systems use probes, either acoustic or light, to measure differences in the pavement surface. 
The South Dakota road profiler collects three ultrasonic profiles, one for each wheelpath and one for the lane center. These profiles are used to calculate (by computer) a mathematical measure of roughness and an estimate of rutting at specified intervals along the roadway.

A hybridized South Dakota road profiler which is an advanced type of South Dakota road profiler combines the three ultrasonic sensors with two laser sensors, one for each wheel path. It simultaneously measures the same roadway using two different sensor types under identical conditions (Virginia Transportation Research Council, 1996).

These integrated analysis units can continuously collect a wide variety of data at high speeds. The data include:

- Transverse profile/rutting

- Grade, cross-slope

- Pavement texture

- Pavement condition or distress

- GPS coordinates

- Panoramic right of way video

- Pavement video

- Feature location

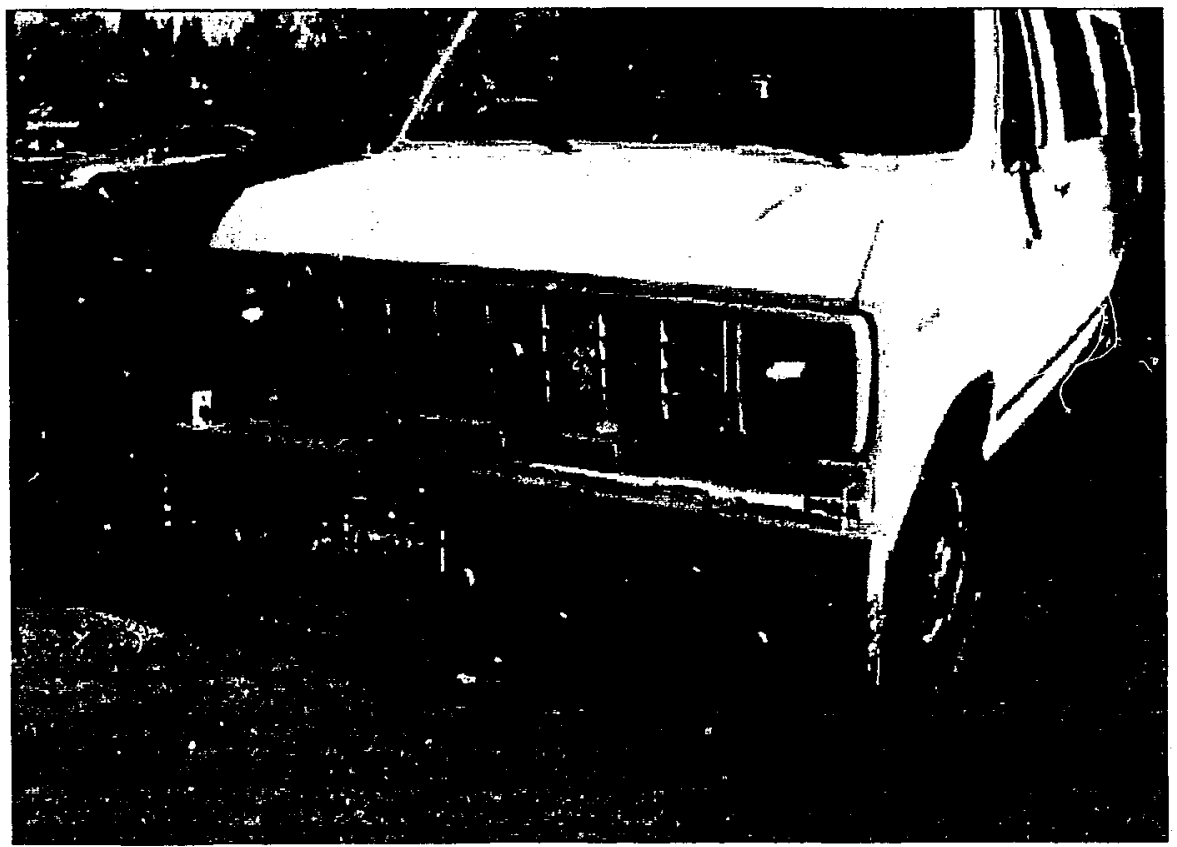

Figure 2.4 Dakota Road Profiler (Van Mounted)

Source: National Center for Asphalt Technology "WSDOT Pavement Guide" 


\subsection{Surface Distress}

Surface distress is discussed in detail in Chapter 1 of this report.

\subsection{Skid Resistance}

Skid resistance is the force developed when a tire that is prevented from rotating, slides along the pavement surface (Highway Research Board, 1972). Skid resistance is an important pavement evaluation parameter because (22):

- Inadequate skid resistance will increase the number of skid related accidents.

- Most agencies have an obligation to provide users with a roadway that is "reasonably" safe.

- Skid resistance measurements can be used to evaluate various types of materials and construction practices.

Skid resistance depends on a pavement surface's micro-texture and macro-texture (Corley-Lay, 1998).

Microtexture refers to the small-scale texture of the pavement aggregate component which controls contact between the tire rubber and the pavement surface. Microtexture is related to the properties of the aggregate.

Macrotexture refers to the large-scale texture of the pavement as a whole due to the aggregate particle arrangement which controls the escape of water from under the tire. (AASHTO, 1976). Macrotexture is related to the mix properties.

Skid resistance changes over time. Skid resistance typically increases in the first two years after construction because the roadway is worn away by traffic, and rough aggregate surfaces become exposed. Skid resistance then starts to decrease over the remaining pavement life as aggregates become more polished. Skid resistance is also typically higher in the fall and winter and lower in the spring and summer.

\subsubsection{Measurement of Skid Resistance}

Skid resistance is generally quantified using some form of friction measurement such as a friction factor or skid number.

Friction factor (like coefficient of friction) (22): $f=F / L$

Skid number: $\mathrm{SN}=100(\mathrm{f})$ 
Where: $\quad F=$ frictional resistance to motion in plane of interface

$L=$ Load perpendicular to interface

In general, the friction resistance of most dry pavements is relatively high. Skidding becomes a problem with wet pavements. The number of accidents on wet pavements is twice as high as on dry pavements. Table No. 2.1 shows some typical Skid Numbers (the higher the SN, the better).

\subsubsection{Measurement Techniques for Skid Resistance}

Skid resistance testing may be carried out in a number of ways. The following are some common methods of measuring the skid resistance:

- The locked wheel tester

- The spin up tester

- Surface texture measurement

\section{2-4.2.1 Locked Wheel Tester}

The most commonly used method for skid resistance testing uses some form of a lock wheel tester. Basically, this method uses a locked wheel skidding along the pavement surface to measure friction resistance.

To take a measurement, the vehicle (or trailer) is brought to the desired testing speed (typically $64 \mathrm{~km} / \mathrm{hr}(40 \mathrm{mph})$ ) and water is sprayed ahead of the test tire to create a wetted pavement surface. The test tire braking system is then applied to lock the test tire. Instrumentation measures the friction force acting between the test tire and the pavement and reports the result as a Skid Number (SN).

Table 2.1: Typical skid resistance values and recommendations

\begin{tabular}{|l|l|}
\hline Skid Number & Comments \\
\hline$<30$ & Take measures to correct \\
\hline$\geq 30$ & Acceptable for low volume roads \\
\hline $31-34$ & Monitor pavement frequently \\
\hline$\geq 35$ & Acceptable for heavily traveled roads \\
\hline
\end{tabular}

Typical Skid Numbers (from Jayawickrama et al., 1996) 


\subsubsection{Spin Up Tester}

A spin up tester has the sarne basic setup as a locked wheel tester but operates in the opposite manner. For a spin up tester, the vehicle (or trailer) is brought to the desired testing speed (typically $64 \mathrm{~km} / \mathrm{hr}$ or $40 \mathrm{mph}$ ) and a locked test wheel is lowered to the pavement surface. The test wheel braking system is then released and the test wheel is allowed to "spin up" to normal traveling speed due to its contact with the pavement. Mathematically, the friction force at the tire/pavement interface at any moment corresponds to the friction if the locked tire was pulled along the pavement at the testing speed (Wambold et al., 1990).

The spin up tester offers two advantages over the locked wheel tester:

1. No force measurement is necessary; the force can be computed by knowing the test wheel's moment of inertia and its rotational acceleration (Wambold et al., 1990). Force measuring devices for the locked wheel tester are expensive.

2. The test tire is in contact with the pavement for a shorter time period while it is locked,significantly reducing test tire wear.

\subsubsection{Surface Texture Measurement}

The pavement skid resistance depends upon the surface macrotexture. Some methods measure a pavement's macrotexture and then correlate the macrotexture with skid resistance which is measured by some other method (22).

The simplest surface texture measurement is the sand patch test (ASTM E 965). The test is carried out on a dry pavement surface by pouring a known quantity of sand on the pavement surface and using a straightedge to spread it in a circular pattern. Sand fills the low spots in the pavement surface. When the sand cannot be spread any further, the diameter of the resulting circle is measured. This diameter can then be correlated to an average texture depth, which can be correlated to skid resistance. A texture depth of about $1.5 \mathrm{~mm}$ ( 0.06 inches) is normally required for heavily traffic areas.

\subsubsection{Image Process Equipment}

Laser or advanced image processing equipment is capable of determining surface macrotexture from a vehicle moving at normal travel speed. The Road Surface Analyzer (ROSAN), a series of non-contact pavement surface texture measurement devices, has been developed by the FHWA's Turner Fairbanks Research Center Pavement Surface Analysis Laboratory. The ROSAN can be used for measuring texture, aggregate 
segregation, grooves, joints, and faulting. Some integrated analysis units can use surface texture measuring to estimate skid resistance.

\subsection{Pavement Structure Evaluation}

Pavement surface deflection measurements are the primary means of evaluating a flexible pavement structure and rigid pavement load transfer (21). Surface deflection is an important pavement evaluation method because the magnitude and shape of pavement deflection is a function of traffic, pavement structure, temperature and moisture. Deflection measurements can be used in back calculation methods to determine pavement structural layer stiffness and the subgrade resilient modulus. Many characteristics of a flexible pavement can be determined by measuring its deflection in response to load. Furthermore, pavement deflection measurements are nondestructive.

"Backcalculation" is a mechanistic evaluation of pavement surface deflection generated by various pavement deflection devices. The basic procedure is to measure the deflection basin and to vary the set of moduli and attempts to match the measured surface deflection and computed deflection (21). The backcalculation process is usually iterative and normally done with computer software. The results of backcalculation will provide the structural layer moduli and subgrade resilient modulus.

A subgrade $M_{R}$ can be backcalculated from Non Destructive Testing (NDT) data using the following equation (9):

$$
M_{R}=\frac{0.24 P}{d_{r} r}
$$

where

$M_{R}=$ Backcalculated subgrade Resilient Modulus, psi

$P=$ Applied load, lbs

$d_{r}=$ measured deflection at radial distance $r$, inches

$r=$ radial distance at which deflection is measured.

This equation for backcalculating $M_{R}$ is based on the fact that, at a point sufficiently distant from the center of the loading, the measured surface deflection is almost entirely due to the deformation in the subgrade and is independent of the load radius (9).

The recommended method for the determination of the $M_{R}$ from NDT backcalculation requires an adjustment factor $(\mathcal{O}$ i.e. 0.33 to make the value calculated consistent with the value used to represent the AASHO subgrade. 
Backcalculation also uses analytical pavement response models to predict the deflections based on a set of given layer thickness values and muduli. With pavement thickness held constant, the response models identify the set of subgrade and pavement layer moduli that produce deflections that are very similar to those measured in the field (17).

\subsubsection{Measurement of Deflection}

Surface deflection is measured in terms of the vertical deflected distance that results from an applied (either static or dynamic) load. The more advanced measurement devices record this vertical deflection in multiple locations and provide a more complete characterization of pavement deflection. The area of pavement deflection under and near the load application is collectively known as the "deflection basin".

\subsubsection{Measurement Techniques}

Four broad categories of nondestructive testing equipment are used:

- Static deflections

- Steady state deflections

- Impact load deflections (FWD)

- Ground Penetration Radar (GPR)

Except in the case of Ground Penetration Radar (GPR), the general principle is to apply a load of known magnitude to the pavement surface and to analyze the deflection. GPR is a way to predict thickness of pavement layers without applying the impulse load.

\subsubsection{Static Deflection Equipment}

Static deflection equipment measures pavement deflection in response to a static load. The most commonly used equipment that makes use of static deflection is the Benkleman Beam (Figure 2.5) developed by the Western Association of State Highway Organizations (WASHO) Road Test in 1952. It is a simple device that operates on the lever arm principle.

It consists of a measuring probe hinged to a reference beam supported on three legs. The deflection at one end of the probe is measured by a dial placed at the other end. The probe is placed between the rear dual tires of a loaded truck and the rebound deflection of the probe is measured after the truck is slowly driven away. By taking several dial readings at different distances from the probe, the deflection basin is 
measured. The Benkelman Beam is low in cost, but it is slow, labour intensive and does not provide a deflection basin.

\subsubsection{Steady State Deflection Equipment}

Steady state deflection equipment measures the dynamic deflection of a pavement produced by an oscillating load. The equipment consists of a dynamic force generator, a motion measuring instrument, a calibration unit and several deflection measuring devices (transducers, accelerometers, seismometers, etc.). The main advantage that steady state deflection equipment has over the static deflection equipment is that it can measure a defiection basin. The most common examples of steady state deflection equipment are the Dynaflect and the Road Rater.

The Dynaflect is shown in Figure 2.6. A static weight of 2,000 to $2,100 \mathrm{lb}$ is applied through a pair of rigid wheels. The dynamic force generator is used to produce a force of $1,000 \mathrm{lbs}$ at 8 cycles per second. The deflection due to the super imposed dynamic force is measured by five transducers.

The sequence of operation is to move the equipment to the test location, to apply the load, and to measure the deflection at each sensor (which is already lowered). The equipment is most suitable for use on thin pavements including low volume rural highways, county roads, municipal streets, and parking lots.

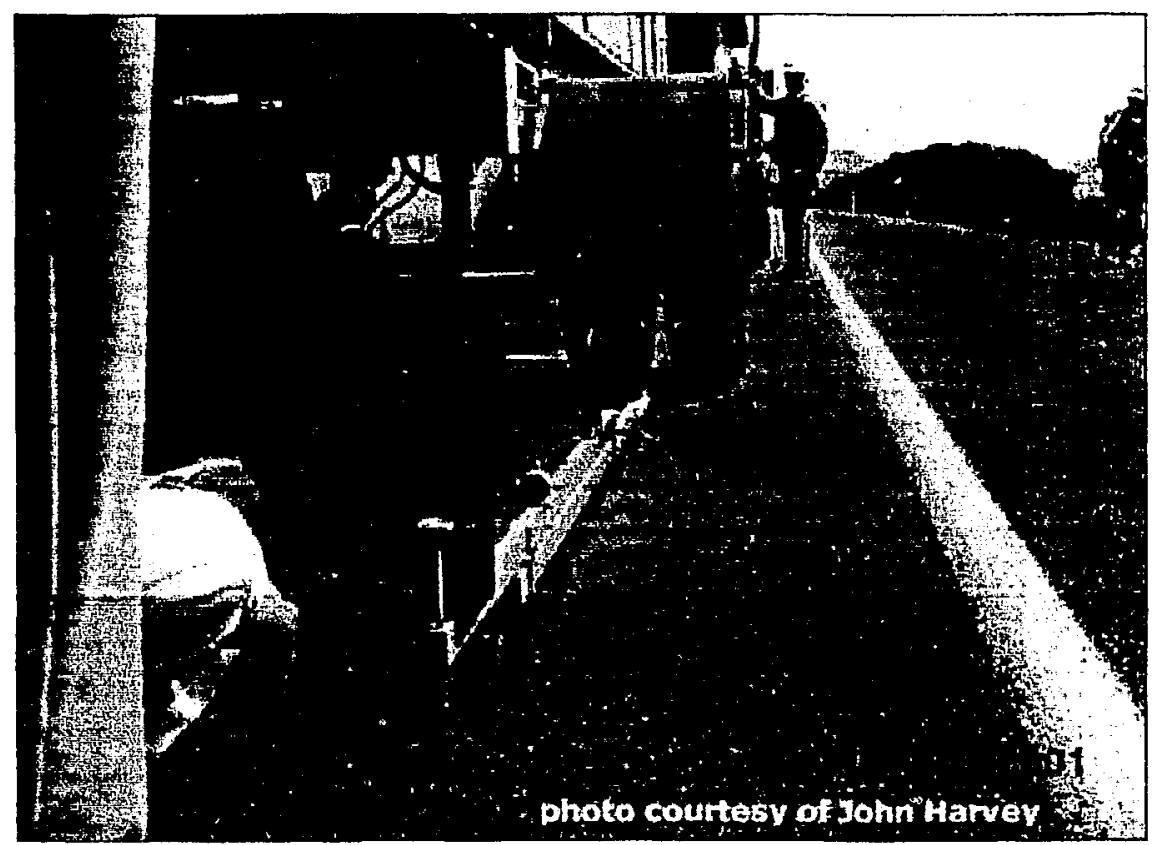

Figure 2.5 Benkelman Beam in Use

Source: National Center for Asphalt Technology "WSDOT Pavement Guide" 
The Road Rater, shown in Figure 2.7, is another popular type of steady state deflection equipment. It must also be stationary to start and operates in a similar fashion to the Dynaflect. It differs from the Dynaflect primarily in the magnitude of the loads, with static loads ranging from 2,400 to $5,800 \mathrm{lbs}$ and dynamic loads ranging from 500 to $8,000 \mathrm{lbs}$. Loading frequency can be varied from 5 to 70 cycles per second and four sensors are used to measure the deflection.

\subsubsection{Impact (Impulse) Load Response}

All impact load devices deliver an impulse load to the pavement surface. The subsequent pavement response is measured by a series of sensors. The most common type of equipment is the Falling Weight Deflectometer (FWD).

The FWD can either be mounted in a vehicle or on a trailer and is equipped with a weight and several velocity transducer sensors. To perform a test, the vehicle is stopped and the loading plate (weight) is positioned over the desired location. The sensors are then lowered to the pavement surface. The impulse force is created by dropping a weight of $110,220,440 \mathrm{lbs}$ from a height of 0.8 to $15 \mathrm{in}$. By varying the drop height and weight, a dynamic force ranging from 1,500 to $24,000 \mathrm{lb}$ can be generated.

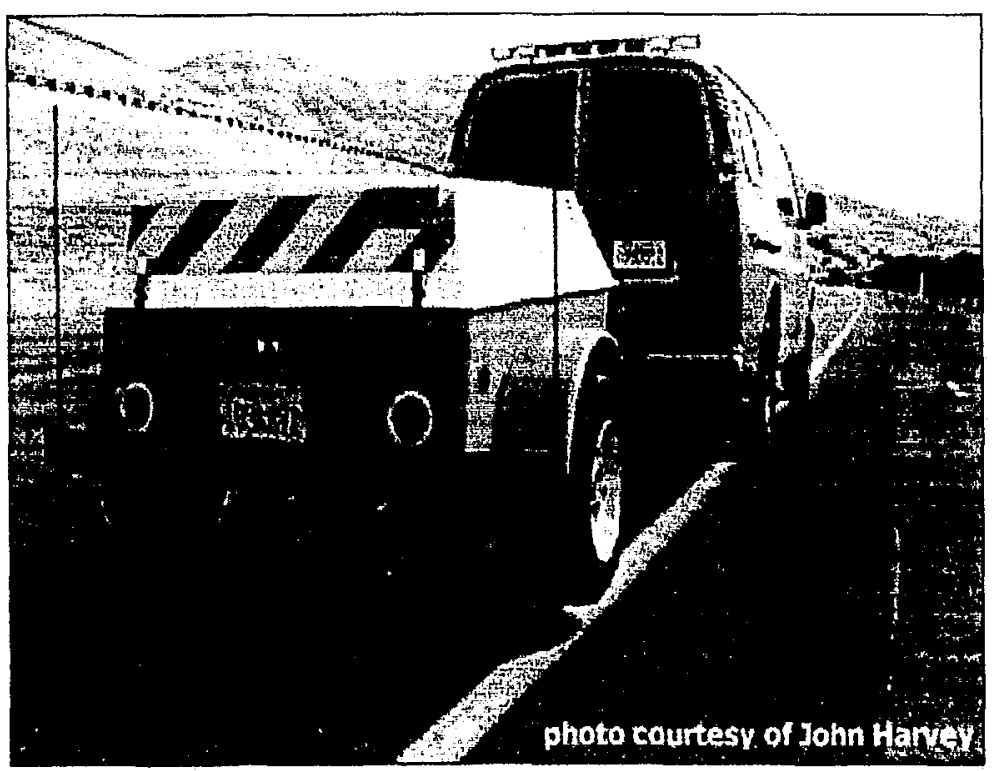

Figure 2.6 Dynaflect

Source: National Center for Asphalt Technology "WSDOT Pavement Guide" 


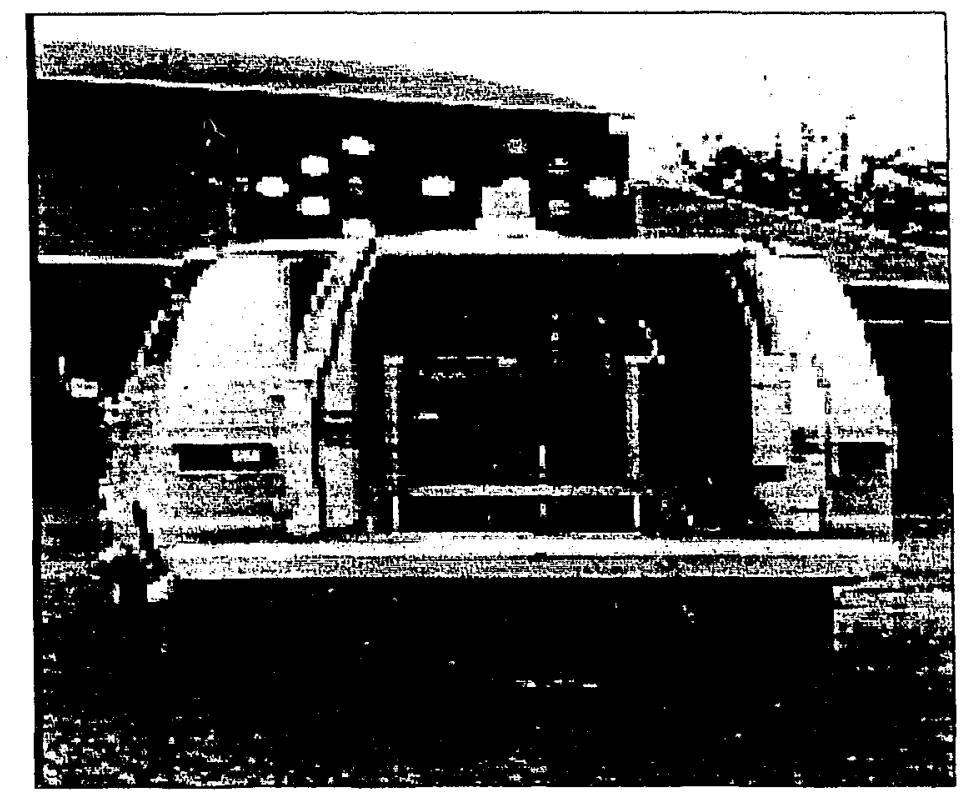

Figure 2.7 Road Rater

Source: National Center for Asphalt Technology "WSDOT Pavement Guide"

Deflections are measured by seven sensors mounted on a bar. The bar is lowered automatically when the loading plate is lowered. One of the six sensors is located the center of the plate while the other sensors are located up to $7.4 \mathrm{ft}$ from the center. Multiple tests can be performed on the same location using different weight drop heights (ASTM, 2000).

The advantage of an impact load response measuring device over a steady state deflection measuring device is that it is quicker, the impact load can be easily varied and it more accurately simulates the transient loading of traffic. FWD is discussed in detail in Chapter 4 of this report.

\subsubsection{Ground Penetration Radar (GPR)}

Most of the Highway agencies rely on destructive testing, e.g. core and borehole information, while the layer information provided by the destructive testing is point specific. As build data information can also lead to over-estimating or under-estimating the needs of pavement rehabilitation. Non-destructive testing like GPR can provide a reasonably accurate continuous pavement structural profile. 


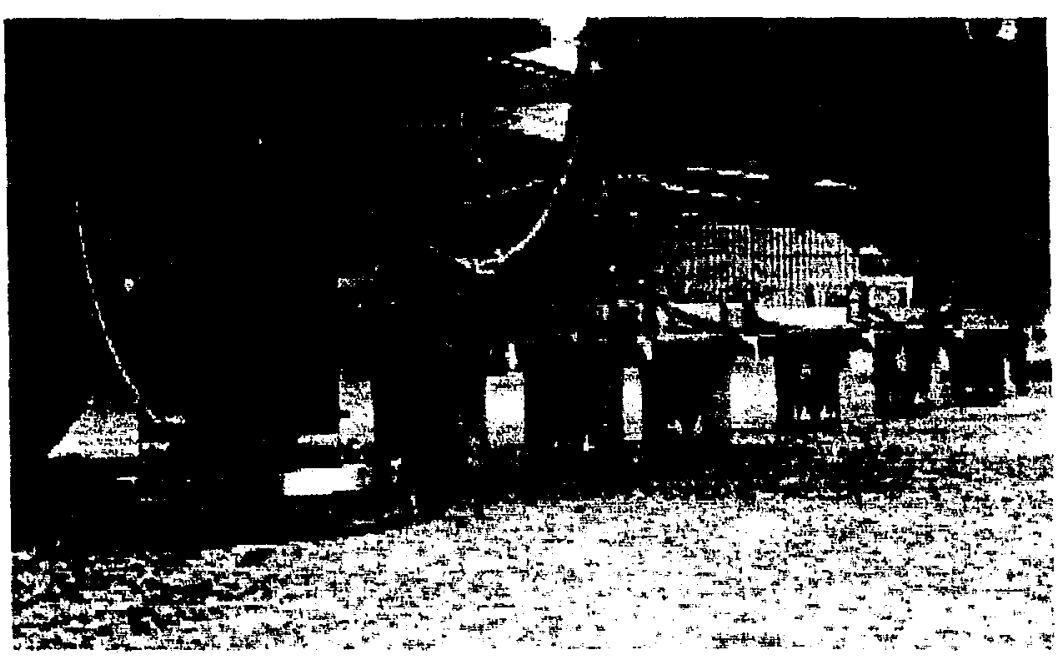

Figure 2.8 FWD Impulse Loading Mechanism

Source: National Center for Asphalt Technology "WSDOT Pavement Guide"

GPR uses a transmitting antenna that emits pulses of high frequency electromagnetic waves into the subsurface without disturbing the ground surface. The antenna is mounted behind the van and is towed along the road surface. The penetrating electromagnetic waves are transmitted downward and reflected by the changes in the dielectric properties of the various pavement layer interfaces to the receiver. The arrival time of the reflection from the layer interface is used to calculate a relative dielectric constant " $\varepsilon$ " and is converted to individual layer thickness.

\subsubsection{Correlations Between Deflection Measuring Equipment}

The following correlations were developed to assess the various deflection measuring equipment results. However, correlations between deflection devices should be used with caution (22).

\section{Benkelman Beam to FWD}

(based on unpublished data collected by the Washington State DOT Materials Laboratory in 1982-1983)

$B B=1.33269+0.93748(F W D)$

Where:

$\mathrm{BB}=$ Benkelman Beam deflection (inches $\times 10^{-3}$ )

FWD = FWD center-of-foad deflection (inches. $\times 10^{-3}$ ) corrected to a 9,000 $\mathrm{lb}$. load applied on a 11.8-inch diameter plate

$R^{2}=0.86 \quad$ Standard Error $=3.20$ mils Sample Size $=713$ 


\section{Benkelman Beam to Dynatiect}

(based on Hoffman and Thompson, 1981)

$B B=20.63(D)$

Where:

$\mathrm{BB}=$ Benkelman Beam deflection (inches $\times 10^{-3}$ )

$\mathrm{D}=$ Dynaflect center-of-load deflection (inches $\times 10^{-3}$ )

$R^{2}=0.72$

\section{Benkelman Beam to Road Rater}

(based on Hoffman and Thompson, 1981)

Comparing a Benkelman Beam load at 9,000 pounds on dual tires with 70-80 psi inflated tires and Road Rater at 8,000 pound peak-to-peak load at $15 \mathrm{~Hz}$ on a 12 inch diameter plate on a stabilized pavement:

$B B=2.57+1.27(R R)$

Where:

$\mathrm{BB}=$ Benkelman Beam deflection (inches $\times 10^{-3}$ ).

$\mathrm{RR}=$ Road Rater (Model 2008) center-of-load deflection at 8,000 pounds and $15 \mathrm{~Hz}$ (inches $\times 10^{-3}$ )

$R^{2}=0.72$

\subsection{PAVEMENT CONDITION RATING SYSTEMS}

For efficient management of a pavement network (for a town, city, county or state), it is essential to establish a method for comparing one pavement with another Pavement management systems usually use some type of pavement condition index. These indices are usually based on the types of pavement and distress. Condition indices vary and may be subjective or objective but they should be relevant, reliable, affordable and appropriate.

Based on roughness, surface distress, skid resistance and deflection measurement, a structure can be assigned a score that gives the overall condition of the pavement. This score is called a pavement condition rating. It is used for the management of pavement networks. Once the pavement condition rating is determined, the values can be used to decide the following: 
- Trigger treatment.

When a pavement's condition rating reaches a certain level, the pavement can be scheduled for maintenance or rehabilitation.

- Determine the extent and cost of repair.

A pavement condition score is a numerical representation of a pavement's overall condition and can be used to estimate the amount of repair work and the likely cost.

- Determine a network condition index:

By combining pavement condition scores for an entire road network, it is possible to estimate a single score that gives a general idea of the network condition.

- Allow equal comparison of different pavements:

Since a pavement condition score presents all kinds of pavement performance measures, two or more pavements with different problems can be compared on an equal basis.

A pavement condition index is simply a scale that is used to describe a pavement condition. Typical pavement condition indices may be based on a scale of 0 to 100 or 1 to 5. A pavement condition index is required to achieve the objectives of the Pavement Management System or PMS i.e. maintaining, upgrading and ensuring the smooth operation of the road network. Two pavement condition index methods are used to describe the present condition of the pavement: the Present Serviceability Index and the Pavement Serviceability Rating.

\subsubsection{Present Serviceability Index (PSI)}

The Present Serviceability Index (PSI) is based on the original AASHO Road Test PSR. $P S R$ is a ride quality rating. Although the PSI is based on the same 5-point rating system as the PSR, it covers more than a simple assessment of ride quality. A panel of observers rides in an automobile and drives over the pavement under investigation.

The raters are asked to provide an opinion on whether the pavement assessed for PSR was "acceptable" or "unacceptable". A pavement with PSR of 3.0 is acceptable and pavement with 2.5 is unacceptable. The PSR is very useful in selecting the "terminal" serviceability (PSI) design input for empirical structural design AASHTO equations. 
Pavement performance can be expressed as the serviceability, trend of a pavement segment with an increasing number of axle applications. Figure 2.9 shows the time when the first rehab is expected.

\subsubsection{Other Pavement Condition Rating Systems}

Another method of evaluating pavements is to deduct points given for specific distress types, severity, and extent combinations from some upper limit or maximum value. The value after the deductions will give an overall rating of a pavement's structural condition. The equations used to convert from severity and extent of a certain distress type to an index number or score vary from state to state (21).

\subsection{FIELD INVESTIGATIONS}

The design and evaluation of any rehabilitation project need a complete and thorough understanding of the factors which affect the overall pavement performance. We normally experience premature failure of rehabilitation and repair treatments because we overlook the underlying cause of distress. The purpose of the field investigation is to collect information on the construction material (subgrade, granular, asphalt), the causes of distress, and the present performance of the pavement. Pavement engineers develop an appropriate rehabilitation solution based on the information collected from the field investigation.

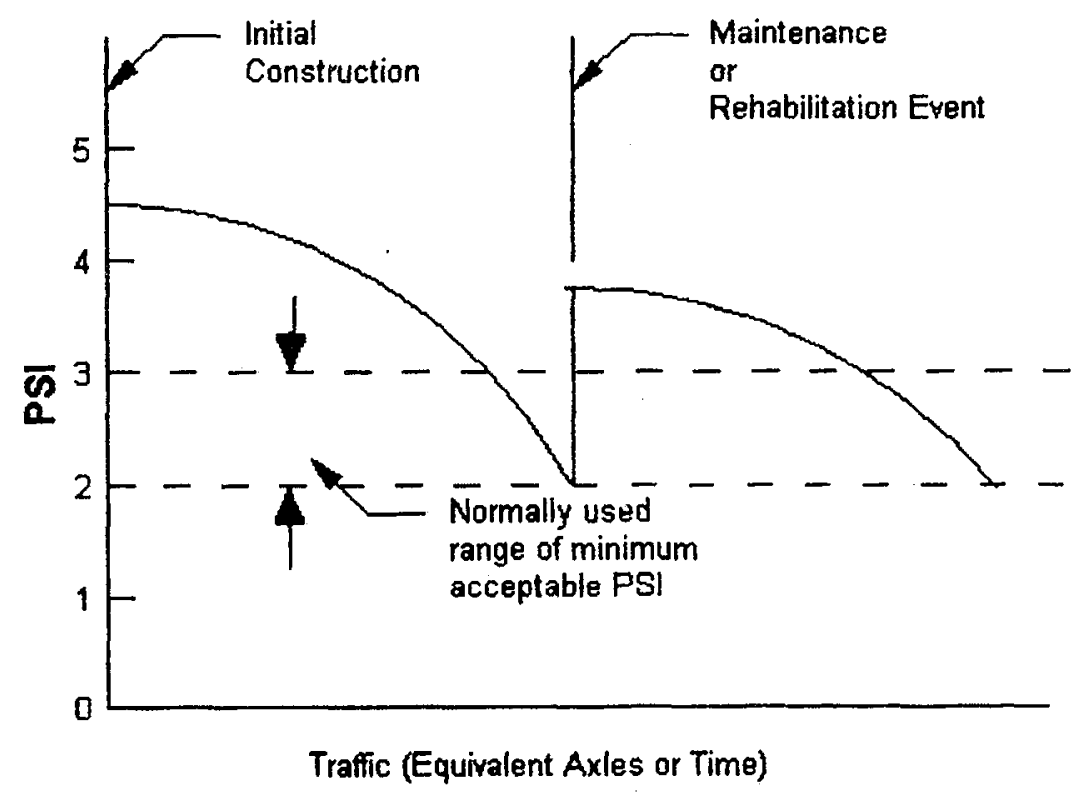

Figure 2.9 Pavement Performance Using Present Serviceability Index (PSI) Source: National Center for Asphalt Technology "WSDOT Pavement Guide" 
The following major factors affect the performance and life of any pavement:

- Subgrade Soil

- Pavement material characteristics

- Traffic loading

- Environment

\subsubsection{Process of Field Investigations:}

\section{Pavement History}

Pavement history details can be collected from office construction files and records. Pavement history provides insight and information about the pavement design, construction, performance and maintenance/rehabilitation carried out during the entire life span of the segment. Pavement history is also important when interpreting and confirming field investigations.

\section{Field Distress Survey}

A field distress survey refers to the evaluation of the pavement to determine the type, extent, and severity of the existing pavement. Field distress surveys were discussed earlier. The field distress survey provides significant information regarding overall pavement condition and the development of appropriate rehabilitation options. MTO has developed a detailed format which defines the different types of distress and their severity levels $(1,2)$.

\section{Structural Evaluation}

A structural evaluation is carried out to determine the capacity of the pavement to carry the future traffic loading. Structural evaluation of the existing pavement is also important for determining the level of support for the future overlay. A typical structural evaluation is carried out by getting information on pavement layer thicknesses through core and borehole data and non destructive testing as described earlier.

\section{Field Sampling and Testing}

A detailed evaluation of the existing material is necessary to perform a pavement distress investigation. A detailed field plan is established to provide information to field personnel about location, frequency and the handling of field samples. Analysis of existing material can be carried out by in-situ field testing and/or by sampling the materials in the field and testing them in the lab. The results of the tests are used to identify the engineering properties of the existing materials and the causes of distress, and to confirm the non destructive test results. 


\section{Laboratory Testing}

Various tests are used in the evaluation of pavement layer and natural soil materials. Each test has its own application and it is very important that each test should be carried out on a representative sample.

- A visual inspection of the loose sample and asphalt cores is carried out to provide the general description of the material.

- General characteristics of the subsurface layer materials are determined through soil classification, gradation, moisture content, density and hydrometer analysis (in the case of subgrade).

- General characteristics of the asphalt bound materials are determined through density, air void content, asphalt content, asphalt cement viscosity, asphalt cement temperature susceptibility, aggregate gradation, aggregate angularity, aggregate soundness and moisture sensitivity.

- Strength related tests are also carried out on candidate samples to establish the strength of various layer materials. These tests include R-value, indirect tensile strength, resilient modulus of unbound materials, resilience modulus of asphalt mixtures, and dynamic modulus of asphalt mixtures.

\subsubsection{Use of Pavement Investigation Results}

The results obtained from the pavement investigation are used to determine the most appropriate rehabilitation and repair treatment. The basic steps used to determine the most suitable option are described below:

\section{Probable Cause(s)}

The primary conclusion of the pavement distress analysis is the determination of one or more causes of the pavement distress found. The engineer must use the analysis to make the final judgmeni regarding what cause or causes need to be addressed in pavement rehabilitation or treatment.

\section{Repair/Rehabilitation Alternatives}

Historically, HMA overlays have Eeen the most common technique used to rehabilitate HMA pavement, but this is not always the case. Overlays have sometimes been constructed without regard to their applicability or to their cost effectiveness. In many cases, it may be more practical or cost effective to perform a different type of rehabilitation. Project constraints sometimes dictate the selection of a specific rehabilitation option. At any rehabilitation project, every pavement option should be considered and evaluated in order to select the most suitable treatment option taking into account short term and long term implications. 
Almost every agency recommends a list of rehabilitation alternatives for various distress treatments. MTO has a list of 12 rehabilitation treatment options. These options are described in Chapter 3 of this report. On any given project, one or more of these HMA rehabilitation treatments may be identified as a feasible solution. Additional analysis is required to determine the best and final solution.

\section{Structural Design Selection}

This step involves the selection and application of procedures for the structural design of an overlay or reconstruction and for the mix design of the new overlay or surface treatment. These processes are relatively straight forward. For MTO projects two structure design procedures (AASHTO and MTO are adopted and compared with each other. In many cases, AASHTO procedures are more conservative and reliable. However, in some cases, MTO design recommendation may be more appropriate, especially for northern Ontario regions where non frost susceptible materials, i.e. granular materials, are needed to combat frost action.

MTO recommends different HMA mixes depending upon traffic, topography, local climate, and the availability of materials. MTO also recommends different Performance Graded Asphalt Cement (PGAC) grades for different regions depending upon climate and traffic.

\section{Cost Analysis}

A Life Cycle Cost Analysis (LCCA) of the different repair treatments is carried out and provides the information necessary for determining a cost effective solution. In most cases, LCCA has a major impact on pavement treatment selection. However, in some cases, project construction limitations, budgetary limitations and future complications do not allow a decision maker to select the most cost effective option. LCCA is described in detail in Chapters 3 of this report.

\section{Treatment Selection:}

After following the rigorous analysis discussed above, the most suitable and cost effective treatment is selected. There are some overriding factors or decision factors that may affect the pavement selection. These factors include the funding available, the possibility of staged construction, traffic control requirements, pavement management practices, the availability of local materials, contractor availability and politics. It is up to the decision maker to consider the various factors and to determine the best treatment solution. 


\section{CHAPTER 3}

\section{LIFE CYCLE COST ANALYSIS AND PAVEMENT SELECTION}

Life cycle cost analysis (LCCA) is an economic tool used by engineers to compare cost options for the projects during a selected analysis period. LCCA is an effective tool for selecting construction, rehabilitation and maintenance treatments. It is the method most recommended by public agencies such as the FHWA and MTO and can be used to evaluate the life cycle costs of paving materials containing waste materials as well as alternative treatments. An example of waste materials that can be used in asphalt mixtures is roof shingles which are being used in alternative treatments all over the world including Canada.

LCCA should be conducted as early as possible in the project's development. The primary purpose of LCCA is to evaluate the long term economic implications of initial pavement decisions.

The process involves several stages:

- Consideration of different options and maintenance strategies

- Analysis period and expected life of maintenance and rehabilitation strategies

- Estimation of agency cost

- Estimation of user and non-user cost

- Computation of economic indicators

- Development of expenditure stream

- Cost Analysis and results

\subsection{Consideration of Different Options and Their Maintenance}

The first step in a LCCA is to identify alternative strategies (including materials) over the analysis period. Each alternative can be compared with shingles.

All the alternatives require certain maintenance treatment until the life reaches the analysis period. Depending of traffic volume, region and environment, MTO generally considers the following options for pavement rehabilitation:

1. Composite pavement

2. Deep strength asphait

3. Concrete pavement

4. White topping

5. Full reconstruction of the pavement

6. Mill/Pave

7. In Place and process (Pulverize and Pave) 

8. Pad and Pave
9. Full depth asphalt removal and pave
10. Hot in Place recycling
11. Cold in Place Recycling (CIR)

\subsubsection{Analysis Period}

The analysis period selected for the LCCA should be sufficiently long to reflect long-term cost differences associated with reasonable design strategies. The expected life is determined, based on interviews with US and local agencies, For example, FHWA recommends an analysis period of at least 35 years while MTO generally considers a period of 30 years. The expected lives of various rehabilitation or maintenance strategies can also be determined and should include average, low and high time periods. The low and high values represent the 10 and 90 percentile values respectively. Based on engineering judgment and experience, MTO generally considers a life of 15 years for newly constructed asphalt pavement and 12 years for mill and pave jobs.

\subsubsection{Estimation of Agency Cost}

The agency cost consists of all costs including preliminary engineering, contract administration, supervision, maintenance, resurfacing and rehabilitation costs over the entire project life.

\subsubsection{User Cost Estimation}

User costs are those incurred by the user over the entire life of the project. They include vehicle operating costs (VOC), and the costs of delays and accidents. IRI can be used to determine the VOC for both type of pavement.

\subsubsection{Economic Indicators}

LCCA is used to evaluate the cost efficiency of various investment options. When all the costs and timing have been calculated or established, Net Present Value (NPV) and Equivalent Uniform Annual Cost (EUAC) are calculated to evaluate the cost effectiveness of different options. NPV is the discounted monetary value of expected net benefits, while EUAC expresses present and future costs in terms of an equalized, annual pavement using a selected discount rate. NPV and EUAC can be calculated with the following formulas: 


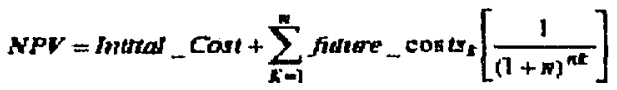

$$
\begin{aligned}
& E U S C=\sum_{x=1}^{n} N P V\left[\frac{1}{1-(1+1)^{n}}\right]
\end{aligned}
$$

Where

$$
\begin{aligned}
& i=\text { discount rate, typically } 3 \text { to } 5 \text { percent } \\
& n=\text { year of expenditure } \\
& k=\text { maintenance or rehabilitation strategy or user cost }
\end{aligned}
$$

\subsection{Economic Benefits of Using Shingles}

A study was carried out in Ontario by John Emery Geotechnical Engineering Limited to evaluate the manufacturing of shingle modified asphalt mixes. The study concluded that several economic benefits can be achieved by using shingles in asphalt mixes. Using shingles can also improve the performance of overlays.

One of the most significant cost savings is incurred by diverting roofing shingle scrap from landfills. Based on a tipping fee of $\$ 90 /$ tonne (typical for the Greater Toronto Area), the cost of disposal for 15,000 to 20,000 tonnes of prompt roofing shingle scrap is about $\$ 1.4$ to $\$ 1.8$ million annually. There are also considerable cost savings to the landfill operator by having additional space available for non recyclable materials (8).

The cost saving of HMA can be substantial when just 5 percent of shingles are added to HMA. If the estimated costs are $\$ 200 /$ tonne for asphalt cement, $\$ 10$ to $\$ 16 /$ tonne for hot mix aggregate, $\$ 90 /$ tonne for tipping fees, and $\$ 20$ /tonne for processing fees (equipment costs), the saving would be estimated about $\$ 2$ to $\$ 3 /$ tonne of HMA. Based on the average cost of $\$ 45 /$ tonne for HMA, a saving of $\$ 2.5 /$ tonne would greater than 5 percent (8). 


\section{CHAPTER 4}

\section{PAVEMENT EVALUATION OF HIGHWAY 401- CASE STUDY}

Soon after World War II, Highway 401 was constructed as a by-pass around Toronto. The bypass consisted of a divided controlled access four lane highway within the corridor more or less now occupied by the express lanes. The expanded core-collector system was initiated in the early and mid 1960's to meet the demand created by growth of Toronto and its suburbs into what is now the Greater Metropolitan Toronto Area (GTA).

Highway 401 is one of the busiest highways in the world. The Average Annual Daily Traffic (AADT) is over 400,000 vehicles as it passes through the GTA. MTO recently proposed the pavement rehabilitation and resurfacing of Highway 401 to correct deficiencies and deterioration of the existing composite pavement. Under this proposal, Morrison Hershfield Limited was selected by MTO to conduct a detailed design and pavement evaluation of the composite pavement of Highway 401's eastbound collector lanes from Avenue Road to Highway 404. The project includes an additional lane which includes Geometric Improvements and widening, from Yonge Street to Bayview Avenue.

The writer selected this project as his case study. In this study, the writer will discuss all the steps involved in the pavement evaluation and rehabilitation of Highway 401's composite pavement. The stretch of Highway 401 under study has 3 to 5 lanes.

Highway 401 is a composite pavement. It consists of a nominal $230 \mathrm{~mm}$ of Jointed Reinforced Concrete Pavement (JRCP) with a slab length of about $17 \mathrm{~m}$. An expansion joint was made at every sixth or seventh transverse joint. An asphalt concrete overlay was placed on top of the JRCP due to the polishing of aggregates.

\subsection{Fleld Investigations Involved in Pavement Evaluation:}

The following field investigation was conducted to assess the present pavement condition. The data collected during the field investigation provided vital information required to design and determine the future rehabilitation strategy for the pavement.

\subsubsection{Visual Pavement Condition:}

A visual survey was conducted to assess the severity, extent, and frequency of joint and crack distress in the pavement. As discussed earlier, Highway 401 has a composite pavement. This means that it is not easy to determine the extent of the cracks. The reflected joint and crack distress severity was assessed in terms of the suspected deterioration of the underlying JRCP. However, where there was a severe crack or 
where joint deterioration in the JRCP was suspected, a clearly defined depression in the asphalt concrete overlay could be observed.

All pavement cracks and joint distress were classified as very severe, severe, moderate or light. The classification was made using subjective judgment, but it was generally based on the suspected JRCP crack or joint opening width.

\subsubsection{Non Destructive Pavement Testing:}

Non destructive testing of the pavement structure was conducted with a heavy Falling Weight Deflectometer (FWD). FWD tests were carried out to determine the k-value (modulus of subgrade reaction) of the subgrade, and elastic moduli of the asphalt and Portland Cement Concrete layers.

Generally, four load applications were applied to the pavement surface. The first application was a seating load to ensure that the FWD load plate was firmly resting on the pavement. The next three loads were approximately 40,50 and $70 \mathrm{kN}$.

Several analysis methodologies were used to analyze the FWD deflection data. The methodologies included:

\section{Deflection Load Transfer (DLT):}

This parameter is calculated as the ratio of the deflection of the unloaded slab to the loaded slab, multiplied by 100 . A joint or crack with a deflection load transfer of $100 \%$ corresponds to a perfect load transfer, while a value of 0 percent corresponds to a no load transfer. Load transfer values greater than $70 \%$ generally indicate good joint/crack load transier.

\section{Differential Deflection:}

The deferential deflection is defined as the deflection on the loaded side of the joint minus the deflection on the unloaded side. This is important in the performance of existing and future asphalt overlays, since large differential deflections increase the rate of initiation and propagation of reflective cracks. It is desirable to have differential deflection values of less than $50 \mu \mathrm{m}$ to provide good performance of an asphalt overlay.

\section{Loss of Support Analysis}

A loss of support analysis is used to analyze the load deflection relationship of data produced by a range of load levels at the same test location. In the case of well supported pavements, the concept predicts a linear load-deflection relationship that, when projected to a load corresponding to zero, also intercepts the deflection axis at 
zero. On the other hand, if a void is present beneath the pavement, the same relationship, will intercept the deflection axis at a positive magnitude for a projected load of zero. Deflection intercepts greater than $50 \mu \mathrm{m}$ generally indicate the presence of voids. As the size of the void increases, the void's intercept value increases.

\section{Maximum Normalized Deflection:}

The maximum deflection, measured in the centre of the load plate, is a good indicator of overall pavement strength. The deflection at this location is a furiction of the pavement layer stiffness and the support capacity of the subgrade.

The normalized deflection at the centre of the slab for the project under study was quite variable, ranging from $56 \mu \mathrm{m}$ to $120 \mu \mathrm{m}$, with an average of $78 \mu \mathrm{m}$.

\subsubsection{Pavement Coring}

Pavement coring was carried out to determine asphalt and concrete thickness and to determine the components of the asphalt layers. The composition and suitability of the asphalt layers were determined for future overlays. The thickness of the asphalt and concrete was also required to determine the pavement layer moduli from FWD test data. Based on the thickness of the asphalt and concrete, the average layer moduli were calculated and found to be $4,577 \mathrm{MPa}$ and $36,613 \mathrm{MPa}$ respectively.

Coring is not only conducted to determine the thickness of the existing pavement, but also to determine the depth to reinforcing steel and any visible corrosion. Coring in flexible pavement through transverse cracks provides vital information about the causes of cracks. If a transverse crack is " $\mathrm{V}$ " shaped, this indicates that the crack started from the top and is due to temperature variation. If the crack is an "inverted V", this indicates that the crack started from the bottom and is moving upward, the result of pavement fatigue.

\subsubsection{Pavement Boreholes}

Borehole drilling through the pavement was carried out to determine the existing asphalt and granular thickness and subgrade types. The granular thickness and subgrade type is required as input data for FWD test and Pavement Design calculations. Samples of the underlying granular materials and subgrade soil were also taken for visual examination and laboratory testing.

\subsection{Laboratory Testing}

The following laboratory tests are generally performed on concrete pavement cores, soil samples and granular samples collected during the field investigation. 
Concrete cores were tested for

- Compressive strength

- Splitting tensile strength

- Chloride ion profiling

- Petrographic examination

Uniaxial unconfined compression tests on pavement concrete core give an indication of the strength of the concrete, while splitting tensile strength tests provide information about the tensile strength of the existing concrete. Table 4.1 presents the thickness of the overlay and concrete, the depth of reinforced steel, the compressive strength and the tensile strength. It was observed that the concrete compressive strength ranged from 58.5 to $63.8 \mathrm{Mpa}$ while the tensile strength ranged between 3.52 and $3.54 \mathrm{MPa}$. The compressive and tensile strengths were used as parameters for design and analysis of the pavement.

Table 4.1 JRCP Core thickness and strength

\begin{tabular}{|c|c|c|c|c|c|c|c|c|}
\hline \multirow[b]{2}{*}{ Location } & \multirow{2}{*}{ Station } & \multirow{2}{*}{ Lane } & \multirow{2}{*}{$\begin{array}{l}\text { Total } \\
\text { Thick } \\
(\mathrm{mm})\end{array}$} & \multirow{2}{*}{$\begin{array}{l}\text { PCC } \\
\text { Thick. } \\
\text { (mm) }\end{array}$} & \multirow{2}{*}{$\begin{array}{l}\text { Aco } \\
\text { Thick. } \\
\text { (mm) }\end{array}$} & \multirow{2}{*}{$\begin{array}{l}\text { Depth to } \\
\text { A. Steel } \\
\text { (mm) }\end{array}$} & \multicolumn{2}{|c|}{ Strength } \\
\hline & & & & & & & $\begin{array}{c}\text { Comp. } \\
\text { MPa }\end{array}$ & $\begin{array}{c}\text { Tensile } \\
\text { MPa }\end{array}$ \\
\hline \multirow{16}{*}{$\begin{array}{c}\text { Highway } 401 \\
\text { Eastbound } \\
\text { Collectors }\end{array}$} & $20+900$ & 3 & 300 & 230 & 70 & - & & 3.54 \\
\hline & $20+950$ & 3 & & & 70 & - & & \\
\hline & $21+950$ & 1 & 300 & 215 & 85 & $90-100$ & & \\
\hline & $22+300$ & 3 & 320 & 215 & 105 & $75-85$ & & \\
\hline & $22+600$ & 2 & 325 & 230 & 95 & 75 & & \\
\hline & $22+900$ & 3 & 305 & 220 & 85 & 65 & & \\
\hline & $23+200$ & 1 & 320 & 225 & 95 & 105 & 63.8 & \\
\hline & $23+600$ & 3 & 280 & 220 & 60 & - & & \\
\hline & $23+900$ & 1 & 300 & 210 & 90 & - & & \\
\hline & $24+304$ & 1 & 300 & 220 & 80 & - & & \\
\hline & $24+600$ & 3 & 305 & 225 & 80 & 80 & & \\
\hline & $25+300$ & 4 & 300 & 225 & 75 & $90-120$ & 58.7 & \\
\hline & $26+100$ & 1 & 325 & 215 & 110 & 65 & & \\
\hline & $26+400$ & 4 & 275 & 230 & 45 & 95 & 58.5 & \\
\hline & $26+700$ & 1 & 270 & 220 & 50 & $85-90$ & & 3.52 \\
\hline & $27+200$ & 4 & 265 & 220 & 45 & - & & \\
\hline
\end{tabular}


The chloride ion content profile provides an indication of the likelihood of reinforced steel corrosion and the remaining life of the reinforced steel. Two cores were tested for chloride ion concentration in this project. Table 4.2 presents the results of the chloride ion testing. It was observed that the concentration of chloride ion was reduced with depth. The generally accepted critical value of chloride ion concentration for the onset of corrosion is considered to be 0.15 percent for new concrete.

Petrographic examination of cores was carried out to determine the size, nature and characteristics of the aggregates used in the concrete mix and also the size and shape of the air voids. It was observed that air entrained concrete with round to angular well graded aggregates with a maximum size of $30 \mathrm{~mm}$ was used.

\section{Soil samples were tested for:}

- Hydrometer analysis

- Natural moisture content

- Atterberg limits

Hydrometer analysis, or grain size distribution, was carried out to determine the clay and silt content of the soil sample and the frost susceptibility of the subgrade material. If the percent passing difference between $75 \mu \mathrm{m}$ and $5 \mu \mathrm{m}$ is greater than $55 \%$, the material

Table 4.2 Chloride lon content in JRCP cores

\begin{tabular}{|c|c|c|c|c|}
\hline Station & Location & $\begin{array}{l}\text { Distance from } \\
\text { Top Surface } \\
\text { (mm) }\end{array}$ & $\begin{array}{l}\text { Depth to } \\
\text { Reinforcing } \\
\text { Steel }(\mathrm{mm})\end{array}$ & $\begin{array}{c}\text { Total Chloride lon } \\
\text { Content (\%) }\end{array}$ \\
\hline \multirow{6}{*}{$23+900$} & \multirow{6}{*}{ Lane 1 IWP } & $0-10$ & & 0.102 \\
\hline & & $20-30$ & & 0.051 \\
\hline & & $40-50$ & & 0.029 \\
\hline & & $60-70$ & & 0.018 \\
\hline & & $80-90$ & & 0.016 \\
\hline & & $100-110$ & & 0.020 \\
\hline \multirow{6}{*}{$24+600$} & \multirow{6}{*}{ Lane 3 OWP } & $0-10$ & & 0.242 \\
\hline & & $20-30$ & & 0.149 \\
\hline & & $40-50$ & & 0.155 \\
\hline & & $60-70$ & & 0.150 \\
\hline & & $80-90$ & 80 & 0.123 \\
\hline & & $100-110$ & & 0.061 \\
\hline
\end{tabular}


will be silty and highly frost susceptible. If it is less than $40 \%$, the material will have low frost susceptibility. Atterberg limits were tested to determine the plasticity of the subgrade material.

\section{Granular samples were tested for:}

- Grain size distribution (Sieve Analysis)

Sieve analysis for the granular samples was performed to determine the suitability of granular materials and also the silt and clay content. Granular materials with high silt or clay content have poor drainage qualities and therefore cannot be used as a free drainage material.

\subsection{Highway 401 Data Analysis}

The FWD and visual data from Morrison Hershfield were collected and analyzed and the following observations were made.

In this project, FWD data were collected for Load Deflection Transfer (LDT) at joints and cracks. Table 4.3 summarizes the LDT for Highway 401 eastbound collectors.

A total of 41 joints and 140 cracks were tested for LDT with distress severities from low to high. It was observed that $61 \%$ LDT results at joint are good and $27 \%$ are poor. This analysis shows that, due to the presence of reinforcement, the load transfer at most of the joints was good. Similarly, it was observed that $61 \%$ LDT results at cracks are poor and $33 \%$ are good. These results show that the concrete slab is broken and needs immediate repair. In the overall project, $54 \%$ of LDT at cracks and joints were poor while $39 \%$ had good LDT.

Table 4.3 Summary of FWD Analysis of Load Deflection Transfer

\begin{tabular}{|c|c|c|c|c|c|}
\hline \multirow{2}{*}{ Area } & \multirow{2}{*}{ Location } & \multicolumn{3}{|c|}{ Load Transfer Efficiency } & \multirow{2}{*}{$\begin{array}{l}\text { Total } \\
\text { Testing }\end{array}$} \\
\hline & & $\begin{array}{c}\text { Good }>70 \\
\%\end{array}$ & $\begin{array}{c}\text { Marginal } 50 \\
\text { to } 69 \%\end{array}$ & Poor $<50 \%$ & \\
\hline \multirow{2}{*}{$\begin{array}{l}401 \text { Collector } \\
\text { lanes }\end{array}$} & Joint & 25 & 5 & 11 & 41 \\
\hline & Crack & 46 & 8 & 86 & 140 \\
\hline & Total: & 71 & 13 & 97 & 181 \\
\hline
\end{tabular}


The visual distress observations were analyzed for repair areas. The total repair area was approximately $8.6 \%$ of the total area occupied by the main lanes. Each lane was also analyzed for the extent of repairs required. The percentage of repair areas for lanes $1,2,3,4$ and 5 was $7.0 \%, 8.6 \%, 9.5 \%, 11.0 \%$, and $4.0 \%$, respectively. Lanes 3 and 4 were the worst due to the concentration of heavy commercial vehicles in these two lanes.

The FWD test results for the entire project were analyzed and showed that almost half of the tested locations show a load transfer efficiency of less than $50 \%$ as shown in Figure 6.1 .

Figures 4.2 to 4.6 summarize the FWD load transfer efficiency test data for lanes 1 to 5 respectively.

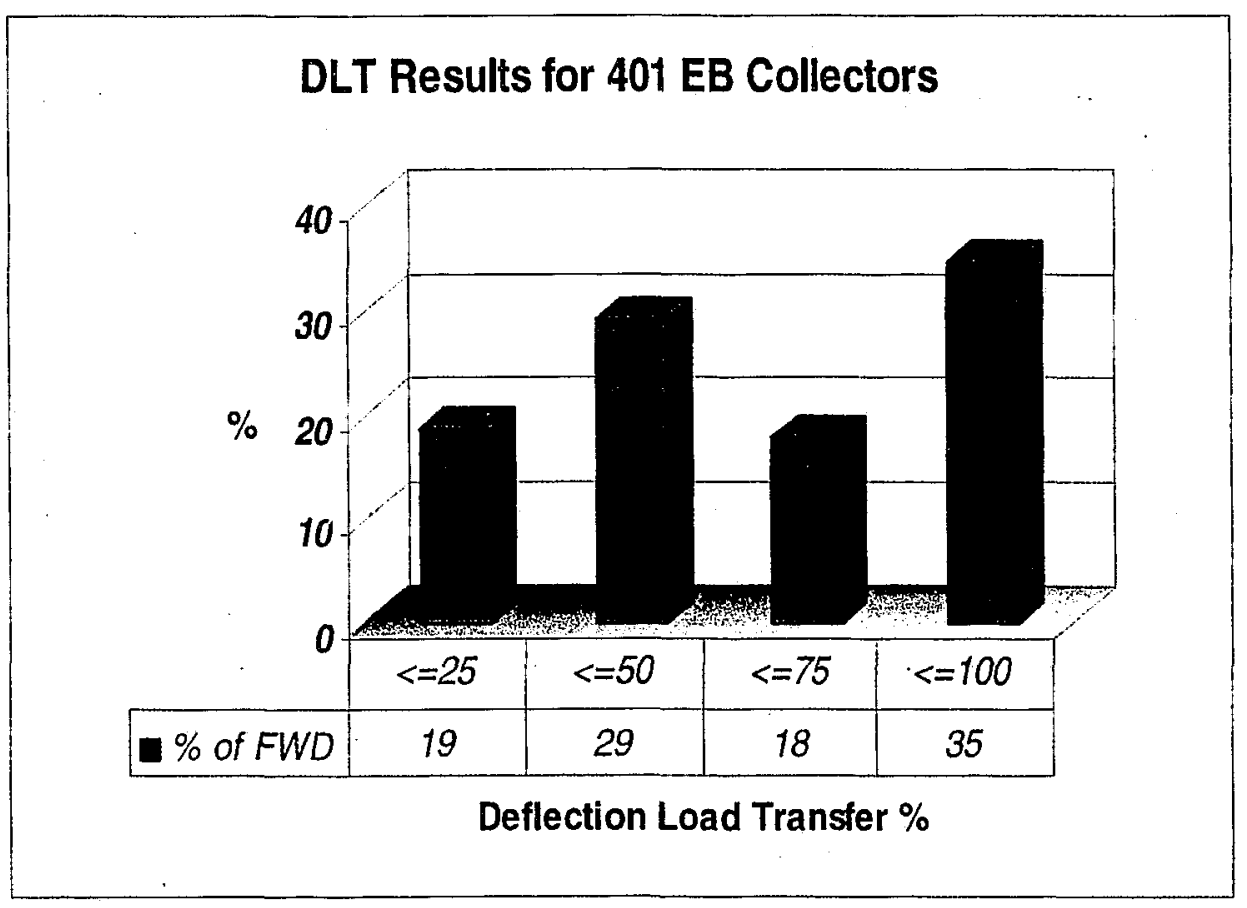

Figure 4.1 Distribution of Deflection Load Transfer results for the Entire Project 


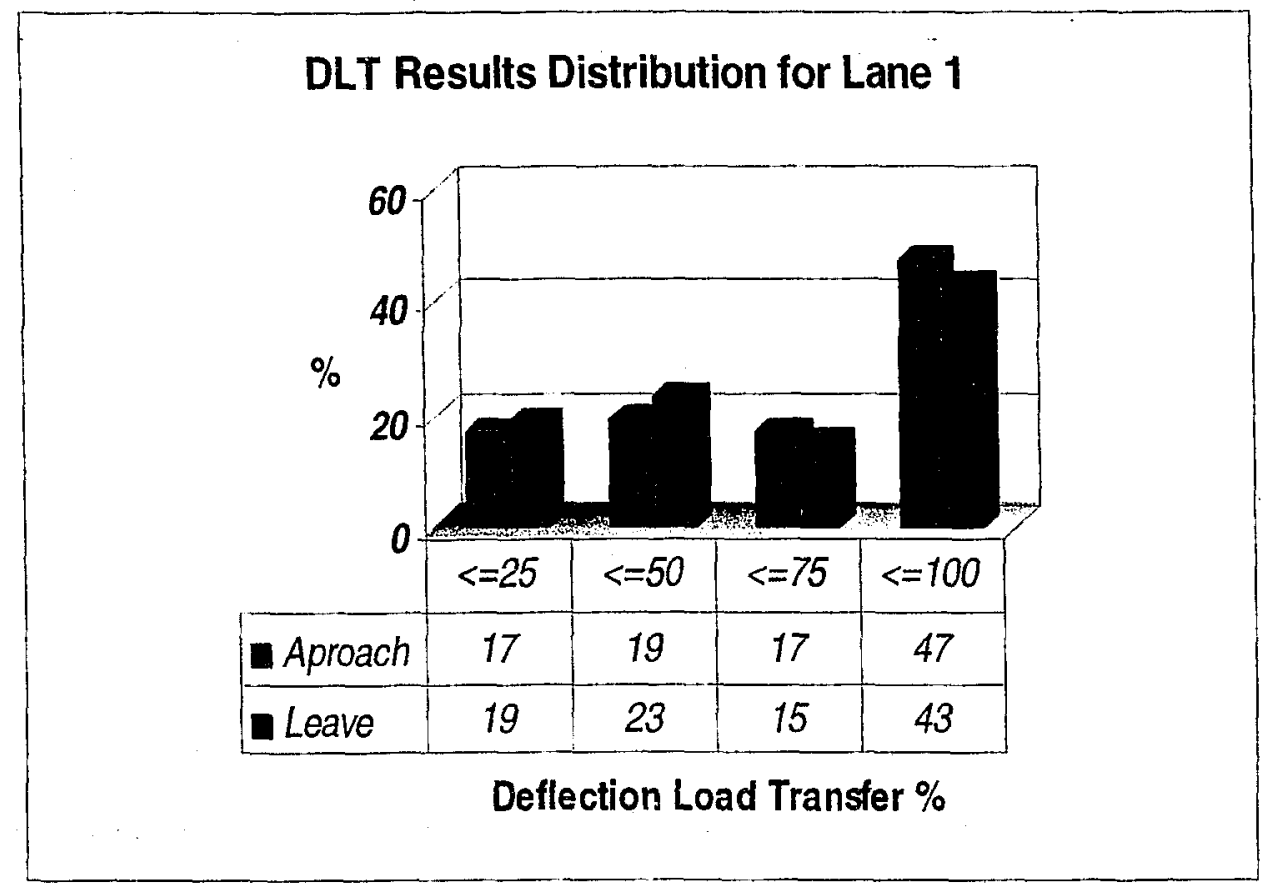

Figure 4.2 Distribution of Deflection Load Transfer results for Lane 1

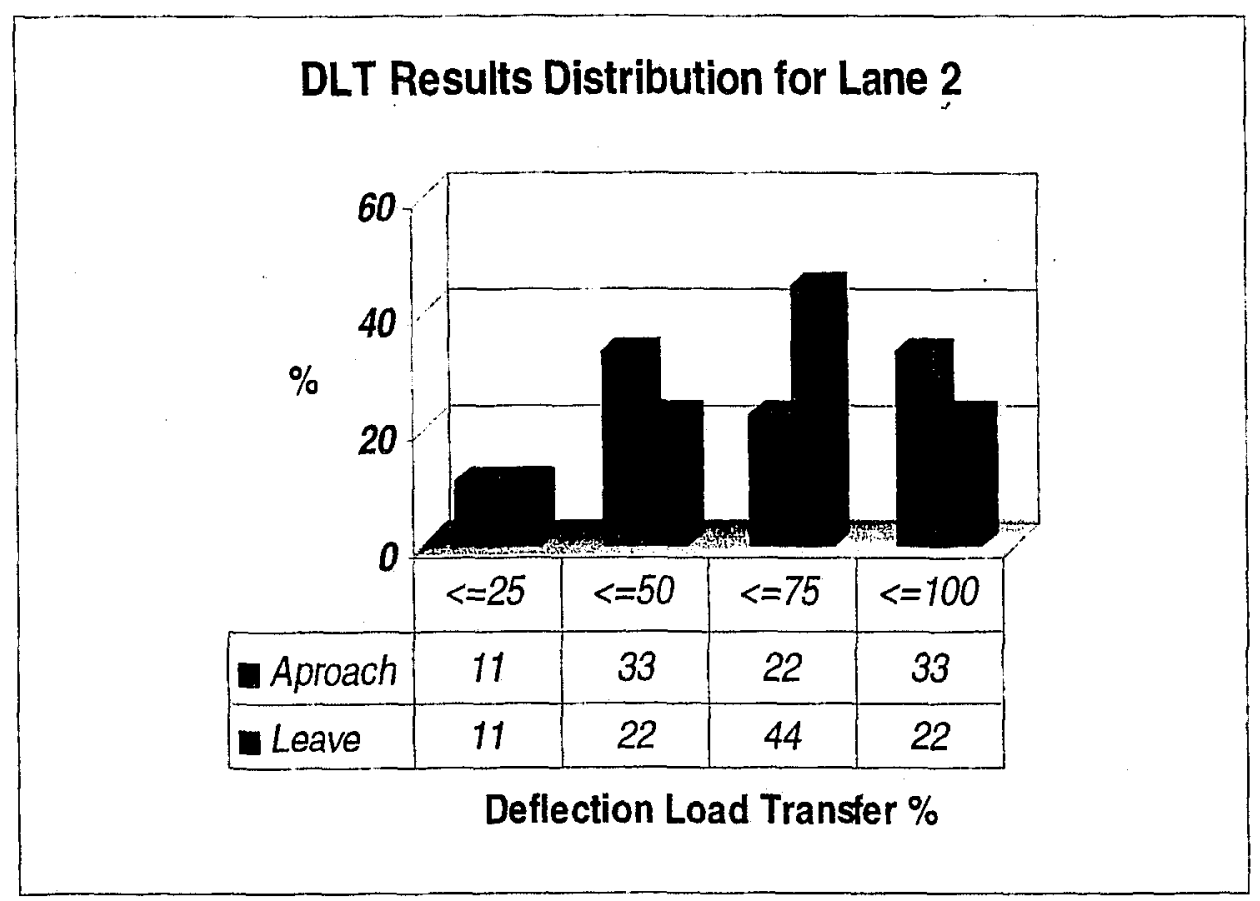

Figure 4.3 Distribution of Deflection Load Transfer results for Lane 2 


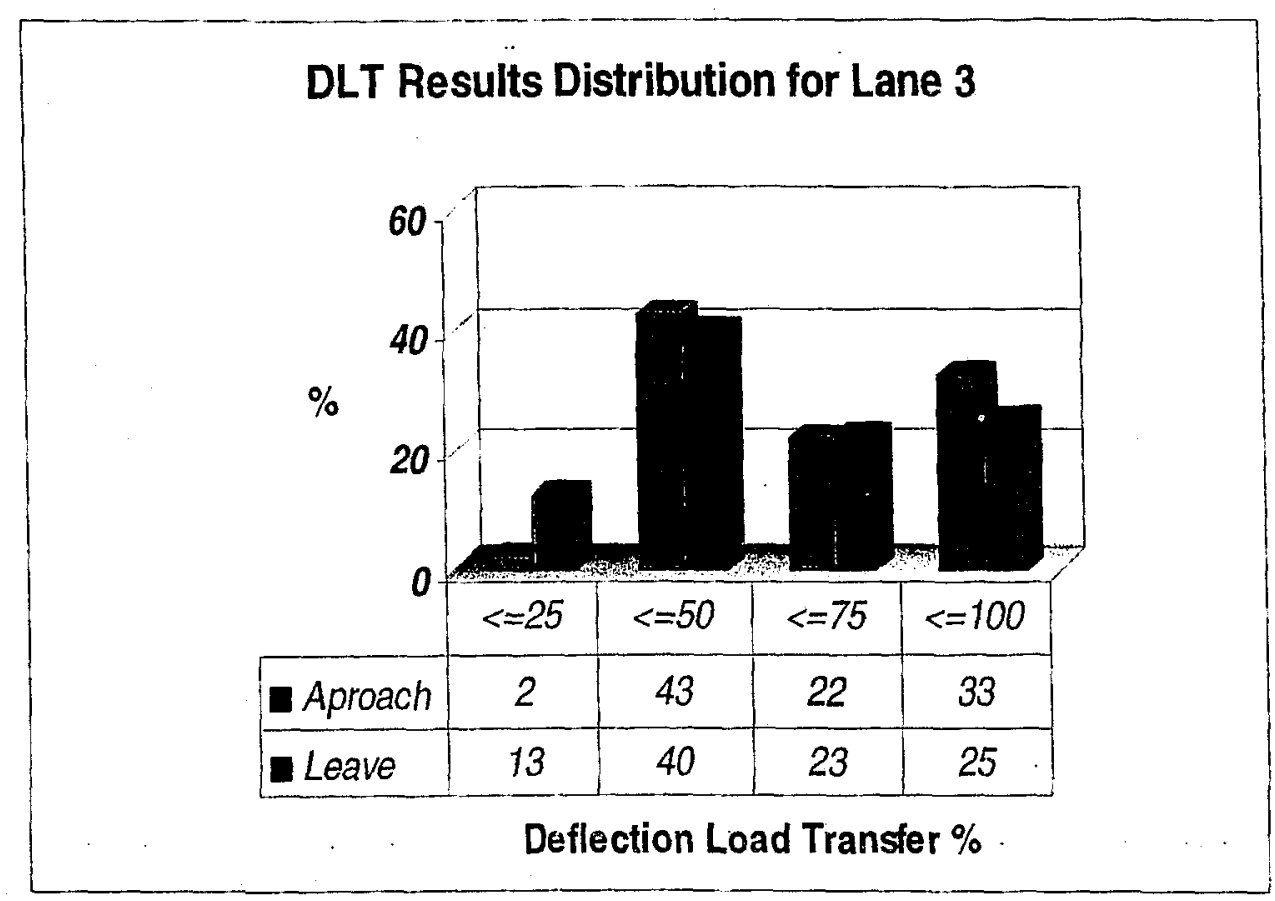

Figure 4.4 Distribution of Deflection Load Transfer results for Lane 3

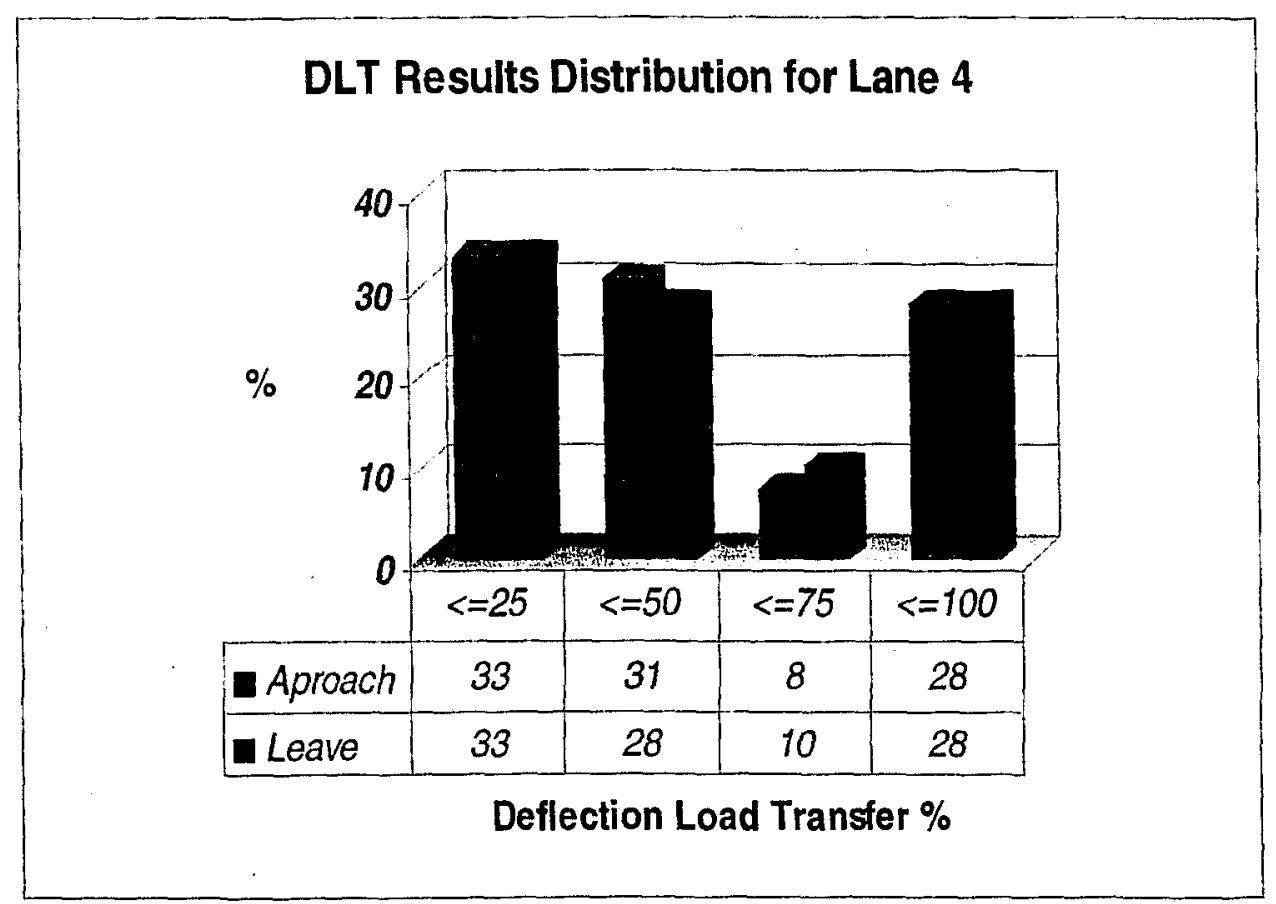

Figure 4.5 Distribution of Deflection Load Transfer results for Lane 4 


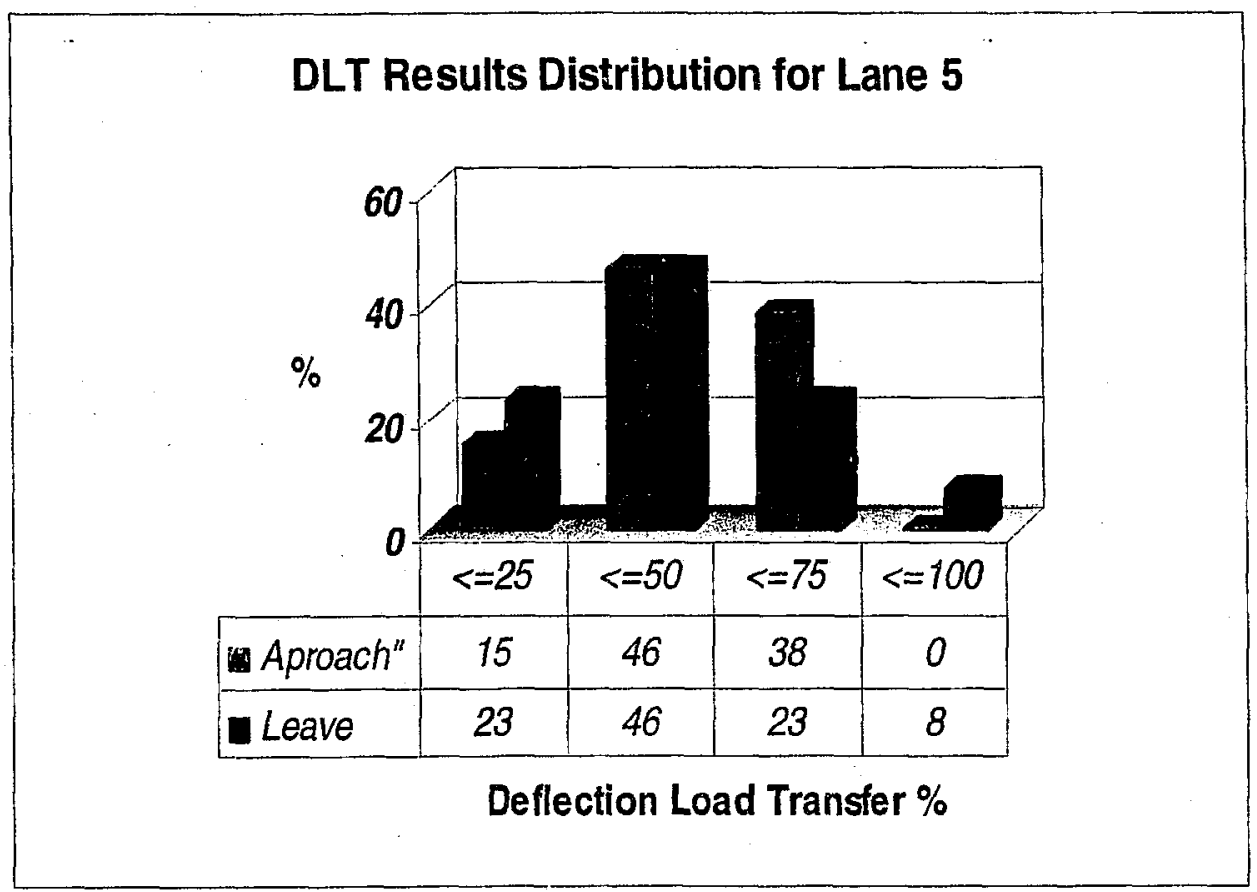

Figure 4.6 Distribution of Deflection Load Transfer results for Lane 5

The data analysis clearly confirmed the visual repair area observations that indicated that the most severe distress was in Lanes 3 and 4 . Distress was less in the lanes less used by heavy traffic (trucks).

\subsection{Traffic Analysis}

The Equivalent Single Axle Loads (ESALs) for any given section of highway are calculated from known or assumed traffic data, including AADT and the percentage of commercial vehicles. The two methods generally used in practice to determine the ESALs are the AASHTO method and the MTO Truck Factor Method. In Ontario, the Truck Factor Method is used to determine the ESALs for any highway. The MTO method was used in this project to determine the ESALs.

The AADT data for Highway 401 eastbound collectors within the study project limits is shown in Table 4.4. Input parameters for the design lane ESAL calculations were taken from the MTO publication Ml-183 'Adaptation and Verification of AASHTO Pavement Design Guide for Ontario Cunditions'.

Table 4.4 input parameters for ESAL calculation.

\begin{tabular}{|c|c|c|c|c|c|}
\hline $\begin{array}{c}2003 \\
\text { AADT }\end{array}$ & $\begin{array}{c}\text { Heavy } \\
\text { Vehicles (\%) }\end{array}$ & $\begin{array}{c}\text { Average } \\
\text { Truck Factor }\end{array}$ & $\begin{array}{c}\text { Lane } \\
\text { Distribution }\end{array}$ & $\begin{array}{c}\text { No. of Days } \\
\text { per Year }\end{array}$ & $\begin{array}{c}\text { Design Life } \\
\text { (Years) }\end{array}$ \\
\hline 84,637 & 10 & 1.9 & 0.6 & 300 & 15 \\
\hline
\end{tabular}


After calculating the ESALs for the base year (2003), projections of future traffic were made. A 2 per cent annual growth rate was assumed to determine the ESALs of the target year which was 2018. Figures 4.7 and 4.8 show the future AADTs and cumulative ESALs respectively assuming a $2 \%$ annual traffic growth rate.

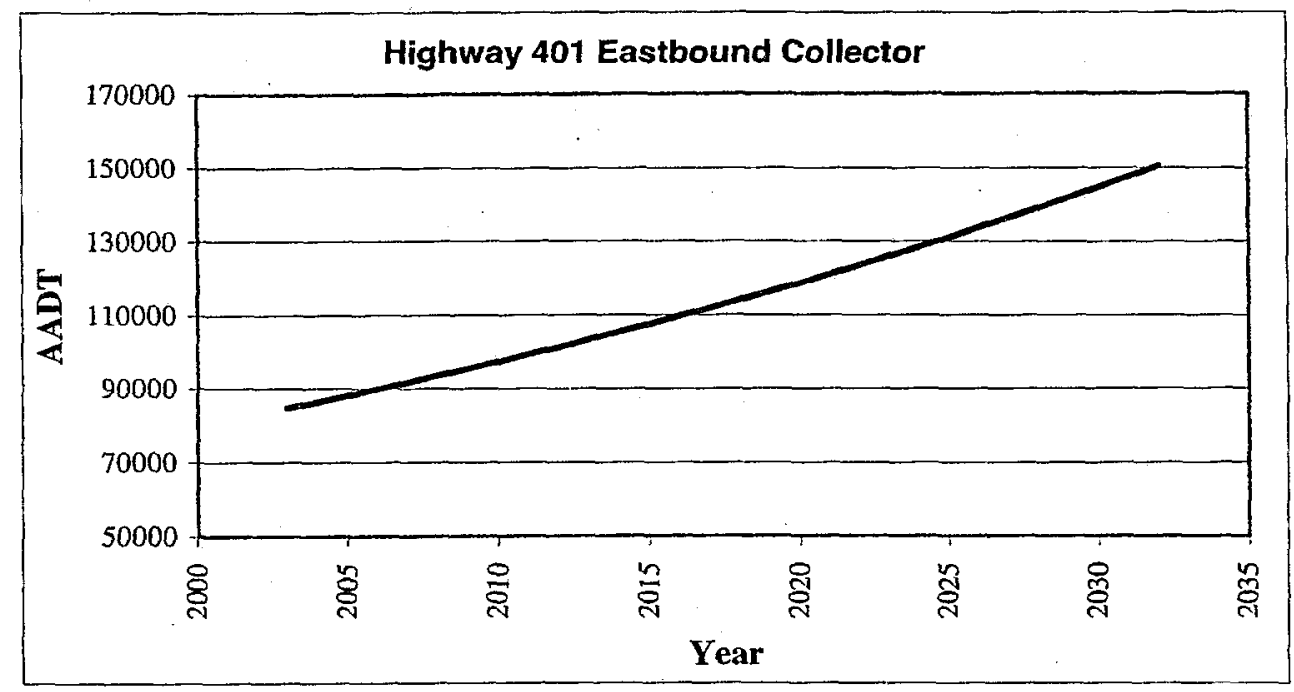

Figure 4.7 Projected AADT with $2 \%$ annual growth rate

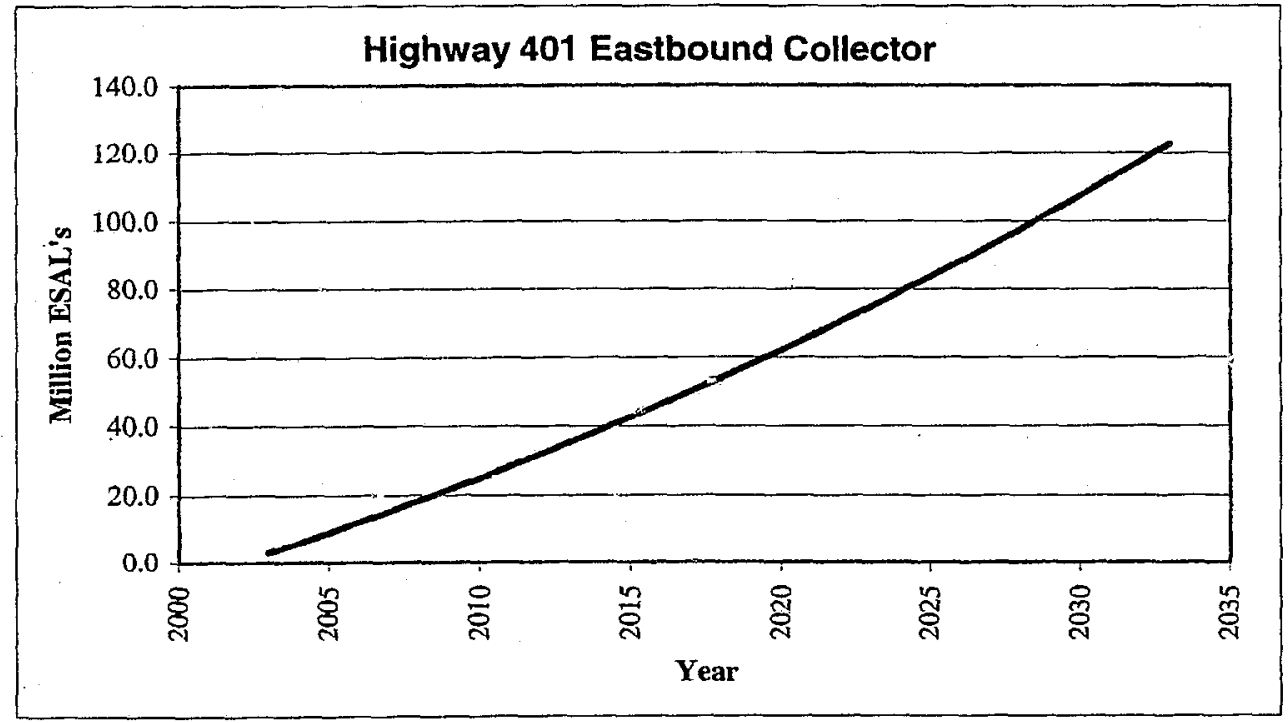

Figure 4.8 Projected ESAL's with $2 \%$ annual growth rate

Reproduced with permission of the copyright owner. Further reproduction prohibited without permission. 


\subsection{Remaining Life Analysis/Prediction}

Remaining Life Analysis (RLA) was performed to develop various rehabilitation options for Life Cycle Cost Analysis (LCCA). The RLA is based on the use of accumulated ESALs (equivalent single axle loads) to predict the structural capacity of the pavement structure at three stages:

- as originally constructed

- after resurfacing

- after major or minor maintenance and/or further strengthening of the pavement structure.

The remaining life analysis (RLA) methodology involves repeating calculations using the present material parameters. For example, the existing concrete was specified at the time of construction, $30+$ years ago, to have a 28-day compressive strength of $25 \mathrm{MPa}$. The compressive strength measured on cores obtained from the collector lanes in this study was over $50 \mathrm{MPa}$. Therefore, when calculations identical to the above are performed using the present day material parameters, and the shorter slab lengths resulting from the transverse cracking of the formerly long slabs, the existing pavement structure is estimated to be able to withstand $80 \pm$ million ESALs before reaching its terminal serviceability level. This ESAL value corresponds approximately to the year 2011(Figure 4.8).It can be concluded that the probable remaining life of the existing JRCP is in the order of 7 years.

In theory, a new pavement whose original material properties do not improve with time will reach its terminal serviceability level sooner than one whose material properties improve with time. For a composite pavement similar in thickness and composition to the pavement in this study, and with unchanged material properties, the terminal serviceability level would have been reached after an accumulation of 50 million ESALs (based on AASHTO methods of pavement structure analysis), which corresponds to the year 2005. On this basis, it can be concluded that the existing pavement has a remaining life of about 1 year. However, a remaining life of 7 years calculated from existing data is more realistic.

The distress survey, as cilscussed earlier, found that the estimated JRCP repair area is about 8 per cent of the total pavement area investigated. Since this low percentage of repair area justifies rehabilitation rather than reconstruction, the rehabilitation strategy recommended in this study is to repair the existing JRCP in such a way that only the asphalt Concrete Overlay $(A C O)$ will require replacement in the future, but not the concrete base. 


\subsection{Design and Recommendations:}

On completion of the extensive analyses discussed, the pavement rehabilitation strategy is selected. Using design parameters calculated from the laboratory and field investigations, the pavement structure is calculated for a given traffic. Pavement structure is generally calculated using both AASHTO and MTO methods. Sensitivity analysis is carried out for both design results. It is observed that AASHTO design results are more conservative than MTO design results. However, MTO design results are more conservative and more realistic for Ontario Northern areas.

Based on pavement design results, a pavement Structure Number (SN) is recommended. In this case, as already discussed, because the estimated JRCP repair area is about $8 \%$ of the total pavement area, full reconstruction of the pavement is not economical and is not recommended. Selective repair of the existing concrete pavement with an overlay is considered to be an economical and feasible pavement rehabilitation option. Based on the fact that grade restriction does not allow overlay in excess of $90 \mathrm{~mm}$, it was decided to fix the $8 \%$ damaged area and to provide an overlay of $90 \mathrm{~mm}$ thickness ( $40 \mathrm{~mm}$ of SMA over $50 \mathrm{~mm}$ of Superpave $19.0 \mathrm{~mm}$ ). This project is to be constructed in 2006 . 


\section{CHAPTER 5}

\section{POTENTIAL USE OF SHINGLES IN ASPHALT MIXTURES INCLUDING OVERLAYS}

There is increasing demand from government and public authorities to recycle the waste materials in roadway construction and maintenance projects. Prospective use of waste material and by products is rational and in most cases cost efficient. Millions of kilogram of roofing shingle waste is produced every year. Historically, about $95 \%$ of this roofing shingle waste, which is non-biodegradable solid waste, was placed in landfills. Approximately 300000 tonnes of asphalt roofing shingles was generated annually in Canada (8).

This Chapter provides a review of the potential use of shingles to improve the performance of the dense graded asphalt mixtures used in new pavements or rehabilitation. This chapter also outlines the results of a preliminary experimental program conducted by the writer to assess the potential use of shingles in asphalt concrete.

Shingles are composed of hard, crushed aggregate, high viscosity asphalt, and fibers that are desirable in some asphalt paving applications. It is not sensible and cost effective to use shingles in all mixes and some roofing waste may not be best candidate for such use (6).

The concept of using asphalt shingles will replace natural round, smooth aggregate particles (certain sands) with the comparatively rough textured manufactured roofing aggregate which improves the resistance to plastic deformation in asphalt mixtures (6). It is observed through various studies carried out that the addition of fibers (fibers in shingles) into asphalt paving mixtures will provide additional tensile resistance to rutting and cracking.

There are two kinds of roofing waste:

1. Manufacturing waste

2. Consumer waste

\section{Manufacturing Waste}

Manufacturing waste is produced from trimming and out of specification shingles during manufacturing process. New shingles typically contains about 20 to $30 \%$ asphalt. The asphalt used in shingle manufacturing is generally air blown that means the viscosity of asphalt used is much higher than asphalt used in paving. They also contain about 10 to 
$20 \%$ extender (mineral filler). Shingles have a fabric (generally fiberglass or cellulose) backing to provide strength and stability. These fibers are typically 5 to $15 \%$ by weight of the shingle (19).

\section{Consumer Waste}

Consumer waste is old shingles produced when old roof is replaced with a new one. Consumer waste contains more than $30 \%$ asphalt; this is because some of the aggregate has been lost due to weathering during its entire service life. In addition, the manufacturing processes have been changed over the years to reduce the asphalt cement proportion.

The asphalt due to oxidation, may be so hardened that it may not flow at normal asphalt plant operating temperatures. In addition to this, fibers in shingles also contributes to hardening of asphalt. The hardened asphalt in shingles which may contribute to temperature or fatigue cracking can be reduced by using soft virgin asphalt cements or adding rejuvenating oils available in the market and are successfully in use in cold in place recycling process (6).

Field waste may contain nails, wood, paper, polyester films and other debris therefore the composition of roofing waste may vary from stockpile to stockpile. It is always advisable to carry out quality testing before incorporation of shingles in to the asphalt mix. It need more research to develop specification for allowable degree of debris and their effects on performance of mixes.

\subsection{Processing of Roofing Waste}

Roofing waste should be shredded to use in asphalt mix. The level of shredding depends on type of roofing shingle and its end use. Most engineers like that the finer the roof waste is shredded, better it is for use in asphalt mix. The aged binder is hard and sometime brittle, therefore field waste is easy to shred as compared to factory waste. Heat generated during grinding softens the asphalt and thus interferes the process.

Due to advancement of technology, roofing shingles can be shredded to any size depending on its end use. Three grades of roofing shingles are available in the market; coarse $(25 \mathrm{~mm}$ to $+4.75 \mathrm{~mm})$, intermediate $(-4.75 \mathrm{~mm}$ to $+1 \mathrm{~mm})$, and fine $(-1 \mathrm{~mm})$. The capability of producing roofing chips passing $4.75 \mathrm{~mm}$ sieve is very encouraging (6). The appearance of these finely ground materials eliminated much of the concern about uniformly blending roofing waste into asphalt. It seems that the intermediate and finer material can easily be blended into asphalt mixture similar to reclaimed asphalt 
pavement (RAP). Cost of shredding is also reduced due to contractor's competition and new cost efficient equipment available in the market.

\section{Problems associated with asphalt shredding:}

Because of high asphalt content, stockpiles of roofing waste will consolidate and form clumps that obstruct handling and affect the incorporation into asphalt mixtures. The material must be delumped before use in asphalt. Ideally, the roofing waste should be shredded and used within a short time after shredding.

To alleviate stockpile lumping problem it is advisable to incorporate fine aggregate with the shredded roofing. A preplanned, controlled quantity of crusher fines would be added. This blend would need to be included during mixture design work to determine the optimum quantity to meet the grading specification.

\subsection{Factors Affecting Recycling of Shingles}

Economics has major impact on recovery and recycling of any waste material including shingles. It is not advisable and cost effective to haul shredded shingles for a very long distance.

Use of shingles in asphalt mixtures can lower the virgin asphalt cement requirement (proved in various studies) and increase the total Hot Mix Asphalt (HMA) tonnage at lower cost. It has also some potential to improve the performance, which extents the service life of the pavement at no additional cost. Therefore, a lower life cycle cost would certainly provide additional incentive for their use in asphalt mixes.

The following technical items should be considered and addresses before deciding to use shingles in any asphalt mixture (6).

- The nature and quantity of the material in roofing waste; including properties of asphalt cement and grain size distribution of the solid material.

- The maximum quantity of the shingles that can be incorporated into paving mixture without adversely altering the engineering properties of the mixture.

- The quantity and grade of asphalt cement and/or rejuvenating oils needed to soften the relatively hard roofing asphalt to a proper paving grade asphalt cement

- Introduction of construction strategy without adverse effect to environment

- Establish the long term performance characteristics of HMA containing roofing shingles by extensive laboratory and field testing programs.

- Determining the local economics of using this waste material in paving mixtures. 


\subsection{Potential Benefits of Using Asphalt Shingles}

Following are the possible potential benefits that can be achieved by using asphalt shingles (8).

- Reduced cost for shingle waste disposal, in addition to conservation of landfill.

- Reduced cost for the production of HMA, resulting from reduction in the use of new materials.

- Possible improved resistance to pavement cracking due to the reinforcement provided by the fibers from shingles.

- Possible improved resistance to permanent deformation due to the combination of the fibers and harder asphalt cement used in shingles.

- Better durability and enhanced resistance to raveling due to increase asphat cement film thickness in the mix.

- Shingles can be an economic fiber source for Stone Mastic Asphalt (SMA) production

\subsection{Description of Experimental Program}

Two asphalt paving mixtures commonly used are selected for the study; Superpave 12.5 which is generally used as surface course and Superpave 19.0 used as binder course. These mixes were compared using shingles and without shingles. The concept of this study was to determine the potential use of shingles in above mentioned mixes. It was observed from previous studies that up to $5 \%$ by weight of mixture of shingles can be used which has a minimum impact on the properties of the mixture (8). Therefore, $5 \%$ of shingles by weight of the mixture was selected for this study. Mixes with $5 \%$ shingles for Superpave 12.5 and Superpave 19.0 and also mixes of Superpave 12.5 and Superpave 19.0 without shingles were prepared and tested in the laboratory. The comparison, analysis and results are presented at the end of this report. The main objective is to use these mixtures in rehabilitation works as an overlay.

\subsection{Materials Used in Study:}

\subsubsection{Coarse Aggregate:}

Superpave has specified coarse and fine aggregate angularity with a high degree of internal friction and thus, high shear strength for rutting resistance. Two types of coarse aggregate with a nominal size of 12.5 and $19.0 \mathrm{~mm}$ are used in this study. Both coarse aggregate was selected from MRT quarry located at Havelock, Ontario, and washed screening as fine aggregate is also from the same quarry. 
Gradation analysis for coarse aggregate was carried out using AASHTO LS 702 and LS 602 methods. The sieve analysis results and graph is presented in Table 5.1, 5.2 and Figure 5.1, 5.2 respectively.

Table: 5.1 Grain Size Analysis Results for $19.0 \mathrm{~mm}$ Course Aggregate

\begin{tabular}{|c|c|c|c|}
\hline SIEVE SIZES & $\begin{array}{c}\text { Cumulative Mass } \\
\text { Retained }\end{array}$ & $\begin{array}{c}\text { Percent } \\
\text { Retained }\end{array}$ & Percent Passing \\
\hline $\mathrm{mm}$ & $g$ & $\%$ & $\%$ \\
\hline 26.5 & 0.00 & 0.00 & 100.00 \\
\hline 19 & 50.10 & 6.47 & 93.53 \\
\hline 16 & 221.00 & 28.52 & 71.48 \\
\hline 13.2 & 532.00 & 68.65 & 31.35 \\
\hline 9.5 & 681.00 & 87.88 & 12.12 \\
\hline 6.7 & 719.25 & 92.82 & 7.18 \\
\hline 4.75 & 757.50 & 97.75 & 2.25 \\
\hline 2.36 & 759.90 & 98.06 & 1.94 \\
\hline 1.18 & 760.10 & 98.09 & 1.91 \\
\hline 0.6 & 763.30 & 98.50 & 1.50 \\
\hline 0.3 & 763.30 & 98.50 & 1.50 \\
\hline 0.15 & 763.80 & 98.57 & 1.43 \\
\hline 0.075 & 764.00 & 98.59 & 1.41 \\
\hline Pan & 766.00 & 98.85 & 1.15 \\
\hline
\end{tabular}




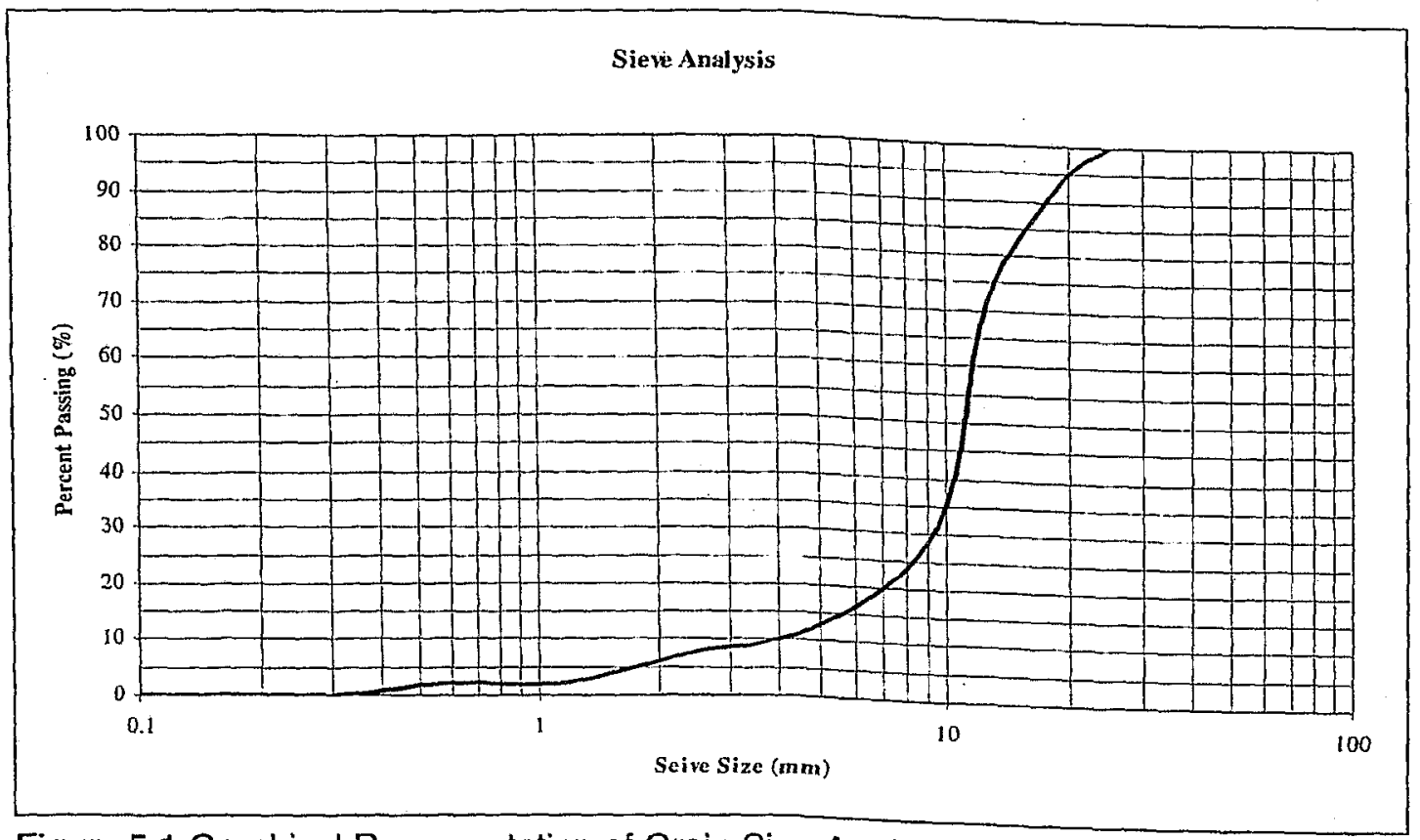

Figure 5.1 Graphical Representation of Grain Size Analysis of $19 \mathrm{~mm}$ coarse aggregate

Table 5.2 Grain Size Analysis Results for $12.0 \mathrm{~mm}$ Course Aggregate

\begin{tabular}{|c|c|c|c|}
\hline SIEVE SIZES & $\begin{array}{c}\text { Cumulative Mass } \\
\text { Retained }\end{array}$ & $\begin{array}{l}\text { Percent } \\
\text { Retained }\end{array}$ & Percent Passing \\
\hline $\mathrm{mm}$ & g & $\%$ & $\%$ \\
\hline 26.5 & 0.00 & 0.00 & 100.00 \\
\hline 19 & 0.00 & 0.00 & 100.00 \\
\hline 16 & 0.00 & 0.00 & 100.00 \\
\hline 13.2 & 0.00 & 0.00 & 100.00 \\
\hline 9.5 & 94.70 & 12.94 & 87.06 \\
\hline 6.7 & 507.40 & 69.34 & 30.66 \\
\hline 4.75 & 693.70 & 94.79 & 5.21 \\
\hline 2.36 & 719.50 & 98.32 & 1.68 \\
\hline 1.18 & 719.90 & 98.37 & 1.63 \\
\hline 0.6 & 720.20 & 98.41 & 1.59 \\
\hline 0.3 & 720.30 & 98.43 & 1.57 \\
\hline 0.15 & 720.40 & 98.44 & 1.56 \\
\hline 0.075 & 721.10 & 98.54 & 1.46 \\
\hline Pan & 726.80 & 99.32 & 0.68 \\
\hline
\end{tabular}




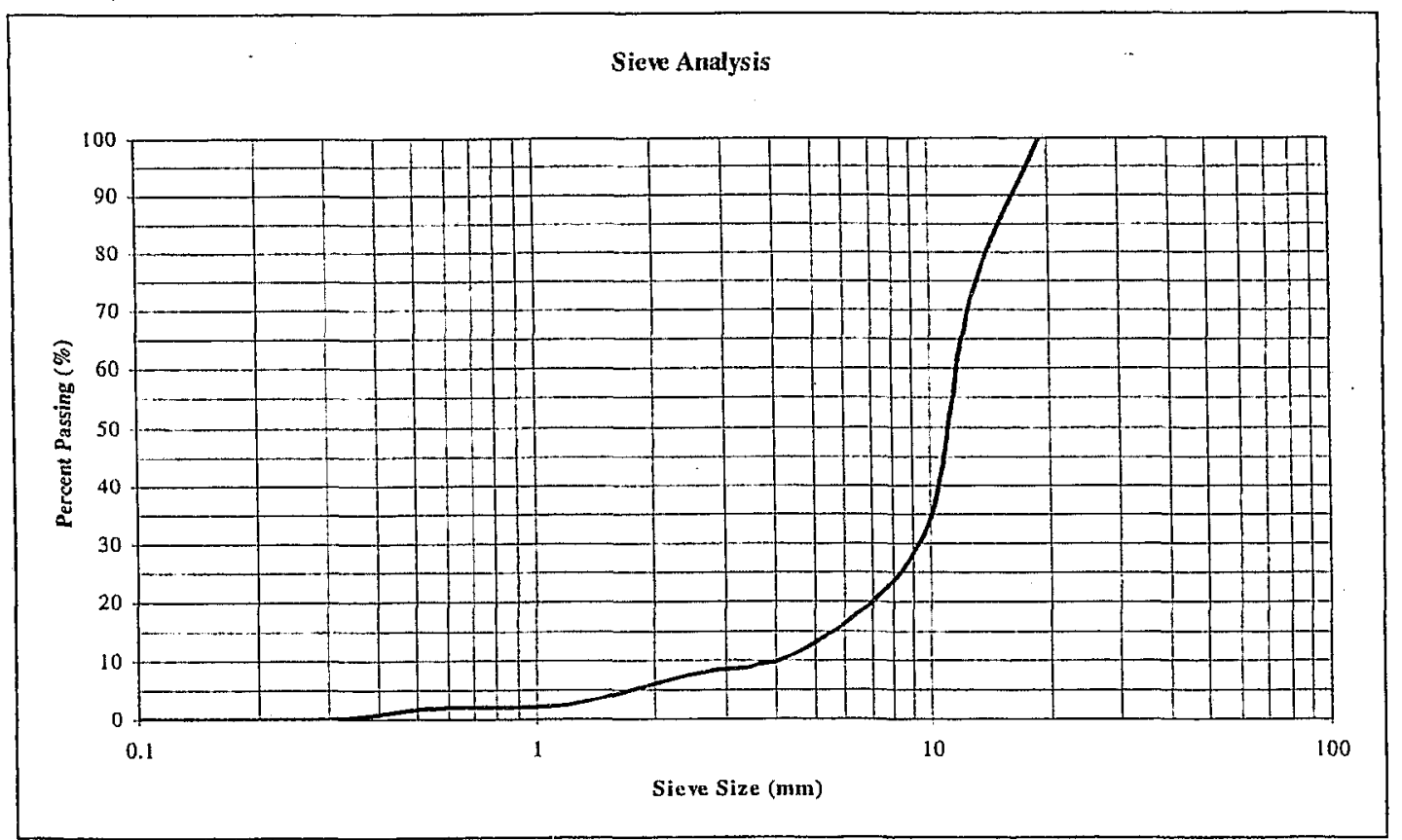

Figure 5.2 Graphical Representation of Grain Size Analysis of $12 \mathrm{~mm}$ coarse aggregate

\subsubsection{Fine Aggregates}

Washed screening from MRT quarry for the fine aggregate has been used. Gradation analysis for fine aggregate was carried out using AASHTO LS 702 method. The sieve analysis results and graph is presented in Table 5.3 and Figure 5.3 respectively.

\subsubsection{Shingles}

The shingles were collected from waste yard near Brampton, Ontario. Asphalt is extracted from the shingles and measured for asphalt content and aggregate gradation. Shingles contain average $30 \%$ binder content. The gradation and graphical representation is given below in Table 5.4 and Figure 5.4, respectively. Asphalt content and gradation of the aggregate was carried out to have an idea of material and their potential effect on the mixture. It should be noted that the consistency of the shingles manufacturing process is normally much greater than the consistency of the production of an asphalt mix. Therefore, the gradation of the aggregate found in the shingles given by a manufacturing plant will be more consistent than will be the gradation of the fine aggregate received from the quarry. 
Table 5.3 Grain Size Analysis Results for Fine Aggregate (sand)

\begin{tabular}{|c|c|c|c|}
\hline SIEVE SIZES & $\begin{array}{c}\text { Cumulative Mass } \\
\text { Retained }\end{array}$ & $\begin{array}{c}\text { Percent } \\
\text { Retained }\end{array}$ & Percent Passing \\
\hline $\mathbf{m m}$ & $\mathbf{g}$ & $\%$ & $\%$ \\
\hline 26.5 & 0.00 & 0.00 & 100.00 \\
\hline 19 & 0.00 & 0.00 & 100.00 \\
\hline 16 & 0.00 & 0.00 & 100.00 \\
\hline 13.2 & 0.00 & 0.00 & 100.00 \\
\hline 9.5 & 0.00 & 0.00 & 100.00 \\
\hline 6.7 & 0.00 & 0.00 & 100.00 \\
\hline 4.75 & 19.50 & 2.07 & 97.93 \\
\hline 2.36 & 97.60 & 10.36 & 89.64 \\
\hline 1.18 & 192.60 & 20.45 & 79.55 \\
\hline 0.6 & 379.00 & 40.23 & 59.77 \\
\hline 0.3 & 686.80 & 72.91 & 27.09 \\
\hline 0.15 & 876.50 & 93.05 & 6.95 \\
\hline 0.075 & 926.70 & 98.38 & 1.62 \\
\hline Pan & 939.70 & 99.76 & 0.24 \\
\hline
\end{tabular}

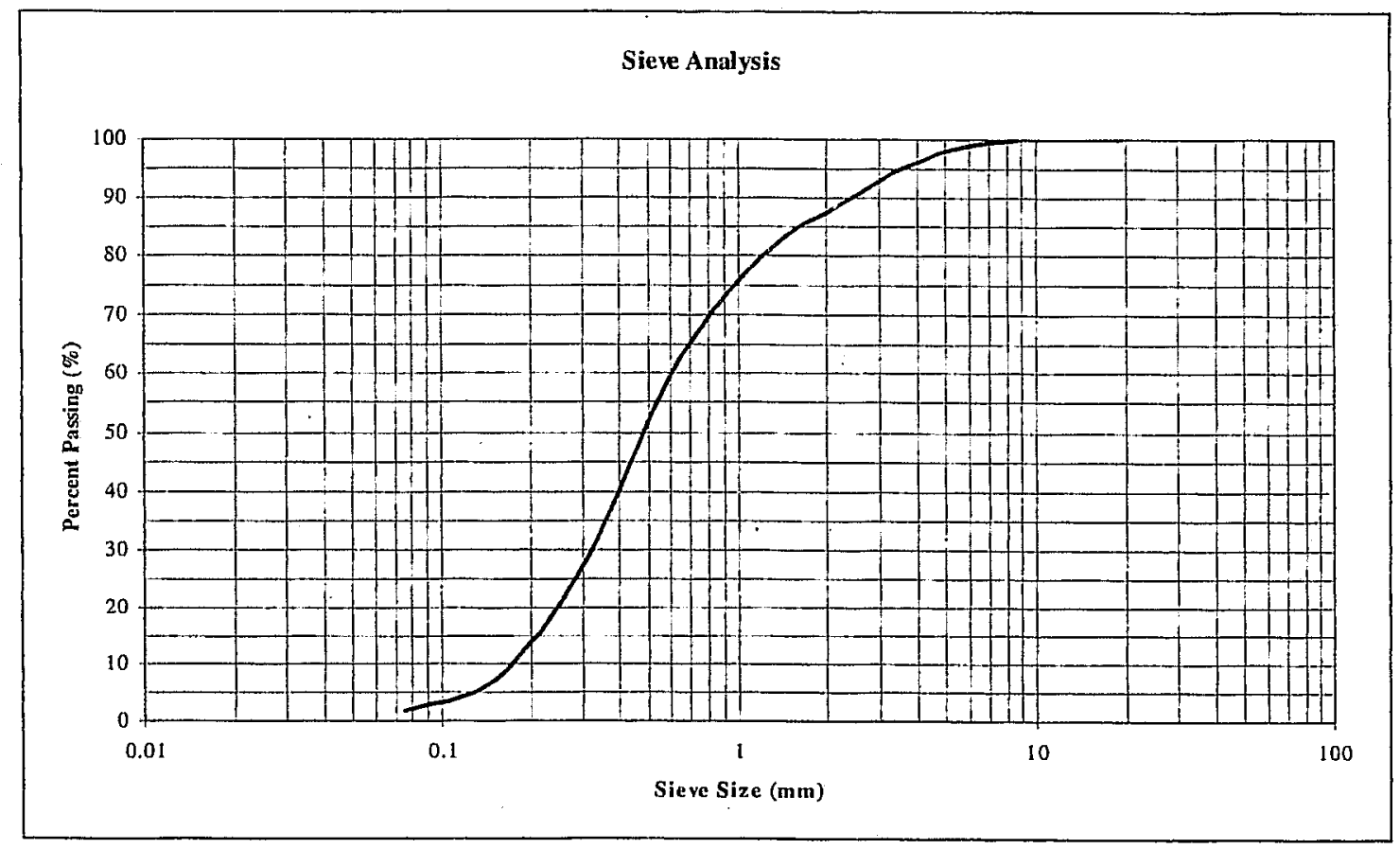

Figure 5.3 Graphical Representation of Grain Size Analysis of fine aggregate (sand) 
Table 5.4 Grain Size Analysis Results for Shingles

\begin{tabular}{|c|c|c|c|}
\hline SIEVE SIZES & $\begin{array}{c}\text { Cumulative Mass } \\
\text { Retained }\end{array}$ & $\begin{array}{c}\text { Percent } \\
\text { Retained }\end{array}$ & Percent Passing \\
\hline $\mathbf{m m}$ & $\mathbf{g}$ & $\%$ & $\%$ \\
\hline 26.5 & 0.00 & 0.00 & 100.00 \\
\hline 19 & 0.00 & 0.00 & 100.00 \\
\hline 16 & 3.60 & 0.47 & 99.53 \\
\hline 13.2 & 29.50 & 3.87 & 96.13 \\
\hline 9.5 & 112.50 & 14.75 & 85.25 \\
\hline 6.7 & 161.50 & 21.18 & 78.82 \\
\hline 4.75 & 192.10 & 25.19 & 74.81 \\
\hline 2.36 & 253.10 & 33.19 & 66.81 \\
\hline 1.18 & 408.70 & 53.59 & 46.41 \\
\hline 0.6 & 511.80 & 67.11 & 32.89 \\
\hline 0.3 & 543.90 & 71.32 & 28.68 \\
\hline 0.15 & 573.00 & 75.14 & 24.86 \\
\hline 0.075 & 595.10 & 78.04 & 21.96 \\
\hline Pan & 598.20 & 78.44 & 21.56 \\
\hline
\end{tabular}

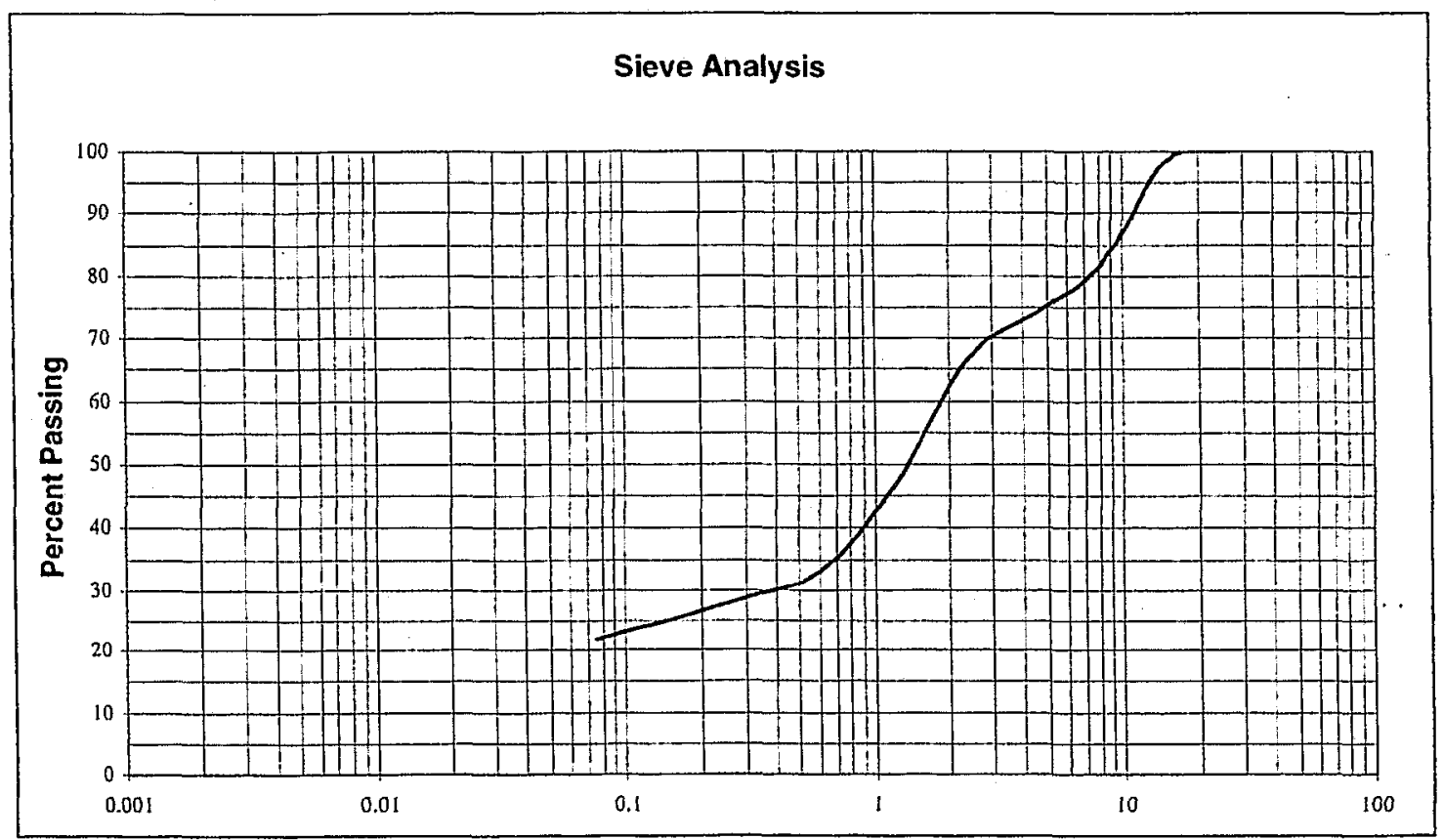

Figure 5.4 Graphical Representation of Grain Size Analysis of shingles 


\subsubsection{Asphalt Cement.}

The asphalt cement used in shingle manufacturing is generally air blown and has significantly higher viscosity as compared to the asphalt cement used in HMA. Moreover, due to aging, asphalt cement in shingles became more stiff. Therefore, a softer asphalt cement i.e. PG 58-28 was selected for this study. However, stiffer asphalt cement i.e PG64-28 may be used if shingles were not included in the mix. The asphalt binder was provided by McAsphalt Industries Limited, Ontario. It should be noted that the effect of aged asphalt over performance graded asphalt is not a part of this study.

\subsection{Mix Design}

The Superpave mix design system incorporates material selection and mix design based on project's climate and design traffic. Superpave modifies the gradation approach and introduced 0.45 power gradation chart. The "point 45 power" chart uses different way to show the cumulative particle size distribution. The vertical axis of the chart is percent passing and horizontal axis is an arithmetic scale of sieve size in millimeters, raised to the 0.45 power.

Superpave specifies the gradation by adding two features to the 0.45 power chart i.e. control points. Control points function as master ranges between which gradation must pass.

A laboratory experimental mix design was developed which requires the blending of different materials as discussed earlier, with various ratios to meet the required Superpave specifications. In this study, the writer fulfilled the requirements of Superpave 12.5 and Superpave 19.5 specification. All of the design aggregate structure for this study met the control points. .

Blends for Superpave 19.0 and Superpave 12.5 with and without shingles were prepared. Various trial blends were prepared to achieve the Superpave volumetric properties. The percentage of each material is presented in Table 5.5 while detailed blending of each mix is presented in Appendix 1 with Tables and Granular size distribution curves.

\subsubsection{Asphalt Concrete Sample Preparation}

Three batches of blended aggregate to appropriate grading were prepared and heated in an oven overnight to a specified temperature. A determined quantity of shredded shingles i.e. $5 \%$ by weight of mix, was thoroughly mixed with the hot aggregate, and the mixture was placed in the oven for a short period i.e. 2 hours. Sequentially, hot asphalt 
Table 5.5 Blend for Various Mixtures

\begin{tabular}{|c|c|c|c|c|}
\hline $\begin{array}{c}\text { Superpave Mix } \\
\text { Type }\end{array}$ & $\begin{array}{c}\text { Coarse } \\
\text { aggregate 19.0 }\end{array}$ & $\begin{array}{c}\text { Coarse } \\
\text { aggregate 12.5 }\end{array}$ & $\begin{array}{c}\text { Fine } \\
\text { Aggregate }\end{array}$ & Shingles \\
\hline Superpave 19.0 & $\%$ & $\%$ & $\%$ & $\%$ \\
\hline & 40 & 33 & 22 & 5 \\
\hline Superpave 12.5 & - & 33 & 24 & - \\
\hline & - & 69 & 26 & 5 \\
\hline
\end{tabular}

bindiar was added and the mixture and was thoroughly blended. The blended material was returned to the oven and held for two hours for absorption and short term aging.

Two mixture specimens were compacted using Superpave Gyratory Compactor (SGC) while the third specimen was held for theoretical maximum density.

\subsubsection{Superpave Gyratory Compactor (SGC)}

The primary device used in Superpave mix design is the Superpave Gyratory Compactor (SGC). Sample preparation was performed using SGC. The basis for the SGC was a Texas gyratory compactor modified to use the compaction principles of a French gyratory compactor. The modified Texas gyratory accomplished the goals of realistic specimen densification and it was reasonably portable. Its $150 \mathrm{~mm}$ sample diameter which would be effectively reasonable for maximum size of aggregates. The SHRP researchers modified the angle by lowering down and speed of gyration and adding real time, specimen height-recording capabilities (11).

The Superpave gyratory compactor has the following parts

- Reaction frame, rotating base and motor

- Loading system, loading ram, and pressure gauge

- Height measuring and recording system

- Mold and Base plate Specimen Extruding dovice

\subsubsection{Gyrations}

Next, a minimum of two specimens for each trial blend were compacted using the SGC. These specimen are prepared for determination of the mixture's maximum theoretical specific gravity (Gmm). An average weight of mix for one specimen should be Approx. 5000 grams is usually sufficient for the compacted specimens. An aggregate weight of 
about 2000 grams is usually sutficient for the specimens used to determine maximum theoretical specific gravity $\left(\mathrm{G}_{\mathrm{mm}}\right)$.

\subsubsection{Required Number of Gyrations}

The number of gyrations used for compaction is determined based on the traffic level; it is explained in Table No 5.6 with reference to Superpave method of mix design guide SP-2 (5). In this study Superpave 19.0 and Superpave 12.5 are chosen. As per their Superpave requirement, the number of gyrations for initial compaction, design compaction and maximum compaction, are as follows.

$\mathrm{N}_{\text {(initial) }}=7$ gyrations

$N_{(\text {design) }}=125$ gyrations

$N_{(\max )}=225$ gyrations

\subsubsection{Calculation for $\% \mathbf{G}_{\mathrm{mm}}$}

Each specimen will be compacted to the design number of gyrations, with specimen height data collected during the compaction process.

During compaction, the height of the specimen is continuously monitored. After compaction is complete, the specimen is extruded from the mold and allowed to cool.

The bulk specific gravity $\left(G_{m b}\right)$ of the specimen is determined using AASHTO T166. The $\mathrm{Gmm}$ of each blend is determined using AASHTO T209. $\mathrm{G}_{\mathrm{mb}}$ is then divided by $\mathrm{G}_{\mathrm{mm}}$ to determine the $\% G_{m m} @ N_{\text {des. }}$. The \% $G_{m m}$ at any number of gyrations $(N x)$ is then calculated by multiplying $\% G_{m m} @ N_{d e s}$ by the ratio of the heights at $N_{\text {des }}$ and $N x$ Superpave gyratory compaction data is analyzed by computing the estimated bulk specific gravity, corrected bulk specific gravity, and corrected percentage of maximum theoretical specific gravity for each desired gyration. During compaction, the height is

Table 5.6 Details about Gyration and traffic (5)

\begin{tabular}{|l|c|c|c|}
\hline \multirow{2}{*}{$\begin{array}{c}\text { Design ESAL } \\
\text { (millions) }\end{array}$} & $\mathbf{N}_{\text {(initial) }}$ & $\mathbf{N}_{\text {(design) }}$ & $\mathbf{N}_{\text {(maximum) }}$ \\
\cline { 2 - 4 } & 6 & 50 & 75 \\
\hline Less than 0.3 & 7 & 75 & 115 \\
\hline From 0.3 to 3 & 8 & 100 & 160 \\
\hline From 3 to 30 & 9 & 125 & 205 \\
\hline Greater than 30 & & & \\
\hline
\end{tabular}


measured and recorded after each gyration. $G_{m b}$ of compacted specimen and $G_{m m}$ of loose mixture are measured. An estimate of $G_{m b}$ at any value of gyration is made by dividing the mass of the mixture by volume of the compaction mould.

\subsection{Results of the Experimental Program}

Four Superpave mixes are designed and investigated for their volumetric properties.

These mixes are as follows;

1. Superpave 19.0 with Shingles

2. Superpave 19.0 without Shingles

3. Superpave 12.5 with Shingles

4. Superpave 12.5 without Shingles

\subsubsection{Superpave 19.0 with Shingles}

Mix design was prepared with $40 \%$ coarse aggregate passing $19.0 \mathrm{~mm}$ sieve, $33 \%$ coarse aggregate passing $12.5 \mathrm{~mm}$ sieve, $22 \%$ fine aggregate (sand) and $5 \%$ shingles. Four trials with various asphalt cement content i.e. $3.5 \%, 4.0 \%, 4.5 \%$ and $5.0 \%$ were prepared. Detailed result sheets are provided in Appendix 2 and 3. A summary of the results is presented in Table 5.7 and Figure 5.5 below.

Table 5.7 Test results for Superpave 19.0 with Shingles

\begin{tabular}{||l|c|c|c|c||}
\hline \multicolumn{1}{|c|}{ Parameters } & \multicolumn{4}{c||}{ Results } \\
\hline \hline AC Content (\%) & 3.5 & 4.0 & 4.5 & 5.0 \\
\hline Gmm & 2.515 & 2.501 & 2.486 & 2.472 \\
\hline Gmb (Measured) & 2.413 & 2.421 & 2.423 & 2.431 \\
\hline$\%$ Gmm @ Nini & 86.7 & 87 & 87.5 & 88.4 \\
\hline$\%$ Gmm @ Ndes & 96.0 & 96.8 & 97.5 & 97.8 \\
\hline Air Voids (\%) Ndes & 4.0 & 3.2 & 2.5 & 2.2 \\
\hline VMA (\%) & 17.1 & 17.3 & 17.7 & 17.8 \\
\hline VFA (\%) & 76.4 & 81.4 & 85.6 & 86.2 \\
\hline Water Absorption of Asphalt mix (\%) & 0.23 & 0.19 & 0.05 & 0.21 \\
\hline Gsb, Bulk Specific Gravity of Aggregate & \multicolumn{5}{|c}{2.81} \\
\hline
\end{tabular}


Figure: 5.5 Superpave 19.0 with Shingles Mix Properties Curve

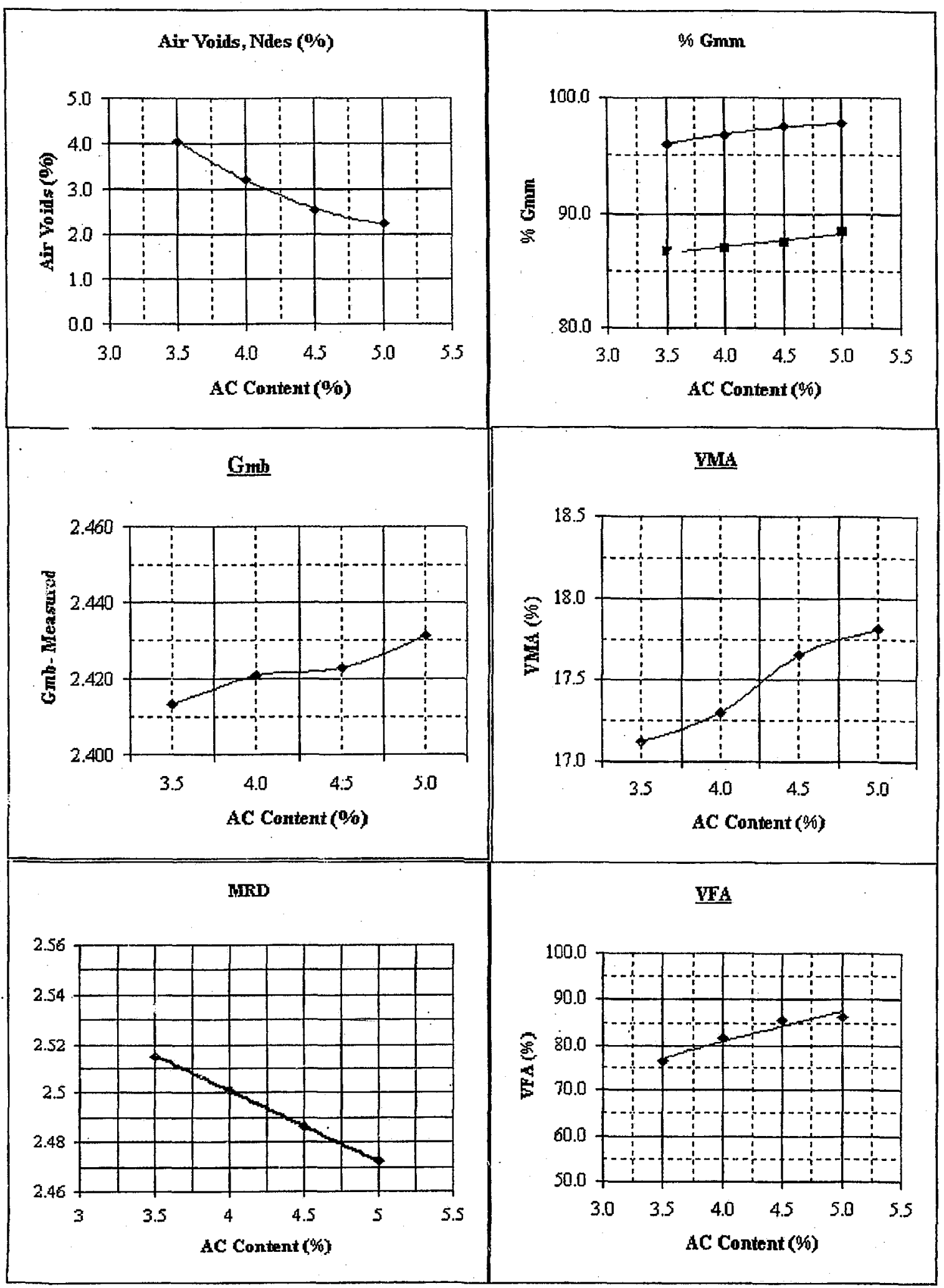


Table 5.8 Test results for Superpave 19.0 with Shingles considering Asphalt Content of Shingles

\begin{tabular}{|c|c|c|c|c|}
\hline Parameters & \multicolumn{4}{|c|}{ Results } \\
\hline AC Content $(\%)$ & 5.1 & 5.7 & 6.2 & 6.8 \\
\hline Gmm & 2.515 & 2.501 & 2.486 & 2.472 \\
\hline Gmb (Measured) & 2.413 & 2.421 & 2.423 & 2.431 \\
\hline$\%$ Gmm @ Nini & 86.7 & 87 & 87.5 & 88.4 \\
\hline \%Gmm@Ndes & 96.0 & 96.8 & 97.5 & 97.8 \\
\hline Air Voids $(\%)$ Ndes & 4.0 & 3.2 & 2.5 & 2.2 \\
\hline VMA $(\%)$ & 18.5 & 18.7 & 19.1 & 19.3 \\
\hline VFA $(\%)$ & 78.2 & 82.9 & 86.7 & 86.2 \\
\hline Water Absorption of Asphalt Mix (\%) & 0.23 & 0.19 & 0.05 & 0.21 \\
\hline Gsb, Bulk Specific Gravity of Aggregate & \multicolumn{4}{|c|}{2.81} \\
\hline
\end{tabular}

Reproduced with permission of the copyright owner. Further reproduction prohibited without permission. 
Figure 5.6 Superpave 19.0 with Shingles Mix Properties Curve considering asphalt. content of Shingles

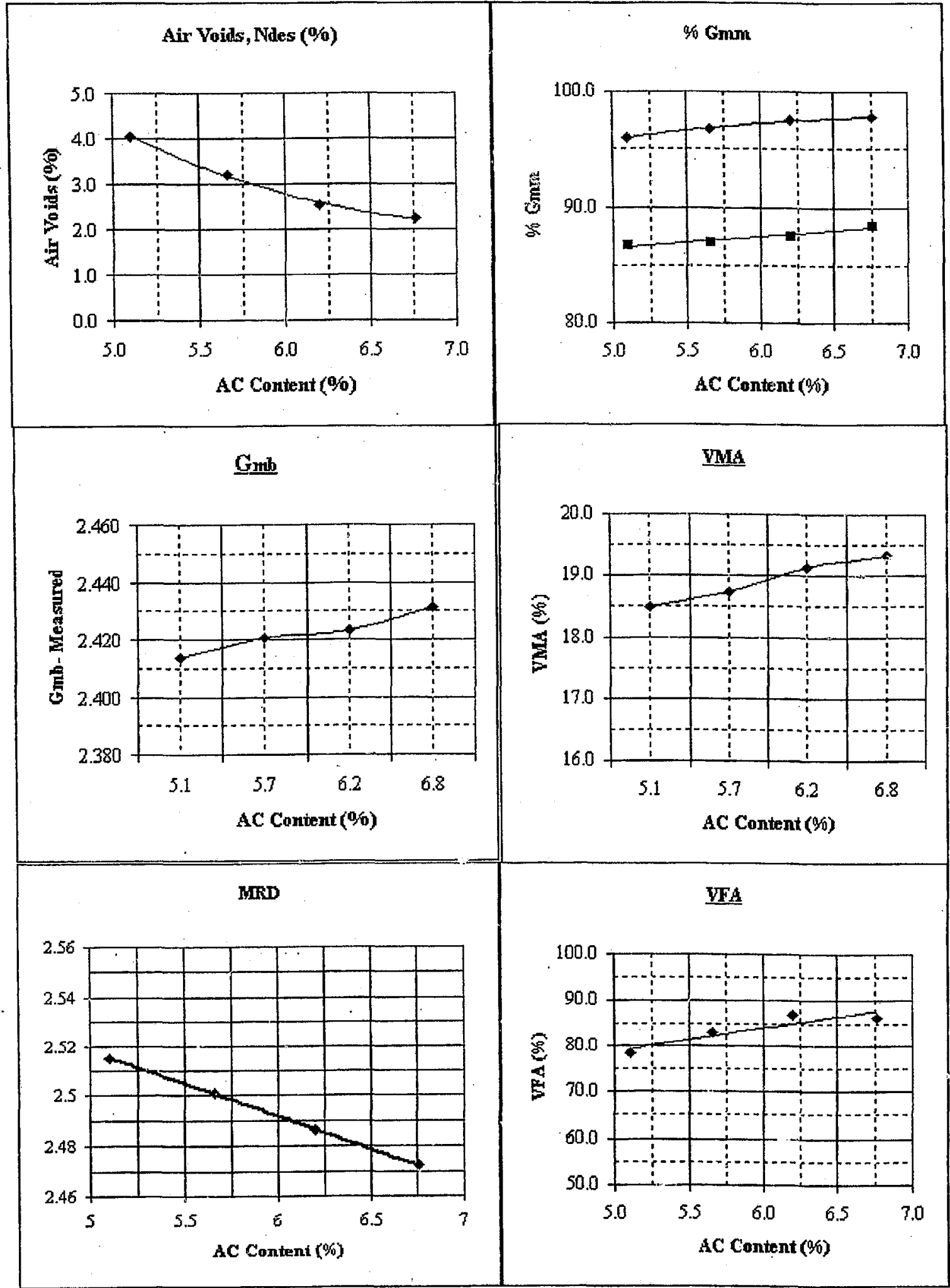

Reproduced with permission of the copyright owner. Further reproduction prohibited without permission. 


\subsubsection{Superpave 19.0 without Shingles}

Mix desigri was prepared with $43 \%$ coarse aggregate passing $19.0 \mathrm{~mm}$ sieve, $33 \%$ coarse aggregate passing $12.5 \mathrm{~mm}$ sieve and $24 \%$ fine aggregate (sand) while no shingles were used in this mix. Four trials with various asphalt cement content i.e. $3.5 \%$, $4.0 \%, 4.5 \%$ and $5.0 \%$ were prepared. Detailed result sheets are provided in Appendix 2 and 3. A summary of the results is presented in Table 5.9 and Figure 5.7 below.

Table 5.9 Test results for Superpave 19.0 without Shingles

\begin{tabular}{|l|c|c|c|c|}
\hline \multicolumn{1}{|c|}{ Parameters } & \multicolumn{4}{c|}{ Results } \\
\hline AC Content (\%) & 3.5 & 4.0 & 4.5 & 5.0 \\
\hline Gmm & 2.545 & 2.532 & 2.516 & 2.499 \\
\hline Gmb (Measured) & 2.400 & 2.408 & 2.414 & 2.426 \\
\hline$\%$ Gmm @ Nini & 84.5 & 85 & 86.1 & 88.4 \\
\hline$\%$ Gmm @ Ndes & 94.3 & 95.1 & 96.0 & 97.8 \\
\hline Air Voids (\%) Ndes & 5.7 & 4.9 & 4.0 & 2.2 \\
\hline VMA (\%) & 17.6 & 17.7 & 18.0 & 18.0 \\
\hline VFA (\%) & 67.7 & 72.4 & 77.5 & 86.2 \\
\hline Water Absorption of Asphalt mix (\%) & 0.37 & 0.20 & 0.24 & 0.21 \\
\hline Gsb, Bulk Specific Gravity of Aggregate & & & 2.81 & \\
\hline
\end{tabular}


Figure 5.7 Superpave 19.0 without Shingles Mix Property Curves

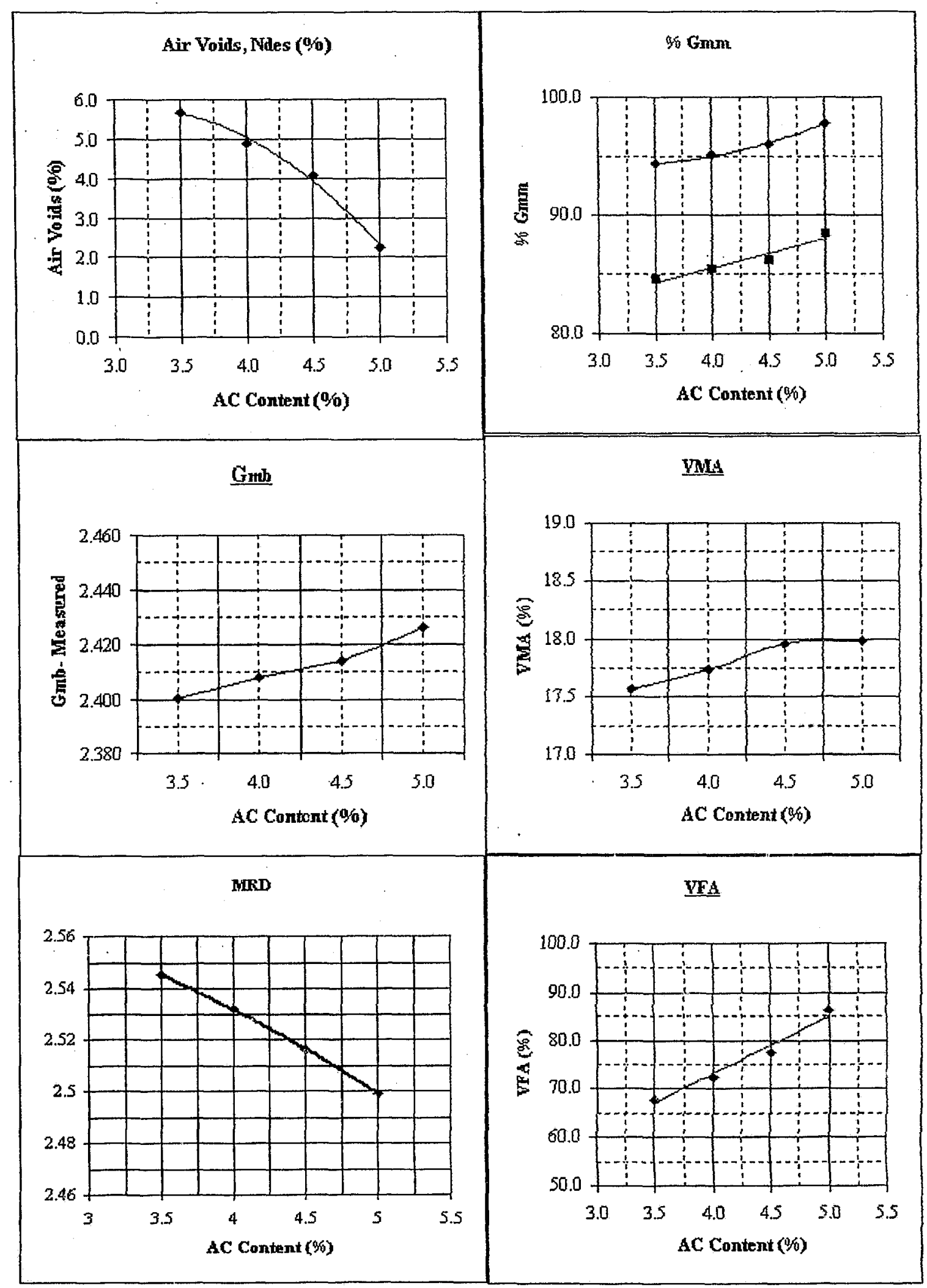

Reproduced with permission of the copyright owner. Further reproduction prohibited without permission. 


\subsubsection{Superpave 12.5 with Shingles}

Mix design was prepared with $69 \%$ coarse aggregate passing $12.5 \mathrm{~mm}$ sieve, $26 \%$ fine aggregate (sand) and $5 \%$ shingles. Four trials with various asphalt cement content i.e. $4.0 \%, 4.5 \%, 5.0 \%$ and $5.5 \%$ were prepared. Detailed result sheets are provided in Appendix 2 and 3 . A summary of the results is presented in Table 5.10 and Figure 5.8 below.

Table 5.10 Test results for Superpave 12.5 with Shingles

\begin{tabular}{|l|c|c|c|c|}
\hline \multicolumn{1}{|c|}{ Parameters } & \multicolumn{4}{c|}{ Results } \\
\hline AC Content (\%) & 3.5 & 4.0 & 4.5 & 5.0 \\
\hline Gmm & 2.528 & 2.518 & 2.500 & 2.492 \\
\hline Gmb (Measured) & 2.406 & 2.418 & 2.420 & 2.430 \\
\hline$\%$ Gmm @ Nini & 85.6 & 86 & 86.4 & 88.4 \\
\hline$\%$ Gmm @ Ndes & 95.2 & 96.0 & 96.8 & 97.8 \\
\hline Air Voids (\%) Ndes & 4.8 & 4.0 & 3.2 & 2.2 \\
\hline VMA (\%) & 17.4 & 17.4 & 17.8 & 17.6 \\
\hline VFA (\%) & 72.3 & 77.1 & 82.0 & 86.2 \\
\hline Water Absorption of Asphalt mix (\%) & 0.40 & 0.22 & 0.13 & 0.21 \\
\hline Gsb, Bulk Specific Graviry of Aggregate & & & 2.8 & \\
\hline
\end{tabular}


Figure 5.8 Superpave 12.5 with Shingles Mix Properties Curves

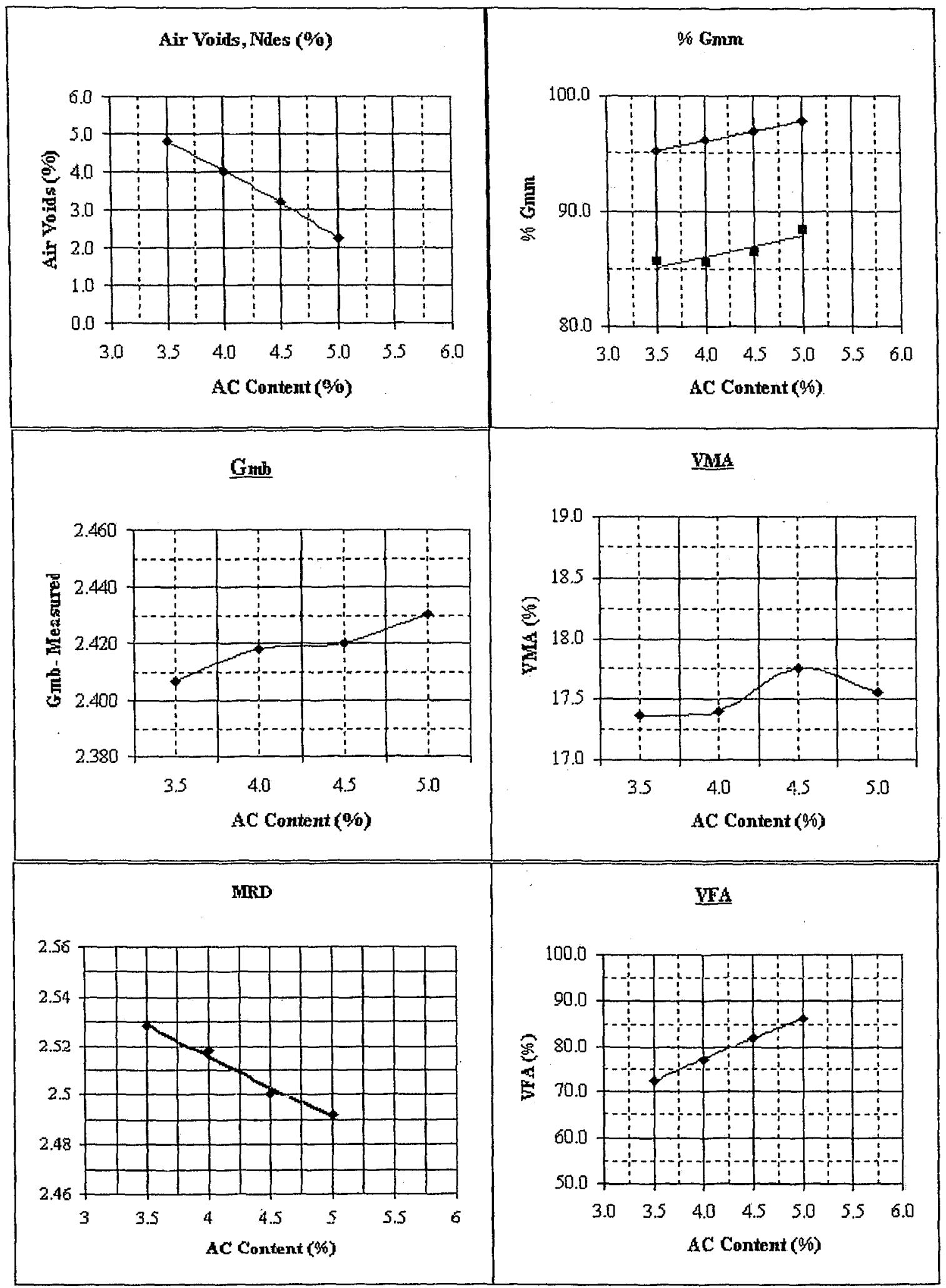


Table 5.11 Test results for Superpave 12.5 with Shingles considering Asphalt Content of Shingles

\begin{tabular}{|l|c|c|c|c|}
\hline \multicolumn{1}{|c|}{ Parameters } & \multicolumn{4}{c|}{ Results } \\
\hline AC Content (\%) & 5.1 & 5.7 & 6.2 & 6.8 \\
\hline Gmm & 2.528 & 2.518 & 2.500 & 2.492 \\
\hline Gmb (Measured) & 2.406 & 2.418 & 2.420 & 2.430 \\
\hline$\%$ Gmm @ Nini & 85.6 & 86 & 86.4 & 88.4 \\
\hline$\%$ Gmm @ Ndes & 95.2 & 96.0 & 96.8 & 97.8 \\
\hline Air Voids (\%) Ndes & 4.8 & 4.0 & 3.2 & 2.2 \\
\hline VMA (\%) & 18.7 & 18.8 & 19.2 & 19.1 \\
\hline VFA (\%) & 74.3 & 78.9 & 83.3 & 86.2 \\
\hline Water Absorption of Asphalt mix (\%) & 0.40 & 0.22 & 0.13 & 0.21 \\
\hline Gsb, Bulk Specific Gravity of Aggregate & & & 2.8 & \\
\hline \hline
\end{tabular}


Figure 5.9 Superpave 12.5 with Shingles Mix Properties Curve considering asphalt content of Shingles

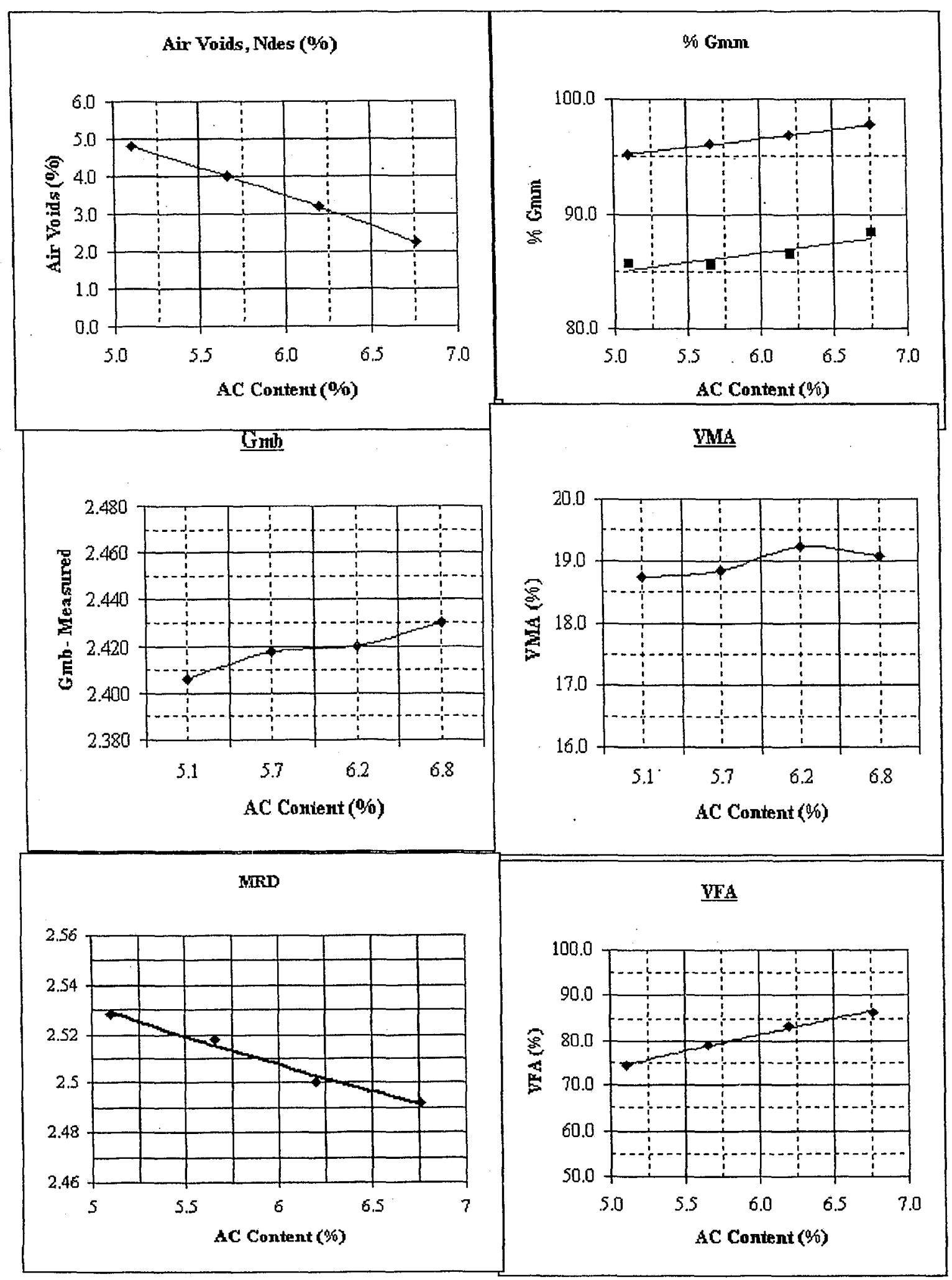

Reproduced with permission of the copyright owner. Further reproduction prohibited without permission. 


\subsubsection{Superpave 12.5 without Shingles}

Mix design was prepared with $72 \%$ coarse aggregate passing $12.5 \mathrm{~mm}$ sieve and $28 \%$ fine aggregate (sand) while no shingles were used in this mix. Four trials with various asphalt cement content i.e. $4.0 \%, 4.5 \%, 5.0 \%$ and $5.5 \%$ were prepared. Detailed result sheets are provided in Appendix 2 and 3. A summary of the results is presented in Table 5.12 and Figure 5.10 below.

Table 5.12 Test results for Superpave 12.5 without Shingles

\begin{tabular}{|l|c|c|c|c|}
\hline \multicolumn{1}{|c|}{ Parameters } & \multicolumn{4}{c|}{ Results } \\
\hline AC Content (\%) & 4.0 & 4.5 & 5.0 & 5.5 \\
\hline Gmm & 2.535 & 2.530 & 2.520 & 2.495 \\
\hline Gmb (Measured) & 2.394 & 2.408 & 2.419 & 2.422 \\
\hline$\%$ Gmm @ Nini & 84.3 & 85 & 84.8 & 88.4 \\
\hline$\%$ Gmm @ Ndes & 94.4 & 95.2 & 96.0 & 97.8 \\
\hline Air Voids (\%) Ndes & 5.6 & 4.8 & 4.0 & 2.2 \\
\hline VMA (\%) & 18.2 & 18.2 & 18.2 & 18.3 \\
\hline VFA (\%) & 69.5 & 73.4 & 77.9 & 86.2 \\
\hline Water Absorption of Asphalt mix (\%) & 0.52 & 0.39 & 0.26 & 0.21 \\
\hline Gsb, Bulk Specific Gravity of Aggregate & & & 2.8 & \\
\hline
\end{tabular}


Figure 5.10 Superpave 12.5 without Shingles Mix Property Curves

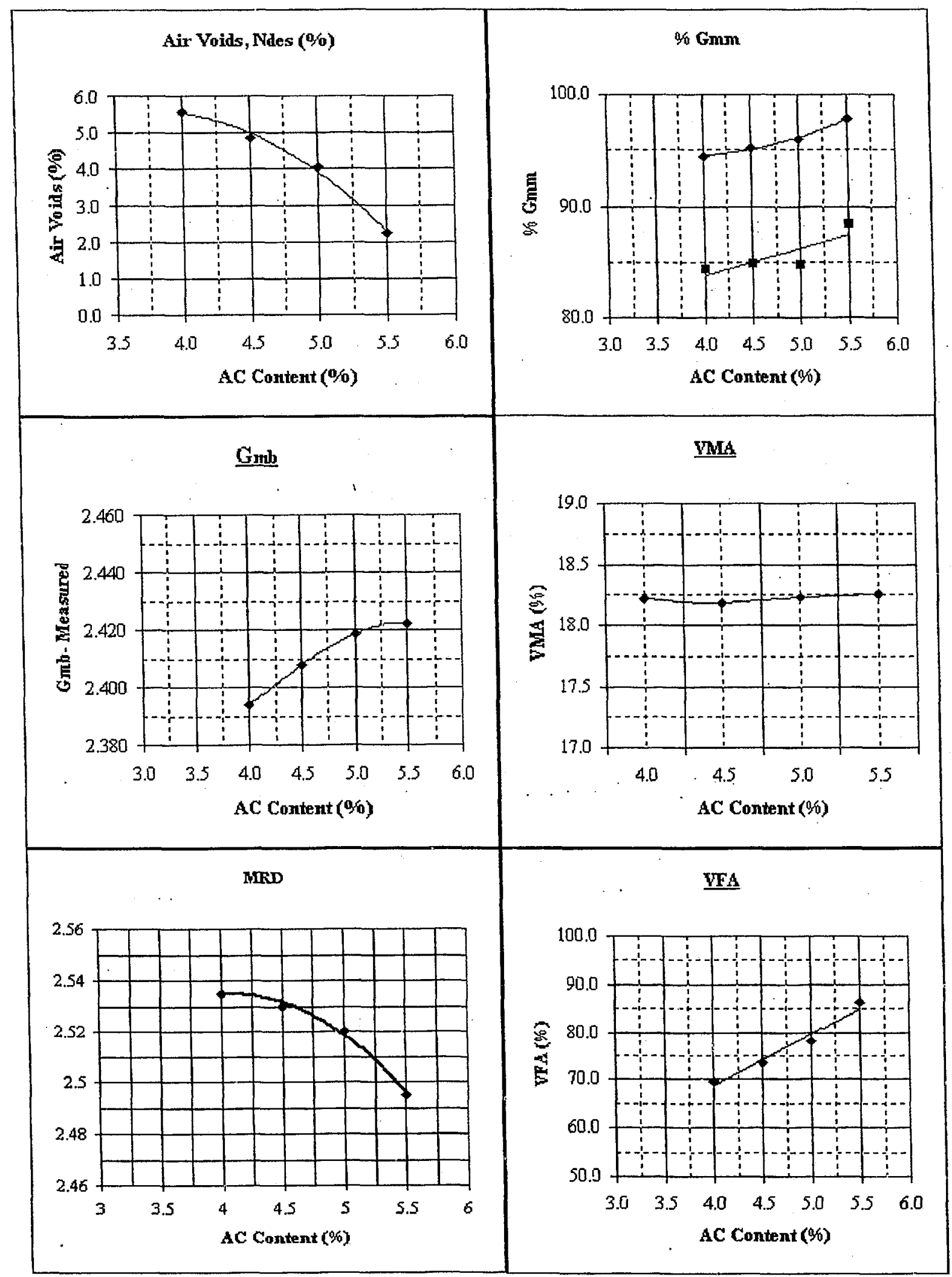

Reproduced with permission of the copyright owner. Further reproduction prohibited without permission. 


\subsection{Field Performance of Shingle Added Mixes:}

A number of trial projects were completed in Ontario since 1994 to evaluate the performance of HMA mixes containing shingles. Some of these trials are as follows (8):

- Homuth Avenue, City of Cambridge

- Town Line Road, Township of North Dumfries

- Regional Road 41, Regional Municipality of Ottawa - Carleton

- MTO Contract 95-31, Highway 86, Waterloo, from Northfield Drive northerly to Conestoga River.

- County Road 2, County of Brant

- Homer Water Boulevard, Region of Waterloo

- Metro Contract T-35-96, Sheppard Avenue, Toronto Transportation

The most significant sections are Highway 86 in Waterloo and Sheppard Ave. in Toronto where asphalt pavement is monitored for surface conditions, thermal cracking and idting resistance.

Both resurfacing projects using shingles were considered to be successful. After three and four years of construction both pavement are performing excellent and exhibiting no significant surface distresses, no visible thermal cracking and rutting.

Considering the highly satisfactory performance of shingles into HMA, this technology should be investigated and adopted for wider use. 


\section{CHAPTER 6 CONCLUSIONS}

It should be noted that due to moving and time constraint only the volumetric properties of Superpave 12.5 and Superpave 19.0 asphalt mixes were evaluated. Further testing is required to assess the long term performance of asphalt mixtures containing shingles.

The following benefits can be achieved by using shingles in asphalt mixes without any major costs.

1. Shingles can lower the virgin asphalt requirements and increase the total tonnage at lower cost. The analysis of the volumetric properties of the mixes showed that there is a saving of 1.0 to $1.5 \%$ in virgin asphalt cement content.

2. Studies suggest that there is some potential for improving the structural characteristics of the mixes due to the incorporation of shingle fibers. Therefore shingles added to mixes may reduce temperature and fatigue cracking.

3. Enhanced structural capacity increases the pavement life and lowers the maintenance cost. Due to higher pavement life and lower maintenance costs, the life cycle cost of the mixes with shingles is reduced. In addition, there are cost savings in landfill charges, the cost of disposal and various Government levies. Life cycle cost analysis carried out by some agencies suggests that there would be a cost saving of $\$ 2.5 /$ tonne, if up to $5 \%$ shingles are incorporated in the mix.

4. Researchers also expect that the addition of fibers in the mix may reduce asphalt drain down when the mixture is hot or not compacted.

\subsection{Other Considerations}

It is not advisable to use shingles only for reducing landfill without a detailed, analysis and economic viability study. Following are some .concerns related to the use of shingles. These concerns should be addressed before shingles are used.

1. Specification and construction guidelines for the use of shingles waste in HMA need to be established.

2. The amounttype of debris present in stockpiles may affect the HMA characteristics. This needs to be investigated and specification is required. 
3. The environmental effects of shingles, if any (shingles may include hazardous material i.e. asbestos), should be studied.

4. The characteristics of asphalt cement in shingles and the effect of this cement on the performance graded asphalt cement need to be investigated before incorporation into HMA.

5. The gradation of aggregates present in shingles s!muld be considered during HMA mix design. 


\section{References}

1. Ministry of Transportation "Manual for Condition Rating of Flexible Pavements; Distress manifestation" SP-024.

2. Ministry of Transportation "Manual for Condition Rating of Rigid Pavements; Distress Manifestation" SP - 005

3. Ministry of Transportation "Pavement. Maintenance Guidelines; Distresses, maintenance alternatives and performance standards" SP - 001

4. "Asphalt Pavement Maintenance" Asphalt institute MS-16 Third edition,

5. "Superpave Level 1 Mix Design" Asphait institute, Superpave Series No.2 (SP-2)

6. Joe W. Button, Devron Williams and James A. Scherocman "Roofing shingles and toner in asphalt pavement" Texas Transportation Institute Research Report $1344-2$ F, 1995

7. Jeffery L. Y. Lee, Dar Hao Chen, Kenneth H. Stokoe, Thomas Suillion "Evaluating the potential for reflection cracking using the Rolling Dynamic Deflectometer" 2004.

8. Eric Yonke, Paul Lum, Donald Budd, Ludomir Uzarowski and John Emery "Evaluation of manufactured shingle modifier asphalt mixes" 1999

9. "Design of Pavement Structures" AASHTO 1993

10. Harolds N. Atkins "Highway materials, Soils and Concrete", Third Edition

11. Thomas Harman, John R. Bukowski, Francis Moutier, Gerald Huber, Robert McGennis "The history and future challenges of gyratory compaction 1939 to 2001" Nov. 14, 2001

12. Ghazi Al Khateeb, Chuch Paugh, Kevin Stuart, Thomas Harman, John D' Angelo "Target and tolerance study for angle of Gyration used in Superpave Gyratory Compactor" 2002

13. John Hinrichson "A comparison of four brands of Superpave Gyratory Compactors" lowa Department of Transportation 
14. Mike Cook, Steve Seeds, Haiping Zhou, Gery Hicks "Guide for investigation and remediation of distress in flexible pavements" 2004

15. Stephen F. Shober and David A Friedrichs "A pavement preservation strategy" Wisconsin Department of Transportation.

16. Fiaja A. Shekharan and Barbara K. Ostrom "Effect of traffic load estimate on pa'vement design" Nov. 10, 2001

17. Eres Consultant Report "FWD Testing of Highway 401 Eastbound Collector Lanes" Year 2003.

18. Cameran Mirza, Ramon Miranda "Pavement Design Report for Highway 401 Eastbound Collectors from Avenue Road to Highway 404" April 2004.

19. M. Nawaz Panhwer "Volumetric Properties of SMA Containing Shingles" Ryerson University, 2004

20. Zubair Ahmed, Khaled Helali, Andris A. Jumikis, Riaz Ahmed Khan "Enhancing the pavement management systems database through incorporation of GPR and Core data" July 2003.

21. Yang $H$. Huang "Pavement Analysis and Design" Second Edition

22. National Center for Asphalt Technology, Washington State Department of Transportation "Pavement Guide Interactive"

23. University of Michigan, Transportation Research Institute, www.umtri.umich.edu/library 


\section{Appendix 1 Aggregate Blends}

Reproduced with permission of the copyright owner. Further reproduction prohibited without permission. 
Mix Blend for Superpave 19.0 without Shingles

\begin{tabular}{|c|c|c|c|c|c|c|c|c|c|c|c|}
\hline Material & \multirow{2}{*}{\multicolumn{2}{|c|}{$\frac{19 \mathrm{~mm} \text { Coarse }}{43 \%}$}} & \multicolumn{2}{|c|}{$12 \mathrm{~mm}$ Coarse } & \multicolumn{2}{|c|}{ Sand } & \multicolumn{2}{|c|}{ Shingles } & \multirow{3}{*}{$\begin{array}{c}\text { Blend } \\
\text { Percenta } \\
\text { ge } \\
\end{array}$} & \multirow{2}{*}{\multicolumn{2}{|c|}{ Target* ${ }^{*}$}} \\
\hline$\%$ Used & & & 33 & & & $\%$ & & $\%$ & & & \\
\hline $\begin{array}{c}\text { Sieves in } \\
\mathrm{mm}\end{array}$ & $\begin{array}{c}\% \\
\text { Passing } \\
\end{array}$ & $\%$ Batch & $\begin{array}{c}\% \\
\text { Passing } \\
\end{array}$ & $\%$ Batch & $\begin{array}{c}\% \\
\text { Passing }\end{array}$ & $\%$ Batch & $\begin{array}{c}\% \\
\text { Passing } \\
\end{array}$ & $\%$ Batch & & $\begin{array}{l}\text { Lower } \\
\text { Limit }\end{array}$ & $\begin{array}{l}\text { Upper } \\
\text { Limit }\end{array}$ \\
\hline 26.500 & 100.00 & 43.00 & 100.00 & 33.00 & 100.00 & 24.00 & 100.00 & 0.00 & 100.00 & 100 & 100 \\
\hline 19.000 & 93.53 & 40.22 & 100.00 & 33.00 & 100.00 & 24.00 & 100.00 & 0.00 & 97.22 & 100 & 100 \\
\hline 16.000 & 71.48 & 30.74 & 100.00 & 33.00 & 100.00 & 24.00 & 100.00 & 0.00 & 87.74 & 100 & 100 \\
\hline 12.500 & 31.36 & 13.48 & 100.00 & 33.00 & 100.00 & 24.00 & 96.13 & 0.00 & 70.48 & 90 & 100 \\
\hline 9.500 & 12.12 & 5.21 & 86.92 & 28.68 & 100.00 & 24.00 & 85.25 & 0.00 & 57.90 & & \\
\hline 6.700 & 7.18 & 3.09 & 30.66 & 10.12 & 100.00 & 24.00 & 78.82 & 0.00 & 37.21 & & \\
\hline 4.750 & 2.25 & 0.97 & 5.21 & 1.72 & 97.93 & 23.50 & 74.81 & 0.00 & 26.19 & & \\
\hline 2.360 & 1.94 & 0.83 & 1.68 & 0.55 & 89.64 & 21.51 & 66.81 & 0.00 & 22.90 & 28 & 58 \\
\hline 1.180 & 1.91 & 0.82 & 1.63 & 0.54 & 79.55 & 19.09 & 46.50 & 0.00 & 20.45 & & \\
\hline 0.600 & 1.50 & 0.65 & 1.59 & 0.52 & 59.77 & 14.34 & 32.89 & 0.00 & 15.51 & & \\
\hline 0.300 & 1.50 & 0.65 & 1.57 & 0.52 & 27.09 & 6.50 & 28.68 & 0.00 & 7.66 & & \\
\hline 0.150 & 1.50 & 0.65 & 1.56 & 0.51 & 8.65 & 2.08 & 24.68 & 0.0 & 3.24 & & \\
\hline 0.075 & 1.43 & 0.61 & 1.46 & 0.48 & 1.62 & .0 .39 & 21.96 & 0.0 & 1.49 & 2 & 10 \\
\hline
\end{tabular}

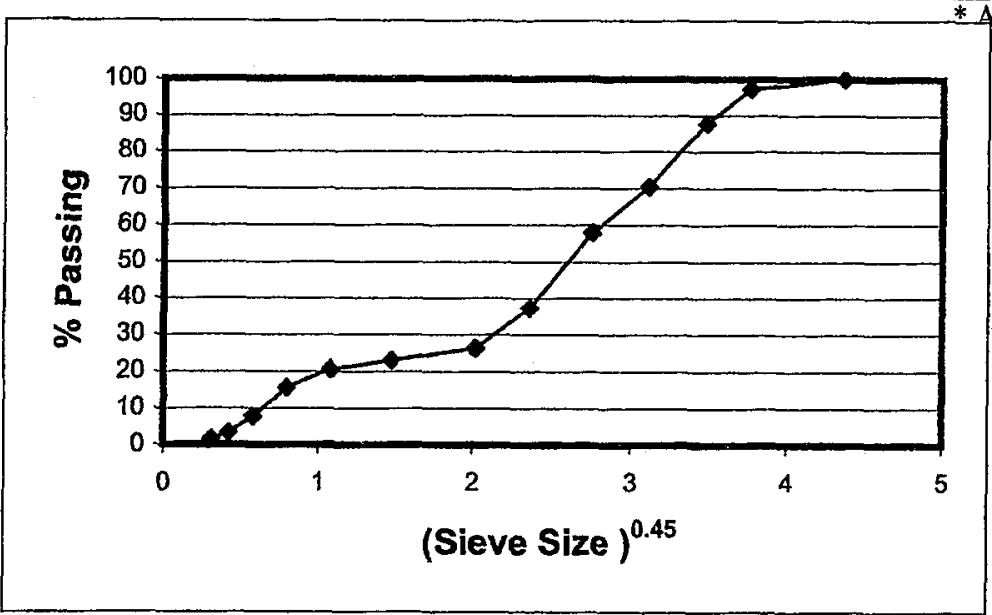


Mix Blend for Superpave 19.0 with $5 \%$ Shingles

\begin{tabular}{|c|c|c|c|c|c|c|c|c|c|c|c|}
\hline Material & \multirow{2}{*}{\multicolumn{2}{|c|}{$\frac{19 \mathrm{~mm} \text { Coarse }}{40 \%}$}} & \multirow{2}{*}{\multicolumn{2}{|c|}{$\frac{12 \mathrm{~mm} \text { Coarse }}{33 \%}$}} & \multirow{2}{*}{\multicolumn{2}{|c|}{$\frac{\text { Sand }}{22 \%}$}} & \multirow{2}{*}{\multicolumn{2}{|c|}{$\frac{\text { Shingles }}{5 \%}$}} & \multirow{3}{*}{$\begin{array}{c}\text { Blend } \\
\text { Percenta } \\
\text { ge }\end{array}$} & \multirow{2}{*}{\multicolumn{2}{|c|}{ Target* $^{*}$}} \\
\hline$\%$ Used & & & & & & & & & & & \\
\hline $\begin{array}{l}\begin{array}{c}\text { Sieves in } \\
\mathrm{mm}\end{array} \\
\end{array}$ & $\begin{array}{c}\% \\
\text { Passing } \\
\end{array}$ & $\%$ Batch & $\begin{array}{c}\% \\
\text { Passing } \\
\end{array}$ & $\%$ Batch & $\begin{array}{c}\% \\
\text { Passing } \\
\end{array}$ & $\%$ Batch & $\begin{array}{c}\% \\
\text { Passing } \\
\end{array}$ & $\%$ Batch & & $\begin{array}{l}\text { Lower } \\
\text { Limit }\end{array}$ & $\begin{array}{l}\text { Upper } \\
\text { Limit } \\
\end{array}$ \\
\hline 26.500 & 100.00 & 40.00 & 100.00 & 33.00 & 100.00 & 22.00 & 100.00 & 5.00 & 100.00 & 100 & 100 \\
\hline 19.000 & 93.53 & 37.41 & 100.00 & 33.00 & 100.00 & 22.00 & 100.00 & 5.00 & 97.41 & 100 & 100 \\
\hline 16.000 & 71.48 & 28.59 & 100.00 & 33.00 & 100.00 & 22.00 & 100.00 & 5.00 & 88.59 & 100 & $\cdot 100$ \\
\hline 12.500 & 31.36 & 12.54 & 100.00 & 33.00 & 100.00 & 22.00 & 96.13 & 4.81 & 72.35 & 90 & 100 \\
\hline 9.500 & 12.12 & 4.85 & 86.92 & 28.68 & 100.00 & 22.00 & 85.25 & 4.26 & 59.79 & & \\
\hline 6.700 & 7.18 & 2.87 & 30.66 & 10.12 & 100.00 & 22.00 & 78.82 & 3.94 & 38.93 & & \\
\hline 4.750 & 2.25 & 0.90 & 5.21 & 1.72 & 97.93 & 21.54 & 74.81 & 3.74 & 27.90 & & \\
\hline 2.360 & 1.94 & 0.78 & 1.68 & 0.55 & 89.64 & 19.72 & 66.81 & 3.34 & 24.39 & 28 & 58 \\
\hline 1.180 & 1.91 & 0.76 & 1.63 & 0.54 & 79.55 & 17.50 & 46.50 & 2.33 & 21.13 & & \\
\hline 0.600 & 1.50 & 0.60 & 1.59 & 0.52 & 59.77 & 13.15 & 32.89 & 1.64 & 15.92 & & \\
\hline 0.300 & 1.50 & 0.60 & 1.57 & 0.52 & 27.09 & 5.96 & 28.68 & 1.43 & 8.51 & & \\
\hline 0.150 & 1.50 & 0.60 & 1.56 & 0.51 & 8.65 & 1.90 & 24.68 & 1.2 & 4.25 & & \\
\hline 0.075 & 1.43 & 0.57 & 1.46 & 0.48 & 1.62 & 0.36 & 21.96 & 1.1 & 2.51 & 2 & 10 \\
\hline
\end{tabular}

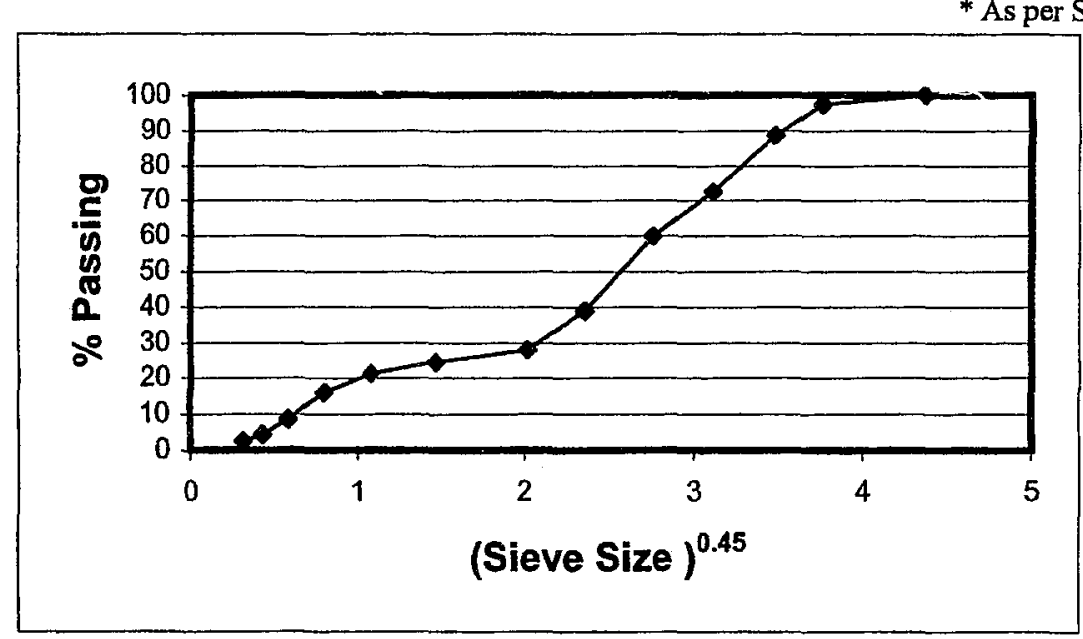


Mix Blend for Superpave 12.5 without Shingles

\begin{tabular}{|c|c|c|c|c|c|c|c|c|c|c|c|}
\hline Material & \multirow{2}{*}{\multicolumn{2}{|c|}{$\frac{19 \mathrm{~mm} \text { Coarse }}{0 \%}$}} & \multicolumn{2}{|c|}{$12 \mathrm{~mm}$ Coarse } & \multicolumn{2}{|c|}{ Sand } & \multirow{2}{*}{\multicolumn{2}{|c|}{$\frac{\text { Shingles }}{0 \%}$}} & \multirow{3}{*}{$\begin{array}{c}\text { Blend } \\
\text { Percenta } \\
\text { ge }\end{array}$} & \multirow{2}{*}{\multicolumn{2}{|c|}{ Target* }} \\
\hline$\%$ Used & & & & $\%$ & 28 & & & & & & \\
\hline $\begin{array}{l}\text { Sieves in } \\
\mathrm{mm}\end{array}$ & $\begin{array}{c}\% \\
\text { Passing }\end{array}$ & $\%$ Batch & $\begin{array}{c}\% \\
\text { Passing }\end{array}$ & $\%$ Batch & $\begin{array}{c}\% \\
\text { Passing } \\
\end{array}$ & $\%$ Batch & $\begin{array}{c}\% \\
\text { Passing } \\
\end{array}$ & $\%$ Batch & & $\begin{array}{l}\text { Lower } \\
\text { Limit }\end{array}$ & $\begin{array}{l}\text { Upper } \\
\text { Limit } \\
\end{array}$ \\
\hline 26.500 & 100.00 & 0.00 & 100.00 & 72.00 & 100.00 & 28.00 & 100.00 & 0.00 & 100.00 & 100 & 100 \\
\hline 19.000 & 93.53 & 0.00 & 100.00 & 72.00 & 100.00 & 28.00 & 100.00 & 0.00 & 100.00 & 100 & 100 \\
\hline 16.000 & 71.48 & 0.00 & 100.00 & 72.00 & 100.00 & 28.00 & 100.00 & 0.00 & 100.00 & 100 & 100 \\
\hline 12.500 & 31.36 & 0.00 & 100.00 & 72.00 & 100.00 & 28.00 & 96.13 & 0.00 & 100.00 & 90 & 100 \\
\hline 9.500 & 12.12 & 0.00 & 86.92 & 62.58 & 100.00 & 28.00 & 85.25 & 0.00 & $9 ? .58$ & & \\
\hline 6.700 & 7.18 & 0.00 & 30.66 & 22.08 & 100.00 & 28.00 & 78.82 & 0.00 & 50.08 & & \\
\hline 4.750 & 2.25 & 0.00 & 5.21 & 3.75 & 97.93 & 27.42 & 74.81 & 0.00 & 31.17 & & \\
\hline 2.360 & 1.94 & 0.00 & 1.68 & 1.21 & 89.64 & 25.10 & 66.81 & 0.00 & 26.31 & 28 & 58 \\
\hline 1.180 & 1.91 & 0.00 & 1.63 & 1.17 & 79.55 & 22.27 & 46.50 & 0.00 & 23.45 & & \\
\hline 0.600 & 1.50 & 0.00 & 1.59 & 1.14 & 59.77 & 16.74 & 32.89 & 0.00 & 17.88 & & \\
\hline 0.300 & 1.50 & 0.00 & 1.57 & 1.13 & 27.09 & 7.59 & 28.68 & 0.00 & 8.72 & & \\
\hline 0.150 & 1.50 & 0.00 & 1.56 & 1.12 & 8.65 & 2.42 & 24.68 & 0.0 & 3.55 & & \\
\hline 0.075 & 1.43 & 0.00 & 1.46 & 1.05 & 1.62 & 0.45 & 21.96 & 0.0 & 1.50 & 2 & 10 \\
\hline
\end{tabular}

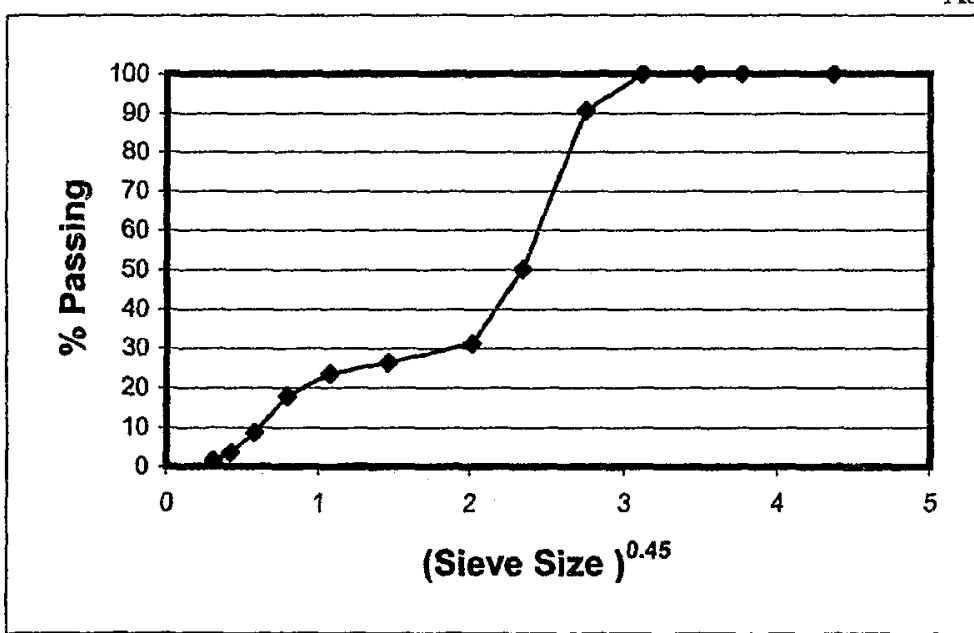

s.t. 
Mix Blend for Superpave 12.5 with $\mathbf{5 \%}$ Shingles

\begin{tabular}{|c|c|c|c|c|c|c|c|c|c|c|c|}
\hline Material & \multirow{2}{*}{\multicolumn{2}{|c|}{$\frac{19 \mathrm{~mm} \text { Coarse }}{0 \%}$}} & \multirow{2}{*}{\multicolumn{2}{|c|}{$\begin{array}{c}12 \mathrm{~mm} \text { Coarse } \\
69 \%\end{array}$}} & \multirow{2}{*}{\multicolumn{2}{|c|}{$\frac{\text { Sand }}{26 \%}$}} & \multirow{2}{*}{\multicolumn{2}{|c|}{$\frac{\text { Shingles }}{5 \%}$}} & \multirow{3}{*}{$\begin{array}{c}\text { Blend } \\
\text { Percenta } \\
\text { ge } \\
\end{array}$} & \multirow{2}{*}{\multicolumn{2}{|c|}{ Target* }} \\
\hline$\%$ Used & & & & & & & & & & & \\
\hline $\begin{array}{c}\text { Sieves in } \\
\mathrm{mm}\end{array}$ & $\begin{array}{c}\% \\
\text { Passing } \\
\end{array}$ & $\%$ Batch & $\begin{array}{c}\% \\
\text { Passing } \\
\end{array}$ & $\%$ Batch & $\begin{array}{c}\% \\
\text { Passing } \\
\end{array}$ & $\%$ Batch & $\begin{array}{c}\% \\
\text { Passing } \\
\end{array}$ & $\%$ Batch & & $\begin{array}{l}\text { Lower } \\
\text { Limit }\end{array}$ & $\begin{array}{l}\text { Upper } \\
\text { Limit }\end{array}$ \\
\hline 26.500 & 100.00 & 0.00 & 100.00 & 69.00 & 100.00 & 26.00 & 100.00 & 5.00 & 100.00 & 100 & 100 \\
\hline 19.000 & 93.53 & 0.00 & 100.00 & 69.00 & 100.00 & 26.00 & 100.00 & 5.00 & 100.00 & 100 & 100 \\
\hline 16.000 & 71.48 & 0.00 & 100.00 & 69.00 & 100.00 & 26.00 & 100.00 & 5.00 & 100.00 & 100 & 100 \\
\hline 12.500 & 31.36 & 0.00 & 100.00 & 69.00 & 100.00 & 26.00 & 96.13 & 4.81 & 99.81 & 90 & 100 \\
\hline 9.500 & 12.12 & 0.00 & 86.92 & 59.97 & 100.00 & 26.00 & 85.25 & 4.26 & 90.24 & & \\
\hline 6.700 & 7.18 & 0.00 & 30.66 & 21.16 & 100.00 & 26.00 & 78.82 & 3.94 & 51.10 & & \\
\hline 4.750 & 2.25 & 0.00 & 5.21 & 3.59 & 97.93 & 25.46 & 74.81 & 3.74 & 32.80 & & \\
\hline 2.360 & 1.94 & 0.00 & 1.68 & 1.16 & 89.64 & 23.31 & 66.81 & 3.34 & 27.81 & 28 & 58 \\
\hline 1.180 & 1.91 & 0.00 & 1.63 & 1.12 & 79.55 & 20.68 & 46.50 & 2.33 & 24.13 & & \\
\hline 0.600 & 1.50 & 0.00 & 1.59 & 1.10 & 59.77 & 15.54 & 32.89 & 1.64 & 18.28 & & \\
\hline 0.300 & 1.50 & 0.00 & 1.57 & 1.08 & 27.09 & 7.04 & 28.68 & 1.43 & 9.56 & & \\
\hline 0.150 & 1.50 & 0.00 & 1.56 & 1.08 & 8.65 & 2.25 & 24.68 & 1.2 & 4.56 & & \\
\hline 0.075 & 1.43 & 0.00 & 1.46 & 1.01 & 1.62 & 0.42 & 21.96 & 1.1 & 2.53 & 2 & 10 \\
\hline
\end{tabular}

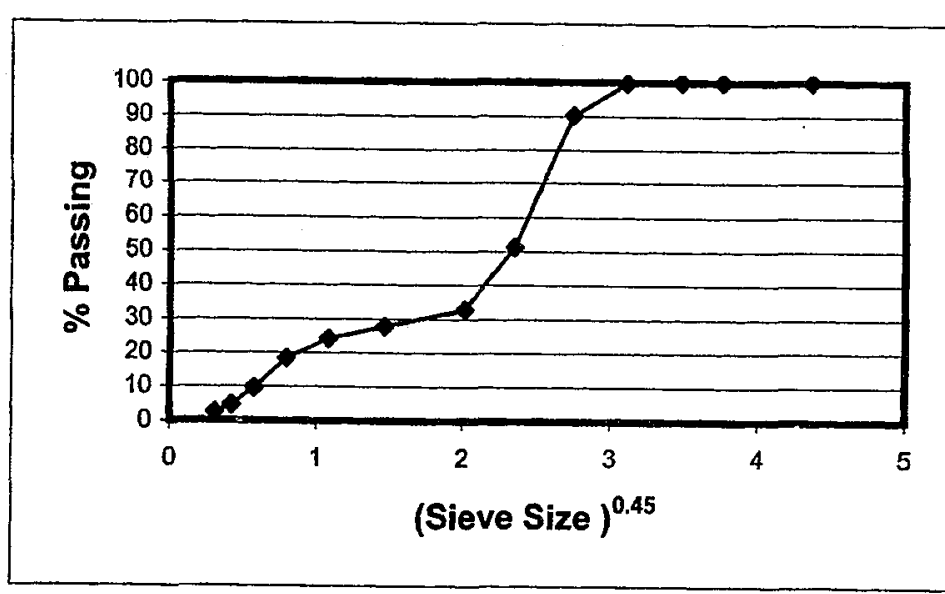

${ }^{*}$ As per Superpave Asphalt mixture gradation Requirements (5) 


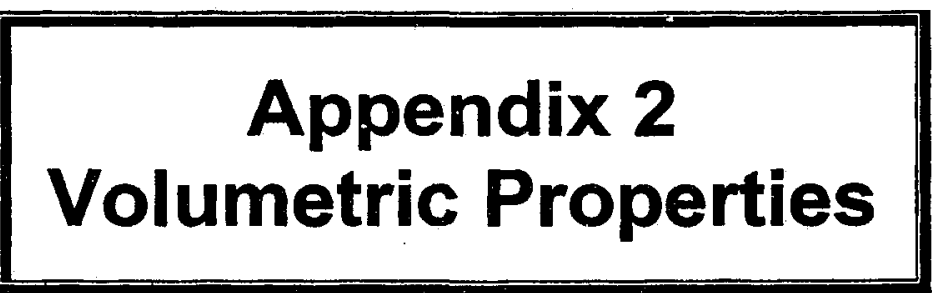




\section{Bitumen Laboratory Worksheet}

Mix Type: Superpave 12.5 at $4 \%$ A.C wo shingles

Date: 02-May-04

Volumetric Properties of the Mix

\begin{tabular}{|l|l|c|c|c|}
\hline & Description & BRIQ. No.1 & BRIQ. No.2 & Average \\
\hline $\mathrm{A}_{1}$ & Mass of Compacted Specimen in Air & 4833.5 & 4844.8 & 4839.15 \\
\hline $\mathrm{A}_{2}$ & $\begin{array}{l}\text { SD Mass of Specimen in Air after } \\
\text { Immersion in Water }\end{array}$ & 4859 & 4870.1 & 4864.55 \\
\hline $\mathrm{B}_{1}$ & Mass of Compacted Specimen in Water & 2843.5 & 2842.9 & 2843.2 \\
\hline $\mathrm{B}_{2}$ & Volume $=\mathrm{A}_{2}-\mathrm{B}_{1}$ & 2015.5 & 2027.2 & 2021.35 \\
\hline $\mathrm{C}$ & Bulk Relative Density $=\mathrm{A}_{1} / \mathrm{B}_{2}$ & 2.398 & 2.390 & 2.394 \\
\hline $\mathrm{C}_{1}$ & Flask No. & 1 & 2 & \\
\hline $\mathrm{D}$ & Mass of Flask and Mixture in Air & 2343 & 2677.1 & 2510.1 \\
\hline $\mathrm{E}$ & Mass of Flask in Air & 542 & 542 & 542 \\
\hline $\mathrm{F}$ & Mass of Mixture in Air $=\mathrm{D}-\mathrm{E}$ & 1801 & 2135.1 & 1968.05 \\
\hline $\mathrm{G}$ & Mass of Flask and Mixture in water & 1563.2 & 1766.4 & 1664.8 \\
\hline $\mathrm{H}$ & Mass of Flask in Water & 473 & 473 & 473 \\
\hline $\mathrm{l}_{1}$ & Mass of Mixture in Water $=\mathrm{G}-\mathrm{H}$ & 1090.2 & 1293.4 & 1191.8 \\
\hline $\mathrm{I}_{2}$ & Volume $=\mathrm{F}-\mathrm{I}_{1}$ & 710.8 & 841.7 & 776.25 \\
\hline $\mathrm{J}$ & Max. Relative Density $=\mathrm{F} / \mathrm{I}_{2}$ & 2.534 & 2.537 & 2.535 \\
\hline $\mathrm{K}$ & Percent Void in Mixture $=\{(\mathrm{J}-\mathrm{C}) / \mathrm{J}\}{ }^{*} 100$ & 5.35 & 5.79 & 5.57 \\
\hline $\mathrm{L}$ & Gb & 2.8 & & \\
\hline $\mathrm{M}$ & VMA $=\left\{100-\left\{(100-\mathrm{AC})^{*} \mathrm{Avg} . \mathrm{C}\right\} / \mathrm{L}\right\}$ & 17.92 & & \\
\hline & & & & \\
\hline & & & & \\
\hline
\end{tabular}




\section{Bitumen Laboratory Worksheet}

Mix Type: Superpave 12.5 at 4.5\% A.C wo shingles Date: 09-Mar-04

Volumetric Properties of the Mix

\begin{tabular}{|l|l|c|c|c|}
\hline & Description & BRIQ. No.1 & BRiQ. No.2 & Average \\
\hline $\mathrm{A}_{1}$ & Mass of Compacted Specimen in Air & 4843.6 & 4846.1 & 4844.85 \\
\hline $\mathrm{A}_{2}$ & $\begin{array}{l}\text { SD Mass of Specimen in Air after } \\
\text { Immersion in Water }\end{array}$ & 4863.4 & 4864.2 & 4863.8 \\
\hline $\mathrm{B}_{1}$ & Mass of Compacted Specimen in Water & 2849.6 & 2853.4 & 2851.5 \\
\hline $\mathrm{B}_{2}$ & Volume $=\mathrm{A}_{2}-\mathrm{B}_{1}$ & 2013.8 & 2010.8 & \\
\hline $\mathrm{C}$ & Bulk Relative Density $=\mathrm{A}_{1} / \mathrm{B}_{2}$ & 2.405 & 2.410 & 2.408 \\
\hline $\mathrm{C}_{1}$ & Flask No. & 1 & 2 & \\
\hline $\mathrm{D}$ & Mass of Flask and Mixture in Air & 2358.8 & 2155.4 & 2257.1 \\
\hline $\mathrm{E}$ & Mass of Flask in Air & 542 & 542 & \\
\hline $\mathrm{F}$ & Mass of Mixture in Air $=\mathrm{D}-\mathrm{E}$ & 1816.8 & 1613.4 & \\
\hline $\mathrm{G}$ & Mass of Flask and Mixture in water & 1571.3 & 1449.2 & 1510.25 \\
\hline $\mathrm{H}$ & Mass of Flask in Water & 473 & 473 & \\
\hline $\mathrm{I}_{1}$ & Mass of Mixture in Water $=\mathrm{G}-\mathrm{H}$ & 1098.3 & 976.2 & \\
\hline $\mathrm{I}_{2}$ & Volume $=\mathrm{F}-\mathrm{I}_{1}$ & 718.5 & 637.2 & \\
\hline $\mathrm{J}$ & Max. Relative Density $=\mathrm{F} / \mathrm{I}_{2}$ & 2.529 & 2.532 & 2.530 \\
\hline $\mathrm{K}$ & Percent Void in Mixture $=\{(\mathrm{J}-\mathrm{C}) / \mathrm{J}\}\}^{* 100}$ & 4.88 & 4.82 & 4.849 \\
\hline $\mathrm{L}$ & Gb $=$ & 2.8 & & \\
\hline $\mathrm{M}$ & VMA $=\left\{100-\left\{(100-\mathrm{AC})^{*}\right.\right.$ Avg. C $\left.\} / \mathrm{L}\right\}$ & 17.88 & & \\
\hline & & & & \\
\hline
\end{tabular}




\section{Bitumen Laboratory Worksheet}

Mix Type: Superpave 12.5 at $5 \%$ A.C wo shingles

Date: 19-Jun-04

Volumetric Properties of the Mix

\begin{tabular}{|l|l|c|c|c|}
\hline & Description & BRIQ. NO.1 & BRIQ. No.2 & Average \\
\hline $\mathrm{A}_{1}$ & Mass of Compacted Specimen in Air & 4837 & 4842 & 4839.5 \\
\hline & $\begin{array}{l}\text { SD Mass of Specimen in Air after } \\
\text { Immersion in Water }\end{array}$ & 4850 & 4854 & 4852 \\
\hline $\mathrm{A}_{2}$ & Mass of Compacted Specimen in Water & 2852 & 2850 & 2851 \\
\hline $\mathrm{B}_{1}$ & Volume $=\mathrm{A}_{2}-\mathrm{B}_{1}$ & 1998 & 2004 & \\
\hline $\mathrm{B}_{2}$ & Bulk Relative Density $=\mathrm{A}_{1} / \mathrm{B}_{2}$ & 2.421 & 2.416 & 2.419 \\
\hline $\mathrm{C}$ & Flask No. & 1 & 2 & \\
\hline $\mathrm{C}_{1}$ & Mass of Flask and Mixture in Air & 1778 & 2052 & 1915.0 \\
\hline $\mathrm{D}$ & Mass of Flask in Air & 542 & 542 & \\
\hline $\mathrm{E}$ & Mass of Mixture in Air $=\mathrm{D}-\mathrm{E}$ & 1236 & 1510 & \\
\hline $\mathrm{F}$ & Mass of Flask and Mixture in water & 1219 & 1383 & 1301 \\
\hline $\mathrm{G}$ & Mass of Flask in Water & 473 & 473 & \\
\hline $\mathrm{H}$ & Mass of Mixture in Water $=\mathrm{G}-\mathrm{H}$ & 746 & 910 & \\
\hline $\mathrm{I}_{1}$ & Volume $=\mathrm{F}-\mathrm{I}_{1}$ & 490 & 600 & \\
\hline $\mathrm{I}_{2}$ & Max. Relative Density $=\mathrm{F} / \mathrm{I}_{2}$ & 2.522 & 2.517 & 2.520 \\
\hline $\mathrm{J}$ & Percent Void in Mixture $=\{(\mathrm{J}-\mathrm{C}) / \mathrm{J}\}{ }^{*} 100$ & 4.02 & 3.99 & 4.009 \\
\hline $\mathrm{K}$ & Gb $=$ & 2.8 & & \\
\hline $\mathrm{L}$ & VMA $=\left\{100-\left\{(100-\mathrm{AC})^{*} \mathrm{Avg} . \mathrm{C}\right\} / \mathrm{L}\right\}$ & 17.94 & & \\
\hline $\mathrm{M}$ & & & & \\
\hline & & & & \\
\hline
\end{tabular}




\section{Bitumen Laboratory Worksheet}

Mix Type: Superpave 12.5 at $5.5 \%$ A.C wo shingles $\quad$ Date: 19-Jun-04

Volumetric Properties of the Mix

\begin{tabular}{|l|l|c|c|c|}
\hline & Description & BRIQ. No.1 & BRIQ. No.2 & Average \\
\hline$A_{1}$ & Mass of Compacted Specimen in Air & 4838 & 4831 & 4834.5 \\
\hline$A_{2}$ & $\begin{array}{l}\text { SD Mass of Specimen in Air after } \\
\text { Immersion in Water }\end{array}$ & 4849 & 4844 & 4846.5 \\
\hline$B_{1}$ & Mass of Compacted Specimen in Water & 2852 & 2849 & 2850.5 \\
\hline$B_{2}$ & Volume $=A_{2}-B_{1}$ & 1997 & 1995 & \\
\hline $\mathrm{C}$ & Bulk Relative Density $=\mathrm{A}_{1} / \mathrm{B}_{2}$ & 2.423 & 2.422 & 2.422 \\
\hline $\mathrm{C}_{1}$ & Flask No. & 1 & 2 & \\
\hline $\mathrm{D}$ & Mass of Flask and Mixture in Air & 1974 & 2052 & 2013.0 \\
\hline $\mathrm{E}$ & Mass of Flask in Air & 542 & 542 & \\
\hline $\mathrm{F}$ & Mass of Mixture in Air $=\mathrm{D}-\mathrm{E}$ & 1432 & 1510 & \\
\hline $\mathrm{G}$ & Mass of Flask and Mixture in water & 1332 & 1377 & 1354.5 \\
\hline $\mathrm{H}$ & Mass of Flask in Water & 473 & 473 & \\
\hline $\mathrm{I}_{1}$ & Mass of Mixture in Water $=\mathrm{G}-\mathrm{H}$ & 859 & 904 & \\
\hline $\mathrm{I}_{2}$ & Volume $=\mathrm{F}-\mathrm{I}_{1}$ & 573 & 606 & \\
\hline $\mathrm{J}$ & Max. Relative Density $=\mathrm{F} / \mathrm{I}_{2}$ & 2.499 & 2.492 & 2.495 \\
\hline $\mathrm{K}$ & Percent Void in Mixture $=\{(\mathrm{J}-\mathrm{C}) / \mathrm{J}\} * 100$ & 3.06 & 2.82 & 2.939 \\
\hline $\mathrm{L}$ & Gb $=$ & 2.8 & & \\
\hline $\mathrm{M}$ & VMA $=\left\{100-\left\{(100-\mathrm{AC})^{*} \mathrm{Avg} . \mathrm{C}\right\} / \mathrm{L}\right\}$ & 18.25 & & \\
\hline & & & & \\
\hline
\end{tabular}




\section{Bitumen Laboratory Worksheet}

Mix Type: Superpave 12.5 at $5.5 \%$ w.o shingles at Nmax $\quad$ Date: 19-Jun-04

Volumetric Properties of the Mix

\begin{tabular}{|l|l|c|c|c|}
\hline & Description & BRIQ. No.1 & BRIQ. No.2 & Average \\
\hline $\mathrm{A}_{1}$ & Mass of Compacted Specimen in Air & 4847 & 4844 & 4845.5 \\
\hline $\mathrm{A}_{2}$ & $\begin{array}{l}\text { SD Mass of Specimen in Air after } \\
\text { Immersion in Water }\end{array}$ & 4856 & 4854 & 4855 \\
\hline $\mathrm{B}_{1}$ & Mass of Compacted Specimen in Water & 2851 & 2849 & 2850 \\
\hline $\mathrm{B}_{2}$ & Volume $=\mathrm{A}_{2}-\mathrm{B}_{1}$ & 2005 & 2005 & \\
\hline $\mathrm{C}$ & Bulk Relative Density $=\mathrm{A}_{1} / \mathrm{B}_{2}$ & 2.417 & 2.416 & 2.417 \\
\hline $\mathrm{C}_{1}$ & Flask No. & 1 & 2 & \\
\hline $\mathrm{D}$ & Mass of Flask and Mixture in Air & 1778 & 2052 & 1915.0 \\
\hline $\mathrm{E}$ & Mass of Flask in Air & 542 & 542 & \\
\hline $\mathrm{F}$ & Mass of Mixture in Air $=\mathrm{D}-\mathrm{E}$ & 1236 & 1510 & \\
\hline $\mathrm{G}$ & Mass of Flask and Mixture in water & 1219 & 1383 & 1301 \\
\hline $\mathrm{H}$ & Mass of Flask in Water & 473 & 473 & \\
\hline $\mathrm{I}_{1}$ & Mass of Mixture in Water $=\mathrm{G}-\mathrm{H}$ & 746 & 910 & \\
\hline $\mathrm{I}_{2}$ & Volume = F - $\mathrm{I}_{1}$ & 490 & 600 & \\
\hline $\mathrm{J}$ & Max. Relative Density $=\mathrm{F} / \mathrm{I}_{2}$ & 2.522 & 2.517 & 2.520 \\
\hline $\mathrm{K}$ & Percent Void in Mixture $=\{(\mathrm{J}-\mathrm{C}) / \mathrm{J}\}^{*} 100$ & 4.16 & 4.00 & 4.082 \\
\hline $\mathrm{L}$ & Gb = & 2.8 & & \\
\hline $\mathrm{M}$ & VMA = $\left\{100-\left\{(100-\mathrm{AC})^{\star} \mathrm{Avg} . \mathrm{C}\right\} / \mathrm{L}\right\}$ & 18.00 & & \\
\hline & & & & \\
\hline
\end{tabular}

Reproduced with permission of the copyright owner. Further reproduction prohibited without permission. 


\section{Bitumen Laboratory Worksheet}

Mix Type: Superpave 12.5 with Shingles at 3.5\% A.C Date: 01-May-04

Volumetric Properties of the Mix

\begin{tabular}{|l|l|c|c|c|}
\hline & Description & BRIQ. No.1 & BRIQ. No.2 & Average \\
\hline $\mathrm{A}_{1}$ & Mass of Compacted Specimen in Air & 4837.3 & 4852 & 4844.65 \\
\hline $\mathrm{A}_{2}$ & $\begin{array}{l}\text { SD Mass of Specimen in Air after Immersion } \\
\text { in Water }\end{array}$ & 4857.9 & 4870 & 4863.95 \\
\hline $\mathrm{B}_{1}$ & Mass of Compacted Specimen in Water & 2845.5 & 2855.8 & 2850.65 \\
\hline $\mathrm{B}_{2}$ & Volume $=\mathrm{A}_{2}-\mathrm{B}_{1}$ & 2012.4 & 2014.2 & \\
\hline $\mathrm{C}$ & Bulk Relative Density $=\mathrm{A}_{1} / \mathrm{B}_{2}$ & 2.404 & 2.409 & 2.406 \\
\hline $\mathrm{C}_{1}$ & Flask No. & 1 & 2 & \\
\hline $\mathrm{D}$ & Mass of Flask and Mixture in Air & 2011.8 & 2211.3 & 2111.6 \\
\hline $\mathrm{E}$ & Mass of Flask in Air & 542 & 542 & \\
\hline $\mathrm{F}$ & Mass of Mixture in Air $=\mathrm{D}-\mathrm{E}$ & 1469.8 & 1669.3 & \\
\hline $\mathrm{G}$ & Mass of Flask and Mixture in water & 1362.5 & 1480.8 & 1421.65 \\
\hline $\mathrm{H}$ & Mass of Flask in Water & 473 & 473 & \\
\hline $\mathrm{I}_{1}$ & Mass of Mixture in Water $=\mathrm{G}-\mathrm{H}$ & 889.5 & 1007.8 & \\
\hline $\mathrm{I}_{2}$ & Volume $=\mathrm{F}-\mathrm{I}_{1}$ & 580.3 & 661.5 & \\
\hline $\mathrm{J}$ & Max. Relative Density $=\mathrm{F} / \mathrm{I}_{2}$ & 2.533 & 2.524 & 2.528 \\
\hline $\mathrm{K}$ & Percent Void in Mixture $=\{(\mathrm{J}-\mathrm{C}) / \mathrm{J}\}^{*} 100$ & 5.10 & 4.54 & 4.819 \\
\hline $\mathrm{L}$ & Gb $=$ & 2.8 & & \\
\hline $\mathrm{M}$ & VMA $=\left\{100-\left\{(100-\mathrm{AC})^{*} \mathrm{Avg} . \mathrm{C}\right\} / \mathrm{L}\right\}$ & 17.50 & & \\
\hline & & & & \\
\hline
\end{tabular}




\section{Bitumen Laboratory Worksheet}

Mix Type: Superpave 12.5 with Shingles at 4.0\% A.C $\quad$ Date: 13-Apr-04

Volumetric Properties of the Mix

\begin{tabular}{|l|l|c|c|c|}
\hline & Description & BRIQ. No.1 & BRIQ. No.2 & Average \\
\hline $\mathrm{A}_{1}$ & Mass of Compacted Specimen in Air & 4846.1 & 4850.4 & 4848.25 \\
\hline $\mathrm{A}_{2}$ & $\begin{array}{l}\text { SD Mass of Specimen in Air after Immersion in } \\
\text { Water }\end{array}$ & 4856.5 & 4861.3 & 4858.9 \\
\hline $\mathrm{B}_{1}$ & Mass of Compacted Specimen in Water & 2851.5 & 2855.8 & 2853.65 \\
\hline $\mathrm{B}_{2}$ & Volume $=\mathrm{A}_{2}-\mathrm{B}_{1}$ & 2005 & 2005.5 & \\
\hline $\mathrm{C}$ & Bulk Relative Density $=\mathrm{A}_{1} / \mathrm{B}_{2}$ & 2.417 & 2.419 & 2.418 \\
\hline $\mathrm{C}_{1}$ & Flask No. & 1 & 2 & \\
\hline $\mathrm{D}$ & Mass of Flask and Mixture in Air & 2410.8 & 2333.3 & 2372.1 \\
\hline $\mathrm{E}$ & Mass of Flask in Air & 542 & 542 & \\
\hline $\mathrm{F}$ & Mass of Mixture in Air $=\mathrm{D}-\mathrm{E}$ & 1868.8 & 1791.3 & \\
\hline $\mathrm{G}$ & Mass of Flask and Mixture in water & 1598.7 & 1553.9 & 1576.3 \\
\hline $\mathrm{H}$ & Mass of Flask in Water & 473 & 473 & \\
\hline $\mathrm{I}_{1}$ & Mass of Mixture in Water $=\mathrm{G}-\mathrm{H}$ & 1125.7 & 1080.9 & \\
\hline $\mathrm{I}_{2}$ & Volume $=\mathrm{F}-\mathrm{I}_{1}$ & 743.1 & 710.4 & \\
\hline $\mathrm{J}$ & Max. Relative Density $=\mathrm{F} / \mathrm{I}_{2}$ & 2.515 & 2.522 & 2.518 \\
\hline $\mathrm{K}$ & Percent Void in Mixture $=\{(\mathrm{J}-\mathrm{C}) / \mathrm{J}\}^{*} 100$ & 3.89 & 4.08 & 3.988 \\
\hline $\mathrm{L}$ & Gb $=$ & 2.8 & & \\
\hline $\mathrm{M}$ & VMA $=\left\{100-\left\{(100-\mathrm{AC})^{*}\right.\right.$ Avg. $\left.\left.\mathrm{C}\right\} / \mathrm{L}\right\}$ & 17.10 & & \\
\hline & & & & \\
\hline
\end{tabular}




\section{Bitumen Laboratory Worksheet}

Mix Type: Superpave 12.5 with Shingles $4.5 \%$ A.C Date: 09-Mar-04

Volumetric Properties of the Mix

\begin{tabular}{|l|l|c|c|c|}
\hline & Description & BRIQ. No.1 & BRIQ. No.2 & Average \\
\hline$A_{1}$ & Mass of Compacted Specimen in Air & 4848.2 & 4845.6 & 4846.9 \\
\hline$A_{2}$ & $\begin{array}{l}\text { SD Mass of Specimen in Air after } \\
\text { Immersion in Water }\end{array}$ & 4855.4 & 4851.2 & 4853.3 \\
\hline$B_{1}$ & Mass of Compacted Specimen in Water & 2852.8 & 2848.1 & 2850.45 \\
\hline$B_{2}$ & Volume $=A_{2}-B_{1}$ & 2002.6 & 2003.1 & \\
\hline $\mathrm{C}$ & Bulk Relative Density $=A_{1} / B_{2}$ & 2.421 & 2.419 & 2.420 \\
\hline$C_{1}$ & Flask No. & 1 & 2 & \\
\hline$D$ & Mass of Flask and Mixture in Air & 2463.1 & 2422.9 & 2443.0 \\
\hline$E$ & Mass of Flask in Air & 542 & 542 & \\
\hline$F$ & Mass of Mixture in Air $=\mathrm{D}-\mathrm{E}$ & 1921.1 & 1880.9 & \\
\hline $\mathrm{G}$ & Mass of Flask and Mixture in water & 1624.8 & 1602.2 & 1613.5 \\
\hline $\mathrm{H}$ & Mass of Flask in Water & 473 & 473 & \\
\hline $\mathrm{I}_{1}$ & Mass of Mixture in Water $=\mathrm{G}-\mathrm{H}$ & 1151.8 & 1129.2 & \\
\hline $\mathrm{I}_{2}$ & Volume $=\mathrm{F}-\mathrm{I}_{1}$ & 769.3 & 751.7 & \\
\hline $\mathrm{J}$ & Max. Relative Density $=\mathrm{F} / \mathrm{I}_{2}$ & 2.497 & 2.502 & 2.500 \\
\hline $\mathrm{K}$ & Percent Void in Mixture $=\{(\mathrm{J}-\mathrm{C}) / \mathrm{J}\}^{*} 100$ & 3.05 & 3.32 & 3.188 \\
\hline $\mathrm{L}$ & Gb $=$ & 2.8 & & \\
\hline $\mathrm{M}$ & VMA $=\left\{100-\left\{(100-\mathrm{AC})^{*} \mathrm{Avg} . \mathrm{C} / / \mathrm{L}\right\}\right.$ & 17.03 & & \\
\hline & & & & \\
\hline
\end{tabular}




\section{Bitumen Laboratory Worksheet}

Mix Type: Superpave 12.5 with Shingles 5.0\% A.C Date: 09-Mar-04

Volumetric Properties of the Mix

\begin{tabular}{|l|l|c|c|c|}
\hline & Description & BRIQ. No.1 & BRIQ. No.2 & Average \\
\hline $\mathrm{A}_{1}$ & Mass of Compacted Specimen in Air & 4842.3 & 4849.2 & 4845.75 \\
\hline $\mathrm{A}_{2}$ & $\begin{array}{l}\text { SD Mass of Specimen in Air after } \\
\text { Immersion in Water }\end{array}$ & 4849.1 & 4853.7 & 4851.4 \\
\hline $\mathrm{B}_{1}$ & Mass of Compacted Specimen in Water & 2855.6 & 2859.7 & 2857.65 \\
\hline $\mathrm{B}_{2}$ & Volume $=\mathrm{A}_{2}-\mathrm{B}_{1}$ & 1993.5 & 1994 & \\
\hline $\mathrm{C}$ & Bulk Relative Density $=\mathrm{A}_{1} / \mathrm{B}_{2}$ & 2.429 & 2.432 & 2.430 \\
\hline $\mathrm{C}_{1}$ & Flask No. & 1 & 2 & \\
\hline $\mathrm{D}$ & Mass of Flask and Mixture in Air & 2850.6 & 2858.5 & 2854.6 \\
\hline $\mathrm{E}$ & Mass of Flask in Air & 542 & 542 & \\
\hline $\mathrm{F}$ & Mass of Mixture in Air $=\mathrm{D}-\mathrm{E}$ & 2308.6 & 2316.5 & \\
\hline $\mathrm{G}$ & Mass of Flask and Mixture in water & 1855.5 & 1859.6 & 1857.55 \\
\hline $\mathrm{H}$ & Mass of Flask in Water & 473 & 473 & \\
\hline $\mathrm{I}_{1}$ & Mass of Mixture in Water $=\mathrm{G}-\mathrm{H}$ & 1382.5 & 1386.6 & \\
\hline $\mathrm{I}_{2}$ & Volume $=\mathrm{F}-\mathrm{I}_{1}$ & 926.1 & 929.9 & \\
\hline $\mathrm{J}$ & Max. Relative Density $=\mathrm{F} / \mathrm{I}_{2}$ & 2.493 & 2.491 & 2.492 \\
\hline $\mathrm{K}$ & Percent Void in Mixture $=\{(\mathrm{J}-\mathrm{C}) / \mathrm{J}\} * 100$ & 2.56 & 2.38 & 2.468 \\
\hline $\mathrm{L}$ & Gb $=$ & 2.8 & & \\
\hline $\mathrm{M}$ & VMA $=\left\{100-\left\{(100-\mathrm{AC})^{*} \mathrm{Avg} . \mathrm{C} / \mathrm{L}\right\}\right.$ & 16.67 & & \\
\hline & & & & \\
\hline
\end{tabular}




\section{Bitumen Laboratory Worksheet}

Mix Type: Superpave 12.5 with Shingles $4.0 \%$ at Nmax

Date: $\quad$ 09-Mar-04

Volumetric Properties of the Mix

\begin{tabular}{|l|l|c|c|c|}
\hline & Description & BRIQ. No.1 & BRIQ. No.2 & Average \\
\hline $\mathrm{A}_{1}$ & Mass of Compacted Specimen in Air & 4846 & 4848 & 4847 \\
\hline & $\begin{array}{l}\text { SD Mass of Specimen in Air after } \\
\mathrm{A}_{2}\end{array}$ & & & \\
\hline $\mathrm{B}_{1}$ & Mass of Compacted Specimen in Water & 2847 & 2848 & 2847.5 \\
\hline $\mathrm{B}_{2}$ & Volume $=\mathrm{A}_{2}-\mathrm{B}_{1}$ & 2007 & 2007 & \\
\hline $\mathrm{C}$ & Bulk Relative Density $=\mathrm{A}_{1} / \mathrm{B}_{2}$ & 2.415 & 2.416 & 2.415 \\
\hline $\mathrm{C}_{1}$ & Flask No. & 1 & 2 & \\
\hline $\mathrm{D}$ & Mass of Flask and Mixture in Air & 2410.8 & 2333.3 & 2372.1 \\
\hline $\mathrm{E}$ & Mass of Flask in Air & 542 & 542 & \\
\hline $\mathrm{F}$ & Mass of Mixture in Air $=\mathrm{D}-\mathrm{E}$ & 1868.8 & 1791.3 & \\
\hline $\mathrm{G}$ & Mass of Flask and Mixture in water & 1598.7 & 1553.9 & 1576.3 \\
\hline $\mathrm{H}$ & Mass of Flask in Water & 473 & 473 & \\
\hline $\mathrm{I}_{1}$ & Mass of Mixture in Water $=\mathrm{G}-\mathrm{H}$ & 1125.7 & 1080.9 & \\
\hline $\mathrm{I}_{2}$ & Volume $=\mathrm{F}-\mathrm{I}_{1}$ & 743.1 & 710.4 & \\
\hline $\mathrm{J}$ & Max. Relative Density $=\mathrm{F} / \mathrm{I}_{2}$ & 2.515 & 2.522 & 2.518 \\
\hline $\mathrm{K}$ & Percent Void in Mixture $=\{(\mathrm{J}-\mathrm{C}) / \mathrm{J}\}^{*} 100$ & 3.99 & 4.20 & 4.096 \\
\hline $\mathrm{L}$ & Gb $=$ & 2.8 & & \\
\hline $\mathrm{M}$ & VMA $=\left\{100-\left\{(100-\mathrm{ACC})^{*} \mathrm{Avg} . \mathrm{C}\right\} / \mathrm{L}\right\}$ & 17.20 & & \\
\hline & & & & \\
\hline
\end{tabular}




\section{Bitumen Laboratory Worksheet}

Mix Type: Superpave 19.0 without Shigles at $3.5 \%$ A.C

Date: $\quad$ 19-Jun-04

Volumteric Properties of the Mix

\begin{tabular}{|l|l|c|c|c|}
\hline & Description & BRIQ. No.1 & BRI.. No.2 & Average \\
\hline $\mathrm{A}_{1}$ & Mass of Compacted Specimen in Air & 4836 & 4838 & 4837 \\
\hline $\mathrm{A}_{2}$ & $\begin{array}{l}\text { SD Mass of Specimen in Air after Immersion } \\
\text { in Water }\end{array}$ & 4856 & 4854 & 4855 \\
\hline $\mathrm{B}_{1}$ & Mass of Compacted Specimen in Water & 2843 & 2837 & 2840 \\
\hline $\mathrm{B}_{2}$ & Volume $=\mathrm{A}_{2}-\mathrm{B}_{1}$ & 2013 & 2017 & \\
\hline $\mathrm{C}$ & Bulk Relative Density $=\mathrm{A}_{1} / \mathrm{B}_{2}$ & 2.402 & 2.399 & 2.400 \\
\hline $\mathrm{C}_{1}$ & Flask No. & 1 & 2 & \\
\hline $\mathrm{D}$ & Mass of Flask and Mixture in Air & 2217 & 2366 & 2291.5 \\
\hline $\mathrm{E}$ & Mass of Flask in Air & 542 & 542 & \\
\hline $\mathrm{F}$ & Mass of Mixture in Air $=\mathrm{D}-\mathrm{E}$ & 1675 & 1824 & \\
\hline $\mathrm{G}$ & Mass of Flask and Mixture in water & 1491 & 1579 & 1535 \\
\hline $\mathrm{H}$ & Mass of Flask in Water & 473 & 473 & \\
\hline $\mathrm{I}_{1}$ & Mass of Mixture in Water $=\mathrm{G}-\mathrm{H}$ & 1018 & 1106 & \\
\hline $\mathrm{I}_{2}$ & Volume $=\mathrm{F}-\mathrm{I}_{1}$ & 657 & 718 & \\
\hline $\mathrm{J}$ & Max. Relative Density $=\mathrm{F} / \mathrm{I}_{2}$ & 2.549 & 2.540 & 2.545 \\
\hline $\mathrm{K}$ & Percent Void in Mixture $=\{(\mathrm{J}-\mathrm{C}) / \mathrm{J}\}^{*} 100$ & 5.77 & 5.58 & 5.675 \\
\hline $\mathrm{L}$ & Gb $=$ & 2.81 & & \\
\hline $\mathrm{M}$ & VMA $=\left\{100-\left\{(100-\mathrm{AC})^{*} \mathrm{Avg} . \mathrm{C}\right\} / \mathrm{L}\right\}$ & 17.99 & & \\
\hline & & & & \\
\hline
\end{tabular}




\section{Bitumen Laboratory Worksheet}

Mix Type: Superpave 18.0 without Shingles at $4.0 \%$ A.C

Date: $\quad$ 19-Jun-04

Volumteric Properties of the Mix

\begin{tabular}{|l|l|c|c|c|}
\hline & Description & BRIQ. No.1 & BRIQ. No.2 & Average \\
\hline$A_{1}$ & Mass of Compacted Specimen in Air & 4778 & 4787 & 4782.5 \\
\hline$A_{2}$ & $\begin{array}{l}\text { SD Mass of Specimen in Air after Immersion } \\
\text { in Water }\end{array}$ & 4787 & 4797 & 4792 \\
\hline$B_{1}$ & Mass of Compacted Specimen in Water & 2803 & 2809 & 2806 \\
\hline$B_{2}$ & Volume $=A_{2}-B_{1}$ & 1984 & 1988 & \\
\hline$C$ & Bulk Relative Density $=A_{1} / B_{2}$ & 2.408 & 2.408 & 2.408 \\
\hline$C_{1}$ & Flask No. & 1 & 2 & \\
\hline$D$ & Mass of Flask and Mixture in Air & 2274 & 2363 & 2318.5 \\
\hline$E$ & Mass of Flask in Air & 542 & 542 & \\
\hline$F$ & Mass of Mixture in Air $=\mathrm{D}-\mathrm{E}$ & 1732 & 1821 & \\
\hline $\mathrm{G}$ & Mass of Flask and Mixture in water & 1521 & 1575 & 1548 \\
\hline $\mathrm{H}$ & Mass of Flask in Water & 473 & 473 & \\
\hline $\mathrm{I}_{1}$ & Mass of Mixture in Water $=\mathrm{G}-\mathrm{H}$ & 1048 & 1102 & \\
\hline $\mathrm{I}_{2}$ & Volume $=\mathrm{F}-\mathrm{I}_{1}$ & 684 & 719 & \\
\hline $\mathrm{J}$ & Max. Relative Density $=\mathrm{F} / \mathrm{I}_{2}$ & 2.532 & 2.533 & 2.532 \\
\hline $\mathrm{K}$ & Percent Void in Mixture $=\{(\mathrm{J}-\mathrm{C}) / \mathrm{J}\} * 100$ & 4.89 & 4.93 & 4.909 \\
\hline $\mathrm{L}$ & Gb $=$ & 2.81 & & \\
\hline $\mathrm{M}$ & VMA $=\left\{100-\left\{(100-\mathrm{AC})^{*} \mathrm{Avg} . \mathrm{C}\right\} / \mathrm{L}\right\}$ & 17.73 & & \\
\hline & & & & \\
\hline
\end{tabular}




\section{Bitumen Laboratory Worksheet}

Mix Type: Superpave 19.0 without Shingles at $4.5 \%$ A.C

Date: 19-Jun-04

Volumteric Properties of the Mix

\begin{tabular}{|c|c|c|c|c|}
\hline & Description & BRIQ. No.1 & BRIQ. No.2 & Average \\
\hline$A_{1}$ & Mass of Compacted Specimen in Air & 4783 & 4787 & 4785 \\
\hline$A_{2}$ & $\begin{array}{l}\text { SD Mass of Specimen in Air after Immersion } \\
\text { in Water }\end{array}$ & 4795 & 4798 & 4796.5 \\
\hline$B_{1}$ & Mass of Compacted Specimen in Water & 2812 & 2817 & 2814.5 \\
\hline$B_{2}$ & Volume $=A_{2}-B_{1}$ & 1983 & 1981 & \\
\hline $\mathrm{C}$ & Bulk Relative Density $=A_{1} / B_{2}$ & 2.412 & 2.416 & 2.414 \\
\hline$C_{1}$ & Flask No. & 1 & 2 & \\
\hline$D$ & Mass of Flask and Mixture in Air & 2148 & 2171 & 2159.5 \\
\hline$E$ & Mass of Flask in Air & 542 & 542 & \\
\hline$F$ & Mass of Mixture in Air $=D-E$ & 1606 & 1629 & \\
\hline G & Mass of Flask and Mixture in water & 1440 & 1455 & 1447.5 \\
\hline $\mathrm{H}$ & Mass of Flask in Water & 473 & 473 & \\
\hline$I_{1}$ & Mass of Mixture in Water $=\mathrm{G}-\mathrm{H}$ & 967 & 982 & \\
\hline $\mathrm{I}_{2}$ & Volume $=F-I_{1}$ & 639 & 647 & \\
\hline $\mathrm{J}$ & Max. Relative Density $=F / I_{2}$ & 2.513 & 2.518 & 2.516 \\
\hline $\mathrm{K}$ & Percent Void in Mixture $=\{(\mathrm{J}-\mathrm{C}) / \mathrm{J}\}^{*} 100$ & 4.03 & 4.02 & 4.027 \\
\hline$L$ & $G b=$ & 2.81 & . & \\
\hline$M$ & $V M A=\left\{100-\left\{(100-A C)^{*}\right.\right.$ Avg. C $\left./ / L\right\}$ & 17.52 & & \\
\hline
\end{tabular}




\section{Bitumen Laboratory Worksheet}

Mix Type: Superpave 19.0 without Shingles at $5 \%$ A.C Date: 19-Jun-04

Volumteric Properties of the Mix

\begin{tabular}{|l|l|c|c|c|}
\hline & Description & BRIQ. No.1 & BRIQ. No.2 & Average \\
\hline$A_{1}$ & Mass of Compacted Specimen in Air & 4796 & 4781 & 4788.5 \\
\hline$A_{2}$ & $\begin{array}{l}\text { SD Mass of Specimen in Air after } \\
\text { Immersion in Water }\end{array}$ & 4804 & 4786 & 4795 \\
\hline$B_{1}$ & Mass of Compacted Specimen in Water & 2826 & 2816 & 2821 \\
\hline$B_{2}$ & Volume $=A_{2}-B_{1}$ & 1978 & 1970 & \\
\hline$C$ & Bulk Relative Density $=A_{1} / B_{2}$ & 2.425 & 2.427 & 2.426 \\
\hline$C_{1}$ & Flask No. & 1 & 2 & \\
\hline$D$ & Mass of Flask and Mixture in Air & 2324 & 2323 & 2323.5 \\
\hline$E$ & Mass of Flask in Air & 542 & 542 & \\
\hline$F$ & Mass of Mixture in Air $=\mathrm{D}-\mathrm{E}$ & 1782 & 1781 & \\
\hline$G$ & Mass of Flask and Mixture in water & 1541 & 1542 & 1541.5 \\
\hline $\mathrm{H}$ & Mass of Flask in Water & 473 & 473 & \\
\hline $\mathrm{I}_{1}$ & Mass of Mixture in Water $=\mathrm{G}-\mathrm{H}$ & 1068 & 1069 & \\
\hline $\mathrm{L}_{2}$ & Volume $=\mathrm{F}-\mathrm{I}_{1}$ & 714 & 712 & \\
\hline $\mathrm{J}$ & Max. Relative Density $=\mathrm{F} / \mathrm{I}_{2}$ & 2.496 & 2.501 & 2.499 \\
\hline $\mathrm{K}$ & Percent Void in Mixture $=\{(\mathrm{J}-\mathrm{C}) / \mathrm{J}\}{ }^{*} 100$ & 2.85 & 2.98 & 2.914 \\
\hline $\mathrm{L}$ & Gb $=$ & 2.81 & & \\
\hline $\mathrm{M}$ & VMA $=\left\{100-\left\{(100-\mathrm{AC})^{*} \mathrm{Avg} . \mathrm{C}\right\} / \mathrm{L}\right\}$ & 17.13 & & \\
\hline & & & & \\
\hline
\end{tabular}




\section{Bitumen Laboratory Worksheet}

Mix Type: Superpave 19.0 with $5 \%$ Shigles at $3.5 \%$ A.C $\quad$ Date: 09-Mar-04

Volumteric Properties of the Mix

\begin{tabular}{|l|l|c|c|c|}
\hline & Description & BRIQ. No.1 & BRIQ. No.2 & Average \\
\hline$A_{1}$ & Mass of Compacted Specimen in Air & 4840.5 & 4830.6 & 4835.55 \\
\hline$A_{2}$ & $\begin{array}{l}\text { SD Mass of Specimen in Air after Immersion } \\
\text { in Water }\end{array}$ & 4852.6 & 4840.4 & 4846.5 \\
\hline$B_{1}$ & Mass of Compacted Specimen in Water & 2845 & 2840.7 & 2842.85 \\
\hline$B_{2}$ & Volume $=A_{2}-B_{1}$ & 2007.6 & 1999.7 & \\
\hline$C$ & Bulk Relative Density $=A_{1} / B_{2}$ & 2.411 & 2.416 & 2.413 \\
\hline$C_{1}$ & Fiask No. & 1 & 2 & \\
\hline$D$ & Mass of Flask and Mixture in Air & 2802.6 & 3109.4 & 2956.0 \\
\hline$E$ & Mass of Flask in Air & 542 & 542 & \\
\hline$F$ & Mass of Mixture in Air $=\mathrm{D}-\mathrm{E}$ & 2260.6 & 2567.4 & \\
\hline $\mathrm{G}$ & Mass of Flask and Mixture in water & 1834.3 & 2019.8 & 1927.05 \\
\hline $\mathrm{H}$ & Mass of Flask in Water & 473 & 473 & \\
\hline $\mathrm{I}_{1}$ & Mass of Mixture in Water $=\mathrm{G}-\mathrm{H}$ & 1361.3 & 1546.8 & \\
\hline $\mathrm{I}_{2}$ & Volume $=\mathrm{F}-\mathrm{I}_{1}$ & 899.3 & 1020.6 & \\
\hline $\mathrm{J}$ & Max. Relative Density $=\mathrm{F} / \mathrm{I}_{2}$ & 2.514 & 2.516 & 2.515 \\
\hline $\mathrm{K}$ & Percent Void in Mixture $=\{(\mathrm{J}-\mathrm{C}) / \mathrm{J}\}^{*} 100$ & 4.08 & 3.97 & 4.028 \\
\hline $\mathrm{L}$ & Gb $=$ & 2.81 & & \\
\hline $\mathrm{M}$ & VMA $=\left\{100-\left\{(100-\mathrm{AC})^{*} \mathrm{Avg} . \mathrm{C}\right\} / \mathrm{L}\right\}$ & 17.55 & & \\
\hline & & & & \\
\hline
\end{tabular}




\section{Bitumen Laboratory Worksheet}

Mix Type: Superpave 19.0 with $5 \%$ Shingles at $4.0 \%$ A.C

Date: $\quad$ 23-Mar-04

Volumteric Properties of the Mix

\begin{tabular}{|l|l|c|c|c|}
\hline & Description & BRIQ. No.1 & BRIQ. No.2 & Average \\
\hline $\mathrm{A}_{1}$ & Mass of Compacted Specimen in Air & 4828.9 & 4833.7 & 4831.3 \\
\hline $\mathrm{A}_{2}$ & $\begin{array}{l}\text { SD Mass of Specimen in Air after Immersion } \\
\text { in Water }\end{array}$ & 4839.7 & 4841 & 4840.35 \\
\hline $\mathrm{B}_{1}$ & Mass of Compacted Specimen in Water & 2843.6 & 2845.5 & 2844.55 \\
\hline $\mathrm{B}_{2}$ & Volume $=\mathrm{A}_{2}-\mathrm{B}_{1}$ & 1996.1 & 1995.5 & \\
\hline $\mathrm{C}$ & Bulk Relative Density $=\mathrm{A}_{1} / \mathrm{B}_{2}$ & 2.419 & 2.422 & 2.421 \\
\hline $\mathrm{C}_{1}$ & Flask No. & 1 & 2 & \\
\hline $\mathrm{D}$ & Mass of Flask and Mixture in Air & 1845.7 & 1833.4 & 1839.6 \\
\hline $\mathrm{E}$ & Mass of Flask in Air & 542 & 542 & \\
\hline $\mathrm{F}$ & Mass of Mixture in Air $=\mathrm{D}-\mathrm{E}$ & 1303.7 & 1291.4 & \\
\hline $\mathrm{G}$ & Mass of Flask and Mixture in water & 1255.1 & 1248.3 & 1251.7 \\
\hline $\mathrm{H}$ & Mass of Flask in Water & 473 & 473 & \\
\hline $\mathrm{I}_{1}$ & Mass of Mixture in Water $=\mathrm{G}-\mathrm{H}$ & 782.1 & 775.3 & \\
\hline $\mathrm{I}_{2}$ & Volume $=\mathrm{F}-\mathrm{I}_{1}$ & 521.6 & 516.1 & \\
\hline $\mathrm{J}$ & Max. Relative Density $=\mathrm{F} / \mathrm{I}_{2}$ & 2.499 & 2.502 & 2.501 \\
\hline $\mathrm{K}$ & Percent Void in Mixture $=\{(\mathrm{J}-\mathrm{C}) / \mathrm{J}\}^{*} 100$ & 3.21 & 3.19 & 3.203 \\
\hline $\mathrm{L}$ & Gb & 2.81 & & \\
\hline $\mathrm{M}$ & VMA $=\left\{100-\left\{(100-\mathrm{AC})^{*} \mathrm{Avg} . \mathrm{C}\right\} / \mathrm{L}\right\}$ & 17.30 & & \\
\hline & & & & \\
\hline
\end{tabular}




\section{Bitumen Laboratory Worksheet}

Mix Type: Superpave 19.0 with $5 \%$ Shingles at $4.5 \%$ A.C

Date: $\quad$ 09-Mar-04

Volumteric Properties of the Mix

\begin{tabular}{|l|l|c|c|c|}
\hline & Description & BRIQ. No.1 & BRIQ. No.2 & Average \\
\hline$A_{1}$ & Mass of Compacted Specimen in Air & 4838.1 & 4832.4 & 4835.25 \\
\hline$A_{2}$ & $\begin{array}{l}\text { SD Mass of Specimen in Air after Immersion in } \\
\text { Water }\end{array}$ & 4840 & 4835 & 4837.5 \\
\hline$B_{1}$ & Mass of Compacted Specimen in Water & 2843.6 & 2840.2 & 2841.9 \\
\hline$B_{2}$ & Volume $=A_{2}-B_{1}$ & 1996.4 & 1994.8 & \\
\hline $\mathrm{C}$ & Bulk Relative Density $=\mathrm{A}_{1} / \mathrm{B}_{2}$ & 2.423 & 2.422 & 2.423 \\
\hline $\mathrm{C}_{1}$ & Flask No. & 1 & 2 & \\
\hline $\mathrm{D}$ & Mass of Flask and Mixture in Air & 2415.3 & 3231 & 2823.2 \\
\hline $\mathrm{E}$ & Mass of Flask in Air & 542 & 542 & \\
\hline $\mathrm{F}$ & Mass of Mixture in Air $=\mathrm{D}-\mathrm{E}$ & 1873.3 & 2689 & \\
\hline $\mathrm{G}$ & Mass of Flask and Mixture in water & 1592.6 & 2080.6 & 1836.6 \\
\hline $\mathrm{H}$ & Mass of Flask in Water & 473 & 473 & \\
\hline $\mathrm{I}_{1}$ & Mass of Mixture in Water $=\mathrm{G}-\mathrm{H}$ & 1119.6 & 1607.6 & \\
\hline $\mathrm{I}_{2}$ & Volume $=\mathrm{F}-\mathrm{I}_{1}$ & 753.7 & 1081.4 & \\
\hline $\mathrm{J}$ & Max. Relative Density $=\mathrm{F} / \mathrm{I}_{2}$ & 2.485 & 2.487 & 2.486 \\
\hline $\mathrm{K}$ & Percent Void in Mixture $=\left\{(\mathrm{J}-\mathrm{C} / / \mathrm{J}\}^{*} 100\right.$ & 2.50 & 2.58 & 2.537 \\
\hline $\mathrm{L}$ & Gb $=$ & 2.81 & & \\
\hline $\mathrm{M}$ & VMA $=\left\{100-\left\{(100-\mathrm{AC})^{\star} \mathrm{Avg} . \mathrm{C}\right\} / \mathrm{L}\right\}$ & 17.22 & & \\
\hline & & & & \\
\hline
\end{tabular}




\section{Bitumen Laboratory Worksheet}

Mix Type: Superpave 19.0 with $5 \%$ Shingles at $5 \%$ A.C $\quad$ Date: 09-Mar-04

Volumteric Properties of the Mix

\begin{tabular}{|l|l|c|c|c|}
\hline & Description & BRIQ. No.1 & BRIQ. No.2 & Average \\
\hline $\mathrm{A}_{1}$ & Mass of Compacted Specimen in Air & 4829.8 & 4844.6 & 4837.2 \\
\hline $\mathrm{A}_{2}$ & $\begin{array}{l}\text { SD Mass of Specimen in Air after } \\
\text { Immersion in Water }\end{array}$ & 4830.4 & 4848 & 4839.2 \\
\hline $\mathrm{B}_{1}$ & Mass of Compacted Specimen in Water & 2842.2 & 2856.7 & 2849.45 \\
\hline $\mathrm{B}_{2}$ & Volume $=\mathrm{A}_{2}-\mathrm{B}_{1}$ & 1988.2 & 1991.3 & \\
\hline $\mathrm{C}$ & Bulk Relative Density $=\mathrm{A}_{1} / \mathrm{B}_{2}$ & 2.429 & 2.433 & 2.431 \\
\hline $\mathrm{C}_{1}$ & Flask No. & 1 & 2 & \\
\hline $\mathrm{D}$ & Mass of Flask and Mixture in Air & 2274 & 2525.3 & 2399.7 \\
\hline $\mathrm{E}$ & Mass of Flask in Air & 542 & 542 & \\
\hline $\mathrm{F}$ & Mass of Mixture in Air $=\mathrm{D}-\mathrm{E}$ & 1732 & 1983.3 & \\
\hline $\mathrm{G}$ & Mass of Flask and Mixture in water & 1504.2 & 1653.9 & 1579.05 \\
\hline $\mathrm{H}$ & Mass of Flask in Water & 473 & 473 & \\
\hline $\mathrm{I}_{1}$ & Mass of Mixture in Water $=\mathrm{G}-\mathrm{H}$ & 1031.2 & 1180.9 & \\
\hline $\mathrm{I}_{2}$ & Volume $=\mathrm{F}-\mathrm{I}_{1}$ & 700.8 & 802.4 & \\
\hline $\mathrm{J}$ & Max. Relative Density $=\mathrm{F} / \mathrm{I}_{2}$ & 2.471 & 2.472 & 2.472 \\
\hline $\mathrm{K}$ & Percent Void in Mixture $=\{(\mathrm{J}-\mathrm{C}) / \mathrm{J}\}^{*} 100$ & 1.71 & 1.57 & 1.640 \\
\hline $\mathrm{L}$ & Gb $=$ & 2.81 & & \\
\hline $\mathrm{M}$ & VMA = $\left\{100-\left\{(100-\mathrm{AC})^{*} \mathrm{Avg} . \mathrm{C}\right\} / \mathrm{L}\right\}$ & 16.95 & & \\
\hline & & & & \\
\hline
\end{tabular}




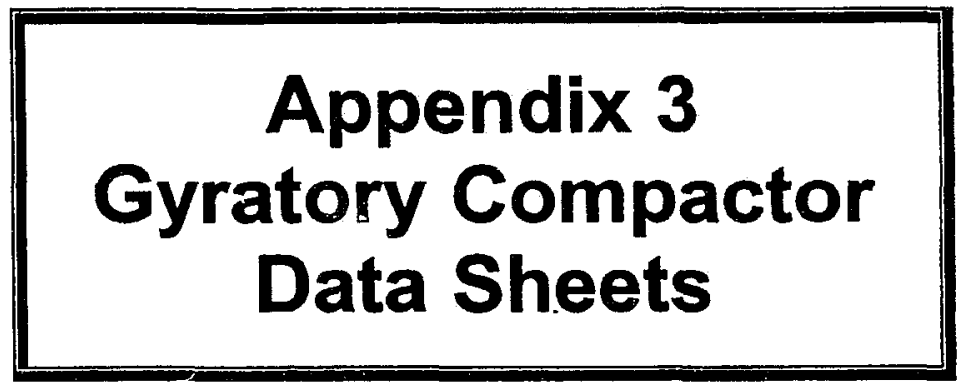

Reproduced with permission of the copyright owner. Further reproduction prohibited without permission. 


\section{RYERSON UNIVERSITY \\ Dpartment of Civil Engineering \\ Superpave BITUMINOUS LABORATORY WORKSHEET}

\begin{tabular}{|l|c|c|c|c|c|c|}
\hline PROJECT NO.: & \multicolumn{2}{|l|}{ M.Eng } & \multicolumn{3}{|c|}{ DATE: } & March, 2004 \\
\hline SUPPLIER & 0.000 & \multicolumn{3}{|c|}{ Mix Type: Superpave 12.5 without Shingles } \\
\hline \% PASS 4.75mm: & 30.0 & Gsb: & 2.800 & $\%$ AC: & 4.0 & MIX NO.: \\
\hline
\end{tabular}

\begin{tabular}{||l|c|c|}
\hline \multicolumn{1}{|c|}{ PARAMETER } & SPECIMEN 1 & SPECIMEN 2 \\
\hline A1: MASS OF COMPACTED SPECIMEN IN AIR & 4833.5 & 4844.8 \\
\hline A2: S.D.MASS IN AIR AFTER IMMERSSION IN $\mathrm{H}_{2} \mathrm{O}$ & 4859 & 4870.1 \\
\hline B1: MASS OF COMPACTED SPECIMEN $\mathrm{IN} \mathrm{H}_{2} \mathrm{O}$ & 2843.5 & 2842.9 \\
\hline B2: VOLUME (= A2-B1) & 2015.5 & 2027.2 \\
\hline C: BULK REL. DENSITY (=A1/B2), Gmb Measured & 2.398 & 2.390 \\
\hline D: MAX. THEORITICAL DENSITY, Gmm & \multicolumn{2}{|c|}{2.535} \\
\hline
\end{tabular}

\begin{tabular}{|c|c|c|c|c|c|c|c|c|}
\hline \multicolumn{9}{|c|}{ Superpave GYRATORY DENSIFICATION DATA } \\
\hline \multicolumn{2}{|c|}{ Mold Diameter, mm } & \multicolumn{3}{|l|}{150} & & & & \\
\hline \multirow{2}{*}{ 范 } & \multicolumn{4}{|c|}{ SPECIMEN 1} & \multicolumn{4}{|c|}{ SPECIMEN 2} \\
\hline & $\begin{array}{c}\text { HEIGHT } \\
(\mathbf{m m})\end{array}$ & $\begin{array}{c}\text { Gimb - } \\
\text { Estimated }\end{array}$ & $\begin{array}{c}\text { Gmb - } \\
\text { Corrected }\end{array}$ & $\% \mathbf{G m m}$ & $\begin{array}{c}\text { HEIGHT } \\
(\mathrm{mm})\end{array}$ & $\begin{array}{c}\text { Gmb - } \\
\text { Estimated }\end{array}$ & $\begin{array}{c}\text { Gmb - } \\
\text { Corrected }\end{array}$ & $\% \mathrm{Gmm}$ \\
\hline 7 & 135.33 & 2.021 & 2.105 & 83.03 & 132.23 & 2.073 & 2.120 & 83.63 \\
\hline 9 & 133.7 & 2.046 & 2.131 & 84.05 & 130.77 & 2.096 & 2.144 & 84.57 \\
\hline 100 & 119.78 & 2.283 & 2.378 & 93.81 & 118.19 & 2.319 & 2.372 & 93.57 \\
\hline 125 & 118.78 & 2.302 & 2.398 & 94.60 & 117.3 & 2.337 & 2.390 & 94.28 \\
\hline \multicolumn{2}{|c|}{ Gyrations } & $\begin{array}{l}\text { Average } \\
\% \text { Gmm }\end{array}$ & \begin{tabular}{|c|}
$\begin{array}{c}\text { Average } \\
\text { Air Voids } \\
(\%)\end{array}$ \\
\end{tabular} & $\begin{array}{l}96.0 \\
94.0 \\
92.0\end{array}$ & & & & \\
\hline \multicolumn{2}{|c|}{7} & 83.33 & 16.7 & 90.0 & & & & 1]1] \\
\hline \multicolumn{2}{|c|}{9} & 84.31 & 15.7 & 86.0 & & & & $\pi$ \\
\hline \multicolumn{2}{|c|}{100} & 93.69 & 6.3 & & & 1 & \# & 冊 \\
\hline \multicolumn{2}{|c|}{125} & 94.44 & 5.6 & 1 & & Gyratio & 1 & \\
\hline
\end{tabular}


RYERSON UNIVERSITY

Dpartment of Civil Engineering

Superpave BITUMINOUS LABORATORY WORKSHEET

\begin{tabular}{||l|l|l|l|l|r|r||}
\hline \hline PROJECT NO.: & \multicolumn{2}{|l|}{ M.Eng } & \multicolumn{3}{|c|}{ DATE: } & March, 2004 \\
\hline SUPPLIER & 0.000 & \multicolumn{3}{|c|}{ Mix Type: Superpave 12.5 without Shingles } \\
\hline \% PASS 4.75mm: & 30.0 & Gsb: & 2.800 & \% AC: & 4.5 & MIX NO.: \\
\hline
\end{tabular}

\begin{tabular}{||l|c|c||}
\hline \multicolumn{1}{|c|}{ PARAMETER } & SPECIMEN 1 & SPECIMEN 2 \\
\hline A1: MASS OF COMPACTED SPECIMEN IN AIR & 4843.6 & 4846.1 \\
\hline A2: S.D.MASS IN AIR AFTER IMMERSSION IN H $\mathrm{O}_{2} \mathrm{O}$ & 4863.4 & 4864.2 \\
\hline B1: MASS OF COMPACTED SPECIMEN IN $\mathrm{H}_{2} \mathrm{O}$ & 2849.6 & 2853.4 \\
\hline B2: VOLUME (= A2-B1) & 2013.8 & 2010.8 \\
\hline C: BULK REL. DENSITY (= A1/B2), Gmb Measured & 2.405 & 2.410 \\
\hline D: MAX. THEORITICAL DENSITY, Gmm & \multicolumn{2}{|c|}{2.530} \\
\hline
\end{tabular}

\begin{tabular}{|c|c|c|c|c|c|c|c|c|}
\hline \multicolumn{9}{|c|}{ Superpave GYRATORY DENSIFICATION DATA } \\
\hline \multicolumn{2}{|c|}{ Mold Diameter, mm } & \multicolumn{7}{|l|}{150} \\
\hline \multirow{2}{*}{ 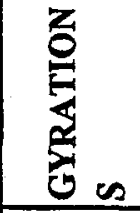 } & \multicolumn{4}{|c|}{ SPECIMEN 1} & \multicolumn{4}{|c|}{ SPECIMEN 2} \\
\hline & $\begin{array}{c}\text { HEIGHT } \\
(\mathbf{m m})\end{array}$ & $\begin{array}{c}\text { Gmb - } \\
\text { Estimated }\end{array}$ & $\begin{array}{c}\text { Gmb - } \\
\text { Corrected }\end{array}$ & $\% \mathbf{G m m}$ & $\begin{array}{c}\text { HEIGHT } \\
(\mathbf{m m})\end{array}$ & $\begin{array}{c}\text { Gmb - } \\
\text { Estimated }\end{array}$ & $\begin{array}{c}\text { Gmb - } \\
\text { Corrected }\end{array}$ & $\% \mathbf{G m m}$ \\
\hline 7 & 135.39 & 2.024 & 2.112 & 83.48 & 134.31 & 2.042 & 2.128 & 84.12 \\
\hline 9 & 133.78 & 2.049 & 2.137 & 84.49 & 132.66 & 2.067 & 2.155 & 85.16 \\
\hline 100 & 119.86 & 2.286 & 2.386 & 94.30 & 119.57 & 2.293 & 2.390 & 94.49 \\
\hline 125 & 118.89 & 2.305 & 2.405 & 95.07 & 118.6 & 2.312 & 2.410 & 95.26 \\
\hline \multicolumn{2}{|c|}{ Gyrations } & $\begin{array}{l}\text { Average } \\
\text { \% Gmm }\end{array}$ & \begin{tabular}{|c|} 
Average \\
Air Voids \\
$(\%)$ \\
\end{tabular} & $\begin{array}{l}96.0 \\
94.0 \\
92.0\end{array}$ & & & 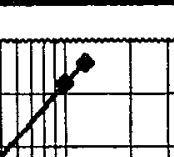 & \\
\hline \multicolumn{2}{|r|}{7} & 83.80 & 16.2 & 90.0 & & & & III] \\
\hline \multicolumn{2}{|c|}{9} & 85 & 15.2 & & & 1 & & 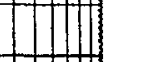 \\
\hline \multicolumn{2}{|c|}{100} & 94.39 & 5.6 & 84.0 & & & & 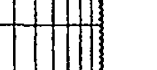 \\
\hline \multicolumn{2}{|c|}{125} & 95.16 & 4.8 & & & & 0 & 1000 \\
\hline
\end{tabular}




\section{RYERSON UNIVERSITY \\ Dpartment of Civil Engineering}

Superpave BITUMINOUS LABORATORY WORKSHEET

\begin{tabular}{||l|c|c|c|c|c|c|}
\hline PROJECT NO.: & \multicolumn{2}{|l|}{ M.Eng } & \multicolumn{3}{|c|}{ DATE: } & March, 2004 \\
\hline SUPPLIER & 0.000 & \multicolumn{2}{|c|}{ Mix Type: Superpave 12.5 without Shingles } \\
\hline \% PASS 4.75mm: & 30.0 & Gsb: & 2.800 & $\%$ AC: & 5.0 & MIX NO.: \\
\hline
\end{tabular}

\begin{tabular}{|l|c|c|}
\hline \multicolumn{1}{|c|}{ PARAMETER } & SPECIMEN 1 & SPECIMEN 2 \\
\hline A1: MASS OF COMPACTED SPECIMEN IN AIR & 4837 & 4842 \\
\hline A2: S.D.MASS IN AIR AFTER IMMERSSION IN H $\mathrm{H}_{2} \mathrm{O}$ & 4850 & 4854 \\
\hline B1: MASS OF COMPACTED SPECIMEN IN $\mathrm{H}_{2} \mathrm{O}$ & 2852 & 2850 \\
\hline B2: VOLUME ( = A2-B1) & 1998 & 2004 \\
\hline C: BULK REL. DENSITY (= A1/B2), Gmb Measured & 2.421 & 2.416 \\
\hline D: MAX. THEORITICAL DENSITY, Gmm & & 2.520 \\
\hline
\end{tabular}

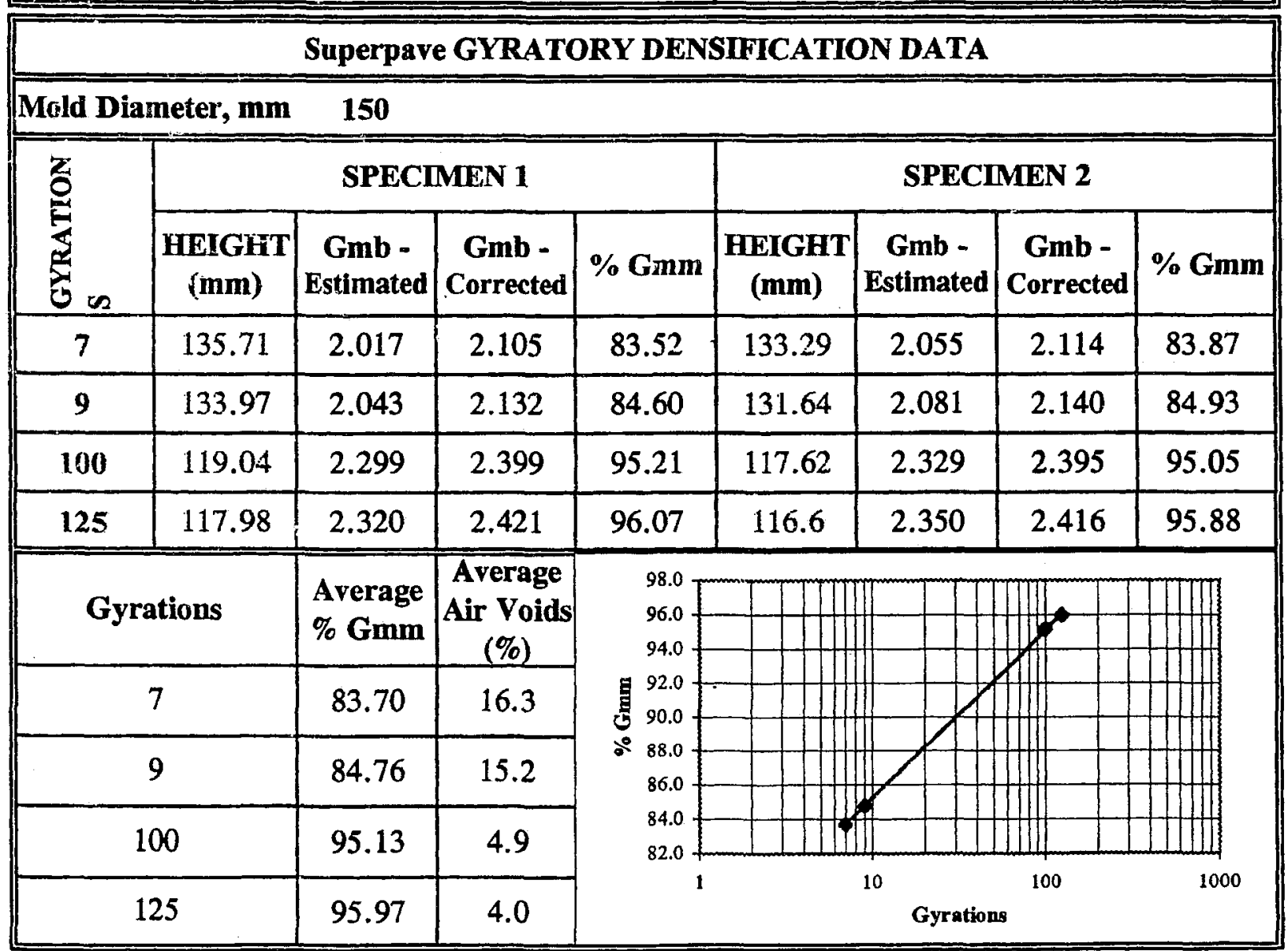

Reproduced with permission of the copyright owner. Further reproduction prohibited without permission. 


\section{RYERSON UNIVERSITY \\ Dpartment of Civil Engineering}

Superpave BITUMINOUS LABORATORY WORKSHEET

\begin{tabular}{|c|c|c|c|c|c|c|}
\hline \multirow{3}{*}{\begin{tabular}{|l|} 
PROJECT NO.: \\
SUPPLIER \\
$\%$ PASS $4.75 \mathrm{~mm}:$ \\
\end{tabular}} & \multicolumn{3}{|l|}{ M.Eng } & & DATE: & March, 2004 \\
\hline & \multicolumn{3}{|l|}{0.000} & \multicolumn{3}{|c|}{ Mix Type: Superpave 12.5 without Shingles } \\
\hline & 30.0 & Gsb: & 2.800 & $\% \mathbf{A C}$ & 5.5 & MXX NO.: \\
\hline
\end{tabular}

\begin{tabular}{||l|c|c|}
\hline \multicolumn{1}{|c|}{ PARAMETER } & SPECIMEN 1 & SPECIMEN 2 \\
\hline A1: MASS OF COMPACTED SPECIMEN IN AIR & 4838 & 4831 \\
\hline A2: S.D.MASS IN AIR AFTER IMMERSSION IN H ${ }_{2} \mathrm{O}$ & 4849 & 4844 \\
\hline B1: MASS OF COMPACTED SPECIMEN IN H $\mathrm{H}_{2} \mathrm{O}$ & 2852 & 2849 \\
\hline B2: VOLUME (= A2-B1) & 1997 & 1995 \\
\hline C: BULK REL. DENSITY (=A1/B2), Gmb Measured & 2.423 & 2.422 \\
\hline D: MAX. THEORITICAL DENSITY, Gmm & & 2.495 \\
\hline
\end{tabular}

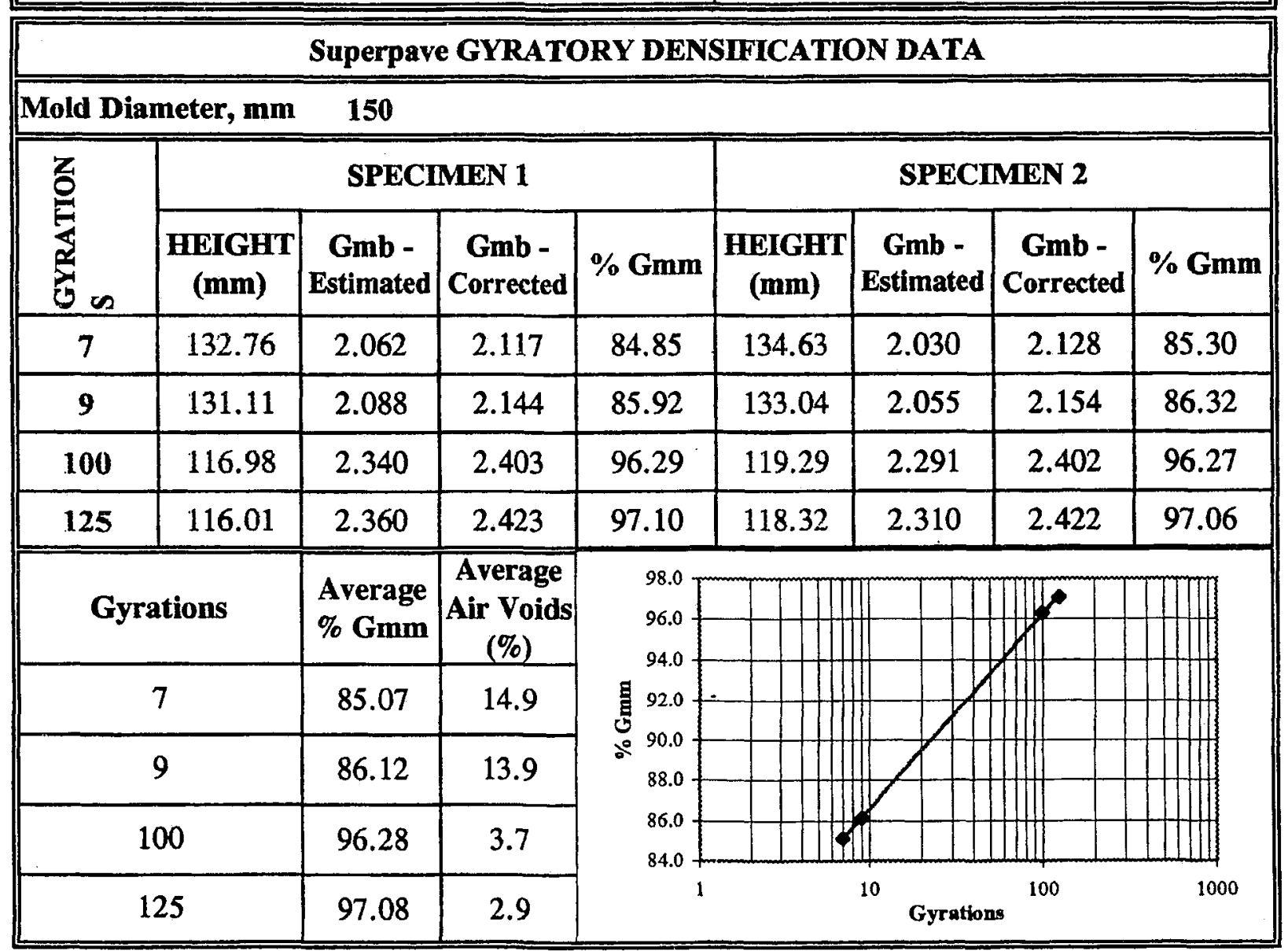


RYERSON UNIVERSITY

Dpartment of Civil Engineering

Superpave BITUMINOUS LABORATORY WORKSHEET

\begin{tabular}{||l|c|c|c|c|c|c|}
\hline \multicolumn{2}{|l|}{ PROJECT NO.: } & \multicolumn{3}{|l|}{ D.Eng } & \multicolumn{3}{|c|}{ DATE: } & March, 2004 \\
\hline SUPPLIER & 0.000 & \multicolumn{2}{|l|}{ Mix Type: Superpave 12.5 with Shingles } \\
\hline$\%$ PASS 4.75mm: & 30.0 & Gsb: & 2.800 & $\%$ AC: & 3.5 & MIX NO.: \\
\hline
\end{tabular}

\begin{tabular}{|l|c|c|}
\hline \multicolumn{1}{|c|}{ PARAMETER } & SPECIMEN 1 & SPECIMEN 2 \\
\hline A1: MASS OF COMPACTED SPECIMEN IN AIR & 4837.3 & 4852 \\
\hline A2: S.D.MASS IN AIR AFTER IMMERSSION IN H2 $\mathrm{O}$ & 4857.9 & 4870 \\
\hline B1: MASS OF COMPACTED SPECIMEN IN H $\mathrm{H}_{2} \mathrm{O}$ & 2845.5 & 2855.8 \\
\hline B2: VOLUME (= A2-B1) & 2012.4 & 2014.2 \\
\hline C: BULK REL. DENSITY (= A1/B2), Gmb Measured & 2.404 & 2.409 \\
\hline D: MAX. THEORITICAL DENSITY, Gmm & & 2.528 \\
\hline \hline
\end{tabular}

\begin{tabular}{|c|c|c|c|c|c|c|c|c|}
\hline \multicolumn{9}{|c|}{ Superpave GYRATORY DENSIFICATION DATA } \\
\hline \multicolumn{2}{|c|}{ Mold Diameter, $\mathbf{m m}$} & \multicolumn{7}{|l|}{150} \\
\hline \multirow{2}{*}{ 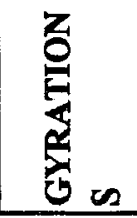 } & \multicolumn{4}{|c|}{ SPECIMEN 1} & \multicolumn{4}{|c|}{ SPECIMEN 2} \\
\hline & $\begin{array}{c}\text { HEIGHT } \\
\text { (mm) }\end{array}$ & $\begin{array}{c}\text { Gmb - } \\
\text { Estimated }\end{array}$ & $\begin{array}{c}\text { Gmb - } \\
\text { Corrected }\end{array}$ & $\%$ Gmm & $\begin{array}{c}\text { HEIGHT } \\
(\mathrm{mm})\end{array}$ & $\begin{array}{c}\text { Gmb - } \\
\text { Estimated }\end{array}$ & $\begin{array}{c}\text { Gmb - } \\
\text { Corrected }\end{array}$ & $\% \mathrm{Gmm}$ \\
\hline 7 & 132.47 & 2.066 & 2.140 & 84.66 & 133.72 & 2.053 & 2.138 & 84.59 \\
\hline 9 & 130.9 & 2.091 & 2.166 & 85.67 & 132.17 & 2.077 & 2.163 & 85.58 \\
\hline 100 & 118.74 & 2.305 & 2.388 & 94.44 & 119.57 & 2.296 & 2.391 & 94.60 \\
\hline 125 & 117.94 & 2.321 & 2.404 & 95.08 & 118.7 & 2.313 & 2.409 & 95.29 \\
\hline \multicolumn{2}{|c|}{ Gyrations } & $\begin{array}{l}\text { Average } \\
\% \mathbf{G m m}\end{array}$ & \begin{tabular}{|c|} 
Average \\
Air Voids \\
$(\%)$
\end{tabular} & ${ }_{94.0}^{96.0}$ & & & fe & \\
\hline \multicolumn{2}{|c|}{7} & 84.62 & 15.4 & & & & & \\
\hline \multicolumn{2}{|c|}{9} & 85.62 & 14.4 & 88.0 & & & & \\
\hline \multicolumn{2}{|c|}{100} & 94.52 & 5.5 & & 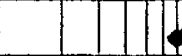 & 1 & & \\
\hline \multicolumn{2}{|c|}{125} & 95.19 & 4.8 & \multicolumn{5}{|c|}{ Gyrations } \\
\hline
\end{tabular}




\section{RYERSON UNIVERSITY \\ Dpartment of Civil Engineering}

Superpave BITUMINOUS LABORATORY WORKSHEET

\begin{tabular}{||l|l|c|c|c|c|c|}
\hline PROJECT NO.: & \multicolumn{2}{|l|}{ M.Eng } & \multicolumn{3}{|c|}{ DATE: } & March, 2004 \\
\hline SUPPLIER & 0.000 & \multicolumn{2}{|c|}{ Mix Type: Superpave 12.5 with Shingles } \\
\hline \% PASS 4.75mm: & 30.0 & Gsb: & 2.800 & $\%$ AC: & 4.0 & MIX NO.: \\
\hline
\end{tabular}

\begin{tabular}{||l|c|c|}
\hline \multicolumn{1}{|c|}{ PARAMETER } & SPECIMEN 1 & SPECIMEN 2 \\
\hline A1: MASS OF COMPACTED SPECIMEN IN AIR & 4846.1 & 4850.4 \\
\hline A2: S.D.MASS IN AIR AFTER IMMERSSION IN $\mathrm{H}_{2} \mathrm{O}$ & 4856.5 & 4861.3 \\
\hline B1: MASS OF COMPACTED SPECIMEN IN $\mathrm{H}_{2} \mathrm{O}$ & 2851.5 & 2855.8 \\
\hline B2: VOLUME (= A2-B1) & 2005 & 2005.5 \\
\hline C: BULK REL. DENSITY (=A1/B2), Gmb Measured & 2.417 & 2.419 \\
\hline D: MAX. THEORITICAL DENSITY, Gmm & \multicolumn{2}{|c|}{2.518} \\
\hline
\end{tabular}

\begin{tabular}{|c|c|c|c|c|c|c|c|c|}
\hline \multicolumn{9}{|c|}{ Superpave GYRATORY DENSIFICATION DATA } \\
\hline \multicolumn{2}{|c|}{ Mold Diameter, $\mathbf{m m}$} & \multicolumn{3}{|l|}{150} & & & & \\
\hline \multirow{2}{*}{$\begin{array}{l}z \\
0 \\
\vdots \\
\sum_{1}^{\prime} \\
0\end{array}$} & \multicolumn{4}{|c|}{ SPECIMEN 1} & \multicolumn{4}{|c|}{ SPECIMEN 2} \\
\hline & $\begin{array}{c}\text { HEIGHT } \\
(\mathrm{mm})\end{array}$ & $\begin{array}{c}\text { Gmb - } \\
\text { Estimated }\end{array}$ & $\begin{array}{c}\text { Gmb - } \\
\text { Corrected }\end{array}$ & $\% \mathrm{Gmm}$ & $\begin{array}{c}\text { HEIGHT } \\
\text { (mm) }\end{array}$ & $\begin{array}{c}\text { Gmb - } \\
\text { Estimated }\end{array}$ & $\begin{array}{c}\text { Gmb - } \\
\text { Corrected }\end{array}$ & $\% \mathbf{G m m}$ \\
\hline 7 & 130.67 & 2.098 & 2.136 & 84.82 & 134.8 & 2.036 & 2.119 & 84.15 \\
\hline 9 & 129.1 & 2.124 & 2.162 & 85.85 & 133.14 & 2.061 & 2.145 & 85.20 \\
\hline 100 & 116.83 & 2.347 & 2.389 & 94.87 & 120.29 & 2.281 & 2.375 & 94.30 \\
\hline 125 & 115.47 & 2.375 & 2.417 & 95.99 & 118.1 & 2.324 & 2.419 & 96.05 \\
\hline \multicolumn{2}{|c|}{ Gyrations } & $\begin{array}{l}\text { Average } \\
\% \text { Gmm }\end{array}$ & \begin{tabular}{|c|} 
Average \\
Air Voids \\
$(\%)$ \\
\end{tabular} & $\begin{array}{l}98.0 \\
96.0 \\
94.0\end{array}$ & & & & \\
\hline \multicolumn{2}{|c|}{7} & 84.49 & 15.5 & 92.0 & & & & \\
\hline \multicolumn{2}{|c|}{9} & 86 & 14.5 & 88.0 & & & & \\
\hline \multicolumn{2}{|c|}{100} & 94.59 & 5.4 & 84.0 & & & & \\
\hline \multicolumn{2}{|c|}{125} & 96.02 & 4.0 & 1 & & ${ }^{10} \mathrm{Gyr}$ & 100 & 1000 \\
\hline
\end{tabular}

Reproduced with permission of the copyright owner. Further reproduction prohibited without permission. 


\section{RYERSON UNIVERSITY \\ Dpartment of Civil Engineering}

Superpave BITUMINOUS LABORATORY WORKSHEET

\begin{tabular}{|l|l|l|l|l|l|l|}
\hline PROJECT NO.: & \multicolumn{2}{|l|}{ M.Eng } & \multicolumn{3}{|c|}{ DATE: } & March, 2004 \\
\hline SUPPLIER & 0.000 & \multicolumn{3}{|c|}{ Mix Type: Superpave 12.5 with Shingles } \\
\hline$\%$ PASS 4.75mm: & 30.0 & Gsb: & 2.800 & $\%$ AC: & 4.5 & MIX NO.: \\
\hline
\end{tabular}

\begin{tabular}{||l|c|c||}
\hline \multicolumn{1}{|c|}{ PARAMETER } & SPECIMEN 1 & SPECIMEN 2 \\
\hline A1: MASS OF COMPACTED SPECIMEN IN AIR & 4848.2 & 4845.6 \\
\hline A2: S.D.MASS IN AIR AFTER IMMERSSION N H $\mathrm{H}_{2} \mathrm{O}$ & 4855.4 & 4851.2 \\
\hline B1: MASS OF COMPACTED SPECIMEN IN H $\mathrm{H}_{2} \mathrm{O}$ & 2852.8 & 2848.1 \\
\hline B2: VOLUME (= A2-B1) & 2002.6 & 2003.1 \\
\hline C: BULK REL. DENSITY (= A1/B2), Gmb Measured & 2.421 & 2.419 \\
\hline D: MAX. THEORITICAL DENSITY, Gmm & & 2.500 \\
\hline
\end{tabular}

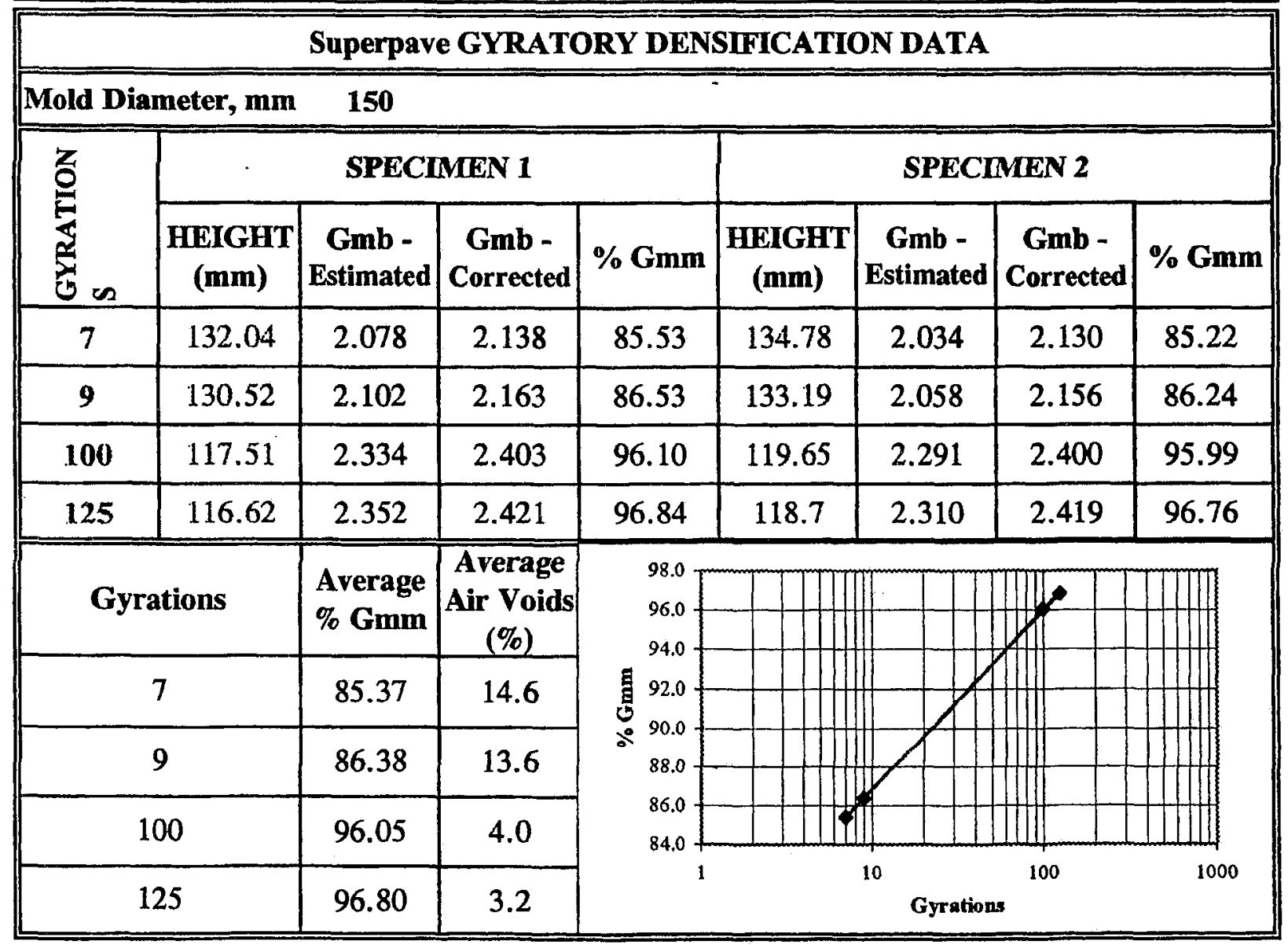


RYERSON UNIVERSITY

Dpartment of Civil Engineering

Superpave BITUMINOUS LABORATORY WORKSHEET

\begin{tabular}{|l|c|c|c|c|c|c|}
\hline PROJECT NO.: & \multicolumn{2}{|l|}{ M.Eng } & \multicolumn{3}{|c|}{ DATE: } & \multicolumn{2}{|c|}{ March, 2004 } \\
\hline SUPPLIER & \multicolumn{2}{|l|}{} & \multicolumn{3}{|c|}{ Mix Type: Superpave 12.5 with Shingles } \\
\hline$\%$ PASS 4.75mm: & 30.0 & Gsb: & 2.800 & \% AC: & 5.0 & MIX NO.. \\
\hline
\end{tabular}

\begin{tabular}{||l|c|c||}
\hline \multicolumn{1}{|c|}{ PARAMETER } & SPECIMEN 1 & SPECIMEN 2 \\
\hline A1: MASS OF COMPACTED SPECIMEN IN AIR & 4842.3 & 4849.2 \\
\hline A2: S.D.MASS IN AIR AFTER IMMERSSION IN $\mathrm{H}_{2} \mathrm{O}$ & 4849.1 & 4853.7 \\
\hline B1: MASS OF COMPACTED SPECIMEN IN $\mathrm{H}_{2} \mathrm{O}$ & 2855.6 & 2859.7 \\
\hline B2: VOLUME (= A2-B1) & 1993.5 & 1994 \\
\hline C: BULK REL. DENSITY (= A1/B2), Gmb Measured & 2.429 & 2.432 \\
\hline D: MAX. THEORITICAL DENSITY, Gmm & \multicolumn{2}{|c|}{2.492} \\
\hline
\end{tabular}

\begin{tabular}{|c|c|c|c|c|c|c|c|c|}
\hline & & Superpav & e GYRATC & ORY DEN & SIFICATIO & DN DATA & & \\
\hline Mold Di & meter, mm & 150 & & & & & & \\
\hline ż & & SPECI & MEN 1 & & & SPECI & MEN 2 & \\
\hline$\sum_{\infty}^{3}$ & $\begin{array}{c}\text { HEIGHT } \\
\text { (mm) }\end{array}$ & $\begin{array}{c}\text { Gmb - } \\
\text { Estimated }\end{array}$ & $\begin{array}{c}\text { Gmb - } \\
\text { Corrected }\end{array}$ & $\%$ Gmm & $\begin{array}{c}\text { HEIGHT } \\
(\mathrm{mm})\end{array}$ & $\begin{array}{c}\text { Gmb - } \\
\text { Estimated }\end{array}$ & $\begin{array}{c}\text { Gmb - } \\
\text { Corrected }\end{array}$ & $\%$ Gmm \\
\hline 7 & 136.26 & 2.011 & 2.113 & 84.79 & 134.63 & 2.038 & 2.137 & 85.77 \\
\hline 9 & 134.52 & 2.037 & 2.140 & 85.89 & 133.04 & 2.062 & 2.163 & 86.79 \\
\hline 100 & 119.55 & 2.292 & 2.408 & 96.64 & 119.29 & 2.300 & 2.412 & 96.79 \\
\hline 125 & 118.53 & 2.312 & 2.429 & 97.47 & 118.32 & 2.319 & 2.432 & 97.59 \\
\hline Gy & ations & $\begin{array}{l}\text { Average } \\
\% \text { Gmm }\end{array}$ & \begin{tabular}{|c|} 
Average \\
Air Voids \\
$(\%)$
\end{tabular} & & & & s. & \\
\hline & 7 & 85.28 & 14.7 & & & & & 0 \\
\hline & 9 & 86.34 & 13.7 & & & & & \\
\hline & 00 & 96.72 & 3.3 & & & & & TI \\
\hline & 25 & 97.53 & 2.5 & & & & 100 & 00 \\
\hline
\end{tabular}




\section{RYERSON UNIVERSITY \\ Dpartment of Civil Engineering}

Superpave BITUMINOUS LABORATORY WORKSHEET

\begin{tabular}{||l|l|l|l|l|c|c|}
\hline PROJECT NO.: & \multicolumn{2}{|l|}{ M.Eng } & \multicolumn{3}{|r|}{ DATE: } & March, 2004 \\
\hline SUPPLIER & 0.000 & \multicolumn{3}{|c|}{ Mix Type: Superpave 19.0 without Shingles } \\
\hline \% PASS 4.75mm: & 30.0 & Gsb: & 2.810 & $\%$ AC: & 3.5 & MIX NO.: \\
\hline
\end{tabular}

\begin{tabular}{||l|c|c|}
\hline \multicolumn{1}{|c|}{ PARAMETER } & SPECIMEN 1 & SPECIMEN 2 \\
\hline A1: MASS OF COMPACTE I SPECIMEN IN AIR & 4836 & 4838 \\
\hline A2: S.D.MASS IN AIR AFTER IMMERSSION IN H ${ }_{2} \mathrm{O}$ & 4856 & 4854 \\
\hline B1: MASS OF COMPACTED SPECIMEN IN H $\mathrm{H}_{2} \mathrm{O}$ & 2843 & 2837 \\
\hline B2: VOLUME (= A2-B1) & 2013 & 2017 \\
\hline C: BULK REL. DENSITY (=A1/B2), Gmb Measured & 2.402 & 2.399 \\
\hline D: MAX. THEORITICAL DENSITY, Gmm & \multicolumn{2}{|c|}{2.545} \\
\hline \hline
\end{tabular}

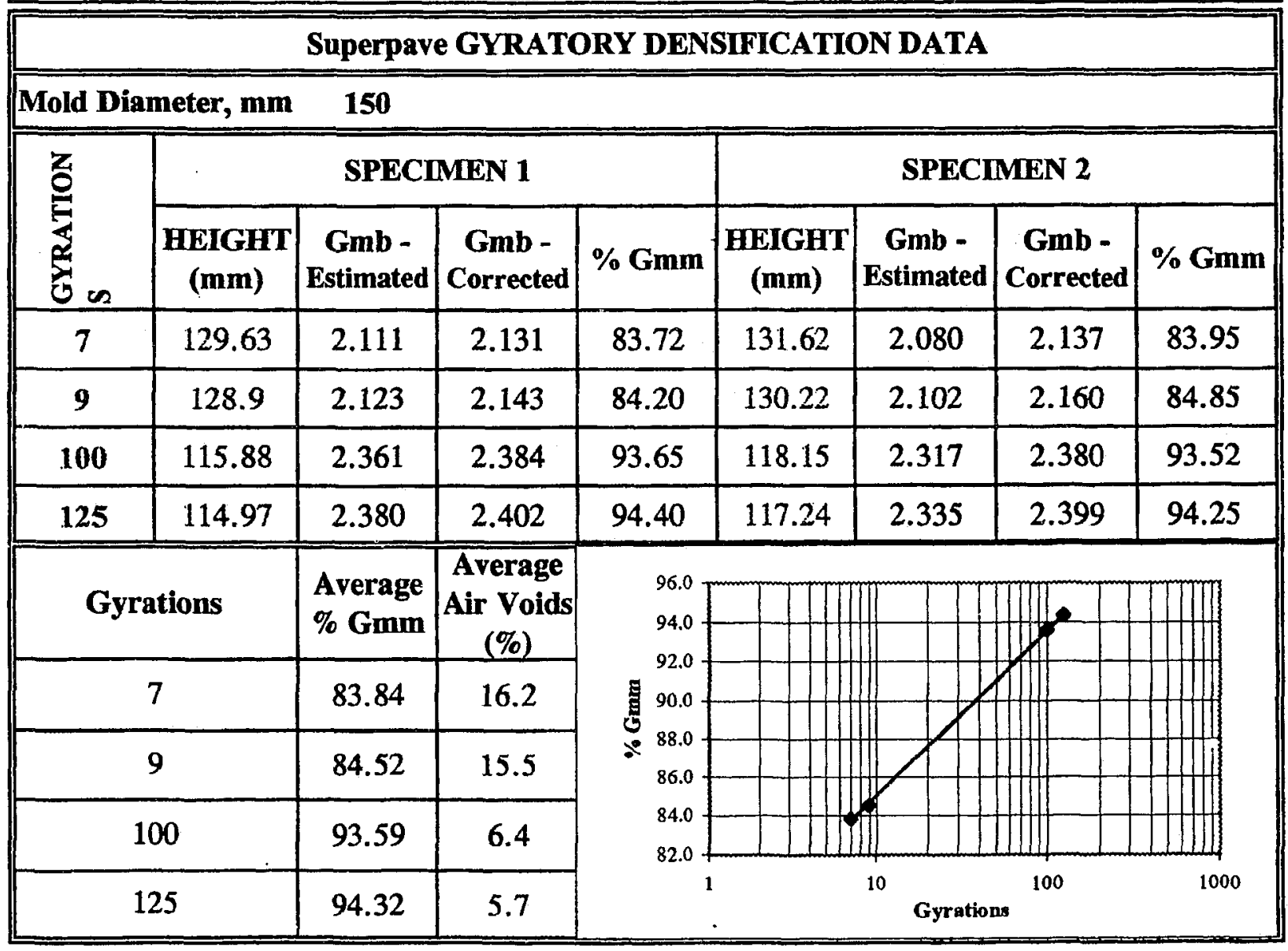




\section{RYERSON UNIVERSITY \\ Dpartment of Civil Engineering}

Superpave BITUMINOUS LABORATORY WORKSHEET

\begin{tabular}{|l|l|l|l|l|r|r|}
\hline PROJECT NO.: & \multicolumn{2}{|l|}{ M.Eng } & \multicolumn{3}{|c|}{ DATE: } & March, 2004 \\
\hline SUPPLIER & 0.000 & \multicolumn{2}{|c|}{ Mix Type: Superpave 19.0 without Shingles } \\
\hline$\%$ PASS 4.75mm: & 30.0 & Gsb: & 2.810 & $\%$ AC: & 4.0 & MXX NO.: \\
\hline
\end{tabular}

\begin{tabular}{||l|c|c||}
\hline \multicolumn{1}{|c|}{ PARAMETER } & SPECIMEN 1 & SPECIMEN 2 \\
\hline A1: MASS OF COMPACTED SPECIMEN IN AIR & 4778 & 4787 \\
\hline A2: S.D.MASS IN AIR AFTER IMMERSSION IN H2O & 4787 & 4797 \\
\hline B1: MASS OF COMPACTED SPECIMEN IN H2 $\mathrm{O}$ & 2803 & 2809 \\
\hline B2: VOLUME (= A2-B1) & 1984 & 1988 \\
\hline C: BULK REL. DENSITY (= A1/B2), Gmb Measured & 2.408 & 2.408 \\
\hline D: MAX. THEORITICAL DENSITY, Gmm & \multicolumn{2}{|c|}{2.532} \\
\hline
\end{tabular}

\begin{tabular}{|c|c|c|c|c|c|c|c|c|}
\hline \multicolumn{9}{|c|}{ Superpave GYRATORY DENSIFICATION DATA } \\
\hline \multicolumn{2}{|c|}{ Mold Diameter, mm } & \multicolumn{3}{|l|}{150} & & & & \\
\hline \multirow{2}{*}{ 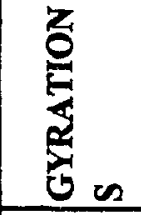 } & \multicolumn{4}{|c|}{ SPECIMEN 1} & \multicolumn{4}{|c|}{ SPECIMEN 2} \\
\hline & $\begin{array}{c}\text { HEIGHT } \\
(\mathrm{mm})\end{array}$ & $\begin{array}{c}\text { Gmb - } \\
\text { Estimated }\end{array}$ & $\begin{array}{c}\text { Gmb - } \\
\text { Corrected }\end{array}$ & $\% \mathbf{G m m}$ & $\begin{array}{c}\text { HEIGHT } \\
\text { (mm) }\end{array}$ & $\begin{array}{c}\text { Gmb - } \\
\text { Estimated }\end{array}$ & $\begin{array}{c}\text { Gmb - } \\
\text { Corrected }\end{array}$ & $\% \mathbf{G m m}$ \\
\hline 7 & 129.67 & 2.085 & 2.136 & 84.36 & 128.87 & 2.102 & 2.138 & 84.45 \\
\hline 9 & 128.1 & 2.110 & 2.162 & 85.39 & 127.45 & 2.125 & 2.162 & 85.39 \\
\hline 100 & 115.82 & 2.334 & 2.391 & 94.45 & 115.22 & 2.351 & 2.392 & 94.46 \\
\hline 125 & 115.01 & 2.351 & 2.408 & 95.11 & 114.4 & 2.367 & 2.408 & 95.10 \\
\hline \multicolumn{2}{|c|}{ Gyrations } & $\begin{array}{l}\text { Average } \\
\% \text { Gmm }\end{array}$ & $\begin{array}{c}\text { Average } \\
\text { Air Voids }\end{array}$ & & & & 4 & \\
\hline \multicolumn{2}{|c|}{7} & 84.41 & 15.6 & & & & & \\
\hline \multicolumn{2}{|c|}{9} & 85 & 14.6 & & & 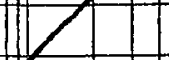 & & 11 \\
\hline \multicolumn{2}{|c|}{100} & 94.45 & 5.5 & 84.0 & & & & \\
\hline \multicolumn{2}{|c|}{125} & 95.11 & 4.9 & & & 10 & as $\quad 100$ & 1000 \\
\hline
\end{tabular}




\section{RYERSON UNIVERSITY \\ Dpartment of Civil Engineering}

Superpave BITUMINOUS LABORATORY WORKSHEET

\begin{tabular}{||l|l|l|l|l|c|c|}
\hline PROJECT NO.: & \multicolumn{2}{|l|}{ M.Eng } & \multicolumn{3}{|c|}{ DATE: } & March, 2004 \\
\hline SUPPLIER & 0.000 & \multicolumn{2}{|c|}{ Mix Type: Superpave 19.0 without Shingles } \\
\hline$\%$ PASS 4.75mm: & 30.0 & Gsb: & 2.810 & $\%$ AC: & 4.5 & MIX NO.: \\
\hline
\end{tabular}

\begin{tabular}{||l|c|c||}
\hline \multicolumn{1}{|c|}{ PARAMETER } & SPECIMEN 1 & SPECIMEN 2 \\
\hline A1: MASS OF COMPACTED SPECIMEN IN AIR & 4783 & 4787 \\
\hline A2: S.D.MASS IN AIR AFTER IMMERSSION IN H $\mathrm{H}_{2} \mathrm{O}$ & 4795 & 4798 \\
\hline B1: MASS OF COMPACTED SPECIMEN IN H $\mathrm{H}_{2} \mathrm{O}$ & 2812 & 2817 \\
\hline B2: VOLUME (= A2-B1) & 1983 & 1981 \\
\hline C: BULK REL. DENSITY (= A1/B2), Gmb Measured & 2.412 & 2.416 \\
\hline D: MAX. THEORITICAL DENSITY, Gmm & \multicolumn{2}{|c||}{2.516} \\
\hline
\end{tabular}

\begin{tabular}{|c|c|c|c|c|c|c|c|c|}
\hline \multicolumn{9}{|c|}{ Superpave GYRATORY DENSIFICATION DATA } \\
\hline \multicolumn{2}{|c|}{ Mold Diameter, mm } & \multicolumn{7}{|l|}{150} \\
\hline \multirow{2}{*}{ 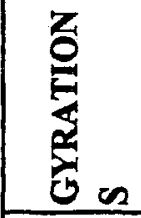 } & \multicolumn{4}{|c|}{ SPECIMEN 1} & \multicolumn{4}{|c|}{ SPECIMEN 2} \\
\hline & $\begin{array}{c}\text { HEIGHT } \\
(\mathbf{m m})\end{array}$ & $\begin{array}{c}\text { Gmb - } \\
\text { Estimated }\end{array}$ & $\begin{array}{c}\text { Gmb - } \\
\text { Corrected }\end{array}$ & $\%$ Gmm & $\begin{array}{c}\text { HEIGHT } \\
(\mathbf{m m})\end{array}$ & $\begin{array}{c}\text { Gmb - } \\
\text { Estimated }\end{array}$ & $\begin{array}{c}\text { Gmb - } \\
\text { Corrected }\end{array}$ & $\% \mathrm{Gmm}$ \\
\hline 7 & 129.29 & 2.093 & 2.143 & 85.17 & 129.08 & 2.098 & 2.140 & 85.04 \\
\hline 9 & 127.76 & 2.118 & 2.168 & 86.19 & 127.59 & 2.123 & 2.165 & 86.03 \\
\hline 100 & 115.69 & 2.339 & 2.395 & 95.18 & 115.16 & 2.352 & 2.398 & 95.32 \\
\hline 125 & 114.86 & 2.356 & 2.412 & 95.87 & 114.29 & 2.370 & 2.416 & 96.04 \\
\hline \multicolumn{2}{|c|}{ Gyrations } & $\begin{array}{l}\text { Average } \\
\% \text { Gmm }\end{array}$ & \begin{tabular}{|c|}
$\begin{array}{c}\text { Average } \\
\text { Air Voids } \\
(\%)\end{array}$ \\
\end{tabular} & $\begin{array}{l}98.0 \\
96.0 \\
94.0\end{array}$ & & & & 11 \\
\hline \multicolumn{2}{|c|}{7} & 85.10 & 14.9 & & & & & \\
\hline \multicolumn{2}{|c|}{9} & 86.11 & 13.9 & 88.0 & & & & \\
\hline \multicolumn{2}{|c|}{100} & 95.25 & 4.8 & 84.0 & & & & 11 \\
\hline \multicolumn{2}{|c|}{125} & 95.96 & 4.0 & . & & Gyrat & & \\
\hline
\end{tabular}




\section{RYERSON UNIVERSITY \\ Dpartment of Civil Engineering}

Superpave BITUMINOUS LABORATORY WORKSHEET

\begin{tabular}{||l|l|l|l|l|l|l||}
\hline PROJECT NO.: & \multicolumn{2}{|l|}{ M.Eng } & \multicolumn{3}{|c|}{ DATE: } & March, 2004 \\
\hline SUPPLIER & 0.000 & \multicolumn{3}{|c|}{ Mix Type: Superpave 19.0 without Shingles } \\
\hline \% PASS 4.75mm: & 30.0 & Gsb: & 2.810 & \% AC: & 5.0 & MIX NO.: \\
\hline
\end{tabular}

\begin{tabular}{||l|c|c|}
\hline \multicolumn{1}{|c|}{ PARAMETER } & SPECIMEN 1 & SPECIMEN 2 \\
\hline A1: MASS OF COMPACTED SPECIMEN IN AIR & 4796 & 4781 \\
\hline A2: S.D.MASS IN AIR AFTER IMMERSSION IN H $2 \mathrm{O}$ & 4804 & 4786 \\
\hline B1: MASS OF COMPACTED SPECIMEN IN $\mathrm{H}_{2} \mathrm{O}$ & 2826 & 2816 \\
\hline B2: VOLUME (= A2-B1) & 1978 & 1970 \\
\hline C: BULK REL. DENSITY (= A1/B2), Gmb Measured & 2.425 & 2.427 \\
\hline D: MAX. THEORITICAL DENSITY, Gmm & \multicolumn{2}{|c|}{2.499} \\
\hline
\end{tabular}

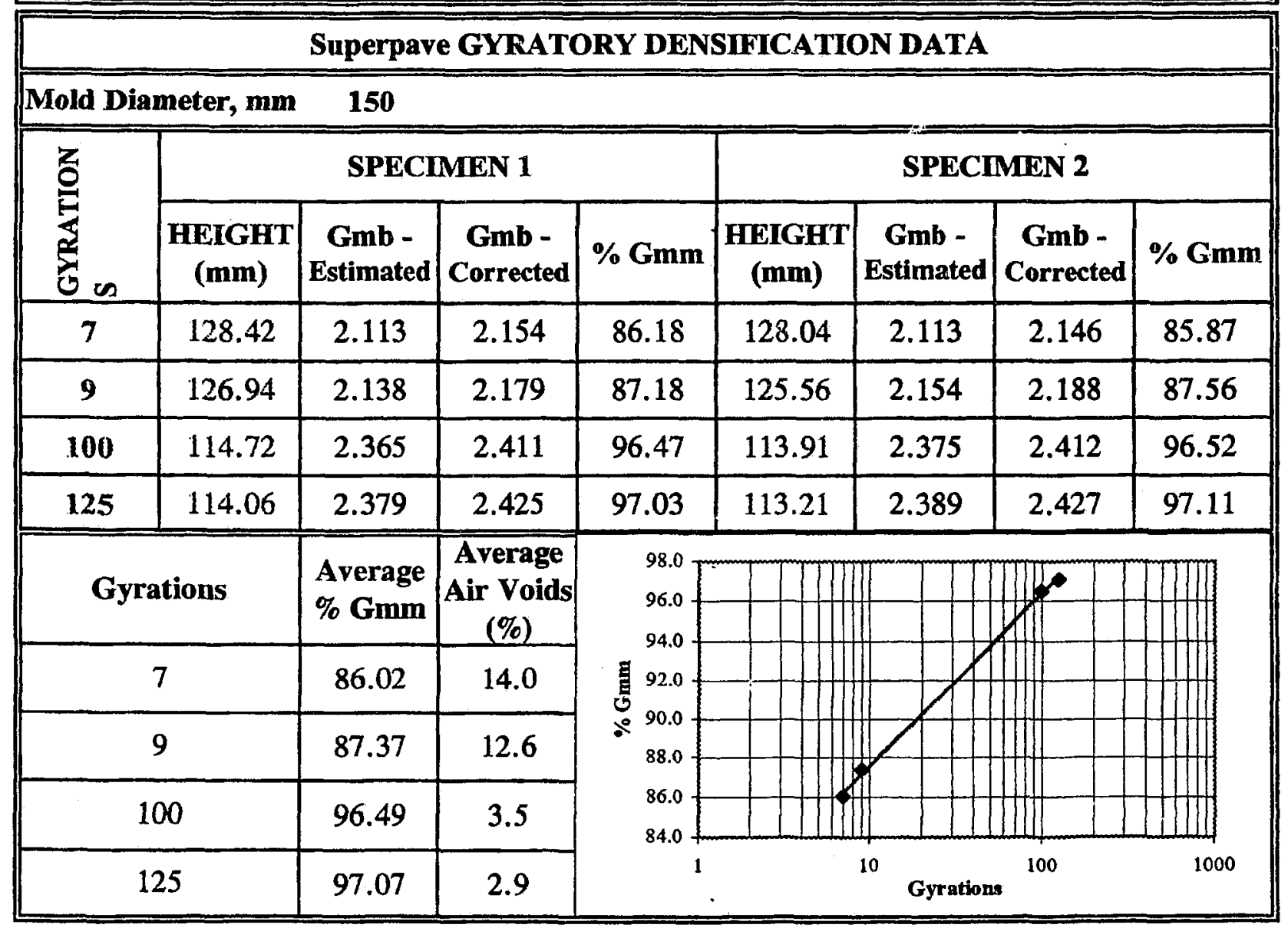

Reproduced with permission of the copyright owner. Further reproduction prohibited without permission. 


\section{RYERSON UNIVERSITY \\ Dpartment of Civil Engineering}

Superpave BITUMINOUS LABORATORY WORKSHEET

\begin{tabular}{|l|l|l|l|l|c|c|}
\hline PROJECT NO.: & \multicolumn{2}{|l|}{ M.Eng } & \multicolumn{3}{|c|}{ DATE: } & March, 2004 \\
\hline SUPPLIER & 0.000 & \multicolumn{3}{|c|}{ Mix Type: Superpave 19.0 with Shingles } \\
\hline \% PASS 4.75mm: & 30.0 & Gsb: & 2.810 & $\%$ AC: & 3.5 & MLX NO.: \\
\hline
\end{tabular}

\begin{tabular}{|l|c|c||}
\hline \multicolumn{1}{|c|}{ PARAMETER } & SPECIMEN 1 & SPECIMEN 2 \\
\hline A1: MASS OF COMPACTED SPECIMEN IN AIR & 4840.5 & 4830.6 \\
\hline A2: S.D.MASS IN AIR AFTER IMMERSSION IN $\mathrm{H}_{2} \mathrm{O}$ & 4852.6 & 4840.4 \\
\hline B1: MASS OF COMPACTED SPECIMEN IN $\mathrm{H}_{2} \mathrm{O}$ & 2845 & 2840.7 \\
\hline B2: VOLUME ( $=$ A2-B1) & 2007.6 & 1999.7 \\
\hline C: BULK REL. DENSITY (=A1/B2), Gmb Measured & 2.411 & 2.416 \\
\hline D: MAX. THEORITICAL DENSITY, Gmm & \multicolumn{2}{|c|}{2.515} \\
\hline
\end{tabular}

\begin{tabular}{|c|c|c|c|c|c|c|c|c|}
\hline & & Superpas & e GYRATC & DRY DEN & SIFICATI & ON DATA & & \\
\hline Mold D & meter, mm & 150 & & & & & & \\
\hline z & & SPEC & MEN 1 & & & SPECI & MEN 2 & \\
\hline 焉 & $\begin{array}{c}\text { HEIGHT } \\
(\mathbf{m m})\end{array}$ & $\begin{array}{c}\text { Gmb - } \\
\text { Estimated }\end{array}$ & $\begin{array}{c}\text { Gmb - } \\
\text { Corrected }\end{array}$ & $\% \mathrm{Gmm}$ & $\begin{array}{c}\text { HEIGHT } \\
(\mathbf{m m})\end{array}$ & $\begin{array}{c}\text { Gmb - } \\
\text { Estimated }\end{array}$ & $\begin{array}{c}\text { Gmb - } \\
\text { Corrected }\end{array}$ & $\%$ Gram \\
\hline 7 & 129.4 & 2.117 & 2.160 & 85.87 & 131.3 & 2.082 & 2.154 & 85.64 \\
\hline 9 & 127.9 & 2.141 & 2.185 & 86.87 & 129.86 & 2.105 & 2.178 & 86.59 \\
\hline 100 & 116.71 & 2.347 & 2.394 & 95.20 & 117.85 & 2.319 & 2.400 & 95.41 \\
\hline 125 & 115.9 & 2.363 & 2.411 & 95.87 & 117.07 & 2.335 & 2.416 & 96.05 \\
\hline & ations & $\begin{array}{l}\text { Average } \\
\% \text { Gmm }\end{array}$ & \begin{tabular}{|c|} 
Average \\
Air Voids \\
$(\%)$ \\
\end{tabular} & $\left.\begin{array}{l}98.0 \\
96.0\end{array}\right]$ & & & 4 & \\
\hline & 7 & 85.75 & 14.2 & 92.0 & & & & $\|$ \\
\hline & 9 & 86.73 & 13.3 & 88.0 & & & III] & III \\
\hline & 00 & 95.31 & 4.7 & & & II & m & 11 \\
\hline & 25 & 95.96 & 4.0 & & & & & \\
\hline
\end{tabular}




\section{RYERSON UNIVERSITY \\ Dpartment of Civil Engineering}

Superpave BITUMINOUS LABORATORY WORKSHEET

\begin{tabular}{||l|c|c|c|c|c|c|}
\hline PROJECT NO.: & \multicolumn{2}{|l|}{ M.Eng } & \multicolumn{3}{|c|}{ DATE: } & March, 2004 \\
\hline SUPPLIER & 0.000 & \multicolumn{3}{|c|}{ Mix Type: Superpave 19.0 with Shingles } \\
\hline$\%$ PASS 4.75mm: & 30.0 & Gsb: & 2.810 & $\%$ AC: & 4.0 & MIX NO.: \\
\hline
\end{tabular}

\begin{tabular}{||l|c|c|}
\hline \multicolumn{1}{|c|}{ PARAMETER } & SPECIMEN 1 & SPECIMEN 2 \\
\hline A1: MASS OF COMPACTED SPECIMEN IN AIR & 4828.9 & 4833.7 \\
\hline A2: S.D.MASS IN AIR AFTER IMMERSSION IN H $\mathrm{H}_{2} \mathrm{O}$ & 4839.7 & 4841 \\
\hline B1: MASS OF COMPACTED SPECIMEN IN H ${ }_{2} \mathrm{O}$ & 2843.6 & 2845.5 \\
\hline B2: VOLUME (= A2-B1) & 1996.1 & 1995.5 \\
\hline C: BULK REL. DENSITY (= A1/B2), Gmb Measured & 2.419 & 2.422 \\
\hline D: MAX. THEORITICAL DENSITY, Gmm & \multicolumn{2}{|c|}{2.501} \\
\hline
\end{tabular}

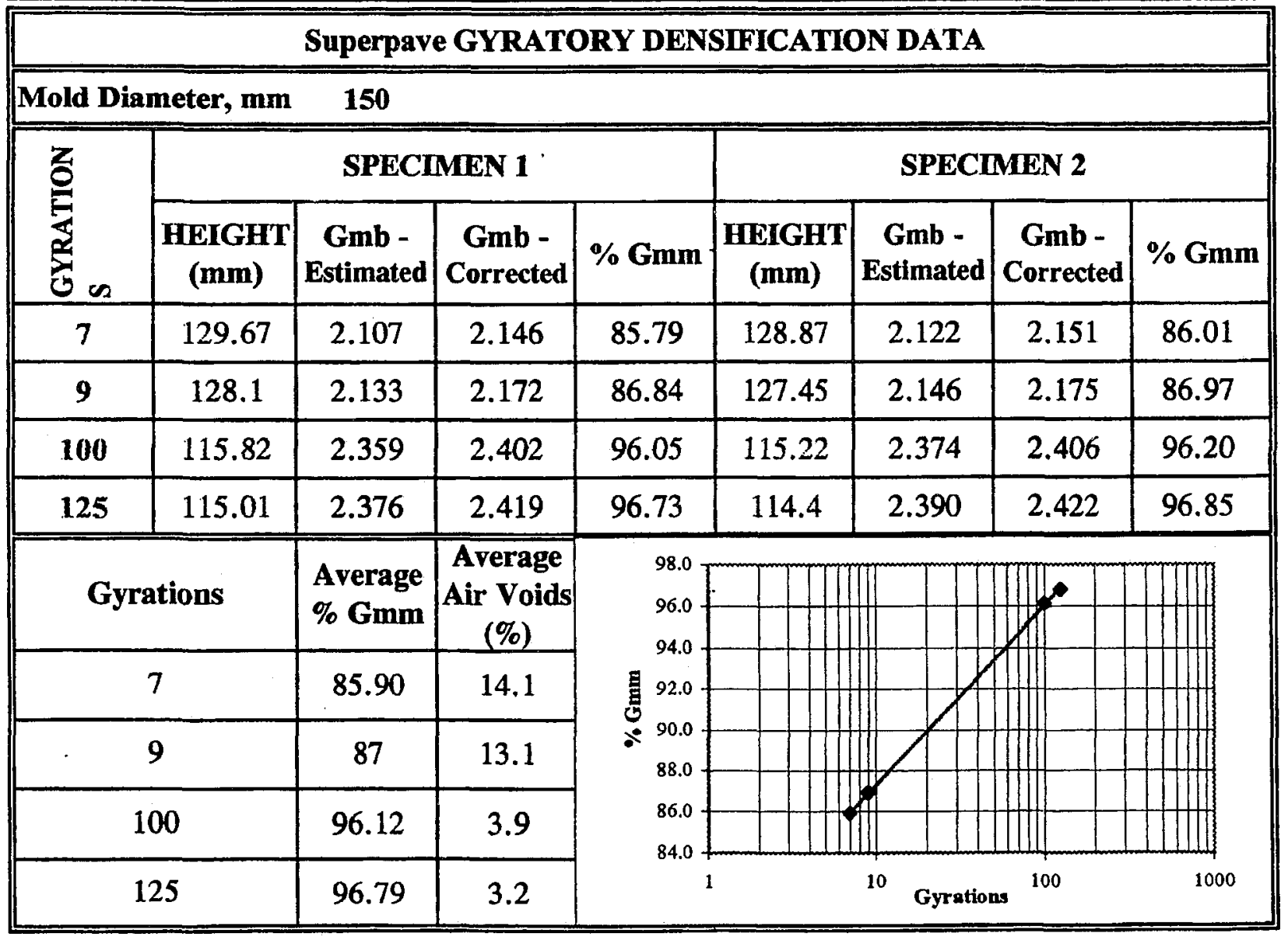




\section{RYERSON UNIVERSITY \\ Dpartment of Civil Engineering}

Superpave BITUMINOUS LABORATORY WORKSHEET

\begin{tabular}{||l|c|c|c|c|c|c|}
\hline PROJECT NO.: & \multicolumn{2}{|l|}{ M.Eng } & \multicolumn{3}{|c|}{ DATE: } & March, 2004 \\
\hline SUPPLIER & 0.000 & \multicolumn{2}{|c|}{ Mix Type: Superpave 19.0 with Shingles } \\
\hline \% PASS 4.75mm: & 30.0 & Gsb: & 2.810 & \% AC: & 4.5 & MIX NO.: \\
\hline
\end{tabular}

\begin{tabular}{|l|c|c|}
\hline \multicolumn{1}{|c|}{ PARAMETER } & SPECIMEN 1 & SPECIMEN 2 \\
\hline A1: MASS OF COMPACTED SPECIMEN IN AIR & 4838.1 & 4832.4 \\
\hline A2: S.D.MASS IN AIR AFTER MMMERSSION IN $\mathrm{H}_{2} \mathrm{O}$ & 4840 & 4835 \\
\hline B1: MASS OF COMPACTED SPECIMEN IN H2 $\mathrm{O}$ & 2843.6 & 2840.2 \\
\hline B2: VOLUME ( $=$ A2-B1) & 1996.4 & 1994.8 \\
\hline C: BULK REL. DENSITY (= A1/B2), Gmb Measured & 2.423 & 2.422 \\
\hline D: MAX. THEORITICAL DENSITY, Gmm & & 2.486 \\
\hline \hline
\end{tabular}

\begin{tabular}{|c|c|c|c|c|c|c|c|c|}
\hline & & Superpav & e GYRAT & ORY DEN & SIFICATIO & ON DATA & & \\
\hline Mold D & meter, mm & 150 & & & & & & \\
\hline & & SPECI & MEN 1 & & & SPECI & MEN 2 & \\
\hline 里 & $\begin{array}{c}\text { HEIGHT } \\
(\mathrm{mm})\end{array}$ & $\begin{array}{c}\text { Gmb - } \\
\text { Estimated }\end{array}$ & $\begin{array}{c}\text { Gmb - } \\
\text { Corrected }\end{array}$ & $\% \mathbf{G m m}$ & $\begin{array}{c}\text { HEIGHT } \\
(\mathrm{mm})\end{array}$ & $\begin{array}{c}\text { Gmb - } \\
\text { Estimated }\end{array}$ & $\begin{array}{c}\text { Gmb - } \\
\text { Corrected }\end{array}$ & $\% \mathrm{Gmm}$ \\
\hline 7 & 129.29 & 2.117 & 2.153 & 86.60 & 129.08 & 2.118 & 2.145 & 86.28 \\
\hline 9 & 127.76 & 2.143 & 2.179 & 87.64 & 127.59 & 2.143 & 2.170 & 87.29 \\
\hline 100 & 115.69 & 2.366 & 2.406 & 96.78 & 115.16 & 2.374 & 2.404 & 96.71 \\
\hline 125 & 114.86 & 2.383 & 2.423 & 97.48 & 114.29 & 2.392 & 2.422 & 97.45 \\
\hline & ations & $\begin{array}{l}\text { Average } \\
\text { \% Gmm }\end{array}$ & $\begin{array}{c}\text { Average } \\
\text { Air Voids } \\
(\%)\end{array}$ & & & & $t$ & m] \\
\hline & 7 & 86.44 & 13.6 & 94.0 & & & & 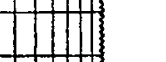 \\
\hline & 9 & 87.46 & 12.5 & & & 7 & & 11 \\
\hline & .00 & 96.75 & 3.3 & & & & IIII & 1 \\
\hline & 25 & 97.46 & 2.5 & 1 & & Gyration & ${ }^{100}$ & \\
\hline
\end{tabular}




\section{RYERSON UNIVERSITY \\ Dpartment of Civil Engineering}

Superpave BITUMINOUS LABORATORY WORKSHEET

\begin{tabular}{|l|l|l|l|l|c|c|}
\hline PROJECT NO.: & \multicolumn{2}{|l|}{ M.Eng } & \multicolumn{3}{|c|}{ DATE: } & March, 2004 \\
\hline SUPPLIER & $0.0 \% 0$ & \multicolumn{3}{|c|}{ Mix Type: Superpave 19.0 with Shingles } \\
\hline$\%$ PASS 4.75mm: & 30.0 & Gsb: & 2.810 & $\%$ AC: & 5.0 & MIX NO.: \\
\hline
\end{tabular}

\begin{tabular}{||l|c|c|}
\hline \multicolumn{1}{|c|}{ PARAMETER } & SPECIMEN 1 & SPECIMEN 2 \\
\hline A1: MASS OF COMPACTED SPECIMEN IN AIR & 4829.8 & 4844 \\
\hline A2: S.D.MASS IN AIR AFTER IMMERSSION IN H $\mathrm{H}_{2} \mathrm{O}$ & 4830.4 & 4848 \\
\hline B1: MASS OF COMPACTED SPECIMEN IN H2 $\mathrm{O}$ & 2842.2 & 2856.7 \\
\hline B2: VOLUME (= A2-B1) & 1988.2 & 1991.3 \\
\hline C: BULK REL. DENSITY (= A1/B2), Gmb Measured & 2.429 & 2.433 \\
\hline D: MAX. THEORITICAL DENSITY, Gmm & & 2.472 \\
\hline
\end{tabular}

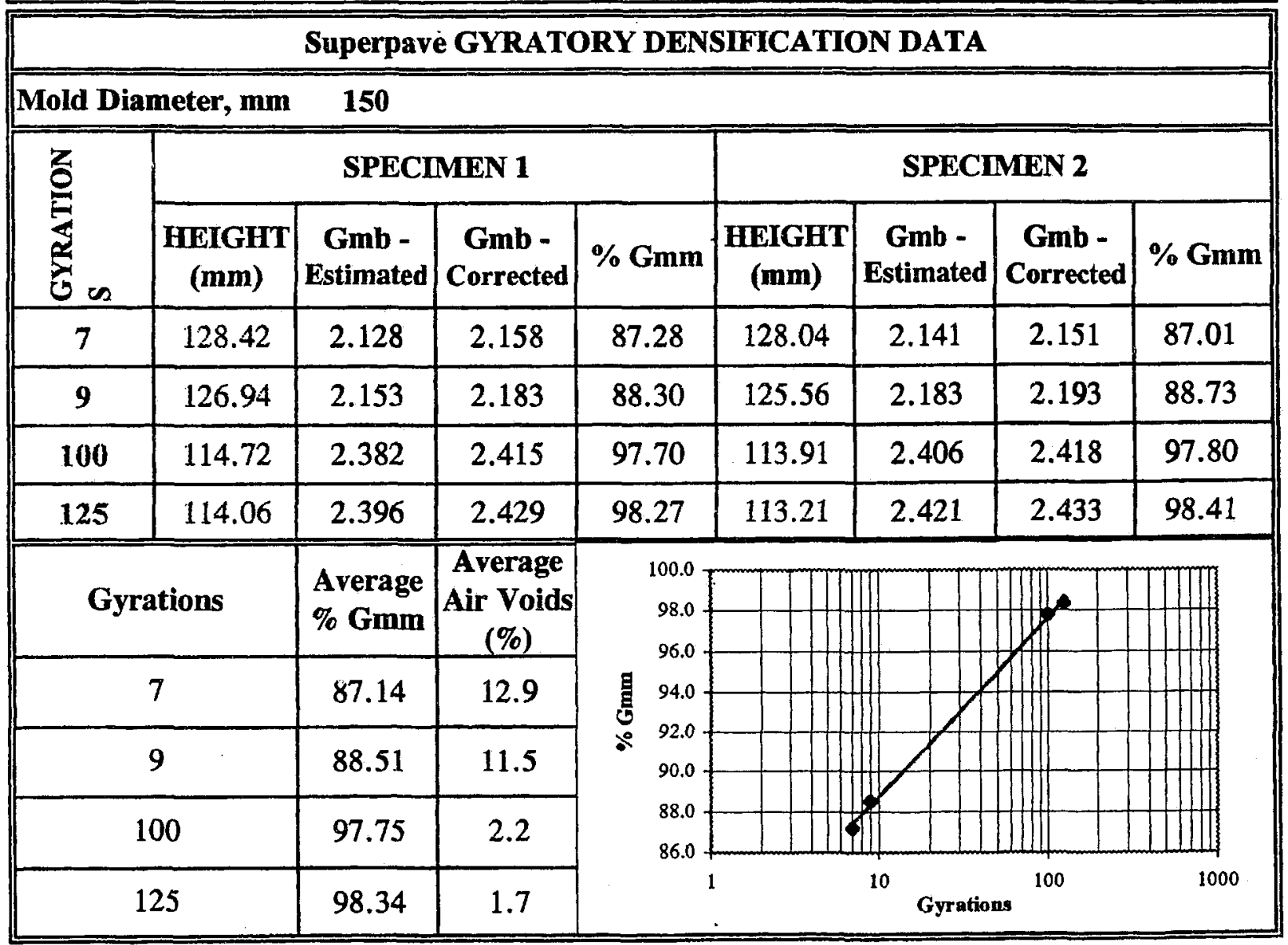

